\title{
Systematic Analysis of
}

\section{Molecular and Cellular Dysfunction}

\author{
in Accelerated Aging Phenotypes
}

\author{
Dissertation \\ for the award of the degree \\ "Doctor rerum naturalium" \\ of the Georg-August-Universität Göttingen
}

within the doctoral program

International Max Planck Research School for Genome Science (IMPRS-GS)

of the Georg-August University School of Science (GAUSS)

submitted by

Gesa Hanna Werner

from Flensburg

Göttingen, 14.07.2021 



\section{Thesis Commitee:}

Prof. Dr. med. Bernd Wollnik (Supervisor)

Institute of Human Genetics, University Medical Center Göttingen

Prof. Dr. rer. nat. Peter Rehling

Departent of Cellular Biochemistry, University Medical Center Göttingen

Prof. Dr. rer. nat. Holger Bastians

Institute of Molecular Oncology, University Medical Center Göttingen

\section{Members of the Examination Board:}

Prof. Dr. med. Bernd Wollnik (Referee)

Institute of Human Genetics, University Medical Center Göttingen

Prof. Dr. rer. nat. Peter Rehling ( $2^{\text {nd }}$ Referee)

Departent of Cellular Biochemistry, University Medical Center Göttingen

Prof. Dr. rer. nat. Holger Bastians

Institute of Molecular Oncology, University Medical Center Göttingen

Prof. Dr. rer. nat. Lutz Walter

Department of Primate Genetics, German Primate Center Göttingen

Prof. Dr. med. Ralf Dressel

Institute for Cellular and Molecular Immunology, University Medical Center Göttingen

Dr. rer. nat. Ufuk Günesdogan

Department of Developmental Biology, Georg-August University Göttingen

Date of the oral exam: 09.09.2021, 08:00 


\section{Summary}

Accelerated aging in multiple tissues is the connecting characteristic of the group of genetic disorders called segmental progeroid syndromes. At young ages, affected patients show many clinical features of aging-associated pathologies such as hair graying, lipodystrophy, osteoporosis, cataracts, hearing loss, arteriosclerosis, diabetes mellitus, and malignancies. Several disease-causing genes for segmental progeroid syndromes have been identified within the last years, and the affected proteins are often involved in genome maintenance or mitochondrial function. Identifying these underlying genetic alterations revealed molecular and cellular mechanisms involved in the pathology of these diseases and furthered our understanding of aging processes and aging-associated diseases in general.

The aim of my thesis was to expand our knowledge of the cellular and molecular mechanisms of aging using a unique collection of fibroblast and DNA samples of patients suffering from a large variety of different progeroid syndromes.

I established an ultra-high coverage mtDNA sequencing approach to detect and quantify lowfrequency mtDNA variants in patient samples. By treatment of control fibroblasts with genotoxic agents, I could show that this approach allows the detection of low-frequency variants in the mitochondrial genome. Analysis of a DNA sample of a patient suffering from Cutis laxa type IC and carrying a homozygous mutation in LTBP4 revealed a significantly increased number of mtDNA variants. LTBP4 encodes a secreted protein that regulates TGFbeta signaling and has previously not been associated with mitochondrial dysfunction. Therefore, these results indicate for the first time a link between LTBP4 and the integrity of the mitochondrial genome.

Additionally, I established a real-time PCR-based method in order to analyze telomere length in DNA samples of patients suffering from progeroid syndromes. I found the anticipated sigmoidal distribution of telomere length by age as well as a high variance of telomere length in the control samples. The decrease of telomere length in two patient samples, a Bloom syndrome patient and a patient suffering from Cutis laxa type IIB, approached significance. 
To characterize telomere attrition in more detail, I collaborated on the optimization of a telomere qFISH method, which I then used to measure telomere length in three fibroblast samples of Bloom syndrome patients. Strikingly, the telomere signal intensity corresponding to telomere length as well as the number of telomere signals were increased in one patient sample. A chromosomal aberration and a delayed cell cycle progression with an increased amount of cells in the $\mathrm{G} 2 / \mathrm{M}$ phase were then detected in these fibroblasts, indicating that to the double set of chromosomes interfered with the measurement. A Southern blot confirmed that the telomere length in these patient samples was not different from the controls.

Further, I analyzed the accumulation of DNA damage and induction of the DNA damage response in patient fibroblasts using the quantification of $\mathrm{yH} 2 \mathrm{AX}$ foci upon treatment with genotoxic reagents. I found an elevated level of $\mathrm{\gamma H} 2 \mathrm{AX}$ foci in two untreated fibroblast samples carrying mutations in GORAB and SLC25A24 indicative of either higher susceptibility of these cells to DNA damage or deficiencies in DNA damage repair processes. Further irradiation treatment caused a significantly elevated level of $\mathrm{\gamma H} 2 \mathrm{AX}$ in two fibroblast samples carrying mutations in the PYCR1 and GORAB genes suggestive of DNA damage repair impairment in these cells.

In summary, the results of my Ph.D. thesis help to establish new methods for the analysis and quantification of aging-associated cellular processes. Using these methods on cells and DNA samples of patients with segmental progeroid syndromes, I could provide new insights into the involved pathomechanisms by identifying a link between LTBP4 and mitochondrial DNA as well as a possible influence of BLM and PYCR1 on telomere length. 


\section{Zusammenfassung}

Zur Gruppe segmentaler progeroider Erkrankungen gehören genetische Erkrankungen, denen beschleunigte Alterungsprozesse in mehreren Geweben zugrunde liegen. Klinische Merkmale dieser Patienten sind altersassoziierte Pathologien in jungen Jahren wie graue Haare, Lipodystrophie, Osteoporose, grauer Star, Schwerhörigkeit, Arteriosklerose, Diabetes mellitus und Tumore. In den vergangenen Jahren wurden viele krankheitsverursachende Gendefekte für segmentale progeroide Erkrankungen identifiziert. Die betroffenen Proteine sind an Genomstabilität und der Funktion der Mitochondrien beteiligt. Die Identifizierung der zugrundeliegenden genetischen Defekte deckte molekulare und zelluläre Mechanismen auf, die unser Verständnis von Alterungspozessen und altersassoziierten Erkankungen im Allgemeinen erweiterte.

Das Ziel meiner Arbeit war, unser Wissen über diese zellulären und molekularen Mechanismen der Alterungsprozesse zu erweitern, indem ich eine einzigartige Sammlung von Fibroblasten und DNA-Proben von Patienten mit verschiedenen progeroiden Erkrankungen untersucht habe.

Dazu habe ich eine Methode zur Sequenzierung der mitochondrialen DNA mit sehr hoher Abdeckung etabliert, um niederfrequente mtDNA-Varianten in Patientenproben zu quantifizieren. Durch die Behandlung von Kontrollfibroblasten mit genotoxischen Substanzen konnte ich zeigen, dass dieser Ansatz die Detektion von niederfrequenten Varianten im mitochondrialen Genom möglich macht. Die Analyse einer DNA-Probe eines von Cutis Laxa Typ IC betroffen Patienten, der eine homozygote Mutation im LTBP4 Gen trägt, deckte eine signifikant erhöhte Anzahl an mtDNA-Varianten auf. LTBP4 kodiert ein sekretiertes Protein, das den TGF-beta Signalweg reguliert und das bisher noch nicht mit mitochondrialer Dysfunktion assoziiert war. Dieses Ergebnis weist auf eine Verbindung von LTBP4 und der Integrität des mitochondrialen Genoms hin. 
Weiterhin habe ich eine Real-Time PCR-basierte Methode zur Analyse der Telomerlänge etabliert und damit die Telomerlänge in DNA-Proben von Patienten gemessen, die an segmentalen progeroiden Erkrankungen leiden. So habe ich die erwartete sigmoidale Verteilung der Telomerlänge mit dem Alter und eine hohe Varianz der Telomerlänge in Kontrollproben zeigen können. Die Verkürzung der Telomerlänge in einer Probe eines BloomSyndrom-Patienten und einer Probe eines Patienten mit Cutis Laxa Typ 1C kommt der Signifikanz nahe.

Um die Verringerung der Telomerlänge detaillierter charakterisieren zu können, habe ich bei der Optimierung einer Telomer-qFISH-Methode kollaboriert und diese Methode dann eingesetzt, um die Telomerlänge in drei Fibroblasten von Bloom-Syndrom-Patienten zu messen. Erstaunlicherweise war in einer Patientenprobe die Signalintensität, die der Telomerlänge entspricht, und die Anzahl der Telomersignale erhöht. In dieser Patientenprobe konnte eine Chromosomenaberration und ein verzögerter Zellzyklus mit einer erhöhten Anzahl an Zellen in der G2/M-Phase nachgewiesen werden. Dies deutet darauf hin, dass der doppelte Chromosomensatz die Messung beeinträchtigte. Mit einem Southernblot konnte ich bestätigen, dass die Telomerlänge in diesen Patientenproben nicht verändert war.

Des Weiteren habe ich die Anreicherung von DNA-Schäden und die DNA-Reparatur in Patientenfibroblasten mittels der Quantifizierung der $\mathrm{pH} 2 \mathrm{AX}$ Foci nach Bestrahlung etabliert und analysiert. So konnte ich eine erhöhte Anzal von $\mathrm{pH} 2 \mathrm{AX}$ Foci in zwei unbehandelten Fibroblastenproben mit Mutationen in den Genen GORAB und SLC25A24 identifizieren, was auf eine höhrere Anfälligkeit für DNA-Schäden oder eine Schwäche der DNA-Reparatur hinweist. Des Weiteren hat die Bestrahlung signifikant mehr $\mathrm{pH} 2 \mathrm{AX}$ Foci in zwei Patientenfibroblasten hervorgerufen, die Mutationen in den Genen PYCR1 und GORAB tragen, was ebenfalls auf eine Beeinträchtigung der DNA-Reparatur in diesen Zellen hindeutet.

Zusammengefasst habe ich in meiner Arbeit neue Methoden zur Quantifizierung von altersassoziierten zellulären Prozessen etabliert und diese Methoden genutzt, um Fibroblasten und DNA-Proben von Patienten mit segmentalen progeroiden Erkrankungen zu analysieren. So konnte ich neue Erkenntnisse zu den beteiligten Pathomechanismen gewinnen, indem ich eine Verbindung von LTBP4 mit der Integrität des mitochondrialen Genoms und einen potentiellen Einfluss von BLM und PYCR1 auf die Telomerlänge identifiziert habe. 


\section{Table of Contents}

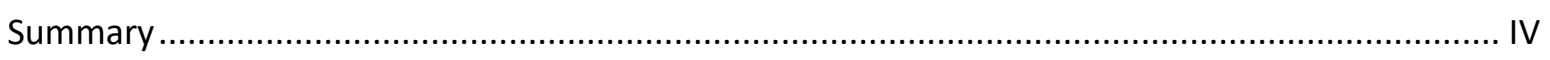

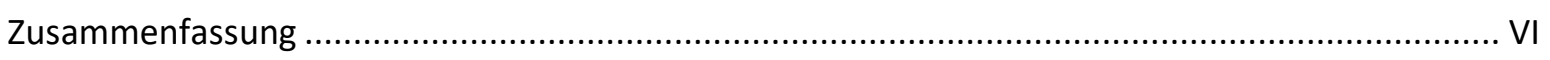

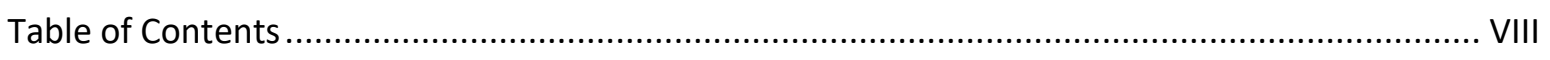

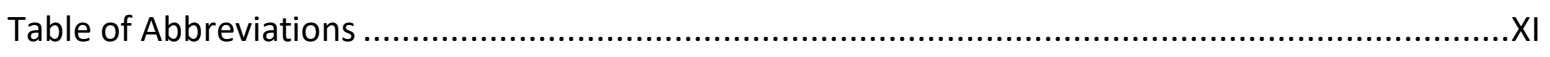

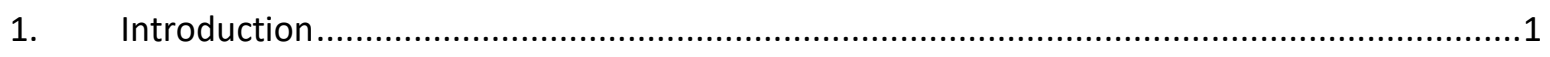

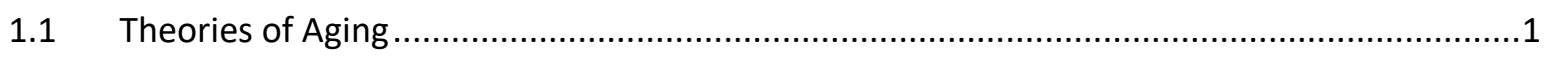

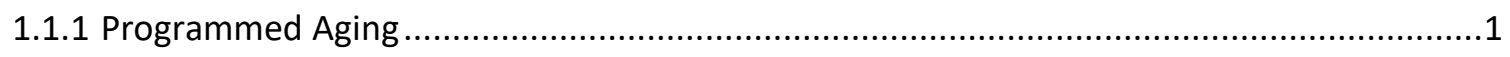

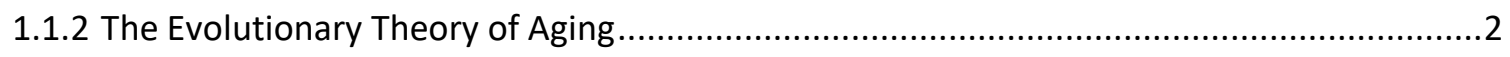

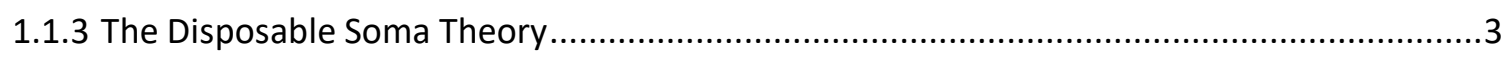

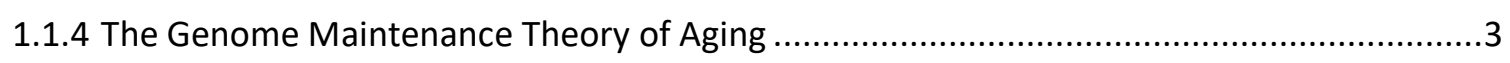

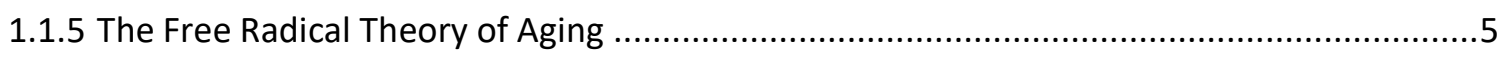

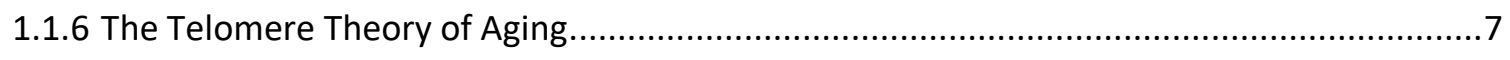

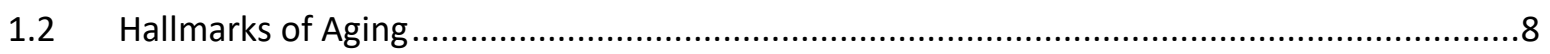

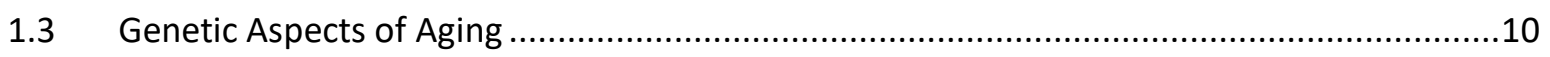

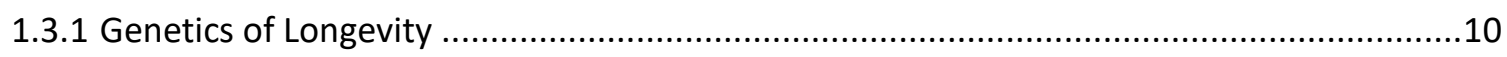

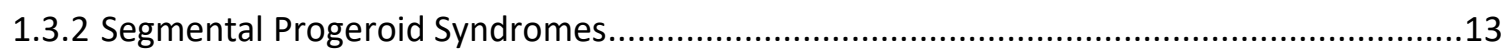

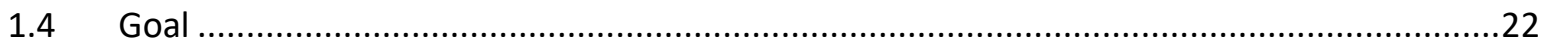

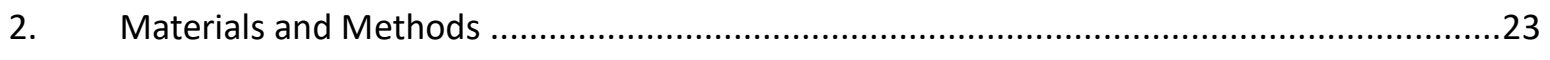

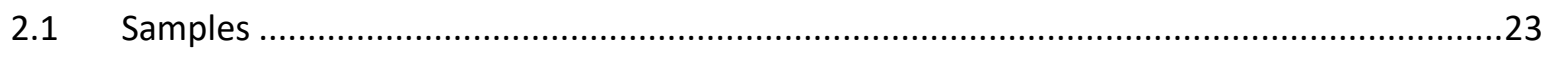

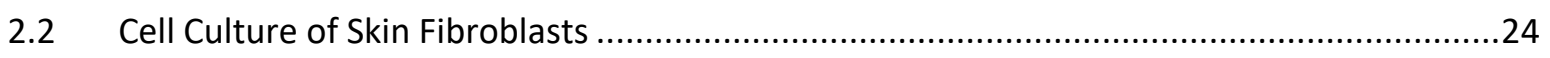

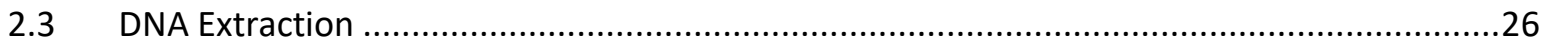

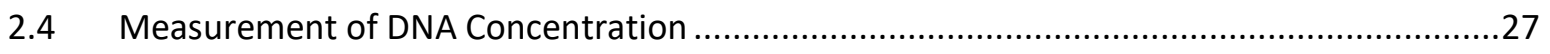

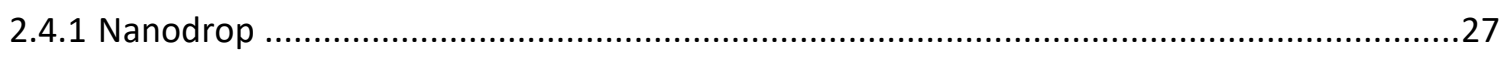

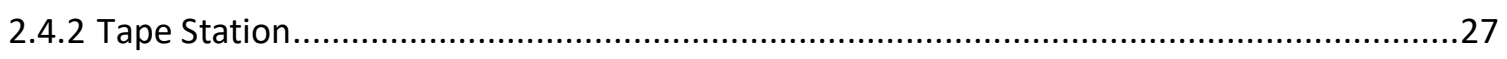

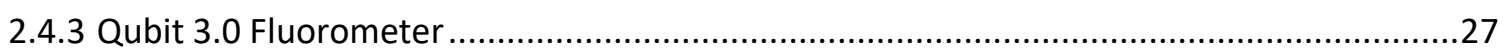




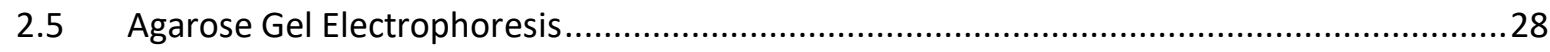

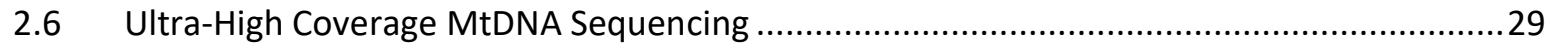

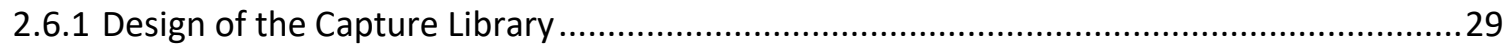

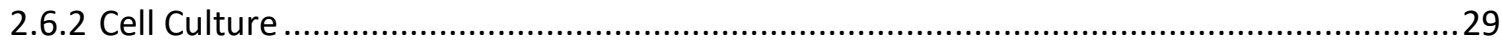

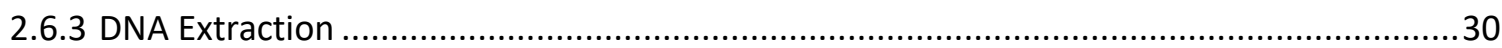

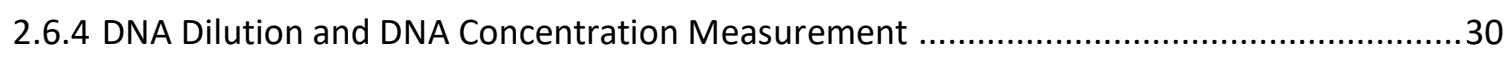

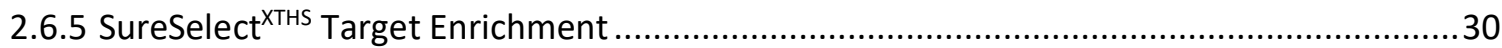

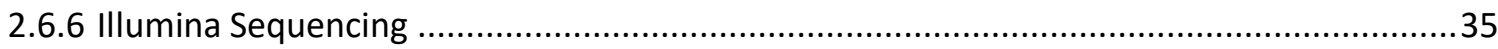

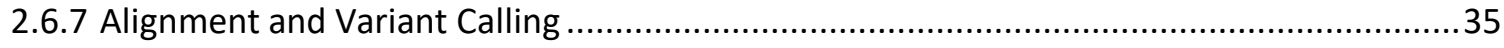

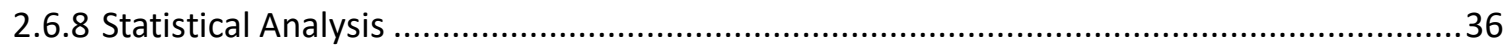

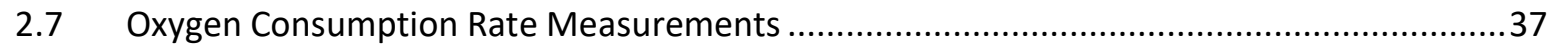

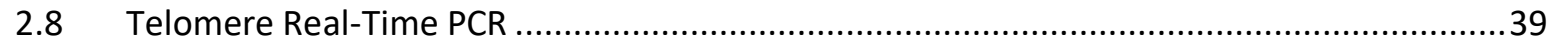

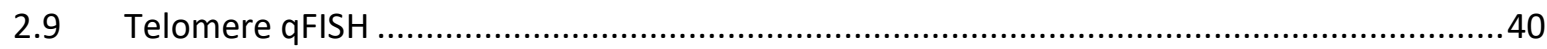

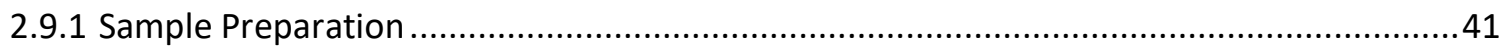

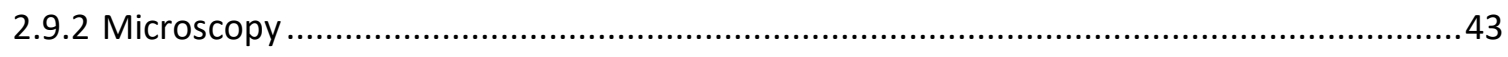

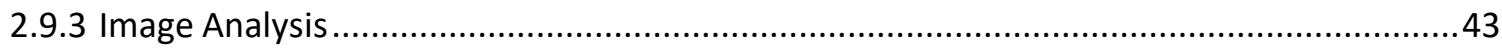

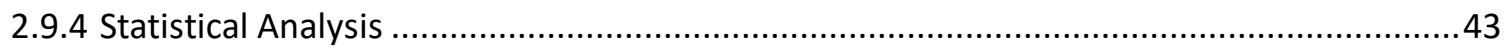

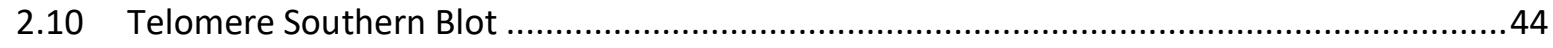

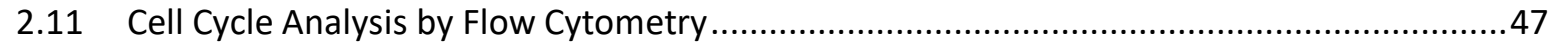

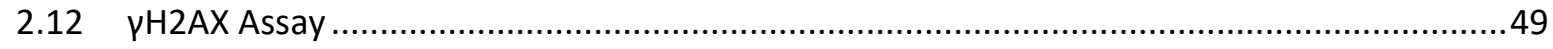

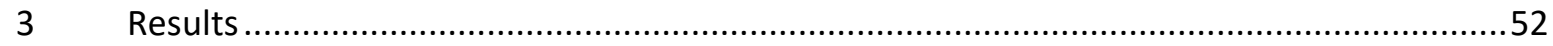

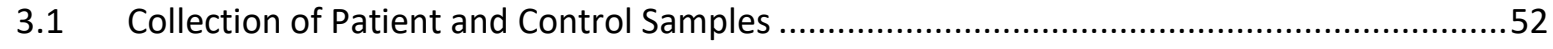

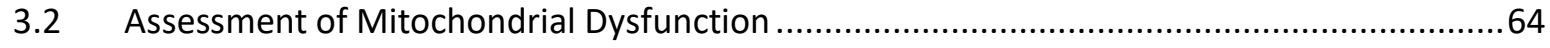

3.2.1 Ultra-High Coverage MtDNA Sequencing of Blood and Fibroblast Samples of Progeria

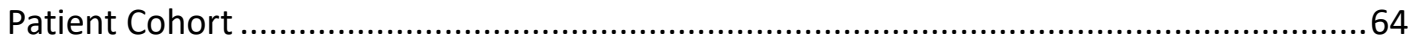

3.2.2 Oxygen Consumption Rate Measurements using Seahorse Mitochondrial Stress Test......83

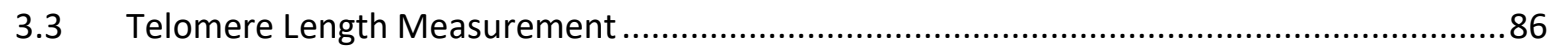


3.3.1 Telomere Length Measurement in Progeroid Syndrome Patients by Telomere Real-Time PCR

3.3.2 Telomere Length Measurement of Fibroblasts from Bloom Syndrome Patients by Optimized QFISH Method .92

3.4 Assessment of Genome Instability. 102

3.4.1 Measurement of DNA Damage and DNA Repair by $\mathrm{yH}$ HAX Assay. 102

4. Discussion. 107

4.1 Assessment of Mitochondrial Dysfunction

4.1.1 Ultra-High Coverage MtDNA Sequencing of Blood and Fibroblast Samples of Progeria Patients Cohort.

4.1.2 Measurement of Oxidative Consumption Rates to Assesses Mitochondrial Dysfunction 112

4.2 Telomere Length Measurement .114

4.2.1 Telomere Length Measurement in Progeroid Syndrome Patients by Telomere Real-Time PCR 116

4.2.2 Telomere Length Measurement of Fibroblasts of Bloom Syndrome Patients by Optimized QFISH Method 118

4.3 Assessment of DNA Damage and DNA Repair by $\mathrm{\gamma H} 2 \mathrm{AX}$ Assay 119

4.4 Patient-Derived Fibroblasts and Blood Samples as In-Vitro Models of Segmental Progeroid Syndromes

4.5 Outlook 125

4.5.1 Ultra-High Coverage MtDNA Sequencing 125

4.5.2 Influence of LTBP4 on MtDNA Maintenance

4.5.3 Telomere Length Measurement by Optimized QFISH Method

4.6 Conclusion

5. References .128

6. Appendix 151

7. Acknowledgments 161

8. Curriculum vitae 162 


\section{Table of Abbreviations}

\begin{tabular}{|c|c|}
\hline Abbreviation & Long form \\
\hline ATP & Adenosine triphosphate \\
\hline BER & Base excision repair \\
\hline $\mathrm{bp}$ & Baise pairs \\
\hline $\mathrm{Ct}$ & Threshold cycle \\
\hline DIN & DNA integrity number \\
\hline DSB & Double strand break \\
\hline gDNA & Genomic DNA \\
\hline $\mathrm{GH}$ & Growth hormone \\
\hline GWAS & Genome-wide association studies \\
\hline HGPS & Hutchinson-Gilford progeria syndrome \\
\hline $\mathrm{HR}$ & Homologous recombination \\
\hline HRD & Helicase RnaseD, C-terminal conserved region \\
\hline IGF-1 & Insulin-like growth factor 1 \\
\hline $\mathrm{kbp}$ & Kilo baise paris \\
\hline MAPK & Mitogen-activated protein kinase \\
\hline MMR & Mismatch repair \\
\hline mtDNA & Mitochondrial DNA \\
\hline nDNA & Nuclear DNA \\
\hline NER & Nucleotide excision repair \\
\hline NGS & Next generation sequencing \\
\hline NHEJ & Non-homologous end joining \\
\hline NTC & No template control \\
\hline NUMTS & Nuclear-encoded mitochondrial fragments \\
\hline OCR & Oxygen consumption rate \\
\hline OMIM & Online Mendelian Inheritance in Man \\
\hline OXPHOS & Oxidative phosphorylation \\
\hline PCR & Polymerase chain reaction \\
\hline qFISH & Quantitative fluorescence in situ hybridization \\
\hline ROS & Reactive oxygen species \\
\hline RNA & Ribonucleic acid \\
\hline $\mathrm{RQC}$ & RecQ helicase conserved region \\
\hline rRNA & Ribosomal RNA \\
\hline RT & Room temperature \\
\hline SCR & Single copy gene \\
\hline SD & Standard Deviation \\
\hline SNP & Single nucleotide polymorphism \\
\hline STED & Stimulated emission depletion \\
\hline STELA & Single telomere length assay \\
\hline TeSLA & Telomere shortest length assay \\
\hline VAF & Variant allele frequency \\
\hline WRS & Werner syndrome \\
\hline
\end{tabular}




\section{Introduction}

Aging is the decline in cell and organ function over time that inevitably leads to death (1). Age is the major risk factor for cardiovascular disease (2), cancer (3), diabetes (4), and dementia (5). While life expectancy increases continuously, the time people suffer from agingassociated diseases also rises (6). The percentage of people worldwide over the age of sixtyfive has grown from $6 \%$ in 1990 to $9 \%$ in 2019 and is predicted to increase to $16 \%$ in 2050 (7). Therefore, society is strongly dependent on further progress in aging research to improve healthy aging and protect millions of people from disability.

\subsection{Theories of Aging}

Many theories of aging and its underlying mechanisms have been published during the past years, but no single theory has explained the phenomenon to complete satisfaction (8). Generally, the theories can be divided into two categories: The theories either answer why we age or how we age. There are only a few broad theories that explain why we age, and they are mutually exclusive: The theory of programmed aging, the evolutionary theory of aging, and the disposable soma theory of aging. Many other theories focus on the mechanisms of aging and attempt to answer the question "How do we age?". Often these theories overlap and complement each other, making it likely that more than one is true. These theories all have in common that the accumulation of cellular and molecular damage in somatic tissue causes aging (9).

\subsubsection{Programmed Aging}

Programmed aging theories assume aging occurs deliberately because a limited life span has evolutionary benefits (10). By eliminating post-reproductive individuals from the population, competition for resources and overpopulation between parents and offspring is avoided, promoting adaptation to changing environments by a succession of generations (11). Two prominent arguments for predetermined aging are often made: There seems to be a good correlation between the lifespan of various species and the number of cell doublings of a single cell type, such as fibroblasts grown in culture (12). This observation hints at an intracellular mechanism that limits lifespan. Moreover, the phenomenon of phenoptosis is 
observed in some plants, insects, and fish: their reproduction requires the death of the mature adult during reproduction. Young pacific salmon, for example, imprint on the water they hatched in, migrate to the ocean to feed and migrate back to their natal stream to spawn and die soon after (13). The stress of swimming upstream and the transfer from seawater to freshwater causes an increase in cortisol level, leading to the degeneration of multiple glands and organs, which causes death by multi-organ failure (14).

\subsubsection{The Evolutionary Theory of Aging}

However, a gene for programmed aging would have no benefit for the survival of the species and would not persist throughout evolution. Peter Medwar proposed in 1952 that natural selection fails to take effect during the post-reproductive phase. Due to a high extrinsic mortality, few individuals reach a high age; thus, the force of selection decreases with age (15). This mechanism might explain the high prevalence of late-onset diseases like Huntington's disease. Huntington's disease is a genetic disease inherited in an autosomaldominant mode and caused by a trinucleotide expansion in the HTT gene. Symptoms are chorea, dystonia, incoordination, and cognitive decline caused by progressive neurodegeneration. The age of onset is determined mainly by the length of the trinucleotide expansion, which often increases through the generations (16). Since the symptoms usually occur beyond the age of thirty, which is well after reproduction in a pre-modern society, the allele would not be efficiently eliminated by selection (17). This "selection shadow" allows the accumulation of mutations with a late deleterious effect to accumulate over generations. This idea is also called the mutation accumulation theory. The antagonistic pleiotropy theory proposed by George Williams goes a step further and suggests the existence of genes with a positive early effect to be favored by selection even though these genes have a deleterious effect at later ages. The theory predicts that late reproduction would delay aging as it would increase the force of natural selection later in life (15). Experimental evidence was gathered in the fruit fly Drosophila melanogaster that supports the evolutionary theory of aging. By preventing younger flies from mating and only allowing older flies to reproduce, aging in this population was delayed, and these flies were less fertile early in life (18). 


\subsubsection{The Disposable Soma Theory}

Thomas Kirkwood published the disposable soma theory of aging in 1979. The basic idea of his theory is that organisms must balance the maintenance of their body against reproduction (19). This idea explains the very different lifespans of similar species. While a mouse is likely to die of predation or freezing in its first year, any energy spent for mechanisms for survival beyond this age only benefits a small fraction of individuals. Thus, mice will invest any excess energy into thermogenesis or reproduction rather than better repair capacity. This compromise is called a life-history trade-off (20). By implication, aging in safe environments will be retarded, whereas aging in hazardous environments will evolve to appear earlier. This theory is supported by an observation of two populations of Virginia opossum Didelphis virginiana: a mainland control group was compared to an opossum population living on an island without predators. The opossums on the island aged more slowly, reproduced longer, and had a reduced litter size (21). The disposable soma theory may also explain why some species like salmon reproduce only once. If the animal is likely to die before the next breeding season, natural selection would favor allocating all resources to reproduction, leaving no resources for somatic maintenance.

\subsubsection{The Genome Maintenance Theory of Aging}

The genome maintenance or DNA damage theory of aging proposes that DNA damage is the root cause of aging. By induction of senescence, exhaustion of regenerative capacity, the decline of mitochondrial function, and induction of protein aggregation, DNA damage could cause aging (22). DNA damage is caused by free radicals, radiation, genotoxic chemicals, chemical instability, replication errors, and endogenous genotoxins. A specialized pathway recognizes each class of DNA lesions. Well-studied DNA repair mechanisms are base excision repair (BER), nucleotide excision repair (NER), mismatch repair (MMR), and double-strand break (DSB) repair. While BER excises mainly oxidative and alkylation DNA damage, NER removes bulky lesions. MMR corrects replication errors and DSBs by non-homologous end joining (NHEJ) or homologous recombination (HR) (23). An overview of DNA damage agents, repair processes, and the consequences of unrepaired DNA damage is given in Figure 1. 
A

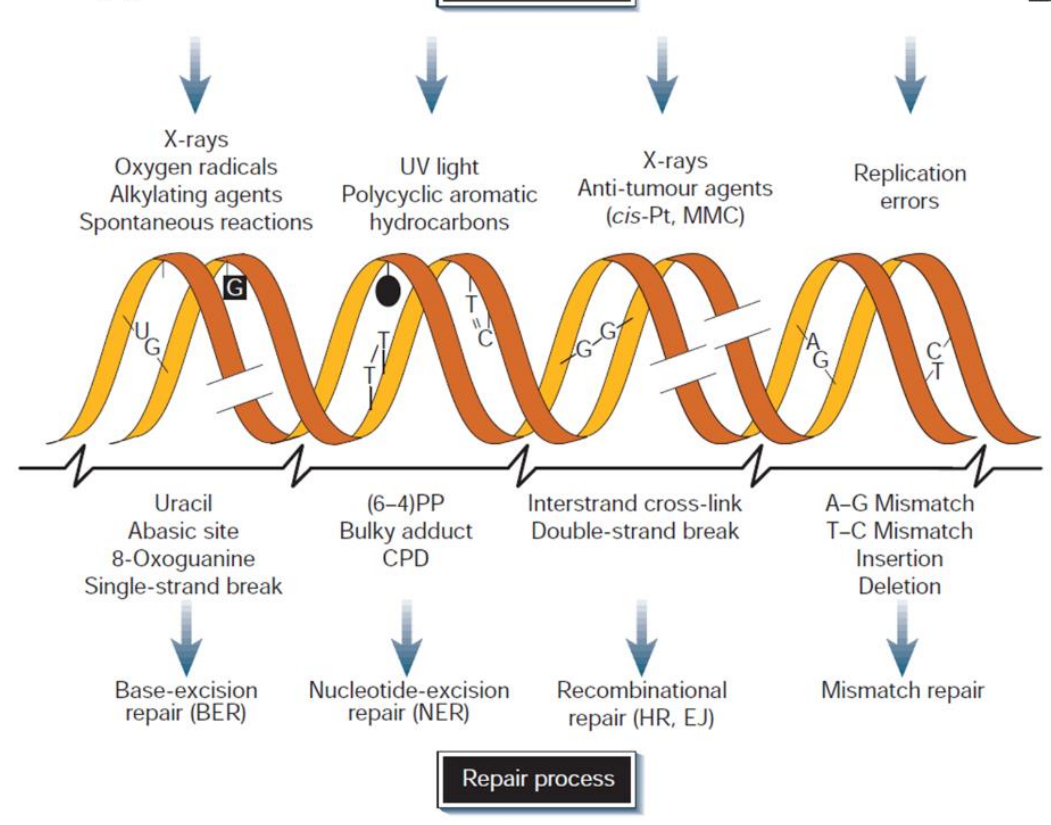

B Consequences

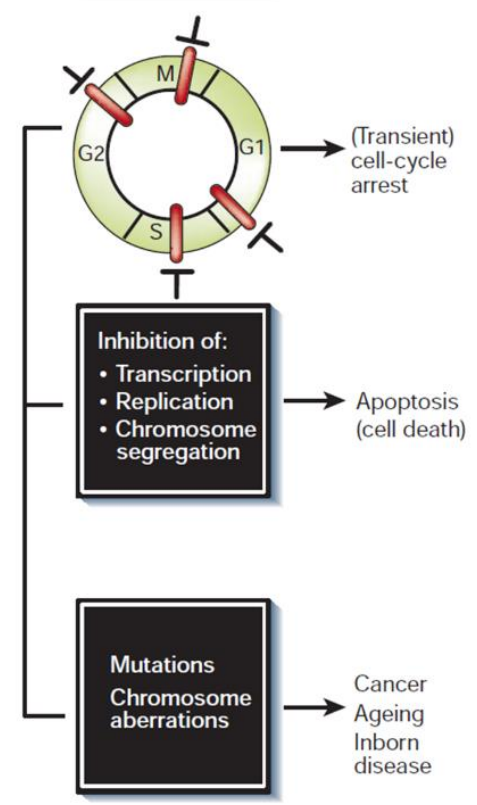

Figure 1: DNA damage, DNA repair mechanisms, and consequences

A: Common DNA damaging agents as UV-light, X-rays, and replication errors (top left) cause DNA lesions such as single-strand breaks, intrastrand cross-links, or double-strand breaks, which can be repaired by the repair mechanisms base excision repair, nucleotide excision repair, recombinational repair, and mismatch repair (bottom). B: The consequences of unrepaired damage are transient cell-cycle arrest, apoptosis, cancer, and aging. The figure was modified after Vermeij, Hoeijmakers and Pothof 2016 (24).

DNA damage leads to mutations. In germline cells, mutations drive evolution by natural selection. Thus with perfect DNA damage repair, no evolutionary development would be possible. On the other hand, the accumulation of mutations in somatic cells causes genomic instability (25). Several lines of arguments support the DNA damage theory of aging $(22,26)$ : The majority of progeroid syndromes are characterized by defects in genome maintenance (27). Xeroderma pigmentosum is caused by mutations in one of the $X P$ genes, which encode critical factors for NER. Patients are extremely sensitive to the sun, suffer from a dramatically increased risk for skin cancer and accelerated skin aging (28). Similarly, cancer survivors, who were treated with genotoxic agents, age faster. Significantly more age-related diseases are found in people treated with genotoxins during childhood due to cancer when comparing them to their siblings (29). On the other hand, mutations accumulate during physiological aging steadily in the genome and thus increase with age (30). Also, there is evidence that DNA repair capacity declines with age (31). Finally, genetic improvement of DNA repair capacity increases lifespan in several model organisms $(32,33)$. The age 1 mutant of the nematode 
Caenorhabditis elegans exhibits an increased DNA repair capacity and resistance to oxidative stress through influence on the insulin/IGF-1 pathway (32). Nevertheless, two questions remain unanswered: [1] Does the number of somatic mutations in any one tissue ever reach a level to cause cellular and subsequently organ dysfunction (22)? [2] Is DNA damage the cause or the effect of aging?

\subsubsection{The Free Radical Theory of Aging}

The free radical theory of aging was first proposed by Harmann in the 1950s and states that free radicals derived from oxygen cause the molecular damage responsible for aging (34). Mitochondria are commonly known as the "power houses" of the cell. Depending on the cell type, each cell contains a few to several hundred mitochondria. Each mitochondrium is contained by a double membrane. Mitochondria convert organic compounds into water and carbon dioxide to Adenosine triphosphate (ATP), the universal energy molecule of the cell. As mitochondria arose from an alpha-proteobacterium being engulfed by an eukaryotic progenitor cell, each mitochondrium contains its own circular DNA (35). The human mitochondrial DNA (mtDNA) consists of 16,569 base pairs, distinguished as the heavy strand, rich in guanine, and the light strand. In total, the mtDNA contains 37 genes encoding two rRNAs, 22 tRNAs, and 13 protein subunits. More than 1,500 proteins needed for mitochondrial regulation and mitochondrial function are encoded in the nuclear DNA (nDNA), targeted to mitochondria, and actively imported. This is also the case for the polymerase $\gamma$ and DNA damage repair proteins (36).

In contrast to the nuclear genome, the mitochondrial genome is present in multiple copies per cell depending on cell type and energy demand. While a muscle cell needs as many as 7,000 copies per cell, cells with low energy demand, such as liver cells, contain only 100 copies (37). Thus a mutation does not exist only in a heterozygous or homozygous state but has a certain level of heteroplasmy in a particular tissue. mtDNA is inherited maternally as the mitochondrium in the egg cell comes from the mother. Mitochondrial diseases are either caused by mutations in the mtDNA or by mutations in nDNA encoding proteins targeted to the mitochondria. The latter type of mitochondrial disease is inherited in the Mendelian fashion (38). Most mitochondrial diseases lead to a defect in oxidative phosphorylation, and 
often tissues highly dependent on aerobic metabolism such as muscles, brain, and heart are affected (39).

During oxidative respiration, oxygen is reduced to a superoxide radical and hydrogen peroxide. These reactive oxygen species (ROS) remain bound to the cytochrome coxidase until the reduction to water is completed. Occasionally, these intermediates are reduced by the addition of a single electron creating a number of different ROS: superoxide anion, the hydroxyl radical, or peroxide (40). Because ROS cause oxidative damage to all biomolecules, the cell produces several antioxidant enzymes to scavenge these free radicals. When these defenses are overwhelmed by ROS, the cell is in a state of oxidative stress. According to the free radical theory of aging, oxidative stress causes a vicious cycle: oxidative damage to mtDNA and proteins impairs the mitochondrial function, which results in the generation of even more ROS (41). Indeed mutations accumulate in mitochondrial DNA at a higher rate than in nuclear DNA (42). This is attributed to the direct exposure to ROS, a different repair capacity in the mitochondria, and the higher error rate of the mitochondrial DNA polymerase $\gamma$ (43). The mutator mouse gives impressive evidence to the causative relation of mtDNA mutation accumulation and aging. The mutant mouse lacks the proofreading activity of the mtDNA polymerase $\gamma$ resulting in an elevated amount of point mutations in the mitochondrial DNA. These mice appear normal until the age of twenty-five weeks, when they develop a progressive progeroid phenotype characterized by weight loss, reduced subcutaneous fat, alopecia, osteoporosis, reduced fertility, graying hair, and hearing loss (44). Also, some segmental progeroid syndromes like Cutis laxa type 3 and Fontain progeroid Syndrome are caused by mutations in genes encoding mitochondrial proteins $(45,46)$. A mutation in the gene SLC25A24 causes Fontain progeroid syndrome, characterized by prenatal and postnatal growth retardation, decreased subcutaneous fat, sparse hair, and craniosynostosis (47). The gene is encoded by the nDNA and encodes the calcium-dependent mitochondrial carrier protein SCaMC-1, which may play a role in protecting the mitochondrium from oxidative stress (48).

On the molecular level, the decrease of energy generation and mitochondrial membrane potential and the increase of ROS production and somatic mutations with age have been observed $(49,50)$. Many mutants have been generated to test this aging theory giving further evidence for the importance of mitochondria and oxidative stress in aging. The Drosophila 
melanogaster mutants overexpressing the two antioxidant enzymes $\mathrm{Cu} / \mathrm{Zn}$-superoxide dismutase and catalase show an increased lifespan. Recently accumulating evidence contradicts the free radical theory of aging. Caenorhabditis elegans mutants lacking each of the five superoxide dismutase genes have a normal or decreased lifespan. On the contrary, lifespan extensions are also observed when worms are exposed to ROS-generating chemicals (51). Evidence indicates that in addition to their damaging role ROS also plays a role as signaling molecules in cell proliferation and survival (52).

\subsubsection{The Telomere Theory of Aging}

The telomere theory of aging has its roots in the 1950s, with the observation of Hayflick and his colleagues that many different human cells have a limited capacity to divide in cell culture (53). Olovnikow later proposed the end replication problem as an explanation for this replicative limit, which could later be proven (54). The linear chromosomes are capped with repetitive sequences (tandem TTAGGG repeats), so-called telomeres, associated with proteins that protect the chromosome ends against degradation. This capping allows the cell to distinguish between chromosome ends and double-strand breaks. At the 3 ' end of telomeres, a short single-stranded sequence forms a hairpin loop structure called T-loop and is accompanied by the shelterin complex. During cell division, the DNA is replicated. Since the DNA polymerase can only move in the $5^{\prime}$ to $3^{\prime}$ direction, this requires an RNA primer to initiate elongation on the lagging strand. When this primer is later removed, there is no mechanism to fill up this gap, thus telomers shorten with each replication (55). The enzyme telomerase extends telomeres in cells with unlimited proliferative potential, such as germ and stem cells. However, most other cell types lack telomerase activity (56). The following observations form the basis of the telomere theory of aging: telomers act like a biological clock that determines the lifespan of each cell. On critically short telomeres, the t-loop conformation could be lost, and the DNA repair machinery recognizes the chromosome end as a double-strand break, a signal to arrest the cell cycle and even enter senescence (57). These senescent cells accumulate in tissues to the point where the functionality of the tissues is compromised (54). Several observations support this theory: [1] Telomere length shortens with age in all species analyzed (58). [2] Mean telomere length in early life and lifespan correlate (59). [3] Telomere length and development of cardiovascular disease, some cancers, Alzheimer's disease, and 
Parkinson's disease are inversely correlated (60-63). [4] Mutant mice with accelerated telomere shortening show accelerated aging, whereas mice with longer telomers show signs of slowed aging $(64,65)$. [5] Moreover, a reduced telomere length is observed in some progeroid syndromes, such as Hutchinson-Gilford progeria syndrome, Dyskeratosis congenita, and Ataxia telangiectasia (66).

However, several strong arguments stand against the telomere theory of aging. First, there is immense variation of telomere length between individuals of the same age. There is no correlation between telomere length and lifespan when comparing species. Mice, for example, have five to ten times longer telomeres than humans and 30 times shorter lifespan (67). Lastly, recent studies suggest that telomere dysfunction occurs independently of telomere length. The view prevails today that telomers act as sensors of extrinsic and intrinsic stress and induce senescence independently of telomere length (68).

The one cause of aging might never be found, as aging is a highly complex process. A consensus is emerging that aging is a multifactorial process, which is influenced, but not caused by certain genes. Understanding the mechanisms causing molecular damage to accumulate and the systems working to repair the damage might help to understand the aging process (9).

\subsection{Hallmarks of Aging}

Disregarding the discussion on the cause of aging, López-Otín et al. published a scientific summary on aging research with the title "Hallmarks of Aging" in 2013 (69). By describing nine hallmarks of aging that are characteristic of aging in diverse organisms, they set a framework for future aging research. Each hallmark fulfills three criteria to varying degrees: [1] The hallmark manifests during normal aging. [2] Its experimental aggravation accelerates aging, and [3] its experimental amelioration retards the normal aging process and thus increases lifespan. The proposed nine hallmarks of aging are genomic instability, telomere attrition, epigenetic alterations, loss of proteostasis, deregulated nutrient sensing, mitochondrial dysfunction, cellular senescence, stem cell exhaustion, and altered intercellular communication. A schematic representation of the nine hallmarks is depicted in Figure 2. 


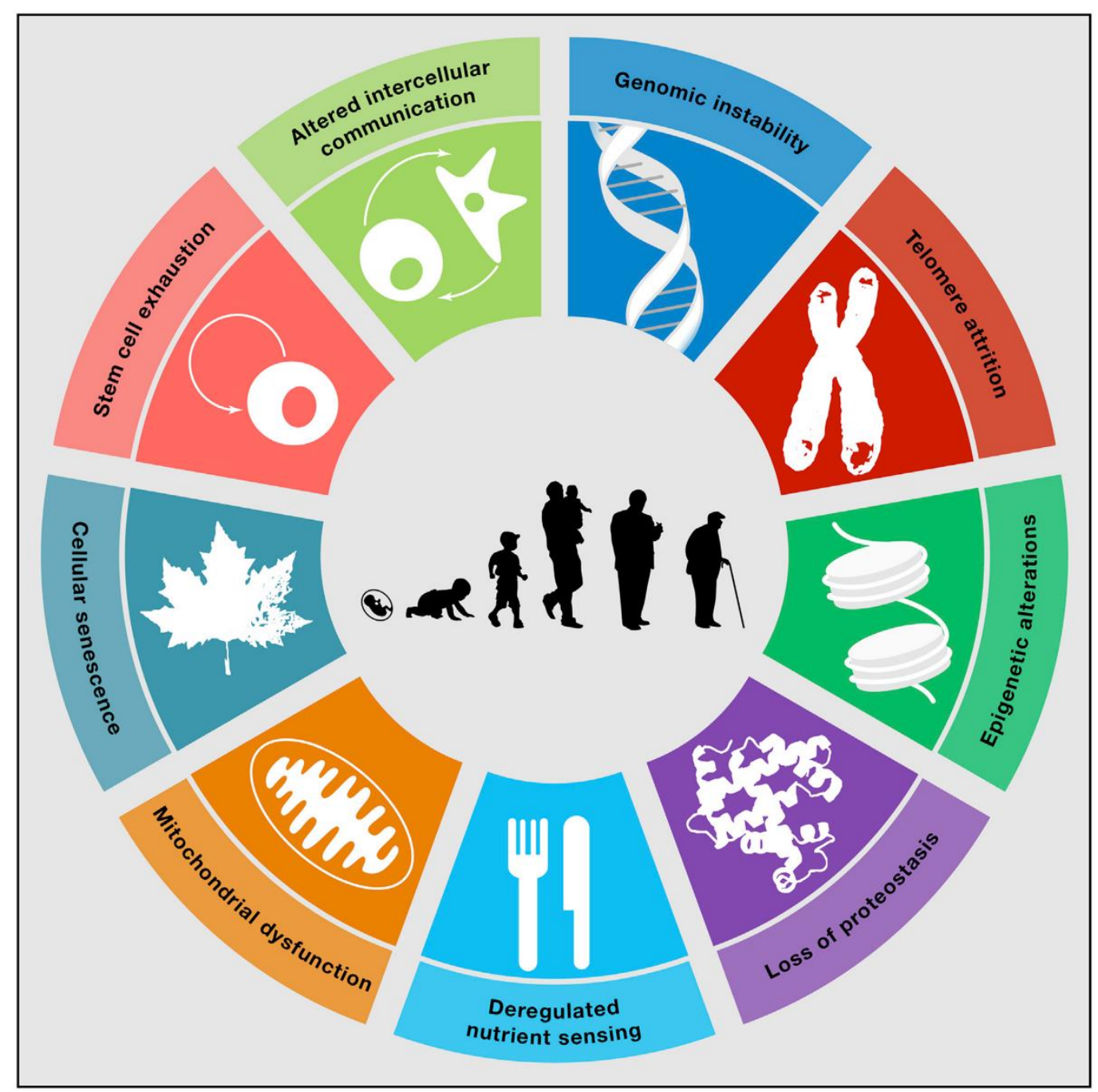

Figure 2: The nine hallmarks of aging

The scheme depicts the nine hallmarks of aging: genomic instability, telomere attrition, epigenetic alterations, loss of proteostasis, deregulated nutrient sensing, mitochondrial dysfunction, cellular senescence, stem cell exhaustion, and altered intercellular communication. The figure is taken from Lopez-Otin et. al. 2013 (69).

The additive effect of hallmarks and the interconnectedness between them challenges the dissection of aging into these categories. The nine hallmarks of aging are divided into three groups to reflect their relation: [1] primary hallmarks, [2] antagonistic hallmarks, and [3] integrative hallmarks. The primary hallmarks are deleterious and cause damage to the cell directly. Primary hallmarks are genome instability, telomere attrition, epigenetic alteration, and loss of proteostasis. The antagonistic hallmarks deregulated nutrient sensing, cellular senescence, and mitochondrial dysfunction are beneficial at low levels but become deleterious at high levels. Finally, the integrative hallmarks stem cell exhaustion, altered intercellular communication affect tissue homeostasis and function (69). 
A tenth hallmark of aging, namely defective autophagy, has been proposed recently. Autophagy is a protein turnover pathway by which defective molecules are delivered to the lysosome for degradation and recycling (70). As the hallmarks genome instability (section 1.1.4), telomere attrition (section 1.1.6), mitochondrial dysfunction (section 1.1.5), and altered nutrient sensing (1.3.1) are described elsewhere, I will elaborate on the hallmark of defective autophagy by describing how it meets the three criteria for a hallmark of aging. [1] Autophagic activities decrease with age and thereby contributing to the accumulation of damaged molecules and organelles. The decline of mitophagy markers with age has been shown in worms (71), flies $(72)$, and humans $(73,74)$. [2] Failure of autophagic processes aggravates in aging-associated diseases. For example, the tissue-specific knockdown of Atg5 and Atg7 in mice leads to neurodegeneration (75). [3] Enhancement of autophagy extends lifespan as overexpression of the ATG5 protein, which is essential for autophagosome formation in mice, enhances autophagy processes, and thereby causes an anti-aging phenotype in the mice, and an extension of lifespan by $17 \%$ (76).

\subsection{Genetic Aspects of Aging}

Aging is universal and highly variable at the same time. Environmental factors such as nutrition, physical activity, and stress influence aging, while variants in our genes might determine how we age (77). With the aid of twin and genome-wide association studies (GWAS), by comparison of the lifespan of various species, and finally, the study of accelerated aging syndromes in humans, a picture of the fundamental involvement of genetics in aging and longevity forms.

\subsubsection{Genetics of Longevity}

Life expectancy at birth in Europe has risen from 33 years in 1800 to 75 years (male) and 80 years (female) in 2001 and is still rising thanks to improvements in health care, lifestyle, and nutrition (78). Life expectancy at birth in 2050 is projected to be 83 years for men and 88 years for women in Germany (79). Thus, the environment has a very strong impact on lifespan. Nevertheless, there is remarkable variability of lifespan in individuals under the same environmental conditions: While some die of age-related diseases in their 60s, a few individuals are still healthy and active at 100 years of age. Family members of long-lived 
individuals have a significant survival advantage over the general population (80). Twin studies on longevity aimed to distinguish genetic from environmental influences and estimate the heritability of lifespan at $25 \%$ (81).

Looking at closely related species with very different lifespans is also an interesting approach to finding genetic causes for longevity. Naked mole rats (Heterocephalus glaber) are the longest living rodents known. They live in sealed borrows in large eusocial colonies. One breeding female mates with few males and is cared for by around 300 workers. In captivity, their maximal lifespan is 32 years, which is eight times longer than the life expectancy of the similarly sized mice. These animals are not only long-lived, but they also show sustained good health, no age-associated rise of mortality risk, and a very low rate of cancer. By comparing their genome to mice and human genomes, several differences were identified. A gene expansion in the genes CEBPY and TINF2 suggests better protection against cellular stress, better control of telomerase activity, and DNA damage signaling. Naked mole rats also display a remarkable resistance to oxidative stress, improved protein homeostasis, and a reduced metabolic rate (82). There are also several long-lived bat species. Brandt's bat (Myotis brandtii) is the longest-lived bat species known to date, with a maximum lifespan of 40 years. These animals rest during the day, feed at night on insects, and hibernate during the winter. Aside from adaptations for echolocation, hibernation, metabolism, reproduction, and visual function, genome analysis reveals changes in growth hormone and insulin-like growth factor 1 (IGF-1) receptors that may contribute to the exceptional longevity of these bats (83).
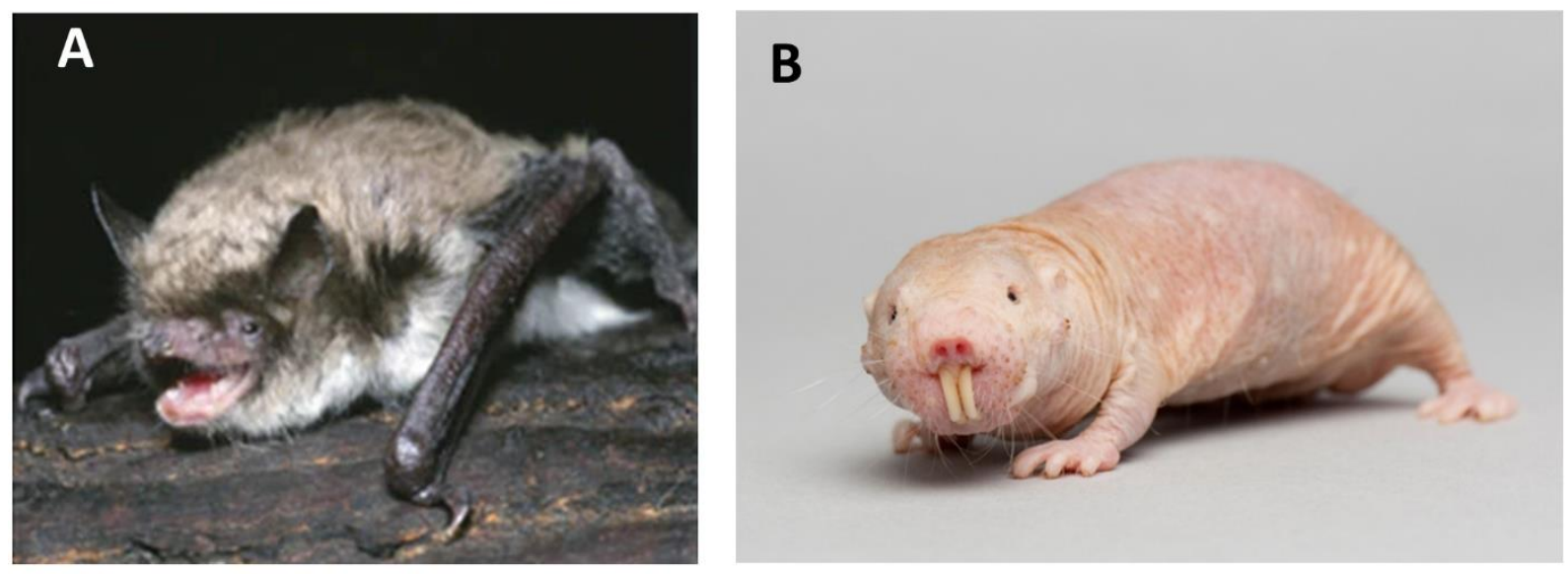

Figure 3: Two long-lived mammal species

The two of the longest-lived mammal species are Brandt's bat (A) and the naked mole rats (B). Figure modified after Seim et al. (83) and Reardon et al. (84). 
GWAS studies have been carried out to find genetic variants modulating human longevity in the past years. In a GWAS study, two groups of participants are compared to find singlenucleotide polymorphisms (SNPs) that occur more often in one group (e.g. centenarians) and are then said to be associated with high age or a certain disease. However, only a few SNPS reach genome-wide significance and can be reproduced by different studies and in different populations. Among these are variants in the APOE gene, which encodes Apolipoprotein $\mathrm{E}$ and is involved in lipid transport to the cell. Additionally, variants in the transcription factor FOXO3, which influences energy metabolism, cell cycle regulation, and inflammation, have been associated with extreme longevity (85).

As FOXO3 is part of the signaling pathway activated by insulin, a link between insulin and aging has thus also been found in humans. Unsurprisingly "Deregulated Nutrient Sensing" is one of the nine hallmarks of aging (see section 1.2). The anterior pituitary gland produces growth hormone (GH). Many cell types react to $\mathrm{GH}$ with the production of IGF-1. The intracellular signaling pathway of IGF-1 is the same as the response elicited by insulin, which signals the presence of glucose to the cells. The intracellular pathway is thus called the "insulin and IGF1 signaling pathway". Among its targets are the FOXO family of transcription factors and the mTOR complexes (86). Polymorphisms or mutations that reduce the effect of GH, the IGF-1 receptor, the insulin receptor, or their downstream effectors such as mTOR and FOXO have been linked to longevity in worm (87), fruit flies (88), mice (89), and humans (85). Consistent with these findings is the fact that this pathway also mediates the beneficial effects of dietary restriction on longevity (90). This pathway is already a target of drugs for the treatment of age-related diseases: Rapamycin, which inhibits mTOR, is used to treat cancer and to prevent rejection of transplanted organs, and metformin, which is used to treat type two diabetes, have both been found to extend lifespan in model organisms. First clues to a beneficial effect in humans independent from cancer and diabetes treatment are already under investigation (91).

In summary, it appears that longevity is a complex polygenic trait that is influenced by the interaction of multiple genetic variants and, to a large part, by the environment (92). 


\subsubsection{Segmental Progeroid Syndromes}

On the other end of the aging spectrum are progeroid syndromes. The word progeria is

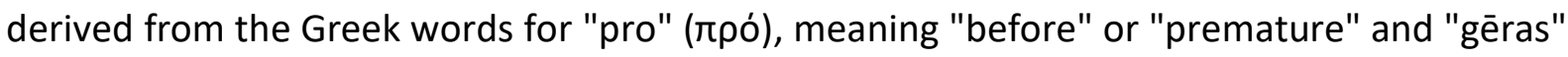
(үñpaৎ) meaning "old age". The suffix "-oid" means "-like" implying that these syndromes only mimic not duplicate some aspects of physiological aging. While in unimodal progeroid syndromes like Alzheimer's disease and Parkinson's disease, only one tissue or organ system is affected by premature aging, two or more tissues are affected in segmental progeroid syndromes (93). A complete list of all syndromes classified as progeroid syndromes and a universal classification are lacking. Classification by the age of onset and the altered molecular system have been suggested $(94,95)$. Typical signs of premature aging in segmental progeroid syndromes are symptoms that occur in the general population at a more advanced age: graying and loss of hair, hearing loss, cataracts, wrinkly skin, diabetes mellitus type 2, osteoporosis, arteriosclerosis, tumors, and dementia. Another common feature of segmental progeroid syndromes, which is not a common feature of aging, is growth retardation due to the fundamental involvement of the mutated genes in cell viability. Since the overall incidence of segmental progeroid syndromes is very rare at 1:50,000 and the syndromes have marked heterogeneity and complexity of the overlapping symptoms, they are primarily diagnosed by genetic testing based on next-generation sequencing (NGS)-based techniques (95). Currently, the newly established Center for Progeroid Syndromes, as part of the Center for Rare Diseases Göttingen (ZSEG), offers genetic testing for 85 genes related to 19 progeroid syndromes (96). While different sources claim there are between 70 and over 100 different segmental progeroid syndromes, the most widely reviewed syndromes are summarized in Table 1 $(95,97)$.

The two main questions regarding aging research on segmental progeroid syndromes are [1] whether they truly recapitulate aging and [2] whether the knowledge we gain from studying these diseases will improve our understanding of physiological aging. The examples of the widely studied segmental progeroid syndromes Hutchinson-Gilford progeria syndrome (HGPS) and Werner syndrome (WRS) answer these two questions positively. In Figure 4, images of patients suffering from HGPS, WRS, Cutis laxa type III, Bloom syndrome, Cutis laxa type IC, and Fontain progeroid syndrome are shown as examples of typical and extensively studied segmental progeroid syndromes. 


\section{Introduction}

Table 1: Overview of segmental progeroid syndromes

\begin{tabular}{|c|c|c|}
\hline Syndrome & Gene & Symptoms \\
\hline $\begin{array}{l}\text { Hutchinson-Gilford progeria } \\
\text { syndrome } \\
\text { (OMIM 176670) }\end{array}$ & $\begin{array}{l}\text { LMNA } \\
\text { (Nuclear envelope) }\end{array}$ & $\begin{array}{l}\text { short stature, low body weight, early loss of hair, } \\
\text { lipodystrophy, scleroderma, decreased joint } \\
\text { mobility, osteolysis, progeroid facial appearance, } \\
\text { cardiovascular complications (98) }\end{array}$ \\
\hline $\begin{array}{l}\text { Mandibuloacral dysplasia } \\
\text { (OMIM 248370, 608612) }\end{array}$ & $\begin{array}{l}\text { LMNA, ZMPSTE24 } \\
\text { (Nuclear envelope) }\end{array}$ & $\begin{array}{l}\text { lipodystrophy, altered skin pigmentation, bone } \\
\text { and growth defects, insulin resistance, dental } \\
\text { abnormalities (99) }\end{array}$ \\
\hline $\begin{array}{l}\text { Néstor-Guillermo progeria } \\
\text { syndrome } \\
\text { (OMIM 614008) }\end{array}$ & $\begin{array}{l}\text { BANF1 } \\
\text { (Nuclear envelope) }\end{array}$ & $\begin{array}{l}\text { altered skin pigmentation, lipodystrophy, growth } \\
\text { and bone defects, alopecia (100) }\end{array}$ \\
\hline $\begin{array}{l}\text { Wiedemann-Rautenstrauch } \\
\text { syndrome } \\
\text { (OMIM 264090) }\end{array}$ & $\begin{array}{l}\text { POLR3A } \\
\text { (Transcription) }\end{array}$ & $\begin{array}{l}\text { intrauterine growth retardation, failure to thrive, } \\
\text { short stature, a progeroid facial appearance, } \\
\text { hypotonia, and variable mental impairment, } \\
\text { dental abnormalities (101) }\end{array}$ \\
\hline $\begin{array}{l}\text { Werner syndrome } \\
\text { (OMIM 277700) }\end{array}$ & $\begin{array}{l}\text { RECQL2 } \\
\text { (Transcription, Replication, DNA } \\
\text { damage repair) }\end{array}$ & $\begin{array}{l}\text { premature graying, thinning of hair, skin atrophy, } \\
\text { bilateral cataracts, diabetes mellitus, osteoporosis, } \\
\text { arteriosclerosis, multiple benign and malignant } \\
\text { neoplasms (102) }\end{array}$ \\
\hline $\begin{array}{l}\text { Ruijs-Aalfs Syndrome } \\
\text { (OMIM 616200) }\end{array}$ & $\begin{array}{l}\text { SPRTN } \\
\text { (DNA damage repair) }\end{array}$ & $\begin{array}{l}\text { cataracts, gray hair, alopecia, osteoporosis, } \\
\text { sarcopenia, increased cancer risk atherosclerosis, } \\
\text { diabetes mellitus (103) }\end{array}$ \\
\hline $\begin{array}{l}\text { Cockayne Syndrome } \\
\text { (OMIM 216400, 133540) }\end{array}$ & $\begin{array}{l}\text { ERCC8, ERCC6 } \\
\text { (DNA damage repair) }\end{array}$ & $\begin{array}{l}\text { ataxia, muscle atrophy, cataracts, retinal } \\
\text { degeneration, neurodegeneration (104) }\end{array}$ \\
\hline $\begin{array}{l}\text { Xeroderma pigmentosum } \\
\text { (OMIM 278700, 610651, } \\
278720,278730,278740, \\
278760,278780,278750) \\
\end{array}$ & $\begin{array}{l}X P A, X P B, X P C, X P D, E R C C 6, D D B 2, \\
E R C C 4, R A D 2, E R C C 5, P O L H \\
\text { (DNA damage repair) }\end{array}$ & $\begin{array}{l}\text { premature photoaging of the skin, } \\
\text { neurodegeneration, skin cancer (105) }\end{array}$ \\
\hline $\begin{array}{l}\text { Bloom syndrome } \\
\text { (OMIM 210900) }\end{array}$ & $\begin{array}{l}\text { RECQL3 (BLM) } \\
\text { (Transcription, Replication, DNA } \\
\text { damage repair) }\end{array}$ & $\begin{array}{l}\text { increased cancer risk, diabetes, chronic } \\
\text { obstructive lung disease, photosensitivity (106) }\end{array}$ \\
\hline $\begin{array}{l}\text { Marfan Lipodystrophy } \\
\text { syndrome } \\
\text { (OMIM 616914) }\end{array}$ & $\begin{array}{l}\text { FBN1 } \\
\text { (Extracellular Matrix) }\end{array}$ & $\begin{array}{l}\text { congenital lipodystrophy, premature birth with } \\
\text { accelerated linear growth, arachnodactyly, digital } \\
\text { hyperextensibility, myopia, dural ectasia, } \\
\text { progeroid appearance with distinct facial features } \\
\text { including proptosis, down slanting palpebral } \\
\text { fissures, retrognathia (107) }\end{array}$ \\
\hline $\begin{array}{l}\text { SHORT syndrome } \\
\text { (OMIM 269880) }\end{array}$ & $\begin{array}{l}\text { PIK3R1 } \\
\text { (Cell signaling) }\end{array}$ & $\begin{array}{l}\text { lipodystrophy, insulin resistance, nephrocalcinosis, } \\
\text { hearing deficits, recognizable facial gestalt } \\
\text { consisting of triangular facies, lack of facial fat, } \\
\text { and hypoplastic nasal alae with overhanging } \\
\text { columella (108) }\end{array}$ \\
\hline $\begin{array}{l}\text { Keppen-Lubinsky syndrome } \\
\text { (OMIM 614098) }\end{array}$ & $\begin{array}{l}\text { KCNJ6 } \\
\text { (Cell signaling) }\end{array}$ & $\begin{array}{l}\text { severely delayed psychomotor development, } \\
\text { hypertonia, hyperreflexia, generalized } \\
\text { lipodystrophy, distinctive dysmorphic features, } \\
\text { including microcephaly, prominent eyes, narrow } \\
\text { nasal bridge, and open mouth (109) }\end{array}$ \\
\hline
\end{tabular}




\begin{tabular}{|c|c|c|}
\hline $\begin{array}{l}\text { Penttinen syndrome } \\
\text { (OMIM 601812) }\end{array}$ & $\begin{array}{l}\text { PDGFRB } \\
\text { (Cell signaling) }\end{array}$ & $\begin{array}{l}\text { prematurely aged appearance involving } \\
\text { lipoatrophy and epidermal and dermal atrophy, as } \\
\text { well as hypertrophic lesions that resemble scars, } \\
\text { thin hair, proptosis, underdeveloped cheekbones, } \\
\text { and marked acroosteolysis (110) }\end{array}$ \\
\hline $\begin{array}{l}\text { Cutis laxa-associated } \\
\text { syndromes } \\
\text { (OMIM 219100, 123700) }\end{array}$ & $\begin{array}{l}\text { FBLN5, FBLN4, LTBP4, ATP6VOA2, } \\
\text { PYCR1, ATP6V1E1, ATP6V1A, } \\
\text { ALDH18A1, ELN (Mitochondria, } \\
\text { Golgi apparatus, Extracellular } \\
\text { matrix) }\end{array}$ & sagging and inelastic skin (111) \\
\hline $\begin{array}{l}\text { Lenz-Majewski hyperostotic } \\
\text { dwarfism } \\
\text { (OMIM 151050) }\end{array}$ & $\begin{array}{l}\text { PTDSS1 } \\
\text { (Cell membrane) }\end{array}$ & $\begin{array}{l}\text { Intellectual disability, sclerosing bone dysplasia, } \\
\text { distinct craniofacial and dental anomalies, loose } \\
\text { skin, and distal limb anomalies, progressive } \\
\text { generalized hyperostosis, severe growth } \\
\text { retardation (112) }\end{array}$ \\
\hline $\begin{array}{l}\text { Rothmund-Thomson syndrome } \\
\text { (OMIM 618625, 268400) }\end{array}$ & $\begin{array}{l}\text { ANAPC1, RECQL4 } \\
\text { (Transcription, Replication, DNA } \\
\text { damage repair) }\end{array}$ & $\begin{array}{l}\text { cataracts, alopecia, osteoporosis, increased cancer } \\
\text { risk, epidermal atrophy (113) }\end{array}$ \\
\hline $\begin{array}{l}\text { Dyskeratosis congenita } \\
\text { (OMIM 613989, 613990, } \\
615190,268130,616553, \\
224230,613987,613988, \\
613989615190,616353, \\
616553,305000)\end{array}$ & $\begin{array}{l}\text { TERT, TINF2, RTEL1, TINF2, ACD, } \\
\text { NOLA3, NOLA2, TCAB1, PARN } \\
\text { (Telomere maintenance) }\end{array}$ & $\begin{array}{l}\text { bone marrow failure, abnormal skin pigmentation, } \\
\text { cancer predisposition, pulmonary and hepatic } \\
\text { fibrosis, leukoplakia, nail dystrophy, } \\
\text { thrombocytopenia, premature hair greying, } \\
\text { osteoporosis, testicular atrophy (114) }\end{array}$ \\
\hline $\begin{array}{l}\text { Ataxia teleangiectasia } \\
\text { (OMIM 208900) }\end{array}$ & $\begin{array}{l}\text { ATM } \\
\text { (DNA damage response) }\end{array}$ & $\begin{array}{l}\text { neurodegeneration, premature exhaustion of } \\
\text { bone marrow, diabetes (115) }\end{array}$ \\
\hline $\begin{array}{l}\text { Restrictive dermopathy } \\
\text { (OMIM 275210) }\end{array}$ & $\begin{array}{l}\text { ZMPSTE24, LMNA } \\
\text { (Nuclear envelope) }\end{array}$ & $\begin{array}{l}\text { intrauterine growth retardation, facial deformities, } \\
\text { enlarged fontanelles, tightly adherent skin, low } \\
\text { bone density, dysplasia of clavicles, congenital } \\
\text { contractures (116) }\end{array}$ \\
\hline $\begin{array}{l}\text { Fanconi anemia } \\
\text { (OMIM 227650) }\end{array}$ & $\begin{array}{l}\text { BRCA2, BRIP1, FANCA, FANCB, } \\
\text { FANCC, FANCD2, FANCE, FANCF, } \\
\text { FANCG, FANCI, FANCL, FANCM, } \\
\text { PALB2, RAD51C, SLX4 } \\
\text { (DNA damage response) }\end{array}$ & $\begin{array}{l}\text { increased cancer risk, bone marrow failure, short } \\
\text { stature, skin abnormalities, developmental } \\
\text { disabilities (117) }\end{array}$ \\
\hline $\begin{array}{l}\text { Trichothiodystrophy } \\
\text { (OMIM 601675) }\end{array}$ & $\begin{array}{l}X P B, X P D, T F B 5 \\
\text { (DNA damage response) }\end{array}$ & $\begin{array}{l}\text { brittle hair, skin photosensitivity, growth } \\
\text { retardation, neurological abnormalities (118) }\end{array}$ \\
\hline $\begin{array}{l}\text { XFE progeroid syndrome } \\
\text { (OMIM 610965) }\end{array}$ & $\begin{array}{l}\text { ERCC4 } \\
\text { (DNA damage response) }\end{array}$ & $\begin{array}{l}\text { failure to thrive during infancy, sun sensitive skin, } \\
\text { premature menopause, impaired intellectual } \\
\text { development, thin and gray hair, short stature, } \\
\text { microcephaly (119) }\end{array}$ \\
\hline $\begin{array}{l}\text { Nijmegen breakage syndrome } \\
\text { (OMIM 251260) }\end{array}$ & $\begin{array}{l}\text { NBN } \\
\text { (DNA damage response) }\end{array}$ & $\begin{array}{l}\text { progressive microcephaly, intrauterine growth } \\
\text { retardation, short stature, recurrent } \\
\text { sinopulmonary infections, increased cancer risk } \\
\text { (120) }\end{array}$ \\
\hline $\begin{array}{l}\text { Seckel syndrome } \\
\text { (OMIM 210600, 606744, } \\
613676,613823,614728 \\
614851,615807,616253 \text { ) } \\
\end{array}$ & $\begin{array}{l}\text { ATR, RBBP8, CENPJ, CEP152, CEP63, } \\
\text { NIN, DNA2, TRAPIP, NSMCE2 } \\
\text { (DNA damage response) }\end{array}$ & $\begin{array}{l}\text { intrauterine growth retardation, dwarfism, } \\
\text { microcephaly with mental retardation, and a } \\
\text { characteristic facial appearance }(121,122)\end{array}$ \\
\hline
\end{tabular}




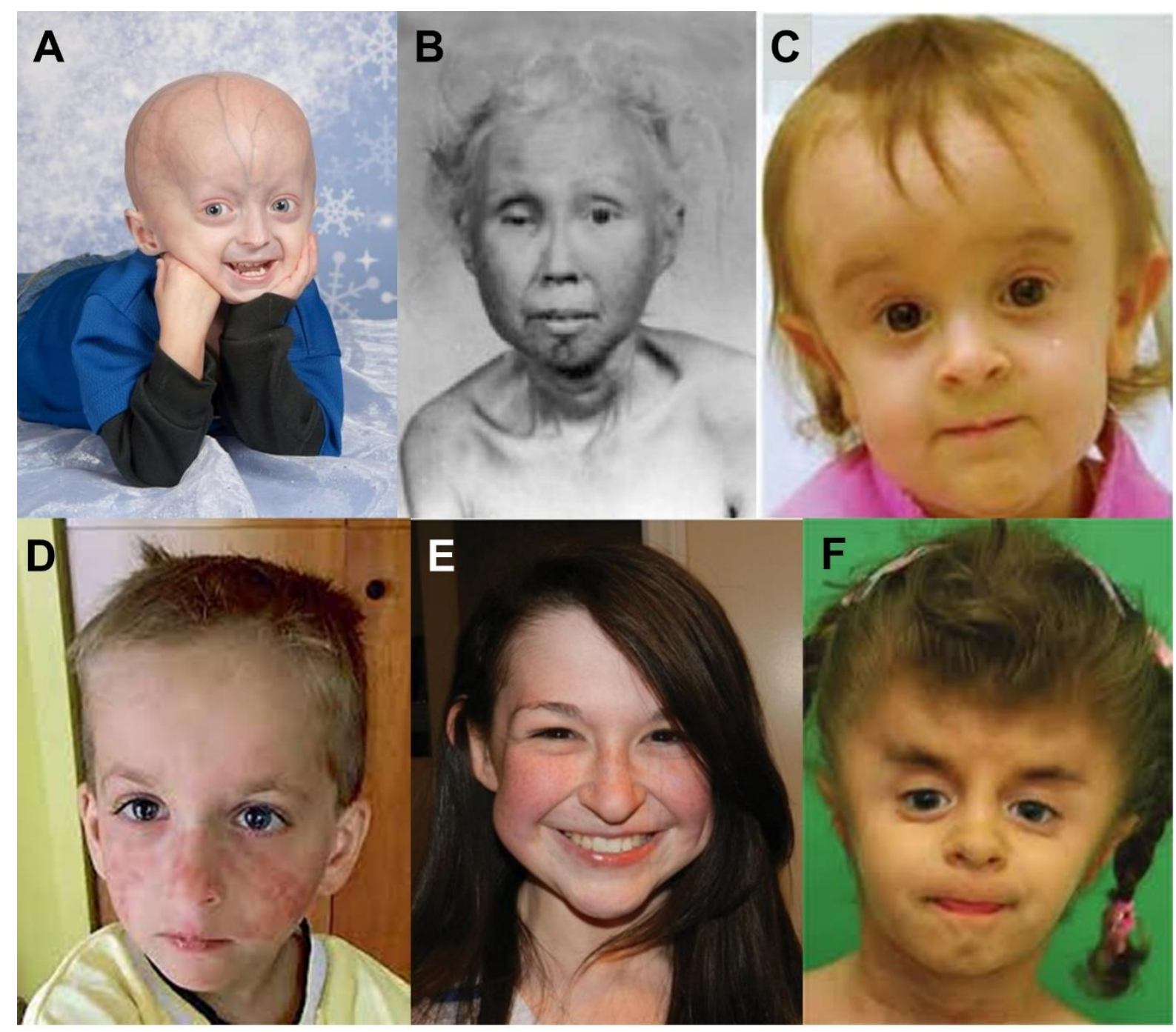

Figure 4: Patients diagnosed with various progeroid syndromes

A: Four-year-old boy with HGPS. Image is taken from (123). B: 48-year-old Japanese-American woman suffering from WRS (124). C: 18-month old girl diagnosed with Cutis laxa type 3. Image is taken from (45).D: Characteristic facial rush of a young boy with Bloom syndrome. Image is taken from (125). E: 14-year-old girl suffering from Cutis Laxa type IC with mild cutis laxa, prominent ears, and hooked nose. The image is taken from (126). F: A 3-year-old girl diagnosed with Fontaine progeroid syndrome. Image is taken from (46).

As HGPS and WRS are two of the best-characterized human progeroid syndromes, their symptoms, pathomechanisms, and current research for treatments will be described in the two following sections.

\subsubsection{Hutchinson-Gilford Progeria Syndrome}

Children affected by HGPS appear normal at birth but develop failure to thrive in the first months. During their first two years, the patients display alopecia, loss of eyebrows and eye 
lashes, growth retardation, wrinkly skin, lipodystrophy, joint contractures, and nail dystrophy. Over time hearing loss, osteoporosis, and sometimes insulin resistance develops. The motor, as well as the intellectual development, are usually normal, and cancer risk is not increased. The patients typically die of complications of arteriosclerosis after myocardial infarction or a stroke. The life expectancy is fifteen years. The genetic cause is a recurrent de novo heterozygous silent point mutation in the LMNA gene (c.1824C >T; p.(G608G)) that activates a cryptic splice site resulting in an in-frame deletion. This truncated form of lamin A is called progerin and lacks a C-terminal protease cleavage site. Consequently, progerin remains permanently farnesylated, resulting in impaired incorporation into the nuclear lamina. Normal lamin processing and the effect of the HGPS-causing mutation on protein maturation are depicted in Figure 5.

(A)

Normal
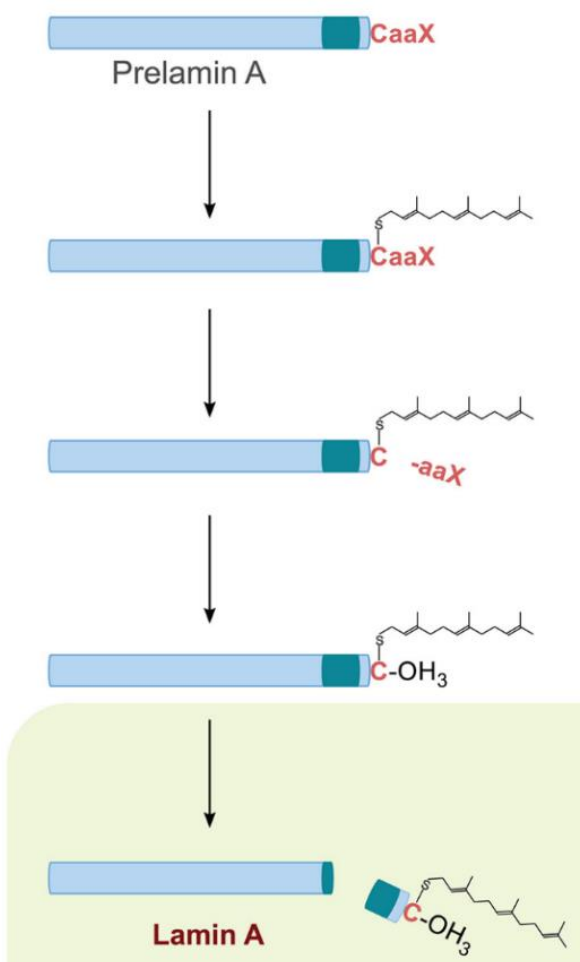

(B)

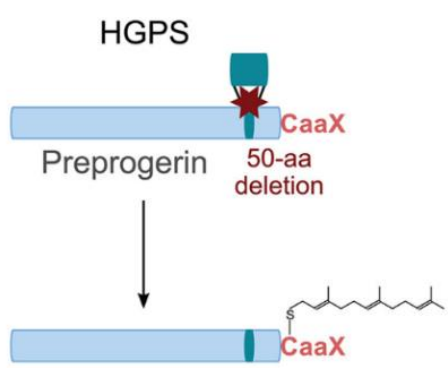

Cleavage

(ZMPSTE24)

arnesylation

(FTase)
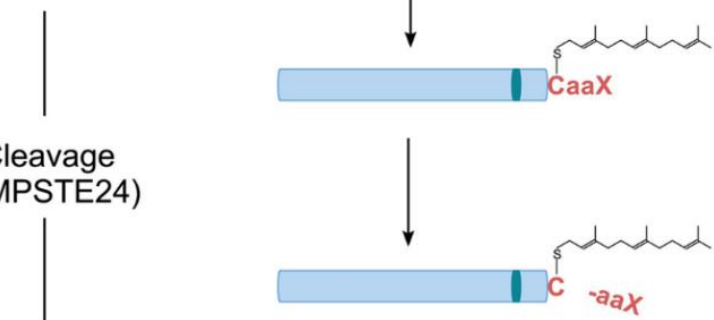

Methylation

(ICMT)

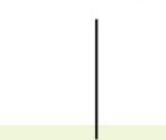

Cleavage

(ZMPSTE24)

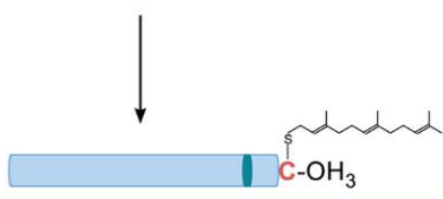

Recognition site deleted

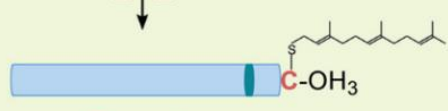

Progerin

Figure 5: Physiological Lamin A processing and the effect of the HGPS-causing mutation

A: After translation of the LMNA transcript, the farnesyl-transferase attaches a farnesyl-residue to the C-terminal end of the prelamin A protein. Then the protease Zmpste 24 cleaves the $C$ terminal domain producing the mature protein Lamin A, which does not contain the farnesyl residue. B: The C.1824 C>T mutation in the $L M N A$ gene causes aberrant splicing resulting in an in-frame deletion. The mutant pre-lamin A lacks the protease recognition site. After farnesylation, the protein is not cleaved, resulting in the permanently farnesylated protein progerin. The figure is taken from (127). 
On a cellular level, this progerin expression results in various defects: a changed nuclear shape, a thickened nuclear lamina, accumulation of DNA damage, genomic instability, telomere shortening, aberrant nucleocytoplasmic transport, and premature senescence. In HGPS, features of accelerated aging are most strikingly displayed, yet some features are not recapitulated: patients do not develop cancer or suffer from neurodegeneration. It has been speculated that the increased cancer risk due to genomic instability would only become evident at a later age. The reason for the lack of neurodegeneration is thought to be due to the lack of progerin expression in the brain (128). The HGPS bears another link to physiological aging: the cryptic splice site that is activated by the silent mutation is also used sporadically without the mutation. Progerin thus also accumulates during physiological aging and may be sufficient to elicit cellular damage (129).

Using HGPS disease models like patient-derived fibroblasts, induced pluripotent stem cells, and the HGPS mouse model, several treatments have been tested and several have shown promise to extend lifespan in patients. The treatment strategies act on different points of the disease mechanism: they aim to inhibit pre-mRNA aberrant splicing (Metformin), to decrease the toxicity of isoprenylated and methylated progerin (FTIS, ZOPRA), to induce progerin clearance (Rapamycin), and to decrease the downstream effects linked to progerin accumulation (130). The first clinical trial of a potential therapy for HGPS was initiated with a farnesyltransferase inhibitor called lonafarnib, which reduces the amount of permanently farnesylated progerin and was originally developed for the treatment of cancer. Researchers reported that children with HGPS receiving lonafarnib showed modest weight gain, reduced vascular stiffness, and increased mean survival by 1.6 years. Many more substances are being evaluated for treatment in preclinical tests in cell culture experiments and mouse models (130). The success of an in vivo base editing strategy in patient-derived fibroblasts and the HGPS mouse model has been published very recently. A single injection at day fourteen of an adenovirus encoding adenine base editors to directly correct the mutation extended the median lifespan of these mice from 215 to 510 days. Thereby demonstrating the high potential of genome editing approaches as possible treatments for HGPS and other genetic diseases (131). 


\subsubsection{Werner Syndrome}

WRS is one of the few premature aging disorders with adult onset. Patients develop normally until early adolescence when the earliest symptom of growth failure can be noticed. In their thirties, patients develop bilateral cataracts, prematurely grey and thinning hair, tight and atrophic skin, hyperkeratosis, and regional subcutaneous atrophy. Age-related disorders including diabetes mellitus type two, ulceration, hypogonadism, osteoporosis, atherosclerosis, and multiple malignancies also manifest. The most common causes of death are cancer and myocardial infarction at a median age of fifty-four years (102).

WRS is caused by homozygous or compound-heterozygous loss-of-function mutations in the WRN gene, which encodes the WRN protein. The protein has a $3^{\prime}-5^{\prime}$ exonuclease domain in its $\mathrm{N}$-terminus, an ATP-dependent 3 '-5' helicase in its central region, and a nuclear localization signal in its C-terminal region. Two other consensus domains are also part of the protein: the "RecQ helicase conserved region" (RQC) and the "helicase, RNaseD, C-terminal conserved region"(HRD). The RQC domain is critical for substrate-specific DNA binding, and the HRD domain also plays a role in DNA binding. Biochemical studies have identified G4 quadruplexes, Holiday junctions, and bubble structures as preferred substrates of the WRN protein, suggesting a function in resolving complex DNA structures. WRN is involved in the DNA damage pathways HR, NHEJ, and BER. Additionally, the WRN protein interacts with several components of the shelterin complex. Thus WRN is involved in DNA damage repair, DNA recombination, DNA transcription, and telomere maintenance (102).

Almost all WRS-causing mutations lead to the complete loss of WRN function. Single nucleotide polymorphisms (SNPs) have also been identified in the WRN gene, causing longevity, increased risk for cardiovascular diseases, and increased cancer risk in humans (132). This finding underlines once more the high relevance of research on progeroid syndromes for aging research in general.

The disease mechanism of WRS bears a link to each of the nine or rather ten hallmarks of aging $(133,134)$. [1] Genomic instability: WRN participates in both pathways of DSB repair (135). In mice lacking the $W R N$ gene, an increased DNA damage sensitivity has been shown (136). [2] Telomere attrition: As WRN promotes telomere maintenance, the loss of WRN results in rapid attrition of telomere length, which is even detectable in human patients (137). [3] Epigenetic 
alterations are found in blood samples from WRS patients, indicating an increased epigenetic age based on methylation biomarkers (138). [4] Loss of proteostasis: Protein aggregates have been found in the cytosol of patient-derived fibroblasts and could be normalized by treatment with the mTOR inhibitor rapamycin (139). [5] Deregulated nutrient sensing is evident in all WRS patients as they suffer from diabetes mellitus type two caused by insulin resistance. [6] Mitochondrial dysfunction: Increased levels of ROS and also oxidative DNA damage has been observed in WRS patient cells $(140,141)$. [7] Cellular senescence: WRN-deficient cells undergo early replicative senescence and show increased senescence-associated beta-galactosidase staining and a senescence-associated secretory phenotype (142). [8] Stem cell exhaustion: In embryonic stem cells with a biallelic WRN knockout mesenchymal stem cells showed impaired proliferation potential (143). [9] Altered intercellular communication: A pro-inflammatory cytokine-stimulated immunological change was detected in serum samples of WRS patients (144). [10] Defective Autophagy: Autophagy and the associated mTOR signaling have been found to be upregulated in WS cells. Long-term treatment with Rapamycin improves proliferation and reduces the accumulation of DNA damage (145). A summary of the role of the WRN protein in the context of the hallmarks of aging is shown in Figure 6.

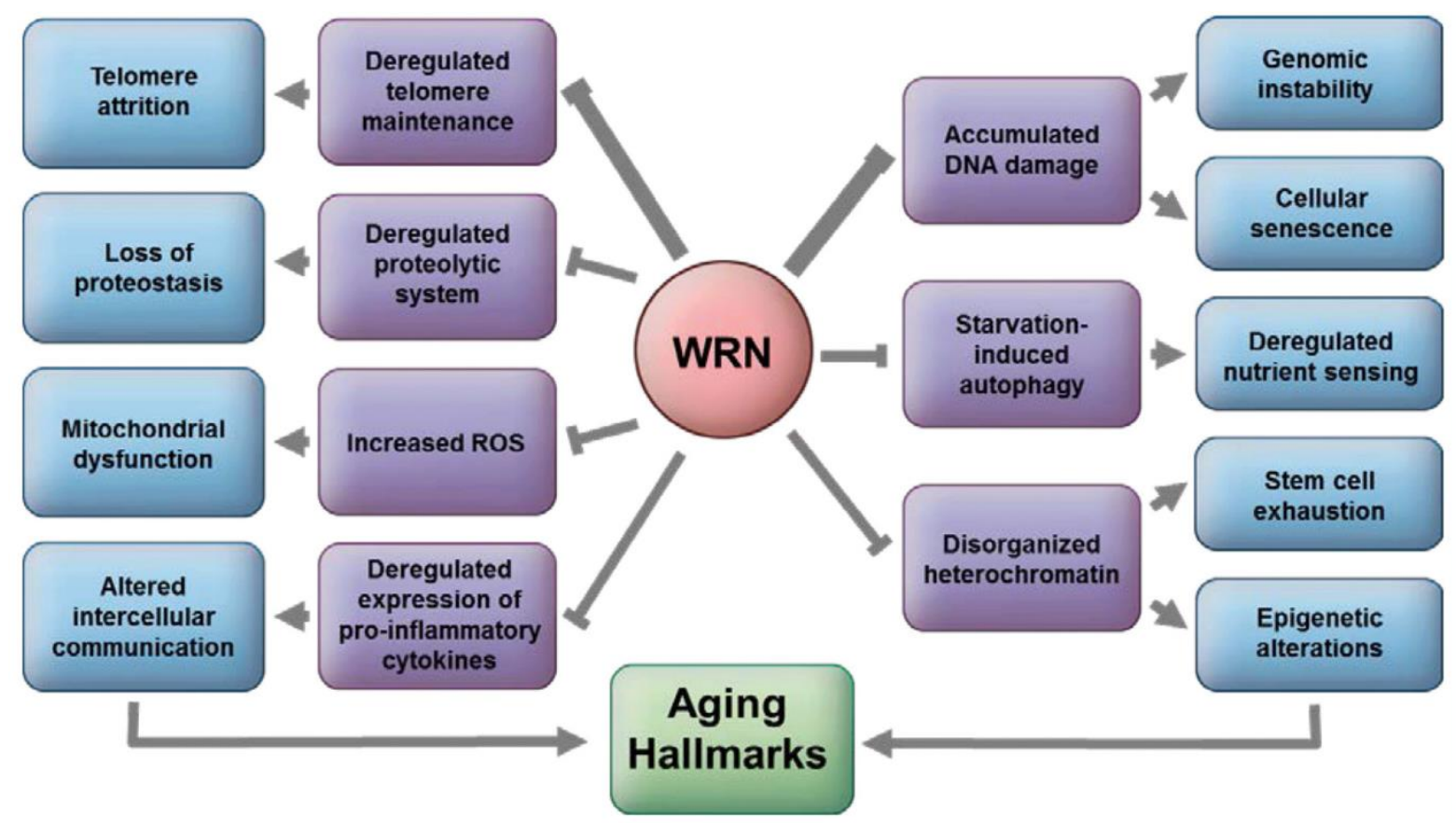

Figure 6: The role of the WRN protein in the context of the hallmarks of aging

Loss of WRN causes accumulation of DNA damage, starvation-induced autophagy, disorganized heterochromatin, deregulated telomere maintenance, deregulation of the proteolytic system, increased ROS, and deregulated expression of pro-inflammatory cytokines. The width of the lines shows the estimated involvement of the WRN protein in these processes. The figure is taken from (134). 
There is no cure or specialized treatment for WRS patients. Clinical management focuses on treating the symptoms and screening for complications common to WRS. Using the models mentioned above for WRS, several therapeutic approaches are being explored. Treatment of WRS fibroblasts with the mTOR inhibitor Rapamycin could be shown to decrease DNA damage accumulation and enhance cell proliferation in fibroblasts (145). Treatment with the selective inhibitor of P38 mitogen-activated protein kinase (MAPK) has been shown to restore the replicative potential in WRS fibroblasts (146). However, neither Rapamycin nor P38 MAPK inhibitors have been tested on WRS patients yet. Nevertheless, these examples of experimental treatments exemplify how research on progeroid syndromes might find targets for their treatment. Much research is needed to further our knowledge on the disease mechanisms of progeroid syndromes and molecular mechanisms of age-associated diseases. Strategies developed to treat progeroid syndromes could in the future also be considered for the treatment of pathologies of aging if they share the same disease mechanisms (94). 


\subsection{Goal}

Studying patients with progeroid syndromes bears the potential to discover molecular mechanisms of aging that contribute to our understanding of the physiological aging process. With the development of Next Generation Sequencing (NGS)-based approaches, the underlying genetic cause for many progeroid syndromes could be identified in the past ten years. However, elucidation of the associated molecular changes and the pathomechanisms causing accelerated aging has only begun. Most studies on progeroid syndromes focus on one syndrome and base their analysis on the protein function of the affected gene.

I aimed to investigate the molecular and cellular dysfunction in accelerated aging phenotypes using a systematic approach with a focus on three hallmarks of aging: genome instability, telomere attrition, and mitochondrial dysfunction. For this approach, I should gather a cohort of patients suffering from different segmental progeroid syndromes and analyze these samples systematically. This might help to find common molecular and cellular mechanisms that are not directly connected to the genetic cause.

In the first part of my thesis, I focus on the contribution of mitochondria to the aging processes. I aimed to develop and establish a novel ultra-high coverage mtDNA sequencing approach to quantify low-frequency mtDNA mutations as a measure of mtDNA damage and then use this method to analyze mtDNA integrity in patient-derived fibroblasts and DNA samples. Secondly, I focus on telomere attrition in aging by establishing and using a telomere real-time PCR for high-throughput measurement of relative telomere length as well as by cooperating on the optimization of the telomere qFISH method to enable a more detailed and sensitive measurement. Lastly, I aimed to analyze genome integrity by quantifying DNA damage markers such as $\mathrm{YH} 2 \mathrm{AX}$ in patient-derived fibroblasts.

In summary, my Ph.D. thesis should help to expand our current knowledge about the pathomechanisms of segmental progeroid syndromes by screening for cellular and molecular dysfunction and deepen our understanding of aging-associated processes in general. 


\section{Materials and Methods}

In the section, materials and methods, the equipment, expandable material, chemicals, solutions, cell lines, and protocols are described. In Table 2 and in Table 3 equipment and expandable material used for multiple methods are listed.

Table 2: Equipment

\begin{tabular}{|l|l|l|}
\hline Equipment & Product Name & Company \\
\hline Pipettes & $\begin{array}{l}\text { Eppendorf Research plus 1000, 200, } \\
100,20,10,2.5\end{array}$ & Eppendorf AG \\
\hline Pipette controller & VWR Accupette & VWR International \\
\hline Freezer & $\begin{array}{l}\text { Liebherr BluPerformance } \\
\text { Liebherr Comfort }\end{array}$ & Liebherr \\
\hline Fridge & $\begin{array}{l}\text { Liebherr Comfort } \\
\text { Liebherr Premium }\end{array}$ & Liebherr \\
\hline Centrifuges & $\begin{array}{l}\text { Heraeus Megafuge 16 Centrifuge } \\
\text { Centrifuge 5418 } \\
\text { Centrifuge 5417R } \\
\text { Megafuge 1.0R } \\
\text { Mini Star Silverline } \\
\text { Mini Centrifuge }\end{array}$ & $\begin{array}{l}\text { Thermo Fisher Scientific Inc. } \\
\text { Eppendorf AG } \\
\text { Eppendorf AG } \\
\text { Thermo Fisher Scientific Inc. } \\
\text { VWR International }\end{array}$ \\
\hline Thermal cycler & Thermal Cycler C1000 Touch & Nippon Genetics Europe GmbH \\
\hline Vortex mixer & vortex-2 Genie & Sio-Rad Laboratories, Inc. \\
\hline Lab water system & Sartirus arium pro & Sartorius AG \\
\hline
\end{tabular}

Table 3: Expendable material

\begin{tabular}{|l|l|l|}
\hline Expandable Material & Product Name & Company \\
\hline Gloves & Nitril Glove Standard M & LLG Labware \\
\hline Pipette tips & $\begin{array}{l}\text { Graduated Filter Tip } 1000 \mu \mathrm{l}, 200 \mu \mathrm{l}, \\
100 \mu \mathrm{l}, 10 / 20 \mu \mathrm{l}\end{array}$ & StarLab International GmbH \\
\hline Transfer pipette & transfer pipete $3.5 \mathrm{ml}$ & Sarstedt AG \& Co. KG \\
\hline Reaction cups & $\begin{array}{l}\text { Safe seal tube } 1.5 \mathrm{ml} \\
\text { micro tube } 1.5 \mathrm{ml}, \mathrm{PP}\end{array}$ & Sarstedt AG \& Co. KG \\
\hline 8-Strip cups & 8-strip cups & Nippon Genetics Europe GmbH \\
\hline Wipes & delicate task wipes & Kimberley-Clark Corporation \\
\hline $50 \mathrm{ml}$ Falcons & $50 \mathrm{ml}$ tube & Greiner Bio-One International GmbH \\
\hline $15 \mathrm{ml}$ Falcon & $15 \mathrm{ml}$ tube & Greiner Bio-One International GmbH \\
\hline Serological pipettes & serological pipettes $25 \mathrm{ml}, 10 \mathrm{ml}, 5 \mathrm{ml}$ & Th. Geyer Ingredients GmbH \& Co. KG \\
\hline
\end{tabular}

\subsection{Samples}

Patients gave written approval prior to blood or skin biopsy donation. All patient samples are listed in Table 41 in section 3.1, and control samples are listed in Table 45 in the appendix. 


\subsection{Cell Culture of Skin Fibroblasts}

The materials used for fibroblast cell culture are listed in Table 4, and the solutions are described in Table 5.

Table 4: Materials for fibroblast cell culture

\begin{tabular}{|l|l|l|}
\hline Material & Product Name & Company \\
\hline Inverted microscope & Primo Vert & Carl Zeiss AG \\
\hline Incubator & Hera cell 150 & Thermo Fisher Scientific Inc. \\
\hline Cell counting chamber & Neubauer 0.100 mm 0.0025 $\mathrm{mm}^{2}$ & Neubauer GmbH \& Co. KG \\
\hline Mr. Frosty & Cry 1 ${ }^{\circ}$ Cooler & Nalgene Thermo Scientific \\
\hline$-80^{\circ}$ C Freezer & $\begin{array}{l}\text { Ultra Low-Temperature Freezer MDF- } \\
\text { DU500VH }\end{array}$ & Panasonic Healthcare \\
\hline$-150^{\circ}$ C Freezer & $\begin{array}{l}\text { Ultra Low-Temperature Freezer MDF- } \\
\text { C2156VAN }\end{array}$ & Panasonic Healthcare \\
\hline Water bath & Julabo SW22 & Julabo GmbH \\
\hline T75 flask & TC flask T75, Stand., Vent. Cap 0021321 & Sarstedt AG \& Co. KG \\
\hline T25 flask & TC flask T25, Stand., Vent. Cap 9021412 & Sarstedt AG \& Co. KG \\
\hline Cryo vial & Cryo tube Vials 161921 & Thermo Fisher Scientific Inc. \\
\hline DMEM & $\begin{array}{l}\text { DMEM (1x) Dulbecco's Modified Eagle } \\
\text { Medium 41966-029 500 ml }\end{array}$ & Gibco- Thermo Fisher Scientific Inc. \\
\hline FCS & FBS Superiour 500 ml 50615 & Sigma Aldrich \\
\hline Pen/Strep & Penicillin-Streptomycin P06-07100 & Pan Biothech \\
\hline Amphotericin B & Amphotericin B Solution A2942-50 ml & Sigma \\
\hline DMSO & $\begin{array}{l}\text { Dimethylsulfoxide for Cell Culture 100 ml } \\
80014081\end{array}$ & PanReac Applichem \\
\hline PBS & $\begin{array}{l}\text { DPBS (1x) Dulbecco's Phosphate Buffered } \\
\text { Saline 14190-094 500ml }\end{array}$ & Gibco- Thermo Fisher Scientific Inc. \\
\hline Trypsin & 0.05\% Trypsin-EDTA (1x) 100 ml 25300-054 & Gibco- Thermo Fisher Scientific \\
\hline
\end{tabular}

Table 5: Solutions for fibroblast cell culture

\begin{tabular}{|l|l|}
\hline Solution & Composition \\
\hline Cell culture medium & $500 \mathrm{ml} \mathrm{DMEM}$ \\
& $50 \mathrm{ml}$ FCS \\
& $5 \mathrm{ml}$ Pen/Strep \\
\hline Freezing medium & $1.4 \mathrm{ml}$ Amphotericin B \\
& $45 \mathrm{ml}$ FCS \\
\hline
\end{tabular}

Fibroblasts were cultured in cell culture medium at $37^{\circ} \mathrm{C}$ and $5 \% \mathrm{CO}_{2}$. When the fibroblasts were grown to confluency, the cells were either seeded for an experiment, passaged, or frozen. As different cell culture flasks were used, the different volumes are listed in Table 6.

Table 6: Overview cell culture flasks

\begin{tabular}{|l|l|l|l|}
\hline & T25 & T75 & T175 \\
\hline Surface area & $25 \mathrm{~cm}^{2}$ & $75 \mathrm{~cm}^{2}$ & $175 \mathrm{~cm}^{2}$ \\
\hline Volume medium & $5 \mathrm{ml}$ & $10 \mathrm{ml}$ & $25 \mathrm{ml}$ \\
\hline Volume trypsin & $1 \mathrm{ml}$ & $3 \mathrm{ml}$ & $5 \mathrm{ml}$ \\
\hline Volume PBS & $5 \mathrm{ml}$ & $10 \mathrm{ml}$ & $25 \mathrm{ml}$ \\
\hline Number of cryo vials & 1 & 2 & 5 \\
\hline
\end{tabular}




\subsubsection{Seeding}

When fibroblasts were used for an experiment, they were seeded at a certain cell density indicatedin the description of the respective method. After washing with PBS, trypsin was applied. After five to ten minutes of incubation in the incubator, the detachment was checked using the microscope. When the detachment was complete, the same amount of medium was added to the cells as was used for trypsinization. The cells were counted with the counting chamber Neubauer Improved and the cell number was calculated by the formula cells per $\mathrm{ml}$ $=$ cells counted per square *10,000* dilution factor. The cell concentration was adjusted by adding medium or centrifugation (300xg, 5 min, RT).

\subsubsection{Passaging}

For passaging, the cells were washed with PBS, trypsin was added to the flask, and the flask was incubated at $37^{\circ} \mathrm{C}$ until the cells detached. Medium was added to the trypsinized cells to split the fibroblasts 1:3, and the cell suspension was applied to three new flasks.

\subsubsection{Harvesting}

The cells were washed with PBS and then trypsinized. After five minutes incubation at $37^{\circ} \mathrm{C}$, medium was added to the cells. The cell suspension was moved to a falcon and centrifuged (300xg, 5 min, RT).

\subsubsection{Freezing}

Trypsin is added to the previously washed cells, and the flask is incubated at $37^{\circ} \mathrm{C}$ until the cells detached. The same volume of medium was added as was used for trypsin. The cell suspension was centrifuged (300xg, $5 \mathrm{~min}, \mathrm{RT}$ ). The supernatant was removed, and the cell pellet was resuspended in freezing medium. $1 \mathrm{ml}$ freezing medium was applied to each cryo vial. The freezing vial with the cells was put into a Mr. Frosty in the $-80^{\circ} \mathrm{C}$ freezer overnight. For long-term storage, the cells were moved to the $-150^{\circ} \mathrm{C}$ freezer. 


\subsubsection{Thawing}

The cryo vial was removed from the freezer, thawed in a $37^{\circ} \mathrm{C}$ water bath. As soon as the content was thawed, it was moved to a cell culture flask with the pre-warmed medium. The medium was changed the following day to remove the dead cells and the DMSO from the medium.

\subsection{DNA Extraction}

DNA from blood samples was extracted by the Department of Molecular Diagnostics of the Institute of Human Genetics. Fibroblast DNA was extracted by the following protocol. The materials used for DNA extraction are listed in Table 7.

Table 7: Material for DNA Extraction

\begin{tabular}{|l|l|l|}
\hline Material & Product Name & Company \\
\hline DNA Extraction Kit & DNeasy Blood \& Tissue Kit & Qiagen \\
\hline Ethanol & Ethanol 2.5 18025 & J.T. Baker \\
\hline
\end{tabular}

The cells were harvested as described in section 2.2. For DNA extraction, the Kit DNeasy Blood and Tissue Kit from Qiagen with the protocol for cultured cells was used. To increase the DNA yield, DNA was eluted twice. $20 \mu \mathrm{l}$ were added to the column and incubated for five minutes. After centrifugation $(6,000 \times \mathrm{xg}, 1 \mathrm{~min}, \mathrm{RT})$ again $20 \mu \mathrm{l}$ pure water were added to the column and incubated overnight at $4^{\circ} \mathrm{C}$ and then centrifuged $(6,000 \mathrm{xg}, 1 \mathrm{~min}, \mathrm{RT})$. 


\subsection{Measurement of DNA Concentration}

The materials used for DNA concentration measurement are listed in Table 8.

Table 8: Material for DNA concentration measurement

\begin{tabular}{|l|l|l|}
\hline Material & Product Name & Company \\
\hline Nanodrop & NanoDrop OneC & Thermo Fisher Scientific \\
\hline Qubit 3.0 & Qubit 3.0 Fluorometer & Invitrogen \\
\hline Tape Station & 220 Tape Station & Agilent Technologies Inc. \\
\hline Vortex mixer & IKA MS 3B Vortexer & Thermo Scientific \\
\hline Reaction cups & Optical Tube, 8x Strip 401428 & Agilent Technologies Inc. \\
\hline Caps & Optical cap, 8x Strip 401425 & Agilent Technologies Inc. \\
\hline Tips & Loading tips (1pK) & Agilent Technologies Inc. \\
\hline Screen tape & $\begin{array}{l}\text { High Sensitivity DNA Screen Tape } \\
\text { Genomic DNA Screen Tape Analysis } \\
\text { Kit }\end{array}$ & Agilent Technologies Inc. \\
\hline Qubit dsDNA broad range assay kit & Qubit dsDNA BR Assay Kit Q32853 & Invitrogen \\
\hline Qubit assay tubes & Qubit assay tubes & Invitrogen \\
\hline
\end{tabular}

DNA concentration was either measured with the Nanodrop or Tape Station. After DNA extraction, samples were incubated at $4^{\circ} \mathrm{C}$ overnight.

\subsubsection{Nanodrop}

DNA concentration was measured with the Nanodrop Spectrometer in a volume of $2 \mu \mathrm{l}$ following manufacturer's instructions.

\subsubsection{Tape Station}

For a precise measurement of DNA concentration and fragment size, the Tape Station was used. Either the Genomic DNA screen tape analysis kit or the high sensitivity DNA screen tape analysis kit was used following manufacturer's instructions.

\subsubsection{Qubit 3.0 Fluorometer}

To assess the DNA concentration before library preparation, the Qubit dsDNA broad range assay kit was used. To prepare the Qubit working solution, $1 \mu$ l of Qubit reagent was added to the Qubit buffer. 1 to $20 \mu$ of DNA was added to 199 to $180 \mu$ l of the working solution. The 
standards were made from $10 \mu \mathrm{l}$ of standard 1 or standard 2 and $190 \mu \mathrm{l}$ of working solution. First, the two standards were measured, and then the samples were measured on the Qubit 3.0 fluorometer.

\subsection{Agarose Gel Electrophoresis}

Agarose gel electrophoresis was performed to access the fragment size or intactness of genomic DNA. The materials used are listed in Table 9.

Table 9: Material for agarose gel electrophoresis

\begin{tabular}{|l|l|l|}
\hline Material & Product Name & Company \\
\hline Gel electrophoresis chamber & gel electrophoresis chamber & Thermo Fisher Scientific \\
\hline Scale & Sartorius C2200P & Sartorius AG \\
\hline Voltage source & Apelex PS304 minipac II & Apelex \\
\hline Microwave & Panasonic NN-E201WM & Panasonic Co. \\
\hline Detection system & FAS V Gel Documentation System & Nippon Genetics Europe \\
\hline Agarose & Agarose 500 g AG02 & Nippon Genetics Europe \\
\hline $10 x$ TBE Buffer & UltraPure 10x TBE Buffer & Invitrogen AG \\
\hline 100 bp ladder & Gene Ruler 100 bp Plus & Thermo Fisher Scientific \\
\hline 1 kb ladder & Gene Ruler 1 kb DNA Ladder & Thermo Fisher Scientific \\
\hline Loading dye & 6x DNA loading dye & Thermo Fisher Scientific \\
\hline Gel Red & $\begin{array}{l}\text { GelRed Nucleic Acid Stein 10,000x in } \\
\text { water 5 ml 41003 }\end{array}$ & Biotium \\
\hline Gel tray & Gel tray & CBS Scientific Co. \\
\hline Gel comb & $\begin{array}{l}\text { Gel comb SGC 14-1516 1.5 mm } \\
\text { Gel comb SGC 14-1020 1 mm }\end{array}$ & CBS Scientific Co. \\
\hline Erlenmeyer flask & Erlenmeyer flask $500 \mathrm{ml}$ & Schott AG \\
\hline Printer & Mitsubishi P96 & Mitsubishi Electric \\
\hline
\end{tabular}

0.5x TBE buffer was used to cast $0.5-3 \%$ agarose gels depending on the fragment size. Agarose was heated to boiling until dissolved. After cooling to approximately $70^{\circ} \mathrm{C}, 10 \mu \mathrm{l}$ GelRed was added. The gel was cast, the bubbles removed, and the comb was set into the chamber. After cooling for at least fifteen minutes, the gel on the gel tray was set to the gel electrophoresis chamber. The ladder and the samples were added to the gel pockets. The samples were mixed in a ratio of 1:6 with loading dye and applied to the pockets of the gel. The voltage was applied first at $80 \mathrm{~V}$ and later turned up to $120 \mathrm{~V}$. The gel was imaged with the detection system. 


\subsection{Ultra-High Coverage MtDNA Sequencing}

To quantify low-frequency variants in the mtDNA, mtDNA was sequenced with ultra-high coverage. Total DNA was extracted from fibroblasts or blood, and the library preparation was done to enrich mtDNA fragments. The material used for mtDNA sequencing is listed in Table 10.

Table 10: Material for mtDNA Sequencing

\begin{tabular}{|l|l|l|}
\hline Material & Product Name & Company \\
\hline Qubit 3.0 & Qubit 3.0 Fluorometer & Invitrogen \\
\hline Tape Station & 4300 Tape Station & Agilent Technologies \\
\hline Magnetic stand & Dynamag & Invitrogen \\
\hline NextSeq & NextSeq platform & Illumina \\
\hline Ethanol & Ethanol 100\% & J.T. Baker \\
\hline $\begin{array}{l}\text { SureSelect XTHS Target Enrichment } \\
\text { Kit }\end{array}$ & $\begin{array}{l}\text { SureSelect XTHS Target Enrichment } \\
\text { Kit ILM Hyb Module Box1 }\end{array}$ & Agilent Technologies \\
\hline $\begin{array}{l}\text { SureSelect XTHS Library Preparation } \\
\text { Kit }\end{array}$ & $\begin{array}{l}\text { Sure Select XTHS Library Preparation } \\
\text { Kit for ILM (Pre-PCR) }\end{array}$ & Agilent Technologies \\
\hline $\begin{array}{l}\text { SureSelect XTHS Enzymatic } \\
\text { Fragmentation Kit }\end{array}$ & $\begin{array}{l}\text { SureSelect XTHS Enzymatic } \\
\text { Fragmentation Kit 96 Reactions }\end{array}$ & Agilent Technologies \\
\hline Ampure beads & AMPure Beads XP A63881 & Beckman Coulter \\
\hline Qubit assay tubes & Invitrogen \\
\hline Qubit dsDNA BR Assay Kit & Qubit dsDNA BR Assay Kit (Q32853) & Invitrogen \\
\hline Tape station screen tape & Tape Station Screen Tape D1000, & Agilent Technologies Co. \\
& $\begin{array}{l}\text { Tape Station Screen Tape High } \\
\text { Sensitive }\end{array}$ & \\
\hline Hydroxyurea & H86-27-5g & Sigma-Aldrich \\
\hline Etoposide & E1383-25mg & Sigma-Aldrich \\
\hline Hydrogen peroxide solution & $95321-100 m l$ & Sigma-Aldrich \\
\hline Crosslinker (UV light) & BLX-254 & Peqlab \\
\hline
\end{tabular}

\subsubsection{Design of the Capture Library}

The SureSelect custom capture library was designed in cooperation with PD Dr. Silke Kaulfuß using the software SureDesign (Agilent Technologies). The probes were designed to capture the human mtDNA.

\subsubsection{Cell Culture}

DNA was extracted from blood in the department for DNA Diagnostics in the Institute of Human Genetics Göttingen or from a fibroblast cell culture using the DNeasy Blood and Tissue Kit (Qiagen). 150,000 cells were seeded in a T25 flask and incubated for five days. The fibroblasts were harvested as described in section 2.2. 
For the generation of positive controls, 150,000 C01 control fibroblasts were seeded in a T25 flask. Except for the untreated control, the cells were treated after 24 hours for two hours with $0.2 \mathrm{mM}$ etoposide, $0.1 \mathrm{mM}$ hydroxyurea, $500 \mu \mathrm{M} \mathrm{H}_{2} \mathrm{O}_{2}, 10 \mu \mathrm{M} \mathrm{H}_{2} \mathrm{O}_{2}$, or once with UV light with a dose of $100 \mathrm{~J} / \mathrm{m}^{2}$. After two hours, the cell culture medium was changed in all flasks. The cells were left to grow for four days before DNA extraction.

\subsubsection{DNA Extraction}

The pellet was dissolved in $200 \mu$ I PBS. DNA is extracted as described in section 2.3. except for

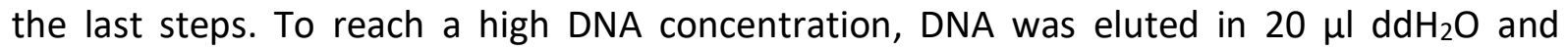
incubated for 10 minutes at RT before centrifugation (10,000xg, RT, $3 \mathrm{~min}$ ). Again $20 \mu \mathrm{l}$ of $\mathrm{ddH}_{2} \mathrm{O}$ were added to the column and incubated at $4^{\circ} \mathrm{C}$ for 12 hours. Then the column was again centrifuged. DNA concentration was assessed by NanoDrop measurement.

\subsubsection{DNA Dilution and DNA Concentration Measurement}

DNA concentration was initially measured using the Qubit dsDNA BR Assay Kit on the QuBit 3 as described in section 2.4. After diluting the DNA to $50 \mathrm{ng} / \mu \mathrm{l}$, the concentration was again measured as before. From this dilution, a dilution of $200 \mathrm{ng}$ DNA in $7 \mu \mathrm{l}$ was prepared.

\subsubsection{SureSelect ${ }^{\mathrm{XTHS}}$ Target Enrichment}

The first step of the library preparation was the fragmentation of the gDNA to 200 to 400 base pair fragments. The master mix was pipetted as described in Table 11. $3 \mu$ l of the fragmentation master mix was added to the $7 \mu$ of the diluted DNA sample. After mixing by pipetting, the samples were incubated in a thermal cycler with the temperature profile described in Table 12.

Table 11: Pipetting scheme for fragmentation master mix

\begin{tabular}{|l|l|l|}
\hline Reagent & Volume for $\mathbf{1}$ reaction $[\boldsymbol{\mu l}]$ & Volume for $\mathbf{8}$ reactions $[\boldsymbol{\mu l}]$ \\
\hline SureSelect Fragmentation Buffer & 2 & 18 \\
\hline SureSelect Fragmentation Enzyme & 1 & 9 \\
\hline Total volume & 3 & \\
\hline
\end{tabular}


Table 12: Temperature profile for fragmentation

\begin{tabular}{|l|l|l|}
\hline Step & Temperature $\left[{ }^{\circ} \mathrm{C}\right]$ & Time [min] \\
\hline 1 & 37 & infinite \\
\hline 2 & 37 & 15 \\
\hline 3 & 65 & 5 \\
\hline 4 & 4 & infinite \\
\hline
\end{tabular}

After fragmentation, $40 \mu \mathrm{lddH_{2 }} \mathrm{O}$ was added to the samples. The next step of library preparation was A-tailing. $20 \mu \mathrm{l}$ of the master mix for end-repair A-tailing was added to the fragmented DNA on ice. After mixing by pipetting as detailed in Table 13, the samples were incubated in a thermal cycler with the temperature profile described in Table 14.

Table 13: Pipetting scheme of master mix for end repair A-tailing

\begin{tabular}{|l|l|l|}
\hline Reagent & Volume for 1 reaction $[\boldsymbol{\mu l}]$ & Volume for $\mathbf{8}$ reactions $[\boldsymbol{\mu l}]$ \\
\hline EndRepair A-Tailing Buffer & 16 & 144 \\
\hline EndRepair A-Tailing Enzyme Mix & 4 & 36 \\
\hline Total volume & 20 & \\
\hline
\end{tabular}

Table 14: Temperature Profile for End Repair A-Tailing

\begin{tabular}{|l|l|l|}
\hline Step & Temperature $\left[{ }^{\circ} \mathbf{C}\right]$ & Time [min] \\
\hline 1 & 20 & infinite \\
\hline 2 & 20 & 15 \\
\hline 3 & 72 & 15 \\
\hline 4 & 4 & infinite \\
\hline
\end{tabular}

For the ligation, the master mix was prepared as described in Table 15. After adding $25 \mu \mathrm{l}$ of the master mix for ligation and $5 \mu$ of the adapter oligo mix to the samples, the samples were mixed by pipetting and incubated in a thermal cycler with the temperature profile described in Table 16.

Table 15: Pipetting scheme of the master mix for ligation

\begin{tabular}{|l|l|l|}
\hline Reagent & Volume for $\mathbf{1}$ reaction $[\boldsymbol{\mu l}]$ & Volume for $\mathbf{8}$ reactions $[\boldsymbol{\mu l}]$ \\
\hline Ligation Buffer & 23 & 207 \\
\hline T4 DNA Ligase & 2 & 18 \\
\hline Total volume & 25 & \\
\hline
\end{tabular}

Table 16: Temperature profile for ligation

\begin{tabular}{|l|l|l|}
\hline Step & Temperature $\left[{ }^{\circ} \mathbf{C}\right]$ & Time $[\mathbf{m i n}]$ \\
\hline 1 & 20 & infinite \\
\hline 2 & 20 & 30 \\
\hline 3 & 4 & infinite \\
\hline
\end{tabular}


Following the ligation, the samples were purified using Ampure beads. After vortexing the beads rigorously to resuspend, $80 \mu \mathrm{l}$ of the beads were pipetted to the samples. Mixing by pipetting was followed by five minutes of incubation at RT. Now the tubes were inserted into the magnet and incubated for five to ten minutes. The supernatant was removed carefully without disturbing the beads. $150 \mu$ of $70 \%$ ethanol was added to the cups and incubated for one minute. The supernatant was removed, and again $150 \mu \mathrm{l}$ of $70 \%$ ethanol was added to the cups. After one minute of incubation, the supernatant was removed completely before inserting the cups into a thermal cycler at $37^{\circ} \mathrm{C}$. After three minutes, the beads were checked

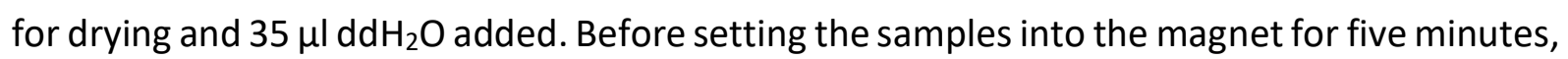
the samples were incubated for two minutes at RT. The supernatant was transferred to new reaction cups, and 13,5 $\mu \mathrm{l}$ of pre-capture PCR master mix, which is described in Table 17, was added to each sample. Also, $2 \mu \mathrm{l}$ XTHS index primers were added to make the later multiplexing possible. The samples were incubated in a thermal cycler with the temperature profile described inTable 18.

Table 17: Pipetting scheme for pre-capture PCR master mix

\begin{tabular}{|l|l|l|}
\hline Reagent & Volume for $\mathbf{1}$ reaction $[\boldsymbol{\mu l}]$ & Volume for $\mathbf{8}$ reactions $[\boldsymbol{\mu l}]$ \\
\hline Herculase II 5x reaction buffer & 10 & 90 \\
\hline 100 mM dNTP mix & 0,5 & 4,5 \\
\hline Forward primer (XTHS) & 2 & 18 \\
\hline Herculase II Fusion DNA polymerase & 1 & 9 \\
\hline Total volume & 13,5 & \\
\hline
\end{tabular}

Table 18: Thermal cycler programme for pre-capture PCR

\begin{tabular}{|l|l|l|l|}
\hline Step & Number of cycles & Temperature $\left[{ }^{\circ} \mathbf{C}\right]$ & Time \\
\hline 1 & 1 & 98 & infinite \\
\hline 2 & 1 & 98 & 2 minutes \\
\hline 3 & 8 & 98 & 30 seconds \\
& & 60 & 30 seconds \\
& & 72 & 1 minute \\
\hline 4 & 1 & 72 & 5 minutes \\
\hline 5 & 1 & 4 & infinite \\
\hline
\end{tabular}

Following the pre-capture PCR, the samples were again purified using Ampure beads. After vortexing the beads rigorously to resuspend, $50 \mu \mathrm{l}$ of the beads were pipetted to the samples. Mixing by pipetting was followed by five minutes of incubation at RT. Then the tubes were inserted into the magnet and incubated for five to ten minutes. The supernatant was removed carefully without disturbing the beads. $150 \mu \mathrm{l}$ of $70 \%$ ethanol was added to the cups and 
incubated for one minute. The supernatant was removed, and again $150 \mu \mathrm{l}$ of $70 \%$ ethanol was added to the cups. After one minute of incubation, the supernatant was removed completely before inserting the cups into a thermal cycler at $37^{\circ} \mathrm{C}$. After three minutes, the

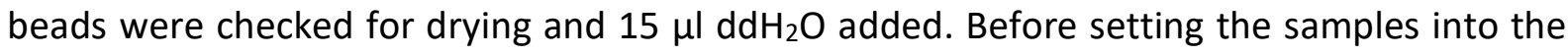
magnet for three minutes, the samples were incubated for two minutes at RT. The supernatant was transferred to new reaction cups and stored on ice.

To measure the DNA concentration and the fragment size, the library was measured on the Tape Station with the D1000 Screen Tape according to the manufacturer's instructions. According to the measurement, the samples were diluted to $1000 \mathrm{ng}$ in $12 \mu \mathrm{l}$. The diluted samples were frozen overnight.

The samples were thawed, and $5 \mu$ S SureSelect XTHS and XT low input blocker mix were added to the samples. The samples were then incubated in a thermal cycler with the temperature profile described in Table 19.

Table 19: Temperature profile for hybridization

\begin{tabular}{|l|l|l|l|}
\hline Step & Number of cycles & Temperature $\left[{ }^{\circ} \mathbf{C}\right]$ & Time \\
\hline 1 & 1 & 95 & 5 minutes \\
\hline 2 & 1 & 65 & 10 minutes \\
\hline 3 & 1 & 65 & 1 minute \\
\hline 4 & 60 & 65 & 1 minute \\
& & 37 & 3 seconds \\
\hline 5 & 1 & 65 & infinite \\
\hline
\end{tabular}

The hybridization solution, which is described in Table 20 and Table 21, was added to the samples at step 3 of the thermal cycling program. After mixing by pipetting, the program was continued.

Table 20: Pipetting scheme for RNase block solution

\begin{tabular}{|l|l|l|}
\hline Reagent & Volume for 1 reaction $[\boldsymbol{\mu l}]$ & Volume for 8 reactions $[\boldsymbol{\mu l}]$ \\
\hline SureSelect RNase block & $0,5 \mu \mathrm{l}$ & 5 \\
\hline $\mathrm{dd}_{2} \mathrm{O}$ & 1,5 & 15 \\
\hline Total volume & 2 & \\
\hline
\end{tabular}


Table 21: Pipetting scheme for hybridization solution

\begin{tabular}{|l|l|l|}
\hline Reagent & Volume for 1 reaction $[\boldsymbol{\mu l}]$ & Volume for 8 reactions $[\boldsymbol{\mu l}]$ \\
\hline $25 \%$ RNase Block Solution & 2 & 18 \\
\hline mtDNA Library & 2 & 18 \\
\hline SureSelect Fast Hybridization Buffer & 6 & 54 \\
\hline $\mathrm{ddH}_{2} \mathrm{O}$ & 3 & 27 \\
\hline Total volume & 13 & \\
\hline
\end{tabular}

The library was then purified using streptavidin-coated magnetic beads. First, the beads were vortexed and then mixed with binding buffer as described in Table 22. The two $1.5 \mathrm{ml}$ cups with streptavidin-coated beads were placed into the magnet and incubated for five minutes. The supernatant was then removed, and again $800 \mu \mathrm{l}$ binding buffer was added to the cups, mixed by pipetting, and again placed onto the magnet for five minutes. After removing the supernatant, the beads were stored in $800 \mu$ l binding buffer.

Table 22: Pipetting Scheme for Steptavidin-Coated Beads

\begin{tabular}{|l|l|l|}
\hline Reagent & Volume for 1 reaction $[\boldsymbol{\mu l}]$ & Volume for 4 reactions $[\boldsymbol{\mu l}]$ \\
\hline Streptavidin-coated magnetic beads & 50 & 200 \\
\hline SureSelect binding buffer & 200 & 800 \\
\hline
\end{tabular}

$200 \mu \mathrm{l}$ streptavidin-coated beads were pipetted into cups, and then $30 \mu \mathrm{l}$ samples were added and mixed by pipetting. The samples were incubated at RT on a shaker at $1,800 \mathrm{rpm}$. Then the samples were centrifuged and placed onto the magnet for one minute. The supernatant was removed, and the samples moved out of the magnet. $200 \mu \mathrm{l}$ wash buffer 1 was added to the samples and mixed by pipetting. Then the samples were moved to $200 \mu \mathrm{l}$ cups, vortexed, and placed onto the small magnet. The supernatant was removed, and the samples were placed into the thermal cycler, which was set to $70^{\circ} \mathrm{C}$. The samples were washed six times with 200 $\mu \mathrm{l}$ wash buffer 2 , followed by a five-minute incubation and one minute on the magnet. After the last washing step, the beads were resuspended in $25 \mu$ l water, and $25 \mu$ l post-capture PCR master mix was added to each sample. The pipetting scheme for the post-capture master mix is described in Table 23, and the temperature profile is detailed in Table 24.

Table 23: Pipetting scheme for post-capture PCR master mix

\begin{tabular}{|l|l|l|}
\hline Reagent & Volume for 1 reaction $[\boldsymbol{\mu l}]$ & Volume for $\mathbf{8}$ reactions $[\boldsymbol{\mu l}]$ \\
\hline Herculase II 5x reaction buffer & 10 & 90 \\
\hline 100 mM dNTP Mix & 0.5 & 4.5 \\
\hline Herculase II Fusion DNA polymerase & 1 & 9 \\
\hline SureSelect post-capture primer mix & 1 & 9 \\
\hline Total volume & 25 & \\
\hline
\end{tabular}


Table 24: Temperature profile for post-capture PCR

\begin{tabular}{|l|l|l|l|}
\hline Step & Number of cycles & Temperature $\left[{ }^{\circ} \mathbf{C}\right]$ & Time \\
\hline 1 & 1 & 98 & 2 minutes \\
\hline 2 & 12 & 98 & 30 seconds \\
& & 60 & 30 seconds \\
& & 72 & 1 minute \\
\hline 3 & 1 & 72 & 5 minutes \\
\hline 4 & 1 & 4 & infinite \\
\hline
\end{tabular}

Following the post-capture PCR, the samples were purified with Ampure beads. After vortexing the beads rigorously to resuspend, $50 \mu \mathrm{l}$ of the beads were pipetted to the samples. Mixing by pipetting was followed by five minutes of incubation at RT. Now the tubes were inserted into the magnet and incubated for five to ten minutes. The supernatant was removed carefully without disturbing the beads. $150 \mu \mathrm{l}$ of $70 \%$ ethanol was added to the cups and incubated for one minute. The supernatant was removed, and again $150 \mu$ of $70 \%$ ethanol was added to the cups. After one minute of incubation, the supernatant was removed completely before inserting the cups into a thermal cycler at $37^{\circ} \mathrm{C}$. After three minutes, the beads were checked for drying and $25 \mu \mathrm{lddH_{2 }} O$ was added. Before setting the samples into the magnet for three minutes, the samples were incubated for two minutes at RT. The supernatant was transferred to new reaction cups and stored on ice.

To finish the library preparation, the samples were measured on the Qubit 3.0 fluorometer with the High Sensitive Kit and on the Tape Station with the High Sensitive Kit, as described in section 2.4. From the two measurements, the volume for the Illumina sequencing was calculated.

\subsubsection{Illumina Sequencing}

The $16 \mathrm{~kb}$ libraries with $150 \mathrm{bp}$ paired-end reads were sequenced on an Illumina NextSeq platform (Illumina). $1.3 \mathrm{pM}$ was added to the flow cell to reach a theoretical coverage of $100,000 x$.

\subsubsection{Alignment and Variant Calling}

The alignment and variant calling was done using the program Seqpilot (JSI Medical Systems). The analysis method with the settings is listed in Table 25. Reads that match to homologous sequences in the genomic DNA were excluded and not used for the alignment. The table of 
variants was exported as a txt-file and imported to MS Excel using different delimiters. MS Excel was then used for data analysis.

Table 25: Seqpilot analysis profile settings

\begin{tabular}{|c|c|}
\hline Setting & Value \\
\hline Reads include primers & yes \\
\hline Randomly shaded reads & no \\
\hline Genome mapping & no \\
\hline \multicolumn{2}{|l|}{ Reads } \\
\hline Minimum absolute coverage & 50 combined \\
\hline Ration read directions & $5 \% / 95 \%$ \\
\hline Both directions minimum absolute coverage & 20 \\
\hline Both directions minimum \% coverage & off \\
\hline \multicolumn{2}{|l|}{ Mutations } \\
\hline Mimimum absolute coverage & 2 per direction \\
\hline Ration read directions & off \\
\hline Minimum \% coverage & off \\
\hline Force combined (\% coverage) & $25 \%$ \\
\hline \multicolumn{2}{|l|}{ Mutation Sorting } \\
\hline Distinct/Other \%coverage & $1 \%$ per direction \\
\hline Distinct / Homopolymer \% coverage (deletion) & $30 \%$ per direction \\
\hline Distinct /Homopolymer \% coverage (insertion) & $20 \%$ per direction \\
\hline \multicolumn{2}{|l|}{ Homopolymer } \\
\hline Homopolymer Region size & 7 \\
\hline \multicolumn{2}{|l|}{ Quality Score } \\
\hline Quality score threshold & 15 \\
\hline Ignore reads threshold & $40 \%$ \\
\hline Low quality score coverage warning & off \\
\hline \multicolumn{2}{|l|}{ Tag Processing and Consensus Building } \\
\hline Active & yes \\
\hline R1 tag length & 0 \\
\hline R2 tag length & 10 \\
\hline Minimum absolute coverage (per base position) & 1 \\
\hline Mininimum \% coverage (per base position) & 50 \\
\hline Ignore consensus read threshold & $50 \%$ \\
\hline Ignore $\mathrm{N}$ tags & yes \\
\hline Ignore low Qs tags & yes \\
\hline
\end{tabular}

\subsubsection{Statistical Analysis}

Graph Pad Prism was employed to create figures and perform statistical tests. The Pearson correlation coefficient was calculated to assess the correlation of read depth with the number of variants called. It measures the linear correlation of two sets of data and results in a value between -1 and 1 . A value of -1 or 1 implies a linear relationship, while a value near 0 implies no linear correlation. The significance of the correlation was then tested by a t-test. The F-test is employed to compare the variances of two sets of data independent of their means. The two-tailed paired t-test was used to compare one patient to one control sample. The twotailed and unpaired t-test was employed to compare the number of variants in the two control 
sample groups from blood and fibroblast DNA. Significance is indicated with asterisks: ${ }^{*} p<0.05, * * p<0.01, * * * p<0.001, * * * * p<0.0001$.

\subsection{Oxygen Consumption Rate Measurements}

Oxygen consumption was measured with the Seahorse XF cell mitochondrial stress test kit to assess mitochondrial dysfunction. The materials used are listed in Table 26, and the solutions are detailed in Table 27.

Table 26: Materials for Seahorse mitochondrial stress test

\begin{tabular}{|l|l|l|}
\hline Material & Product Name & Company \\
\hline Seahorse analyzer & Seahorse XFe96 Analyzer & Agilent \\
\hline Cell plate & Seahorse Xfe96 Extracellular Flux Assay Kits & Agilent \\
\hline Drug plate & Seahorse Xfe96 Cell Culture Micro Plates & Agilent \\
\hline Seahorse XF medium & Seahorse XF base medium, without phenol red, 500 ml & Agilent \\
\hline Calibrant & Seahorse XF Calibrant Solution $500 \mathrm{ml}$ & Agilent \\
\hline Pyruvate solution & Seahorse XF $100 \mathrm{mM}$ pyruvate solution, $50 \mathrm{ml}$ & Agilent \\
\hline Glutamine solution & Seahorse XF $200 \mathrm{mM}$ glutamine solution, $50 \mathrm{ml}$ & Agilent \\
\hline Oligomycin & O4876-25mg & Sigma \\
\hline FCCP & C2920-10mg & Sigma \\
\hline Rotenone & R8875-1g & Sigma \\
\hline Antimycin A & A8674-50mg & Sigma \\
\hline Galactose & G0750-100g & Sigma \\
\hline $\begin{array}{l}\text { CyQuant cell proliferation } \\
\text { kit }\end{array}$ & $\begin{array}{l}\text { CyQUANT Cell Proliferation Assay, for cells in culture, } \\
\text { C7026 }\end{array}$ & Invitrogen \\
\hline
\end{tabular}

The cartridge plate was hydrated with XF calibrant with $180 \mu \mathrm{l}$ per well and incubated overnight at $37^{\circ} \mathrm{C}$ without $\mathrm{CO}_{2} .25,000$ fibroblasts per well were added in a volume of $80 \mu \mathrm{l}$ to the cell plate. The cell culture medium described in section 2.2. was used. The pipette was held at an angle, and the cell suspension was pipetted to the wall to avoid impairment of the well surface. The four plate corners were filled with medium for the background measurement. At most, four different fibroblast lines were plated into a 96-well plate to generate at least 23 technical replicates. The cells were incubated at $37^{\circ} \mathrm{C}$ with $\mathrm{CO}_{2}$.

First, the drug solutions were prepared and pipetted to the ports $A, B$ and $C$ with a multichannel pipette. The cartridge was then loaded into the instrument to equilibrate. Then the cells were checked for detachment and confluence. Then the cell culture medium was removed from the microplate by aspiration. The bottom of the plate should not be touched with the pipette to avoid the removal of the cells. Then $180 \mu$ medium was added to the wells holding the pipette again at a $45^{\circ}$ angle and pipetting to the walls. The cells were checked for 
detachment and confluence again. Then the cell plate was incubated for 30 minutes at $37^{\circ} \mathrm{C}$ without $\mathrm{CO}_{2}$. When the equilibration finished, the cell culture plate was also loaded to the instrument, and the program started.

After the measurement had finished, the cell culture medium was removed from the cell plate by inversion of the plate and frozen at $-80^{\circ} \mathrm{C}$. The cell number was evaluated using the CyQuant cell proliferation kit. After thawing the plate, $200 \mu \mathrm{l}$ CyQuant solution was added to each well. After 5 minutes of incubation protected from light, the fluorescence was measured with filters for $480 \mathrm{~nm}$ excitation and $520 \mathrm{~nm}$ emission. These data were used to normalize the measurement.

Table 27: Solutions for the Seahorse mitochondrial stress test

\begin{tabular}{|c|c|}
\hline Solution & Composition \\
\hline Oligomycin stock solution, $10 \mathrm{mM}$ & $\begin{array}{l}5 \mathrm{mg} \quad \text { Oligomycin } \\
630 \mu \mathrm{l} \quad \text { DMSO } \\
\text { Aliquot and store at }-20^{\circ} \mathrm{C} \text {. }\end{array}$ \\
\hline FCCP, $5 \mathrm{mM}$ & $\begin{array}{l}1.8 \mathrm{mg} \quad \text { FCCP } \\
1.5 \mathrm{ml} \text { DMSO } \\
\text { FCCP is stored at } 4^{\circ} \mathrm{C} \text {. Always prepare freshly. }\end{array}$ \\
\hline Rotenone stock solution, $20 \mathrm{mM}$ & $\begin{array}{l}1 \mathrm{~g} \quad \text { Rotenone } \\
250 \mathrm{ml} \text { DMSO } \\
\text { Aliquot and store at }-20^{\circ} \mathrm{C} \text {. Watch for precipitation! }\end{array}$ \\
\hline Antimycin A stock solution, $10 \mu \mathrm{M}$ & $\begin{array}{l}25 \mathrm{mg} \quad \text { Antimycin } \mathrm{A} \\
4.5 \mathrm{ml} \text { DMSO } \\
\text { Aliquot and store at }-20^{\circ} \mathrm{C} \text {. }\end{array}$ \\
\hline Galactose, $500 \mathrm{mM}$ & $\begin{array}{ll}4.5 \mathrm{~g} \quad \text { Galactose } \\
50 \mathrm{ml} \quad \text { Seahorse } \mathrm{XF} \text { medium } \\
\text { Aliquot and store at }-20^{\circ} \mathrm{C} . \\
\end{array}$ \\
\hline Seahorse medium & $\begin{array}{ll}100 \mathrm{ml} & \text { Seahorse XF medium } \\
2 \mathrm{ml} & \text { Galactose }(500 \mathrm{mM}) \\
1 \mathrm{ml} & \text { Pyruvate }(100 \mathrm{mM}) \\
1 \mathrm{ml} & \text { Glutamine }(200 \mathrm{mM}) \\
\text { Store at } & 4^{\circ} \mathrm{C} . \\
\end{array}$ \\
\hline Solution A & $\begin{array}{ll}5 \mathrm{ml} & \text { Seahorse XF medium } \\
15 \mu \mathrm{l} & \text { Oligomycin } 10 \mathrm{mM} \\
\end{array}$ \\
\hline Solution B & $\begin{array}{ll}5 \mathrm{ml} & \text { Seahorse XF medium } \\
15 \mu \mathrm{l} & \text { FCCP } 5 \mathrm{mM} \\
\end{array}$ \\
\hline Solution C & $\begin{array}{ll}5 \mathrm{ml} & \text { Seahorse XF medium } \\
10 \mu \mathrm{l} & \text { Rotenone } 20 \mathrm{mM} \\
5 \mu \mathrm{l} & \text { Antimycin A } 10 \mu \mathrm{M} \\
\end{array}$ \\
\hline CyQuant solution & $\begin{array}{ll}11 \mathrm{ml} & \text { Cell Lysis Buffer } \\
19 \mathrm{ml} & \text { pure water } \\
50 \mu \mathrm{l} & \text { CyQuant GR dye }\end{array}$ \\
\hline
\end{tabular}

For data analysis, the software Wave (Agilent Technologies) was used. Graph Pad Prism was used to perform statistical tests and to compile the figures. Each patient fibroblast line was compared to two age-matched control fibroblasts using a one-way ANOVA analysis. Significance is indicated with asterisks: ${ }^{*} p<0.05, * * p<0.01, * * * p<0.001, * * * * p<0.0001$. 


\subsection{Telomere Real-Time PCR}

The telomere real-time PCR compares the total length of telomere fragments to the number of reference genes in one sample to assess relative telomere length. The materials used for the telomere real-time PCR are listed in Table 28.

Table 28: Material used for telomere real-time PCR

\begin{tabular}{|l|l|l|}
\hline Material & Product name & Company \\
\hline Real-Time PCR cycler & Quant Studio 5 & Thermo Fisher Scientific \\
\hline $\begin{array}{l}\text { Quantstudio Design and Analysis } \\
\text { Software }\end{array}$ & $\begin{array}{l}\text { Quantstudio Design and Analysis } \\
\text { Software }\end{array}$ & Thermo Fisher Scientific \\
\hline 384 Well Plates & 384 Well PCR Plates TF-0384 & Thermo Fisher Scientific \\
\hline Foil & qPCR Seal 4ti-0560 & 4titude \\
\hline Centrifuge & Megafuge 1-0R & Heraeus \\
\hline Mastermix & FastStart Essential DNA Green Master & Roche \\
\hline Telomere and SCR primer & $\begin{array}{l}\text { Relative Human Telomere Length } \\
\text { Quantification qPCR Assay Kit }\end{array}$ & ScienCell \\
\hline
\end{tabular}

DNA was extracted according to section 2.3. DNA samples were diluted at 1:10 with pure water and incubated overnight at $4^{\circ} \mathrm{C}$. DNA concentration and intactness were analyzed according to section 2.4 with the Tape station. A sample was excluded from analysis if the DIN number was below 7. All DNA samples were diluted to $0.5 \mathrm{ng} / \mu \mathrm{l}$ and incubated overnight at $4^{\circ} \mathrm{C}$ again. Mastermixes for the telomere and the SCR reaction were prepared as indicated in Table 29. $2 \mu \mathrm{l} 0.5 \mathrm{ng} / \mu \mathrm{l}$ DNA sample was added to $8 \mu \mathrm{l}$ master mix per well. On each plate, each sample was analyzed in triplicates, and each plate was analyzed three times. The cycling conditions are detailed in Table 30. The relative telomere length was calculated by the $\Delta \Delta C T$ method.

Data analysis was done in cooperation with Dr. rer. nat. Andreas Leha, Department of Medical Statistics, University Medical Center Göttingen in the context of the statistical consultation for Ph.D. students.

Table 29: Pipetting Scheme for Telomere Real-Time PCR

\begin{tabular}{|l|l|}
\hline Solution & Composition \\
\hline Telomere mastermix & $5 \mu \mathrm{l}$ Mastermix \\
& $1 \mu \mathrm{l}$ Telomere primer \\
\hline SCR mastermix & $2 \mu \mathrm{l} \quad$ pure water \\
& $5 \mu \mathrm{l}$ Mastermix \\
& $1 \mu \mathrm{l}$ SCR primer \\
\hline
\end{tabular}


Table 30: Cycling conditions of the telomere real-time PCR

\begin{tabular}{|c|c|c|c|c|c|}
\hline Step & Cycles & $\begin{array}{l}\text { Temperature } \\
{\left[{ }^{\circ} \mathrm{C}\right]}\end{array}$ & $\begin{array}{l}\text { Temperature } \\
\text { Change }\left[{ }^{\circ} \mathrm{C} / \mathrm{s}\right]\end{array}$ & $\begin{array}{l}\text { Signal } \\
\text { acquisition }\end{array}$ & Time \\
\hline $\begin{array}{l}\text { Initial } \\
\text { Denaturation }\end{array}$ & 1 & 95 & 1.99 & & $10 \mathrm{~min}$ \\
\hline Denaturation & \multirow[t]{3}{*}{40} & 95 & 1.99 & & $20 \mathrm{~s}$ \\
\hline Annealing & & 52 & 1.77 & & $20 \mathrm{~s}$ \\
\hline Extension & & 72 & 1.77 & signal acquisition & $45 \mathrm{~s}$ \\
\hline \multirow{3}{*}{$\begin{array}{l}\text { Melting Curve } \\
\text { Analysis }\end{array}$} & \multirow[t]{3}{*}{1} & 95 & 1.99 & \multirow{3}{*}{$\begin{array}{l}\text { continuous signal } \\
\text { acquisition }\end{array}$} & $1 \mathrm{~s}$ \\
\hline & & 60 & 1.77 & & $20 \mathrm{~s}$ \\
\hline & & 95 & 0.075 & & $15 \mathrm{~s}$ \\
\hline
\end{tabular}

\section{$2.9 \quad$ Telomere qFISH}

The novel telomer qFISH method was used to measure relative telomere length. Instruments and materials used to perform the method are described in Table 31. Details for the preparation of solutions are given in Table 32.

Table 31: Materials for telomer qFISH

\begin{tabular}{|l|l|l|}
\hline Material & Product Name & Company \\
\hline Microscope & $\begin{array}{l}\text { Olympus IX83 inverted microscope } \\
\text { with Abberior QUAD Scanner }\end{array}$ & Abberior and Olympus \\
\hline Slides & $\begin{array}{l}\text { Menzel-Gläser Superfrost Plus } \\
\text { Microscope Slides }\end{array}$ & Thermo Scientific \\
\hline Cuvettes & 100 ml Cuvette & Schott \\
\hline Fixogum & Fixogum & Marabu \\
\hline Multi-chamber water bath & Multi-chamber water bath & Julabo \\
\hline Hybrite & ThermoBrite & Leica \\
\hline Roti-Histofix & Roti Histofix 4\% & Carl Roth \\
\hline Hybridization buffer B & Hybridization Buffer B & Oxford Gene Technology \\
\hline PNA telomere probe & $\begin{array}{l}\text { Alexa488-labeled C-rich Telomere } \\
\text { Probe (TelC Star635P) }\end{array}$ & Eurogentec \\
\hline KCl & Potassium chloride P9541-1kg & Sigma \\
\hline NaCl & Sodium chloride S3014-1kg & Sigma \\
\hline Trisodium citrate dihydrate & Trisodium citrate dihydrate 5 kg & Roth \\
\hline $37 \%$ HCl & Hydrochloric Acid 2,5 I & J.T. Baker \\
\hline Pepsin & Pepsin 10108057001 & Roche \\
\hline Methanol & Methanol 34860-1I & Sigma \\
\hline RNase A & RNase A & Qiagen \\
\hline Salmon sperm DNA & $\begin{array}{l}\text { UltraPure Salmon Sperm DNA } \\
\text { Solution }\end{array}$ & Invitrogen \\
\hline Tween-20 & Tween-20 P9416-100 ml & Sigma \\
\hline DAPI & $\begin{array}{l}\text { Prolong Gold Antifade Reagent wit } \\
\text { DAPI }\end{array}$ & Invitrogen \\
\hline Nail polish & P & \\
\hline
\end{tabular}


Table 32: Solutions for telomere qFISH

\begin{tabular}{|c|c|}
\hline Solution & Composition \\
\hline $0.005 \mathrm{M}$ Sodium citrate solution & 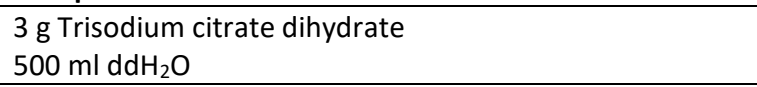 \\
\hline $0.08 \mathrm{M} \mathrm{KCl}$ solution & 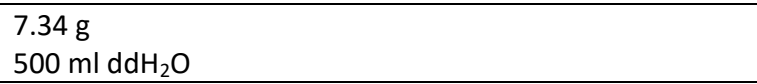 \\
\hline PNA stock solution & 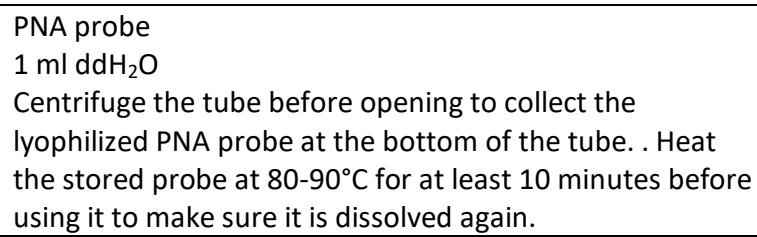 \\
\hline $20 \times$ SSC & 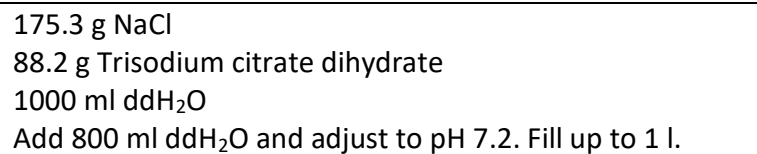 \\
\hline $1 \mathrm{M} \mathrm{HCl}$ & 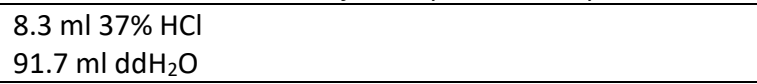 \\
\hline Pepsin stock solution $(0,05 \mathrm{~g} / \mathrm{ml})$ & 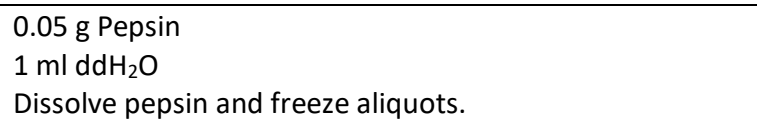 \\
\hline Hypotonic solution & $\begin{array}{l}5 \mathrm{ml} 0.005 \mathrm{M} \text { Sodium citrate solution } \\
5 \mathrm{ml} 0.08 \mathrm{M} \mathrm{KCl} \text { solution } \\
\text { Always prepare freshly and warm to } 37^{\circ} \mathrm{C} \text { before use. }\end{array}$ \\
\hline Carnoy's fixative & $\begin{array}{l}35 \mathrm{ml} \text { Methanol } \\
12.5 \mathrm{ml} 100 \% \text { Acetic Acid } \\
\text { Always prepare freshly and keep at }-20^{\circ} \mathrm{C} \text { until use. }\end{array}$ \\
\hline $2 \times S S C$ & 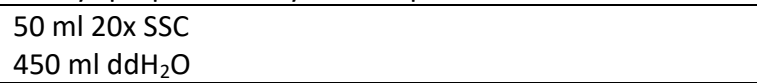 \\
\hline RNase A solution $(100 \mu \mathrm{g} / \mathrm{ml})$ & $\begin{array}{l}1.6 \mu \mathrm{l} \text { RNase } A \\
500 \mu \mathrm{l} 2 \text { xSSC }\end{array}$ \\
\hline Hybridization solution & $\begin{array}{l}100 \mu \mathrm{l} \text { Hybridization solution B } \\
1 \mu \mathrm{l} \text { Salmon sperm DNA } \\
0.1 \mu \mathrm{l} \text { PNA stock solution } \\
\text { Always prepare freshly. }\end{array}$ \\
\hline Pepsin working solution & 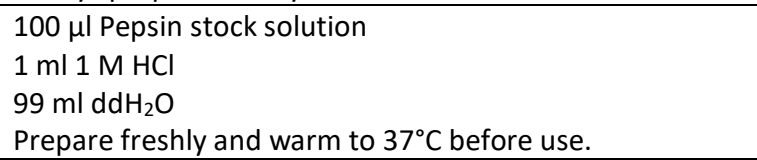 \\
\hline Washing solution & 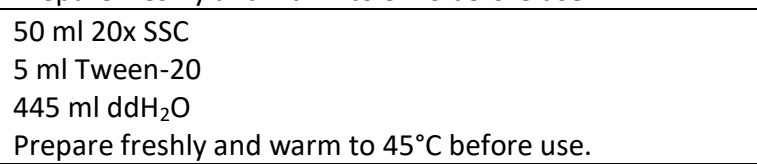 \\
\hline $1 \times \mathrm{SSC}$ & 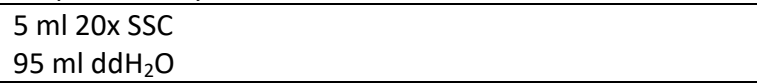 \\
\hline
\end{tabular}

\subsubsection{Sample Preparation}

Fibroblasts were cultured as described in section 2.2. Fibroblasts were seeded to a T75 flask and grown for four days to $70 \%$ confluency. After harvesting the cells, they were centrifuged (300xg, $5 \mathrm{~min}, \mathrm{RT}$ ) and washed with PBS. After another centrifugation step, the supernatant was removed except for approximately $2 \mathrm{ml}$ of pellet and PBS. The pellet was resuspended by slow vortexing. Then $10 \mathrm{ml}$ of ice-cold Carnoy fixative was added dropwise while vortexing slowly. By centrifugation (300xg, 10 minutes, RT), the cells were pelleted. This fixation was 
repeated twice. After the third fixation step, the supernatant was removed except for approximately $1 \mathrm{ml}$, and the cell suspension was resuspended by pipetting.

The slides were incubated in $70 \%$ ethanol at $-20^{\circ} \mathrm{C}$ before washing twice with cold water. The slide was flicked to the side to remove the water. The slides were propped up to a $45^{\circ}$ angle, and $20 \mu \mathrm{l}$ of the solution with fixed cells were dropped onto the slide from a distance of $5 \mathrm{~cm}$. Directly afterward, $2 \mathrm{ml}$ of Carnoy fixative was washed across the slide to remove debris. The slides were dried on a hot plate for one minute. On a microscope with 20x magnification and phase contrast, the cell density was then checked. If the cells overlayed each other, the cell suspension was diluted with Carnoy fixative, and if the cells were too sparse, the cell suspension was centrifuged to increase the cell density.

Before starting, the cuvettes were warmed to the appropriate temperatures. The slides were immersed in PBS at room temperature for fifteen minutes to rehydrate. Subsequently, the slides were incubated in Roti-Histofix at $37^{\circ} \mathrm{C}$ for five minutes. Then the slides were washed twice in PBS for five minutes at $37^{\circ} \mathrm{C}$. Before continuing, the slides were air-dried. Then $100 \mu \mathrm{l}$ RNase A solution was added to each slide, and a coverslip was used and fixed with Fixogum to prevent drying. The slides were incubated at $37^{\circ} \mathrm{C}$ on the hybrite for one hour. Following the incubation, the fixogum and the coverslip were removed. The slides were then washed three times in $2 \times \mathrm{SSC}$ at RT. Before incubating the slides in Pepsin solution at $37^{\circ} \mathrm{C}$ for five minutes, the slides were washed in water. Then the slides were washed twice in PBS for three minutes at $37^{\circ} \mathrm{C}$. The slides were then fixed in Roti-Histofix at $37^{\circ} \mathrm{C}$ for five minutes. After washing twice in PBS for five minutes at RT, the slide preparation continued.

After washing in PBS at RT for five minutes, the slides were dehydrated for one minute each in ice-cold $70 \%, 85 \%$, and $100 \%$ ethanol. Finally, the slides were air-dried. Before continuing, the slides were heated to $80^{\circ} \mathrm{C}$ for five minutes on the hybrite. The hybridization buffer was heated to $85^{\circ} \mathrm{C}$ for five minutes before use. $100 \mu \mathrm{l}$ of hybridization buffer was added to the area with nuclei on each slide. The area was covered with a coverslip and fixed with fixogum. The slides were then denatured for 10 minutes at $80^{\circ} \mathrm{C}$. Finally, the slides were placed into a dark and damp chamber at $4{ }^{\circ} \mathrm{C}$ overnight.

On the following day, the slides were immersed in washing solution at room temperature to remove the fixogum and the coverslip. The slides were washed twice in washing solution for 
10 minutes at $60^{\circ} \mathrm{C}$ and for one minute at room temperature. The wash was continued by washing the slides in 2x SSC for two minutes, 1x SSC for two minutes, and water for two minutes before air-drying. When the slides were dehydrated, DAPI was dropped onto the slide, and a coverslip is dropped onto the slide. After drying in the dark overnight, the slides were sealed with nail polish.

\subsubsection{Microscopy}

The slides were imaged in confocal and STED mode using the custom-build setup based on the Olympus IX83 inverted microscope with an Abberior QUAD scanner. The slides were mounted on a 100x oil immersion objective, and nuclei were identified using the DAPI channel. 3Dconfocal imaging was performed, and in addition, a single frame was acquired in STED mode.

\subsubsection{Image Analysis}

The image analysis was done by Niko Schwenzer using his own fully automated image analysis routine. In ImageJ Fiji, Images were manually masked by the DAPI signal to exclude background signals. Telomere signals were smoothed by a Gaussian filter and subjected to a 3D spot detection routine based on a foci detection algorithm with a background threshold of 30 counts and a minimum spot size of 10 voxels (147).

\subsubsection{Statistical Analysis}

Graph Pad Prism was used to perform statistical tests and to compile the figures. Each patient fibroblast line was compared to the three control fibroblasts using a one-way ANOVA analysis. Significance is indicated with asterisks: ${ }^{*} p<0.05,{ }^{* *} p<0.01, * * * p<0.001, * * * * p<0.0001$. 


\subsection{Telomere Southern Blot}

The Southern blot was done to measure telomere length and thus validate the measurements of the telomere qFISH method. The materials needed for telomere the Southern blot are summarized in Table 33. The solutions are listed in Table 34.

Table 33: Materials for the telomere Southern blot

\begin{tabular}{|c|c|c|}
\hline Material & Product Name & Company \\
\hline Roller mixer & roller mixer RM5 & Assistant \\
\hline Orbital shaker & orbital shaker IKA-Vibrax-VxR electric & IKA \\
\hline Hybridization oven & $0407-8505115981-00$ & Bachofer Laboratoriumsgeräte \\
\hline Imaging device & c300 & azure biosystems \\
\hline Blotting equipment & $\begin{array}{l}\text { Burboblotter Rapid Downwater } \\
\text { Transfer System }\end{array}$ & Schleicher\&Schuell \\
\hline \multicolumn{3}{|l|}{ Glass plates } \\
\hline Hybridization tube & Hybridization tube $35 \times 300 \mathrm{~mm}$ & Chemglass Life Science \\
\hline $\begin{array}{l}\text { Telo TAGGG Telomere Length Assay } \\
\text { Kit }\end{array}$ & $\begin{array}{l}\text { Telo TAGGG Telomere Length Assay } \\
\text { Kit }\end{array}$ & Roche \\
\hline Nylon membrane & $\begin{array}{l}\text { Amersham Hybond-XL nylon } \\
\text { membrane }\end{array}$ & GE Healthcare \\
\hline Whatman paper & $\begin{array}{l}\text { Gel-blotting-Paper } 580 \times 600 \mathrm{~mm} \\
V E=50\end{array}$ & Th.Geyer \\
\hline \multicolumn{3}{|l|}{ Transparent foil } \\
\hline Tris bufffer & Tris buffer grade $5 \mathrm{~kg}$ & Applichem \\
\hline EDTA & $\begin{array}{l}\text { Ethylenediamine Tetraacetic acid } \\
\text { disodium salt dihydrate }\end{array}$ & MP Biomedicals, Inc \\
\hline $37 \% \mathrm{HCl}$ solution & Hydrochloric Acid 2,5 I & J.T.Baker \\
\hline $\mathrm{NaOH}$ & Sodium hydroxide $5 \mathrm{~kg}$ & Merck \\
\hline $\mathrm{NaCl}$ & Sodium chloride $5 \mathrm{~kg}$ & Roth \\
\hline Trisodium citrate dihydrate & Tri-sodium citrate 2 hydrate $5 \mathrm{~kg}$ & Roth \\
\hline $10 \%$ SDS & $\begin{array}{l}\text { Sodium dodecyl sulfate solution } 10 \% \\
\text { in } \mathrm{H} 2 \mathrm{O} 71736-100 \mathrm{ml}\end{array}$ & Sigma \\
\hline Agarose & Agarose Standard 3810.3 & Roth \\
\hline Hinf I & Hinf I & New England Biolabs \\
\hline Rsa I & Rsal & New England Biolabs \\
\hline BSA & BSA, Molecular Biology Grade B9000S & New England Biolabs \\
\hline NE buffer 4 & NEbuffer4 B7004S & New England Biolabs \\
\hline
\end{tabular}

Table 34: Solutions for the telomere Southern blot

\begin{tabular}{|l|l|}
\hline Solution & Composition \\
\hline 0.5 M EDTA & $93.05 \mathrm{~g} \quad$ EDTA \\
& $400 \mathrm{ml}$ pure water \\
& Adjust pH with NaOH plates to 8.0, fill up to $500 \mathrm{ml}$, autoclave, and store at \\
& RT. \\
\hline $50 x$ TAE buffer & $242 \mathrm{~g} \quad$ Tris acetate $(\mathrm{MW}=121.14 \mathrm{~g} / \mathrm{mol})$ \\
& $700 \mathrm{ml}$ pure water \\
& $57.1 \mathrm{ml} \quad$ Acetic acid \\
& $100 \mathrm{ml} \quad 0.5 \mathrm{M}$ EDTA $(\mathrm{pH} 8.0)$ \\
& Fill up to 1 I and store at RT. \\
\hline DNA Digestion Mix & $18 \mu \mathrm{l} \quad$ DNA $(1 \mu \mathrm{g})$ \\
& $3 \mu \mathrm{N} \quad$ NE Buffer 4 \\
& $3 \mu \mathrm{l} \quad$ 10x BSA \\
& $3 \mu \mathrm{l} \quad$ Hinfl \\
& $3 \mu \mathrm{l} \quad$ Rsal \\
\hline
\end{tabular}




\begin{tabular}{|c|c|}
\hline DNA samples for gel electrophoresis & $\begin{array}{ll}30 \mu \mathrm{l} & \text { DNA Digestion Mix } \\
7.5 \mu \mathrm{l} & \text { Gel electrophoresis loading buffer (Bottle 7) }\end{array}$ \\
\hline Molecular weight marker & $\begin{array}{l}4 \mu \mathrm{l} \quad \text { DIG molecular weight marker } \\
12 \mu \mathrm{l} \quad \text { pure water } \\
4 \mu \mathrm{l} \quad \text { Gel electrophoresis loading buffer (Bottle 7) } \\
10 \mu \mathrm{l} \text { of the marker is added to the first lane, and } 10 \mu \mathrm{l} \text { is added to the last } \\
\text { lane of the gel. }\end{array}$ \\
\hline 1x TAE buffer (Solution 1) & $\begin{array}{l}20 \mathrm{ml} \text { 50x TAE buffer } \\
980 \mathrm{ml} \text { pure water } \\
\text { Store the solution at RT. }\end{array}$ \\
\hline $0.25 \mathrm{M} \mathrm{HCl}$ (Solution 2) & $\begin{array}{l}20 \mathrm{ml} \quad 37 \% \mathrm{HCl} \text { Solution } \\
980 \mathrm{ml} \text { pure water } \\
\text { Store the solution at RT. }\end{array}$ \\
\hline Denaturation solution (Solution 3) & $\begin{array}{l}20,0 \mathrm{~g} \quad \mathrm{NaOH} \\
87.6 \mathrm{~g} \mathrm{NaCl} \\
\text { Weigh the reagents and fill up to } 1 \text { I with pure water. Store the solution at RT. }\end{array}$ \\
\hline Neutralization solution (Solution 4) & $\begin{array}{l}60.5 \mathrm{~g} \quad \text { Tris } \\
175,3 \mathrm{~g} \mathrm{NaCl} \\
\text { Weigh the reagents and add } 700 \mathrm{ml} \text { pure water. Adjust the } \mathrm{pH} \text { to } 7.5 \text { with } 37 \% \\
\mathrm{HCl} \text { solution. Fill up to } 1 \text { I and store the solution at RT. }\end{array}$ \\
\hline 20x SSC buffer (Solution 5) & $\begin{array}{l}175 \mathrm{~g} \quad \mathrm{NaCl} \\
77.5 \mathrm{~g} \quad \text { Trisodium citrate dihydrate } \\
\text { Weigh the reagents and add } 700 \mathrm{ml} \text { pure water. Adjust the } \mathrm{pH} \text { to } 7.0 \text { with } 37 \% \\
\mathrm{HCl} \text { solution. Fill up to } 1 \text { I and store at RT. }\end{array}$ \\
\hline 2x SSC buffer (Solution 6) & $\begin{array}{l}100 \mathrm{ml} 20 \times \mathrm{SSC} \\
900 \mathrm{ml} \quad \text { pure water } \\
\text { Dilute and store at RT. }\end{array}$ \\
\hline $\begin{array}{l}\text { DIG Easy hybridization solution } \\
\text { (Solution 7) }\end{array}$ & $\begin{array}{l}\text { DIG Easy Hyb granules (Bottle } 8 \text { ) } \\
64 \mathrm{ml} \text { pure water } \\
\text { Reconstitute the bottle with water and incubate at } 37^{\circ} \mathrm{C} \text { until completely } \\
\text { dissolved. Prepare the solution several hours before use. Prewarm before use } \\
\text { to } 42^{\circ} \mathrm{C} \text {. The reconstituted solution remains stable for } 3 \text { months at RT. }\end{array}$ \\
\hline Hybridization solution & $\begin{array}{l}1.4 \mu \mathrm{l} \quad \text { Telomere probe (Bottle 9) } \\
7 \mathrm{ml} \quad \text { DIG Easy hybridization solution (Solution 7) } \\
\text { At least } 6.5 \mathrm{ml} \text { hybridization solution are needed for } 200 \mathrm{~cm}^{2} \text { blotting } \\
\text { membrane. }\end{array}$ \\
\hline Stringent wash buffer 1 (Solution 8 ) & $\begin{array}{ll}990 \mathrm{ml} & 2 \times \mathrm{SSC} \\
10 \mathrm{ml} & 10 \% \mathrm{SDS} \text { solution } \\
\text { Store the solution at } 37^{\circ} \mathrm{C} \text { to avoid precipitation. }\end{array}$ \\
\hline Stringent wash buffer 2 (Solution 9) & $\begin{array}{l}100 \mathrm{ml} 2 \times \mathrm{SSC} \\
890 \mathrm{ml} \text { pure water } \\
10 \mathrm{ml} 10 \% \text { SDS solution } \\
\text { Store the solution at } 37^{\circ} \mathrm{C} \text { to avoid precipitation. }\end{array}$ \\
\hline 1x Washing buffer (Solution 10) & $\begin{array}{l}25 \mathrm{ml} 10 x \text { Washing buffer (Bottle 10) } \\
225 \mathrm{ml} \text { pure water } \\
\text { Store the solution at RT. }\end{array}$ \\
\hline 1x Blocking solution (Solution 11) & $\begin{array}{l}5 \mathrm{ml} \quad \text { 10x Blocking buffer (Bottle 12) } \\
45 \mathrm{ml} \quad 1 \times \text { Maleic acid buffer } \\
\text { Prepare before use and do not store. }\end{array}$ \\
\hline 1x Maleic acid buffer (Solution 12) & $\begin{array}{l}9 \mathrm{ml} \quad 10 x \text { Maleic acid buffer (Bottle 11) } \\
81 \mathrm{ml} \quad \text { pure water } \\
\text { Dilute and store at RT. }\end{array}$ \\
\hline $\begin{array}{l}\text { Anti-DIG-AP working solution } \\
\text { (Solution 13) }\end{array}$ & $\begin{array}{l}45 \mathrm{ml} \quad \text { 1x Maleic acid buffer } \\
5 \mathrm{ml} \quad \text { 10x Blocking Buffer (Bottle 12) } \\
5 \mathrm{\mu l} \quad \text { Anti-DIG-AP (Bottle 13) } \\
\text { Spin down the vial to precipitate aggregated antibodies. Prepare immediately } \\
\text { before use and do not store. }\end{array}$ \\
\hline 1x Detection buffer (Solution 14) & $\begin{array}{l}5 \mathrm{ml} \quad 10 x \text { Detection buffer (Bottle 14) } \\
45 \mathrm{ml} \text { pure water } \\
\text { Store at RT. }\end{array}$ \\
\hline
\end{tabular}


The DNA was extracted according to section 2.3. DNA concentration was measured by the Nanodrop spectrometer and then on the Tape Station according to section 2.4. If the DNA sample has a DIN value above 7, the sample is not degraded and may be used for telomere Southern blot. The DNA sample was diluted to $1 \mu \mathrm{g}$ in $18 \mu \mathrm{l}$. The DNA digestion mix was incubated for three hours at $37^{\circ} \mathrm{C}$. The digested DNA was analyzed on a $0.8 \%$ gel for complete digestion. $5 \mu \mathrm{l}$ gel electrophoresis loading buffer (Bottle 7) was added to the mix to stop the digestion. A $0,8 \%$ agarose gel in 1x TAE buffer was prepared without ethidium bromide or GelRed according to section 2.5. $10 \mu \mathrm{l}$ DIG molecular weight marker and $20 \mu$ digested DNA with loading buffer were added to the pockets of the gel. The gel was run at $80 \mathrm{~V}$ in $1 \mathrm{x}$ TAE buffer (Solution 1) for 2-4 hours until the bromophenol blue tracking dye had almost reached the bottom of the gel.

The agarose gel was submerged in $\mathrm{HCl}$ solution (Solution 2) for 10 minutes and agitated at RT until the bromophenol blue stain had changed color to yellow. The gel was rinsed twice with pure water and then submerged in denaturation solution (Solution 3) twice for 15 minutes at RT. The gel was rinsed twice with pure water and then submerged in neutralization solution (Solution 4) for twice 15 minutes RT. The Southern blot equipment was then assembled. From top to bottom 23 dry Whatman paper, two Whatman paper soaked in 2x SSC (Solution 6), the nylon membrane (as large as the gel, handled with forceps), the agarose gel with the digested DNA samples and three Whatman paper soaked in 20x SSC (Solution 5) were piled on top of each other. Then a bridge was built with Whatman paper from the reservoir to the top of the pile. The pile was weighted down with a heavy bottle. The reservoir was filled with 20x SSC, and the blotting took place overnight. Successful blotting was indicated by an evenly thin gel. The place of the gel pockets and the upper right corner were marked with a pen on the nylon membrane. The gel was kept damp between two Whatman papers from the bottom of the stack. The membrane was fixed by baking at $80^{\circ} \mathrm{C}$ for two hours between two Whatman papers and two glass plates.

A glass tube with a screw top was filled with $2 \times$ SSC, and the membrane was transferred with forceps to the tube with the DNA side facing inward. The bubbles were removed with a silicon scraper and washed for 10 minutes on a roller mixer. $7 \mathrm{ml}$ of $42^{\circ} \mathrm{C}$ warm DIG Easy Hyb granules solution (Solution 7) was added for prehybridization to the tube and incubated for one hour 
at $42^{\circ} \mathrm{C}$ in the hybridization oven. $7 \mathrm{ml}$ hybridization solution was added to the tube and incubated for three hours or overnight at $42^{\circ} \mathrm{C}$ in the hybridization oven.

The membrane was then washed thrice in $50 \mathrm{ml}$ stringent wash buffer I (Solution 8) for five minutes on the roller mixer at RT. The wash was continued with prewarmed stringent wash buffer II (Solution 9) thrice for 12 minutes in the hybridization oven at $50^{\circ} \mathrm{C}$. The membrane was washed twice for five minutes with $50 \mathrm{ml}$ wash buffer (Solution 10) for five minutes on the roller mixer at RT. The membrane was blocked with $50 \mathrm{ml}$ blocking buffer (Solution 11) for 40 minutes at RT on the roller mixer. The treatment of the membrane continued with the incubation with $50 \mathrm{ml}$ Anti-DIG-AP working solution (Solution 13) for 40 minutes at RT on the roller mixer. After washing thrice for ten minutes with washing buffer (Solution 10), $50 \mathrm{ml}$ detection buffer (Solution 14) was added to the tube and incubated at RT for five minutes on the roller mixer. The membrane was then removed from the tube and placed into a box. 10 $\mathrm{ml}$ substrate solution was added with a pipette. The box was held at an angle so that the solution flowed over the membrane, was collected with the pipette at the bottom, and dripped over the membrane again. The substrate solution was not dripped directly onto the membrane as that causes stains. For detection, the membrane was placed between two foils, bubbles were removed, and the luminescence was detected with the imaging device.

The Southern blot image was analyzed by the software ImageQuantTL (GE Healthcare). The position of the marker was used as reference points to determine the position of the telomeric smear of the samples. The lane profile was exported to MS Excel, and the harmonic mean was calculated as described by Lincz et al. (148).

\subsection{Cell Cycle Analysis by Flow Cytometry}

A flow cytometry measurement was performed to analyze the cell cycle progression of fibroblasts. The materials used are listed in Table 35, and solutions are described in Table 36. 
Table 35: Material used for flow cytometry

\begin{tabular}{|l|l|l|}
\hline Material & Product Name & Company \\
\hline BD Facs Canto II & BD Facs Canto II & BD Biosciences \\
\hline tubes & $5 \mathrm{ml}$ tubes $75 \times 12 \mathrm{ml}$, PS & Sarstdt \\
\hline Propidium lodide & $1 \mathrm{mg} / \mathrm{ml} \mathrm{P4864-10} \mathrm{ml}$ & Sigma \\
\hline Ethnol & Ethanol $100 \%$ & J. T. Baker \\
\hline RNase A & RNase A & Qiagen \\
\hline
\end{tabular}

Table 36: Solutions used for flow cytometry

\begin{tabular}{|l|l|}
\hline Solution & Composition \\
\hline 70\% Ethanol & $7 \mathrm{ml} \mathrm{Ehtanol} \mathrm{100 \%}$ \\
& $3 \mathrm{ml} \quad \mathrm{ddH}_{2} \mathrm{O}$ \\
\hline RNase A solution & $250 \mu \mathrm{l} \quad \mathrm{PBS}$ \\
& $0.5 \mu \mathrm{l} \quad$ RNase A \\
\hline
\end{tabular}

250,000 fibroblasts were seeded in T75 flasks and incubated for four days at $37^{\circ} \mathrm{C}$. The cells were harvested by collecting the medium in a $50 \mathrm{ml}$ falcon. After washing the cells with PBS, the PBS was also collected into the falcon. After adding $3 \mathrm{ml}$ trypsin to the flask and incubating the flask for five minutes in the incubator, $3 \mathrm{ml}$ of medium were added to the flask to rinse the cells from the flask. The cell suspension was also added to the $50 \mathrm{ml}$ falcon. The cell suspension was centrifuged ( $300 \mathrm{xg}, 5 \mathrm{~min}, \mathrm{RT})$, the supernatant was removed, and the cell pellet was resuspended in PBS and moved to a $15 \mathrm{ml}$ falcon. After another centrifugation step, the supernatant was removed except for $300 \mu \mathrm{l}$. Now the pellet was resuspended, and $700 \mu \mathrm{l}$ ice-cold $70 \%$ ethanol was added dropwise while vortexing gently. Following this ethanol fixation, the cells were incubated for at least 24 hours at $4^{\circ} \mathrm{C}$. To stain the cells, the falcon was centrifuged (500x g, $5 \mathrm{~min}, \mathrm{RT}$ ). The supernatant was removed, and the cells were washed with cold PBS. After another centrifugation step, the pellet was resuspended in $250 \mu$ l RNase A solution and moved to a $1.5 \mathrm{ml}$ cup. The cells were then incubated at $37^{\circ} \mathrm{C}$ on a thermal mixer at $300 \mathrm{rpm}$. Next, $10 \mu \mathrm{l}$ of propidium iodide was added to the sample. The cups were wrapped in tin foil and again incubated at $37^{\circ} \mathrm{C}$ for thirty minutes on the thermal mixer at 300 rpm. Then the samples were moved to tubes. The samples were analyzed in the Core Facility Cell-Sorting of the University Medical Center Göttingen by Sabrina Becker on the BD FACS Canto II using the software BD FACSDiva. The data were analyzed using Microsoft Excel and Graph Pad Prism. The one-way ANOVA analysis was applied to evaluate differences between each patient and the four control samples. Significance is indicated with asterisks: ${ }^{*} p<0.05$, $* * p<0.01, * * * p<0.001, * * * * p<0.0001$. 


\subsection{2 pH2AX Assay}

The $\mathrm{yH} 2 \mathrm{AX}$ staining was performed to assess DNA damage repair after treatment with different genotoxic chemicals. The materials used for the staining are listed in Table 37 and solutions are detailed in Table 38.

Table 37: Material for $\mathrm{YH} 2 \mathrm{AX}$ staining

\begin{tabular}{|c|c|c|}
\hline Material & Product name & Company \\
\hline Orbital shaker & VWR Rocker & VWR \\
\hline Roller mixer & SRT6D & Stuart \\
\hline Confocal microscope & Olympus IX81 & Olympus \\
\hline Microscope software & Olympus Fluoview Ver. 4.2a & Olympus \\
\hline Focinator software & Focinator V2-31 & \\
\hline Image J & ImageJ 1.51j8 & \\
\hline 24 Well plate & 24 Well Cell Culture Plate 7696792 & Labsolute \\
\hline Cover slips & Menzel-Gläser Cover Slips 13 mm \#1 & Thermo Scientific \\
\hline Glass slides & $\begin{array}{l}\text { Menzel-Gläser Superfrost Plus } \\
\text { microscope slides }\end{array}$ & Thermo Scientific \\
\hline PBS & DPBS (1x)14190-144 & Gibco \\
\hline PFA & Paraformaldehyd 158127-100g & Sigma-Aldrich \\
\hline Triton & Triton X-114-500 ml & Sigma \\
\hline BSA & Albumin Faktion V 80762 & Roth \\
\hline Tween & Tween20 H5151 & Promega \\
\hline DAPI & Fluoroshield with DAPI F6057-20 ml & Sigma \\
\hline pH2AX antibody & $\begin{array}{l}\text { Anti-phospho-Histone H2A.X } \\
\text { (Ser139),clone JBW301 }\end{array}$ & EMD Millipore Corporation \\
\hline M555 antibody & $\begin{array}{l}\text { AlexaFluor555 goat-anti mouse IgG } 2 \\
\mathrm{mg} / \mathrm{ml}\end{array}$ & invotrogen \\
\hline
\end{tabular}

Table 38: Solutions for $\mathrm{yH} 2 \mathrm{AX}$ Staining

\begin{tabular}{|c|c|}
\hline Solution & Composition \\
\hline $4 \%$ PFA & $\begin{array}{l}20 \mathrm{~g} \text { PFA } \\
500 \mathrm{ml} \text { PBS } \\
\text { Add } 400 \mathrm{ml} \mathrm{PBS} \text { to a glass beaker on a stir plate in a ventilated hood. Heat while stirring to } \\
\text { approximately } 60^{\circ} \mathrm{C} \text {. Add } 20 \mathrm{~g} \text { of PFA powder to the heated PBS solution. Raise the } \mathrm{pH} \text { by } \\
\text { adding } 1 \mathrm{M} \mathrm{NaOH} \text { dropwise from a pipette until the solution clears. Once the } \\
\text { paraformaldehyde is dissolved, the solution should be cooled to room temperature. Adjust } \\
\text { the } \mathrm{pH} \text { with } \mathrm{HCl} \text { Solution to } 6.9 \text {. Adjust the volume to } 500 \mathrm{ml} \text { with PBS. Freeze until use. }\end{array}$ \\
\hline $10 \%$ Triton-PBS & $\begin{array}{l}1 \mathrm{~g} \quad \text { Triton } \\
10 \mathrm{ml} \quad \text { PBS } \\
\text { Put on roller mixer until dissolved. }\end{array}$ \\
\hline 10\% Tween-PBS & $\begin{array}{l}1 \mathrm{~g} \quad \text { Tween } \\
10 \mathrm{ml} \quad \text { PBS } \\
\text { Put on roller mixer until dissolved. }\end{array}$ \\
\hline $0.5 \%$ Triton-PBS & $\begin{array}{ll}2.5 \mathrm{ml} & 10 \% \text { Triton-PBS } \\
47.5 \mathrm{ml} & \text { PBS }\end{array}$ \\
\hline Blocking solution & $\begin{array}{l}1.5 \mathrm{~g} \quad \mathrm{BSA} \\
500 \mu \mathrm{l} \quad 10 \% \text { Tween } \\
49.5 \mathrm{ml} \text { PBS } \\
\text { Put on roller mixer until dissolved. }\end{array}$ \\
\hline Antibody solution & $\begin{array}{ll}1 \mu \mathrm{l} & \text { Antibody } \\
1000 \mu \mathrm{l} & \text { Blocking solution }\end{array}$ \\
\hline
\end{tabular}


Cells were seeded in 24-well plates at 50,000 cells per well according to section 2.224 hours prior to harvesting. Cells were treated with radiation at a dose rate of $1 \mathrm{~Gy} / \mathrm{min}$ delivered by a RS 225 X-Ray Research System (Gulmay Medical Systems, Xstrahl Ltd, Camberley, Surrey, UK) operated at $200 \mathrm{kV}, 15 \mathrm{~mA}$, and with $0.5 \mathrm{~mm}$ copper filtration. The slides were fixed after 24 hours and 48 hours after the treatment to assess DNA repair. The untreated cells were also fixed at the same time as the cells 24 hours after treatment. To fix the cells medium was removed, and the cells were washed once with PBS. Then $200 \mu \mathrm{l}$ of $4 \%$ PFA solution was added to the well and incubated for ten minutes. Then the cells were washed thrice with PBS and stored in the fridge until staining.

The PBS was removed, and the cells were permeabilized with $0.5 \%$ triton-PBS solution for ten minutes. Then the cells were blocked with blocking solution for one hour at room temperature on an orbital shaker. $\mathrm{\gamma H} 2 \mathrm{AX}$ antibody was diluted 1:1000 in bocking solution and added in a volume of $100 \mu \mathrm{l}$ as a drop to the coverslip. The primary antibody was incubated overnight in the fridge in a damp box. The coverslips were washed thrice for five minutes with blocking solution before adding the secondary antibody in a 1:1000 dilution in blocking solution to the coverslip. The cells were incubated at RT in a damp box on the orbital shaker for one hour. Then the cells were washed thrice for five minutes with blocking solution and twice with PBS. The coverslip was fished out of the well with tweezers and put face-down on a $5 \mu$ drop of DAPI with polymerizing agent on the slide. The slides were dried for 24 hours at RT and then stored at $4^{\circ} \mathrm{C}$. The slides were imaged with a confocal microscope with a 100x objective. The settings are detailed in Table 39.

Table 39: Confocal Microscope Settings

\begin{tabular}{|l|l|l|}
\hline & DAPI & Cy3 \\
\hline Wavelength & 405 & 543 \\
\hline Laserpower & $25 \%$ & $60 \%$ \\
\hline HV & 800 & 800 \\
\hline Gain & $1 \mathrm{x}$ & $1,5 x$ \\
\hline Offset & $100 \%$ & $20 \%$ \\
\hline
\end{tabular}

Three biological replicates were prepared, and 15 images per condition (untreated, 24 hours after treatment, and 48 hours after treatment) and replicate were taken. The images were then analyzed by the Focinator software to count the foci automatically (149). The settings for the Focinator software are listed in Table 40. 
Table 40: Settings of automatic foci counting

\begin{tabular}{|l|l|}
\hline Setting & Value \\
\hline Number of foci channels & 1 \\
\hline ROl channel & back \\
\hline Foci count 1 & front \\
\hline Noise & 3800 \\
\hline Cutoff & 3800 \\
\hline Area correction & 80 \\
\hline Auto threshold method & Intermodes \\
\hline Cell size from & 500 \\
\hline Cell size to 90000 & \\
\hline Exclude cells on image edge & yes \\
\hline Colocalization & no \\
\hline Fill holes & yes \\
\hline Watershed & no \\
\hline
\end{tabular}

The data were analyzed using MS Excel and Graph Pad Prism. The one-way ANOVA analysis was applied to evaluate differences between each patient the control samples. Significance is indicated with asterisks: ${ }^{*} p<0.05,{ }^{*} p<0.01, * * * p<0.001, * * * * p<0.0001$. Additionally, pairwise comparisons of one patient sample with one control sample were performed with the unpaired t-test. 


\section{$3 \quad$ Results}

\subsection{Collection of Patient and Control Samples}

Our research group has gathered a patient cohort of twenty-five patients with accelerated aging phenotypes over the course of many years. Patients showed typical signs of segmental progeroid syndromes and accelerated aging symptoms. The patient cohort is divided into two subgroups: For fifteen patients, primary fibroblasts were available (fibroblast patient cohort), and for thirteen patients, DNA samples derived from blood (blood patient cohort) were included in the study. For two patients, both a DNA sample from blood and a fibroblast sample were available. Thus, the patient cohort consisted of 25 patients. Patient samples are designated with a " $P$ ", a number, and the mutated gene for easy recognition. As an example, P01-PYCR1 is a sample from a patient suffering pathogenic mutations in the PYCR1 gene. The detailed phenotype description, syndrome classification, and mutations are given in the following section. If the patient was published before, the phenotype description was taken from the publication, and the reference is given at the end of the paragraph. Table 41 summarizes the information on the syndrome, mutated gene, gene function, protein function, age at the time of biopsy, and the available material. Control samples are designated with " $\mathrm{C}$ " and a number. The control samples are listed in Table 45 in the appendix.

\section{P01-PYCR1}

The three-year-old patient from Syria presented with intrauterine growth retardation, lax and wrinkly skin, hernias, osteopenia, an abnormal corpus callosum, and mental retardation. The patient was diagnosed with autosomal-recessive Cutis laxa type IIB due to the identification of the homozygous deletion c.797+2_797+5del in PYCR1 predicted to result in the deletion p.(Lys215_Asp319del) on protein level. This patient was previously published as A.S. (45).

\section{P02-PYCR1}

The ten-week-old patient from the United States of America presented with intrauterine growth retardation, lax and wrinkly skin, hip dislocation, hernias, an abnormal corpus callosum, mental retardation, and cataracts. The patient was diagnosed with autosomalrecessive Cutis laxa type IIB due to the identification of the homozygous missense mutation 
c.752G $>$ A in PYCR1. The point mutation results in the amino acid change p.(Arg251His). This patient was previously published as E.U. (45).

\section{P03-PYCR1}

The four-year-old patient was born to healthy and non-consanguineous parents. He was born at term, after a normal pregnancy and uncomplicated birth with a progeroid appearance. At the last examination, the boy presented with an average height growth, microcephalia, fine hair, a long face, frontal bossing, intertemporal narrowing, esotropia, flabby cheeks, evident nose-lip furrow, thin lip, sharp chin with wrinkles at the root of neck, down-set ears with a big helix, lumbar lordosis, and a protruding abdomen. The skin appeared thin, inelastic, and translucent with pronounced wrinkling, mainly on the extensor side of joints. Fat tissue was poorly represented, and venous reticules were evident. Finger joints were hyper lax and thumbs proximally dislocated. He was diagnosed with autosomal recessive Cutis laxa type IIB due to the identification of the compound heterozygous missense mutations $c .355 \mathrm{C}>\mathrm{T}$ and c.356C $>T$ in PYCR1. These mutations result in the amino acid changes p.(Arg119Cys) and p.(Arg119His). This patient was previously published as MF (150).

\section{P04-ALDH18A1}

The two-year-old patient presented with intrauterine growth retardation, postnatal growth delay, lax, wrinkled, thin, and translucent skin, joint hyperlaxity, hernias, adducted thumbs, microcephaly, psychomotor retardation, and hypotonia. The patient was diagnosed with autosomal-dominant Cutis laxa type 3 due to the identification of a heterozygous missense mutation c.412C $>\mathrm{T}$ in the $A L D H 18 A 1$ gene resulting in the amino acid change p.(Arg138Trp). This patient was previously published as the index patient of Family 1 (151).

\section{P05-GORAB}

The fifteen-year-old patient suffering from Geroderma osteodysplasticum was described previously as GT2 (152). No phenotype description of the patient was available. Typical symptoms of Geroderma osteodysplasticum include wrinkly skin, sagging cheeks, flat feet, osteoporosis, and joint hyperextensibility (153). The compound heterozygous mutations c.1367G>T and c.1050_1053delTCCT in the GORAB gene causing premature transcription 
termination (p.(Glu46*) and p.(Phe350Leufs*26)) were identified as causative mutations of Geroderma osteodysplasticum.

\section{P06-SLC25A24}

The seven-year-old girl presented with failure to thrive, coronal craniosynostosis, brachycephaly, broad forehead, depressed supraorbital ridge, midface hypoplasia, prognathia, short and down slanting palpebral fissures, microphthalmia, low anterior and posterior hairline, coarse scalp hair, hypertrichosis, wrinkled skin, syndactyly, hypoplastic labia majora, low-set, dysplastic ears, wound healing disorder. The heterozygous de novo missense mutation c.650G $>A$ in the SLC25A24 gene causing the amino acid change p.(Arg217His) was identified as the causative mutation for Fontaine progeroid syndrome in this patient. The patient was previously published as patient two (46).

\section{P07-SLC25A24}

The one-year-old girl of Turkish descent weighed 1,700 g (-3,4 standard deviations (SD)) and was $29.4 \mathrm{~cm}$ (-3 SD) long at birth. The symptoms intrauterine growth retardation, postnatal short stature, failure to thrive, microcephaly, coronal craniosynostosis, brachycephaly, large anterior fontanelles, broad forehead, midface hypoplasia, prognathia, protrusion, short and downslanting palpebral fissures, microphthalmia, eyelid anomalies, low anterior, and posterior hair, coarse scalp hair, hypertrichosis, wrinkled skin, dermal translucency, reduced subcutaneous fat tissue, small nails, short distal phalanges, hypoplastic labia majora, oligodontia, highly arched palate, conductive hearing impairment, low-set, dysplastic ears, hypertrophic left ventricle, umbilical hernia, bilateral urolithiasis and delayed psychomotor development with normal outcome were noted. The heterozygous de novo missense mutation c.650G $>A$ in the SLC25A24 gene that causes the amino acid change p.(Arg217His) and was identified as the causative mutation for Fontaine progeroid syndrome. The patient was described as patient four previously (46).

\section{P08-BLM}

The fibroblasts with the catalog ID GM02520B were purchased from the Coriell Institute, New York, USA. The cells were derived from a skin biopsy of a ten-year-old girl with Bloom syndrome. She presented with sun sensitivity, and increased sister chromatid exchange in 
fibroblasts was observed. The two compound-heterozygous mutations c.2923delC and c.2824-1077_2999+310del1583, in the BLM gene were found to be causative of Bloom syndrome. The official gene name is RECQL3, yet the older name $B L M$ is still often in use as it is easier to pronounce. For easier readability and with the apparent connection to the syndrome name, I will use the gene name BLM.

\section{P09-BLM}

The fibroblasts with the catalog ID GM02932B were purchased from Coriell Institute, New York, USA. The Jewish man was 28 years old at the time of the skin biopsy. He was clinically affected by Bloom syndrome. He was born at term with a birth weight of 1,760 g. At the age of 17 his weight was $55.5 \mathrm{~kg}$, and his height $161.3 \mathrm{~cm}$. He developed sun-sensitive facial telangiectasias, acanthosis nigricans, diabetes mellitus, and had undescended testes. In fibroblasts, an increased chromosomal breakage and an increased sister chromatid exchange rate were observed. Post UV irradiation, unscheduled DNA synthesis was described. In this patient, the homozygous mutation c.2207_2212delinsTAGATTC in the BLM gene was identified as causative of Bloom syndrome.

\section{P10-BLM}

The fibroblasts with the catalog ID GM02548D were purchased from Coriell Institute, New York, USA. The African American boy was six years old at the time of the skin biopsy. He was clinically affected by Bloom syndrome. No symptoms were cataloged. Increased sister chromatid exchange and increased unscheduled DNA synthesis after UV irradiation were noted. The two heterozygous mutations c.1544dupA and c.2254C $>T$ in the $B L M$ gene were identified as causative of Bloom syndrome.

\section{P11-YRDC}

The patient was born after $37+0$ weeks of gestation to healthy, distantly consanguineous parents from northern Iraq. His birth weight was 1,740 g (- 3.1 SD), his birth length $46 \mathrm{~cm}$ (- $1.8 \mathrm{SD})$, and his head circumference at birth $29 \mathrm{~cm}$ (- $3.6 \mathrm{SD})$. He developed tonic-clonic seizures and primary liver and kidney dysfunction neonatally. The newborn screening revealed hypothyroidism. He required assisted ventilation. Furthermore, he showed generalized loss of subcutaneous fat with a progeroid appearance, hypertrichosis, arachnodactyly, and adducted 
thumbs as well as facial dysmorphisms including low-set and large appearing ears, micro-and retrognathia, long, smooth philtrum, and wrinkled skin. He had congenital intestinal malrotation and needed surgery due to meconium ileus. After surgery, he developed renal failure and intracranial hemorrhage and died at the age of 12 days. The homozygous missense mutation c.662T>C, p.(Ile221Thr) was identified in YRDC gene (Schmidt, Wollnik et al., unpublished).

\section{P12-ATP6V0A2}

The patient was born to consanguineous parents of Afghan origin and presented with wrinkled skin, a large fontanel, and no mental retardation. This case was published by Fischer et al. 2012 (154). A homozygous missense mutation at the position c.1A>T of the ATP6VOA2 gene was identified as the genetic cause of autosomal-recessive Cutis laxa type IIA.

\section{P13-AHCTF1}

The patient had a syndromic appearance and respiratory problems postnatally. At four months, the boy presented to the genetic counselor with microcephaly, failure to thrive, small stature, dentes neonatales, craniofacial dysmorphies, and unclear hearing and vision. The heterozygous de novo variant c.6329 C>G in the AHCTF1 gene resulting in p.Ser211Cys on protein level was identified, yet no genetic syndrome has been associated with this gene (Wollnik, personal communication).

\section{P14-PRKDC}

Prenatal sonography of this patient showed oligohydramnios and intrauterine growth reduction at four months after gestation. After a preterm caesarian section, the birthweight was $2670 \mathrm{~g}$, height $40 \mathrm{~cm}$, and head circumference $33.5 \mathrm{~cm}$. She displayed poor feeding and poor sucking, and growth development stopped at four months. A bilateral club foot was noted. Seizures began at five months. At six months, microcephaly, short stature, photosensitive skin, mental retardation, delayed neural development, severe hypotonia, poor vision, and poor hearing were noted. Brain MRI showed generalized atrophy and basal calcification. A skin biopsy was taken at the age of eight years. Due to the quadriradial formation of chromosomes in metaphase spreads, the clinical diagnosis of Bloom syndrome was given. The heterozygous mutation c. $9521 \mathrm{C}>\mathrm{T}$ in the $P R K D C$ gene was identified by exome 
sequencing, which causes Immunodeficiency 26 with or without neurologic abnormalities (Wollnik et al., unpublished).

\section{P15-CHD6}

The two-year-old boy presented with a hypoplastic left heart, sacral dysgenesis, bilateral talipes equinovarus, rib abnormalities (coat hanger shaped), mild upslanting palpebral fissures, mild protrusion of left ear, mild fingernail hypoplasia, mild diastasis recti, unusual crease in the sacral area, sacrum not complete on palpation, tight hips, and absent knee dimples. By exome sequencing, the heterozygous de novo mutation c.7987G $>\mathrm{A}$, p.(Asp2663Asn) in the CHD6 gene was identified. Based on his highly recognizable phenotype, he was diagnosed with Hallermann-Streiff syndrome and published (155). Typical symptoms of Hallermann-Streiff syndrome are craniofacial dysmorphism, eye malformations, a distinctive facial appearance, hair and skin abnormalities, and short stature. Patients suffering from Hallermann-Streiff syndrome also present with aspects of premature aging. The molecular basis of Hallermann-Streiff syndrome is largely unknown (156).

\section{P16-LMNA}

The twelve-year-old girl suffered from high weight, hypercholesterolemia, insulin resistance, hirsutism, and acanthosis nigricans. Lipodystrophy was diagnosed after identification of the heterozygous LMNA mutation c.1606G>A, p.(Glu536Lys) (Wollnik et al., unpublished).

\section{P17-XPC}

The two-year-old boy was diagnosed with Xeroderma pigmentosum due to the identification of the homozygous c.1643_1644delTG, p.(Val548Alafs*25) mutation in the XPC gene (Wollnik et al., unpublished). Typical symptoms of Xeroderma pigmentosum are increased sensitivity to sunlight with the development of carcinomas at an early age. Patients with a severe phenotype also suffer from neurologic symptoms (105).

\section{P18-TDD}

A ten-year-old boy presented with typical symptoms of Trichothiodystrophy such as brittle hair, photosensitivity, intellectual disability, and short stature. Mutations in ERCC2 and ERCC3 
were excluded by panel sequencing. A trio-based exome sequencing did not uncover any disease-causing mutations (Wollnik et al., unpublished).

\section{P19-POLD1}

The 29-year-old patient was diagnosed with Mandibular hypoplasia, deafness, progeroid features, and lipodystrophy syndrome due to the heterozygous mutation c.1812_1814delCTC, p.(Ser605del) in the POLD1 gene (Wollnik et al., unpublished).

\section{P2O-SHOC2}

The four-year-old boy suffered from mental retardation, small stature, macrocephaly, sparse hair, muscle weakness, mitral regurgitation, and hemangiomatosis. He was diagnosed with Noonan-like syndrome due to the mutation c.4A>G, p.(Ser2Gly) in the SOC2 gene (Wollnik et al., unpublished).

\section{P21-LTBP4}

The six-year old boy presented with cutis laxa, secondary pulmonary hypertonia, hypoplastic kidney arteries, muscular hypotonia, eye mobility disorder, developmental delay, and failure to thrive. The homozygous mutation c.1827delG in the LTBP4 gene was identified and Cutis Laxa type IC was diagnosed (Wollnik et al., unpublished).

\section{P22-HSS}

The patient was born with $52 \mathrm{~cm}$ body length, 3,310 g weight, and $35 \mathrm{~cm}$ head circumference. While no dwarfism or microcephaly was reported, the patient displayed a mild developmental delay. Muscular hypotonia, but no myopathy or movement deficiency was observed. Facial characteristics include micrognathia, prominent forehead, small nose, prominent veins, and low-set ears. The patient suffers from congenital cataracts and lower subcutaneous fat tissue. No skeletal abnormalities, organ deformation, autoimmune diseases, or cutis laxa have been observed. The highly recognizable facial gestalt lead to the suspected diagnosis of HallermannStreiff syndrome (Wollnik et al., unpublished). 


\section{P23-PYCR1}

The two-year-old boy presented with microcephaly, drinking weakness, low birth weight, and progeroid appearance. The homozygous missense mutation c.540+1G>A, p.? in the PYCR1 gene was found causative, and he was diagnosed with Cutis laxa type 3 (Wollnik et al., unpublished).

\section{P24-BLM}

The patient presented with immune deficiency, failure to thrive, growth delay, shortness, hypo-, hyperpigmented skin lesions, and multiple café-au-lait spots. The karyotype analysis revealed normal male karyotype $(46, X Y)$, and a pathologically high sister chromatid exchange was observed. The mutation c.3164G>C, p.(Cys1055Ser) was identified in the BLM gene suggesting the diagnosis of Bloom syndrome (Wollnik et al., unpublished).

\section{P25-BLM}

The younger sister of P24-BLM reported with immune deficiency, failure to thrive, growth delay, short stature, hypo-, hyperpigmented skin lesions, and multiple café-au-lait spots. Karyotype analysis revealed a normal female karyotype(46, XX) with a pathologically high sister chromatid exchange. The c.3164G>C, p.(Cys1055Ser) was found in the BLM gene giving the diagnosis of Bloom Syndrome (Wollnik et al., unpublished).

\section{P26-BLM}

The sixteen-years old boy was referred to genetic counseling because of growth delay, shortness, hypo- and hyperpigmented skin lesions on his body, and erythematous lesions on his face that are exaggerated by sunshine. He also suffered from recurrent infections. He was born preterm at 30 gestation weeks. The birth weight was $1900 \mathrm{~g}$. Respiratory infections and asthma attacks were observed frequently. Additionally, he underwent surgery for cryptorchidism. His actual weight is $29 \mathrm{~kg}$ (-3 SD), his body height is $143 \mathrm{~cm}$ (-4 SD). A6 hypogammaglobulinemia, and a karyotype of $46, \mathrm{XY}$ with an increased spontaneous breakage rate, was diagnosed. The homozygous mutation c.572_573delGA, p.(Arg191Lysfs*4) was identified in the BLM gene, and Bloom syndrome was diagnosed (Wollnik et al., unpublished). 


\section{P27-LONP1}

The twelve-year-old girl was born to consanguineous parents of Palestinian origin. Her birth weight was $2400 \mathrm{~g}$ with $47 \mathrm{~cm}$ in length. At 12 years, she weighed $20 \mathrm{~kg}$ and had a body height of $120 \mathrm{~cm}$. Her symptoms include an aged appearance at birth, relative macrocephaly, wide fontanelle, and sutures, sparse scalp hair, prominent scalp veins, small facial bones, flat malar region, large eyes, down-slanting palpebral fissures, large beaked nose, short philtrum, micrognathia, low set prominent ears, neonatal teeth, altered dentition, lack of subcutaneous fat, scoliosis, and psychomotor retardation. The homozygous c.70C $>\mathrm{G}$ mutation in the LONP1 gene was found causative of CODAS syndrome. A phenotype description was previously published (157).

\section{Control Cohort}

Age- and sex-matched control samples are of extreme importance in aging research. Fibroblast control samples from apparently healthy children were purchased from the Coriell Institute. Blood control samples from individuals between the age of 0 and 60 have been chosen from our pool of individuals who underwent exome sequencing for research purposes. Most of the samples from individuals between the age of 0 and 20 were derived from individuals who were diagnosed with a genetic syndrome. Patients suffering from syndromes with a mechanistic link to DNA damage and aging were excluded. Samples from individuals between the age of 20 and 60 were chosen from a pool of apparently healthy relatives of these patients. The detailed information for each control sample is listed in Table 45 in the appendix. All individuals or their legal representatives gave written informed consent for research purposes before participating in this study. 
Table 41: Overview of patients with different accelerated aging phenotypes

\begin{tabular}{|c|c|c|c|c|c|c|c|c|c|c|}
\hline Patient ID & $\begin{array}{l}\text { Reference } \\
\text { ID }\end{array}$ & Syndrome & Gene & Mutation & Effect on Protein & $\begin{array}{l}\text { Gene } \\
\text { function }\end{array}$ & $\begin{array}{l}\text { Protein } \\
\text { Localization }\end{array}$ & $\begin{array}{l}\text { Age } \\
\text { (yrs) }\end{array}$ & Material & $\begin{array}{l}\text { Publi- } \\
\text { cation }\end{array}$ \\
\hline P01-PYCR1 & Goe615, SM & $\begin{array}{l}\text { Cutis laxa, autosomal } \\
\text { recessive, type IIB } \\
\text { (OMIM 612940) } \\
\end{array}$ & PYCR1 & $\begin{array}{l}\text { c.797+2_797+5del } \\
\text { homozygous } \\
\text { (NM 006907.2) }\end{array}$ & $\begin{array}{l}\text { p.(Lys215_Asp319 } \\
\text { del) }\end{array}$ & $\begin{array}{l}\text { Proline } \\
\text { biosynthesis }\end{array}$ & Mitochondria & 3 & Fibroblasts & (45) \\
\hline P02-PYCR1 & $\begin{array}{l}\text { Goe 1311, } \\
\text { EG }\end{array}$ & $\begin{array}{l}\text { Cutis laxa, autosomal } \\
\text { recessive, type IIB } \\
\text { (OMIM 612940) } \\
\end{array}$ & PYCR1 & $\begin{array}{l}\text { c.752G }>A \\
\text { homozygous } \\
\text { (NM_006907.4) } \\
\end{array}$ & p.(Arg251His) & $\begin{array}{l}\text { Proline } \\
\text { biosynthesis }\end{array}$ & Mitochondria & $<1$ & Fibroblasts & (45) \\
\hline P03-PYCR1 & $\begin{array}{l}\text { Goe1312, } \\
\text { NG2827 }\end{array}$ & $\begin{array}{l}\text { Cutis laxa, autosomal } \\
\text { recessive, type IIB } \\
\text { (OMIM 612940) }\end{array}$ & PYCR1 & $\begin{array}{l}c .355 \mathrm{C}>\mathrm{T} \\
\mathrm{c} .356 \mathrm{C}>\mathrm{T} \\
\left(\mathrm{NM} \_006907.4\right)\end{array}$ & $\begin{array}{l}\text { p.(Arg119Cys) } \\
\text { p.(Arg119His) }\end{array}$ & $\begin{array}{l}\text { Proline } \\
\text { biosynthesis }\end{array}$ & Mitochondria & 4 & Fibroblasts & $(150)$ \\
\hline $\begin{array}{l}\text { P04- } \\
\text { ALDH18A1 }\end{array}$ & $\begin{array}{l}\text { Goe616, } \\
\text { Yaz }\end{array}$ & $\begin{array}{l}\text { autosomal dominant Cutis } \\
\text { laxa } 3 \text { (OMIM 616603) }\end{array}$ & $A L D H 18 A 1$ & $\begin{array}{l}\text { c. } 412 \mathrm{C}>\mathrm{T} \\
\text { de novo, heterozygous } \\
\text { (NM_002860.4) }\end{array}$ & p.(Arg138Trp) & $\begin{array}{l}\text { Proline } \\
\text { biosynthesis }\end{array}$ & Mitochondria & 2.5 & Fibroblasts & $(151)$ \\
\hline $\begin{array}{l}\text { P05- } \\
\text { GORAB }\end{array}$ & $\begin{array}{l}\text { Goe618, } \\
\text { TD }\end{array}$ & $\begin{array}{l}\text { Gerodermia osteodysplastica } \\
\text { (OMIM 231070) }\end{array}$ & GORAB & $\begin{array}{l}\text { c.136G>T } \\
\text { c.1050_1053delTCCT } \\
\text { (NM_152281) }\end{array}$ & $\begin{array}{l}\text { p.(Glu46*) } \\
\text { p.(Phe350Leufs*2 } \\
\text { 6) }\end{array}$ & $\begin{array}{l}\text { Golgi } \\
\text { transport }\end{array}$ & $\begin{array}{l}\text { Golgi } \\
\text { Apparatus }\end{array}$ & 15 & Fibroblasts & $(152)$ \\
\hline $\begin{array}{l}\text { P06- } \\
\text { SLC25A24 }\end{array}$ & $\begin{array}{l}\text { Goe620, } \\
13-0618\end{array}$ & $\begin{array}{l}\text { Fontaine progeroid syndrome } \\
\text { (OMIM 612289) }\end{array}$ & $S L C 25 A 24$ & $\begin{array}{l}\text { c.650G }>A \\
\text { heterozygous, de novo } \\
\text { (NM_013386) }\end{array}$ & p.(Arg217His) & $\begin{array}{l}\text { Carrier } \\
\text { protein }\end{array}$ & Mitochondria & 5.5 & Fibroblasts & (46) \\
\hline $\begin{array}{l}\text { P07- } \\
\text { SLC25A24 }\end{array}$ & Goe247 & $\begin{array}{l}\text { Fontaine progeroid syndrome } \\
\text { (OMIM 612289) }\end{array}$ & SLC25A24 & $\begin{array}{l}\text { c.650G }>A \\
\text { heterozygous, de novo } \\
\text { (NM_013386) }\end{array}$ & p.(Arg217His) & $\begin{array}{l}\text { Carrier } \\
\text { protein }\end{array}$ & Mitochondria & 1 & Fibroblasts & (46) \\
\hline P08-BLM & $\begin{array}{l}\text { Goe1306, } \\
\text { GM02520 }\end{array}$ & $\begin{array}{l}\text { Bloom syndrome } \\
\text { (OMIM 604610) }\end{array}$ & $B L M$ & $\begin{array}{l}\text { c.2923delC } \\
\text { c.2824- } \\
\text { 1077_2999+310del1583 } \\
\text { (NM_000057.3) }\end{array}$ & $\begin{array}{l}\text { p.(Gln975fs) } \\
\text { p.(Val942fs) }\end{array}$ & Helicase & Nucleus & 11 & Fibroblasts & \\
\hline P09-BLM & $\begin{array}{l}\text { Goe1308, } \\
\text { GM02932 }\end{array}$ & $\begin{array}{l}\text { Bloom syndrome } \\
\text { (OMIM 604610) }\end{array}$ & $B L M$ & $\begin{array}{l}\text { c.2207_2212delinsTAGAT } \\
\text { TC } \\
\text { homozygous } \\
\text { (NM_000057.4) }\end{array}$ & p.(Tyr736Leufs*5) & Helicase & Nucleus & 28 & Fibroblasts & \\
\hline
\end{tabular}


Results

\begin{tabular}{|c|c|c|c|c|c|c|c|c|c|c|}
\hline Patient ID & $\begin{array}{l}\text { Reference } \\
\text { ID }\end{array}$ & Syndrome & Gene & Mutation & Effect on Protein & $\begin{array}{l}\text { Gene } \\
\text { function }\end{array}$ & $\begin{array}{l}\text { Protein } \\
\text { Location }\end{array}$ & $\begin{array}{l}\text { Age } \\
\text { (yrs) }\end{array}$ & Material & $\begin{array}{l}\text { Publi- } \\
\text { cation }\end{array}$ \\
\hline P10-BLM & $\begin{array}{l}\text { Goe1039, } \\
\text { GM02548 }\end{array}$ & $\begin{array}{l}\text { Bloom syndrome } \\
\text { (OMIM 604610) }\end{array}$ & $B L M$ & $\begin{array}{l}\text { c.1544dupA } \\
\text { c.2254C>T } \\
\text { (NM_000057.3) }\end{array}$ & $\begin{array}{l}\text { p.(Asn515Lysfs*2) } \\
\text { p.(Gln752*) }\end{array}$ & Helicase & Nucleus & 6 & Fibroblasts & \\
\hline P11-YRDC & Goe800 & & $Y R D C$ & $\begin{array}{l}\text { c.662T>C } \\
\text { homozygous } \\
\text { (NM_024640.4) }\end{array}$ & p.(Ile221Thr) & $\begin{array}{l}\text { tRNA } \\
\text { modification }\end{array}$ & Mitochondria & $<1$ & $\begin{array}{l}\text { Fibroblasts, } \\
\text { DNA from } \\
\text { Blood } \\
\end{array}$ & \\
\hline $\begin{array}{l}\text { P12- } \\
\text { ATP6V0A2 }\end{array}$ & $\begin{array}{l}\text { Goe619 } \\
10-1252\end{array}$ & $\begin{array}{l}\text { Cutis laxa, autosomal } \\
\text { recessive, type IIA } \\
\text { (OMIM 219200) }\end{array}$ & ATP6VOA2 & $\begin{array}{l}\text { c.1A>G } \\
\text { homozygous } \\
\text { (NM_012463.4) }\end{array}$ & p.(Met1?) & $\begin{array}{l}\text { Proton } \\
\text { channel }\end{array}$ & $\begin{array}{l}\text { Golgi } \\
\text { Apparatus }\end{array}$ & 3 & Fibroblasts & (154) \\
\hline $\begin{array}{l}\text { P13- } \\
\text { AHCTF1 }\end{array}$ & $\begin{array}{l}\text { Goe486 } \\
51076\end{array}$ & & AHCTF1 & $\begin{array}{l}\text { c.6329C>G } \\
\text { heterozygous, de novo } \\
\text { (NM_015446.5) }\end{array}$ & p.(Ser2110Cys) & $\begin{array}{l}\text { Transcription } \\
\text { factor }\end{array}$ & Nucleus & $<1$ & $\begin{array}{l}\text { Fibroblasts, } \\
\text { DNA from } \\
\text { Blood }\end{array}$ & \\
\hline $\begin{array}{l}\text { P14- } \\
\text { PRKDC }\end{array}$ & K3525 & $\begin{array}{l}\text { Immunodeficiency } 26 \text {, with or } \\
\text { without neurologic } \\
\text { abnormalities } \\
\text { (OMIM 615966) }\end{array}$ & PRKDC & $\begin{array}{l}\text { c.9521C>T } \\
\text { heterozygous } \\
\text { (NM_006904.7) }\end{array}$ & p.(Prp3174Leu) & $\begin{array}{l}\text { DNA damage } \\
\text { sensor }\end{array}$ & Nucleus & 8 & Fibroblasts & \\
\hline P15-CHD6 & Goe456 & $\begin{array}{l}\text { Hallerman-Streiff syndrome } \\
\text { (OMIM 234100) }\end{array}$ & CHD6 & $\begin{array}{l}\text { c.7987G>A } \\
\text { heterozygous, de novo } \\
\text { (NM_032221.5) }\end{array}$ & p.(Asp2663Asn) & $\begin{array}{l}\text { Chromatin } \\
\text { remodeling }\end{array}$ & Nucleus & 2 & Fibroblasts & (155) \\
\hline P16-LMNA & $\begin{array}{l}\text { Goe613, } \\
51388\end{array}$ & $\begin{array}{l}\text { Lipodystrophy } \\
\text { (OMIM 515660) }\end{array}$ & LMNA & $\begin{array}{l}\text { c.1606G }>\text { A heterozygous } \\
\text { (NM_170707.4) }\end{array}$ & p.(Glu536Lys) & $\begin{array}{l}\text { Nuclear } \\
\text { envelope }\end{array}$ & Nucleus & 11 & $\begin{array}{l}\text { DNA from } \\
\text { Blood }\end{array}$ & \\
\hline P17-XPC & 51459 & $\begin{array}{l}\text { Xeroderma pigmentosa } \\
\text { (OMIM 278720) }\end{array}$ & $X P C$ & $\begin{array}{l}\text { c.1643_1644delTG } \\
\text { homozygous } \\
\text { (NM_004628.5) }\end{array}$ & p.(Val548Alafs*25 & $\begin{array}{l}\text { DNA damage } \\
\text { sensor }\end{array}$ & Nucleus & 2 & $\begin{array}{l}\text { DNA from } \\
\text { Blood }\end{array}$ & \\
\hline P18-TDD & $\begin{array}{l}\text { Goe1129 } \\
51582\end{array}$ & Trichothiodystrophy & & & & & & 10 & $\begin{array}{l}\text { DNA from } \\
\text { Blood }\end{array}$ & \\
\hline $\begin{array}{l}\text { P19- } \\
\text { POLD1 }\end{array}$ & 51593 & $\begin{array}{l}\text { Mandibular hypoplasia, } \\
\text { deafness, progeroid features, } \\
\text { and lipodystrophy syndrome } \\
\text { (OMIM 615381) }\end{array}$ & POLD1 & $\begin{array}{l}\text { c.1812_1814delCTC } \\
\text { heterozygous } \\
\text { (NM_001256849.1) }\end{array}$ & p.(Ser605del) & $\begin{array}{l}\text { DNA } \\
\text { polymerase }\end{array}$ & Nucleus & 29 & $\begin{array}{l}\text { DNA from } \\
\text { Blood }\end{array}$ & \\
\hline $\begin{array}{l}\mathrm{P} 20- \\
\text { SHOC2 }\end{array}$ & 50396 & $\begin{array}{l}\text { Noonan syndrome-like with } \\
\text { loose anagen hair } \\
\text { (OMIM 607721) }\end{array}$ & SHOC2 & $\begin{array}{l}\mathrm{c} .4 \mathrm{~A}>\mathrm{G} \\
\text { heterozygous } \\
(\mathrm{NM} \text { 007373) }\end{array}$ & p.(Ser2Gly) & Cell signaling & $\begin{array}{l}\text { Nucleus and } \\
\text { Cytoplasm }\end{array}$ & 4 & $\begin{array}{l}\text { DNA from } \\
\text { Blood }\end{array}$ & \\
\hline P21-LTBP4 & 36893 & $\begin{array}{l}\text { Cutis laxa, autosomal } \\
\text { recessive, type IC } \\
\text { (OMIM 613177) }\end{array}$ & LTBP4 & $\begin{array}{l}\text { c.1827delG } \\
\text { homozygous } \\
\text { (NM_001042544.1) }\end{array}$ & $\begin{array}{l}\text { p.(Asn610Thrfs*1 } \\
64)\end{array}$ & $\begin{array}{l}\text { Regulator of } \\
\text { TGF-beta } \\
\text { signaling }\end{array}$ & $\begin{array}{l}\text { Extracellular } \\
\text { Matrix }\end{array}$ & 5 & $\begin{array}{l}\text { DNA from } \\
\text { Blood }\end{array}$ & \\
\hline
\end{tabular}


Results

\begin{tabular}{|c|c|c|c|c|c|c|c|c|c|c|}
\hline Patient ID & $\begin{array}{l}\text { Reference } \\
\text { ID }\end{array}$ & Syndrome & Gene & Mutation & Effect on Protein & $\begin{array}{l}\text { Gene } \\
\text { function }\end{array}$ & $\begin{array}{l}\text { Protein } \\
\text { Location }\end{array}$ & $\begin{array}{l}\text { Age } \\
\text { (yrs) }\end{array}$ & Material & $\begin{array}{l}\text { Publi- } \\
\text { cation }\end{array}$ \\
\hline P22-HSS & Goe524 & $\begin{array}{l}\text { Hallermann-Streiff syndrome } \\
\text { (OMIM 234100) }\end{array}$ & & & & & & 2 & $\begin{array}{l}\text { DNA from } \\
\text { Blood }\end{array}$ & \\
\hline P23-PYCR1 & $\begin{array}{l}\text { Goe836, } \\
52445\end{array}$ & $\begin{array}{l}\text { Cutis laxa, autosomal } \\
\text { recessive, type IIB } \\
\text { (OMIM 612940) }\end{array}$ & PYCR1 & $\begin{array}{l}\text { c.540+1G>A } \\
\text { homozygous } \\
\text { (NM_006907.4) }\end{array}$ & p.? & $\begin{array}{l}\text { Proline } \\
\text { biosynthesis }\end{array}$ & Mitochondria & 0 & $\begin{array}{l}\text { DNA from } \\
\text { Blood }\end{array}$ & \\
\hline P24-BLM & Goe30 & $\begin{array}{l}\text { Bloom syndrome } \\
\text { (OMIM 604610) }\end{array}$ & $B L M$ & $\begin{array}{l}\text { c.3164G>C } \\
\text { homozygous } \\
\text { (NM_000057.4) }\end{array}$ & p.(Cys1055Ser) & Helicase & Nucleus & 16 & $\begin{array}{l}\text { DNA from } \\
\text { Blood }\end{array}$ & \\
\hline P25-BLM & Goe31 & $\begin{array}{l}\text { Bloom syndrome } \\
\text { (OMIM 604610) }\end{array}$ & $B L M$ & $\begin{array}{l}\text { c.3164G>C } \\
\text { homozygous } \\
\text { (NM_000057.4) }\end{array}$ & p.(Cys1055Ser) & Helicase & Nucleus & 10 & $\begin{array}{l}\text { DNA from } \\
\text { Blood }\end{array}$ & \\
\hline P26-BLM & Goe34 & $\begin{array}{l}\text { Bloom syndrome } \\
\text { (OMIM 604610) }\end{array}$ & $B L M$ & $\begin{array}{l}\text { c.572_573delGA } \\
\text { homozygous } \\
\text { (NM_000057.4) }\end{array}$ & p.(Arg191Lysfs*4) & Helicase & Nucleus & 16 & $\begin{array}{l}\text { DNA from } \\
\text { Blood }\end{array}$ & \\
\hline $\begin{array}{l}\text { P27- } \\
\text { LONP1 }\end{array}$ & K3053 & $\begin{array}{l}\text { CODAS syndrome } \\
\text { (OMIM 600373) }\end{array}$ & LONP1 & $\begin{array}{l}\text { c. } 70 \mathrm{C}>\mathrm{G} \\
\text { homozygous } \\
\text { (NM 004793) }\end{array}$ & p.(Leu24Val) & Peptidase & Mitochondria & 12 & $\begin{array}{l}\text { DNA from } \\
\text { Blood }\end{array}$ & $(157)$ \\
\hline
\end{tabular}




\subsection{Assessment of Mitochondrial Dysfunction}

The free radical theory of aging suggests DNA damage and accumulating mtDNA mutations to be one of the causes and drivers of aging. Mitochondrial dysfunction was assessed from two angles: the amount of low-frequency mutations in mtDNA was quantified, and in five patient fibroblast samples, mitochondrial dysfunction was assessed by oxygen consumption measurements.

\subsubsection{Ultra-High Coverage MtDNA Sequencing of Blood and Fibroblast Samples of Progeria Patient Cohort}

Theories of aging include a link between mitochondria and DNA damage. The notion is conceivable that mitochondrial dysfunction causes or is caused by a higher burden of mtDNA mutations. My research question was hence: Is the level of mtDNA mutations and especially low-frequency mutations with a variant allele frequency (VAF) below $5 \%$ increased in samples of patients suffering from segmental progeroid syndromes? To address this question, we developed a method to sequence the mtDNA with ultra-high read depth to quantify lowfrequency mtDNA variants. Since this novel and unique method was for the first time established for my thesis, the procedure is now described in detail.

\subsubsection{Development of a Method to Quantify Low-Frequency MtDNA Mutations}

The workflow of the mtDNA sequencing method was as follows: The first step was to extract total DNA from a fibroblast culture or a blood sample. During the library preparation, the DNA samples were enriched for mtDNA fragments. Finally, the samples were sequenced on the Illumina NextSeq platform. Data were then analyzed using the software programs Seqpilot and MS Excel.

The molecular probes were designed in cooperation with PD Dr. rer. nat. Silke Kaulfuß using the software SureDesign (Agilent Technologies). In total, 371 probes covered the complite mitochondrial genome with a total probe size of $16,571 \mathrm{bp}$.

The SureSelect XTHS NGS target enrichment workflow was used for library preparation. $200 \mathrm{ng}$ total DNA was fragmented enzymatically to 200 to $400 \mathrm{bp}$ fragments. The resulting fragments 
were submitted to an end-repair and an A-tailing step. Each fragment was then ligated to an individual molecular barcode. As this ligation happened previous to any amplification, PCR errors could be detected when calculating the consensus reads from reads with the same molecular barcode. In the next step, sample-specific index primers for later multiplexing were ligated to the fragments while amplifying the adaptor-ligated library. Next, the DNA fragments were hybridized to target-specific probes. These probes were labeled with biotin so that they could be captured using streptavidin-coated magnetic beads. Thus, DNA fragments that did not hybridize to the probes were discarded while a magnet held back the fragments with probes. Another amplification step followed this enrichment step. After purification, the DNA quality and quantity were assessed as a last step of the library preparation.

The calculation for sequencing was done using a theoretical coverage of $100.000 x$. The samples were multiplexed and sequenced on a Illumina NextSeq platform. Depending on the calculated sequencing data of the whole run, output coverage varied between every single run.

Raw sequencing data (fastq-files) were imported into the software Seqpilot. The settings for alignment and variant calling were modified from the pre-set analysis settings to detect lowfrequency somatic mutations for quantitative analysis rather than germline mutations, as it is the case for diagnostic panel sequencing. The settings are described in Table 25 in the methods section 2.6. The molecular barcodes, which were annealed to each original molecule, were used to calculate a consensus sequence of reads with the same molecular barcode. Thus, PCR errors could be distinguished from low-frequency mutations. The minimal absolute coverage was set to "50 combined" excluding positions with coverage below 50 reads together in both sequencing directions from analysis. The "ratio read direction" was set to " $5 \%$ / 95\%" to exclude variants where less than $5 \%$ of the reads were located in a region that was covered from more than $95 \%$ with reads from only one direction. A variant was called if it was present on a minimum number of two reads per direction. Thus a variant was present on at least four consensus reads, corresponding to four original mtDNA fragments. Figure 7 depicts the workflow of the high-coverage mtDNA sequencing method schematically, which I established during my Ph.D. thesis. 
A) DNA Extraction and Purification

Cell Harvesting from

Fibroblasts or Blood

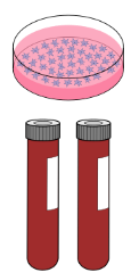

B) Library Preparation \& Target Enrichment

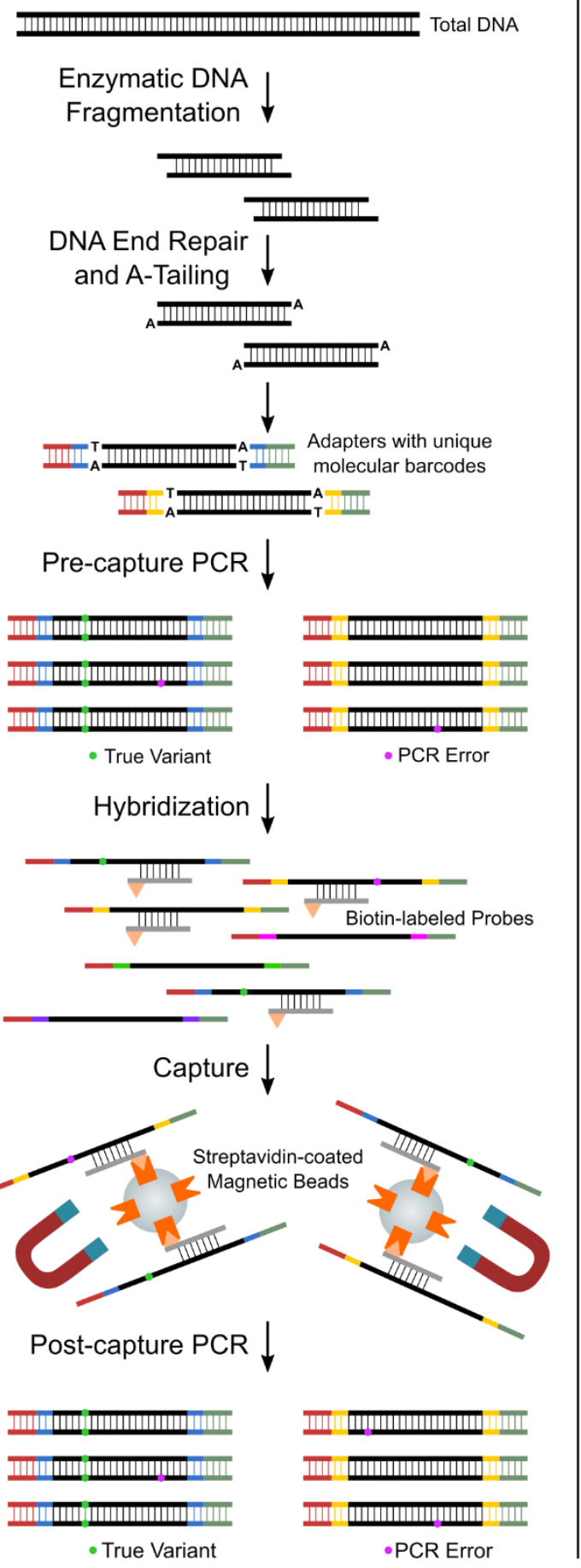

DNA Wash DNA

Binding and Dry Elution

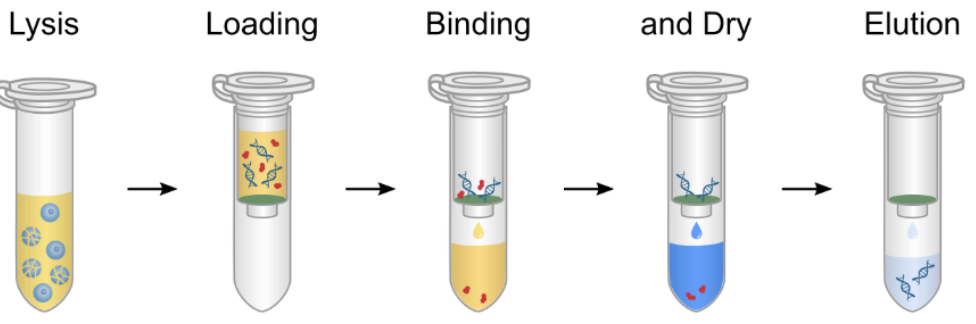

C) Illumina Sequencing
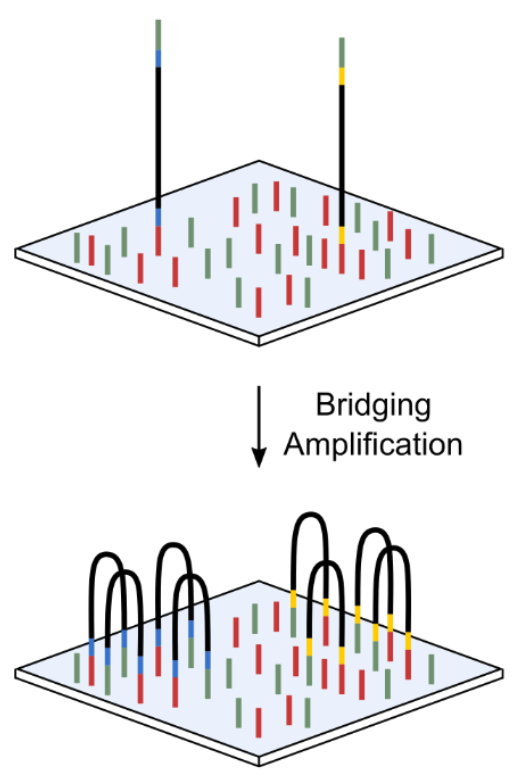

Paired-end

Sequencing

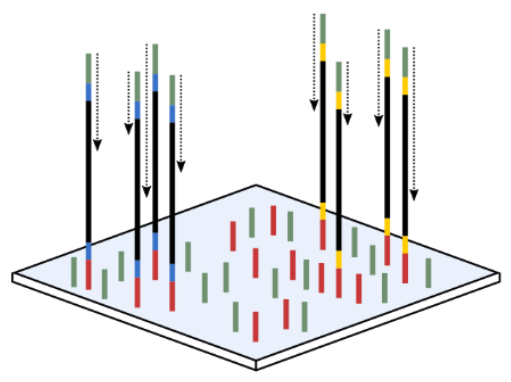

D) Alignment \& Variant Calling

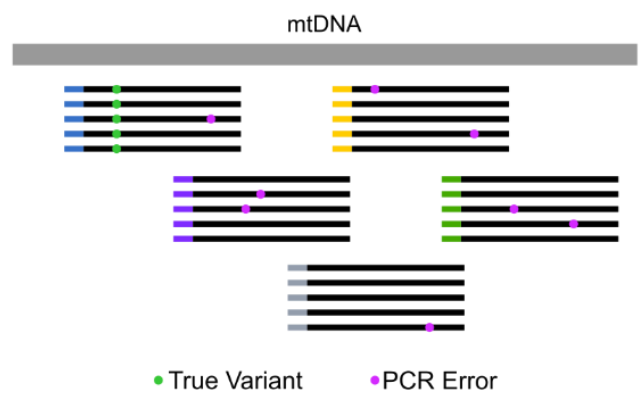

Figure 7: Workflow of the newly established high-coverage mtDNA sequencing method 
Figure 7: Workflow of the newly established high-coverage mtDNA sequencing method

A: DNA was extracted from fibroblasts or a blood sample. B: During the library preparation and target enrichment, the DNA sample was fragmented before the A-tailing step. Adaptor ligation was performed. Molecular barcodes were ligated to the DNA fragments before the first amplification step. The pre-capture PCR was then followed by the hybridization of the molecular probes. The target enrichment was then achieved by the biotin-labeled molecular probes that anneal sequence-specifically to the mtDNA fragments and could be captured by magnetic streptavidin-coated beads. Fragments that did not hybridize to molecular probes were washed away while a magnet traped the magnetic beads. This step was followed by another PCR step to enrich the target sequences. C: Paired-end sequencing was then performed on an Illumina NextSeq platform. D: The sequencing data were imported to Seqpilot for alignment and variant calling. The molecular barcodes were used to calculate the consensus reads from the original reads containing true variants and PCR errors. Variant calling was then performed to find lowfrequency variants. Via the molecular barcodes, a true variant could be distinguished from PCR errors and sequencing errors. Parts of the image were adapted from Yamaguchi et al. 2019 (158).

The variant table (txt-file) was analyzed using MS Excel. For each variant, information on the mutation type, position, base change, reads with variant, the total number of consensus reads at this position, VAF, length, and the variant in HGVS nomenclature was given. An example of the a variant table given out by Seqpilot is given in Table 42.

Table 42: Example of a variant table exported from Seqpilot

\begin{tabular}{|c|c|c|c|c|c|c|c|c|}
\hline Index & $\begin{array}{l}\text { Mutation } \\
\text { type }\end{array}$ & Position & $\begin{array}{l}\text { Base } \\
\text { change }\end{array}$ & $\begin{array}{l}\text { Reads } \\
\text { with } \\
\text { variant }\end{array}$ & $\begin{array}{l}\text { Total } \\
\text { number of } \\
\text { consensus } \\
\text { reads }\end{array}$ & $\begin{array}{l}\text { VAF } \\
\text { (\%) }\end{array}$ & Length & c. HGVS \\
\hline 1 & Conversion & 16 & $A \rightarrow T$ & 4 & 1822 & 0.2 & 0 & g.16A $>T$ \\
\hline 2 & Conversion & 26 & $C \rightarrow T$ & 4 & 2772 & 0.1 & 0 & g. $26 \mathrm{C}>\mathrm{T}$ \\
\hline 3 & Conversion & 49 & $A \rightarrow T$ & 5 & 4419 & 0.1 & 0 & g. $49 \mathrm{~A}>\mathrm{T}$ \\
\hline 4 & Conversion & 111 & $A \rightarrow T$ & 4 & 4681 & 0.08 & 0 & g.111A $>T$ \\
\hline 5 & Indel & $\begin{array}{l}146 . .150 \\
/ 5 b p\end{array}$ & $\begin{array}{l}\text { TCATT } \rightarrow \\
\text { CCANC }\end{array}$ & 14 & 4677 & 0.2 & 5 & $\begin{array}{l}\text { g.146_150 } \\
\text { delinsCCANC }\end{array}$ \\
\hline 6 & Indel & $\begin{array}{l}146 . .150 \\
/ 5 b p\end{array}$ & $\begin{array}{l}\text { TCATT } \rightarrow \\
\text { CCATC }\end{array}$ & 401 & 4677 & 8.5 & 5 & $\begin{array}{l}\text { g.146_150 } \\
\text { delinsCCATC }\end{array}$ \\
\hline 7 & Indel & $\begin{array}{l}146 . .152 \\
/ 7 b p\end{array}$ & $\begin{array}{l}\text { TCATTCT } \rightarrow \\
\text { CCATCCC }\end{array}$ & 3022 & 4570 & 60.1 & 7 & $\begin{array}{l}\text { g.146_152 } \\
\text { delinsCCATCCC }\end{array}$ \\
\hline 8 & Indel & $\begin{array}{l}146 . .152 \\
/ 7 b p\end{array}$ & $\begin{array}{l}\text { TCATTCT } \rightarrow \\
\text { CCNTCCC }\end{array}$ & 415 & 4570 & 9.0 & 7 & $\begin{array}{l}\text { g.146_152 } \\
\text { delinsCCNTCCC }\end{array}$ \\
\hline 9 & Indel & $\begin{array}{l}146 . .152 \\
/ 7 \mathrm{bp}\end{array}$ & $\begin{array}{l}\text { TCATTCT } \rightarrow \\
\text { CCATCNC }\end{array}$ & 68 & 4570 & 0.1 & 7 & $\begin{array}{l}\text { g.146_152delins } \\
\text { CCATCNC }\end{array}$ \\
\hline 10 & Conversion & 146 & $T \rightarrow C$ & 392 & 4496 & 8.7 & 0 & g.146T>C \\
\hline
\end{tabular}

In MS Excel, the variant table was analyzed by different Count-if functions to give an overview of the variants called. With this strategy, the following questions could be answered: [1] How many variants with a VAF above $0.1 \%$ are called? [2] How many variants were called with a 
VAF between $0.1 \%$ and $0.5 \%$ ? [3] What is the relative amount of variants called between $0.1 \%$ and $0.5 \%$ ? [4] How many variants are $T$ to $C$ point mutations? [5] What are the relative amounts of each mutation type (point mutations, indel, deletion, insertion)?

\subsubsection{Establishment of the Method to Quantify Low-Frequency MtDNA Mutations Using Fibroblast Samples Treated with Genotoxins and a Disease Control Sample}

\subsection{Testing Different Settings for Variant Calling}

Different settings for variant calling were compared using the sequencing data of the untreated C01 control fibroblasts. The Seqpilot settings are described in detail in the methods section 2.6. In Table 25, the three different Seqpilot analysis profile settings I, II, and III, which differ in the inclusion of the molecular barcodes and the minimum absolute number of consensus reads containing the variant, are shown, and the effect on the analysis of the same sample is detailed. The effect of the molecular barcoding on the original read depth was evident as with the inclusion of the molecular barcodes, an original read depth of $300,000 x$ was reached compared to $247,000 x$ in the same sample without including the molecular barcodes into the analysis. Thus without using the molecular barcodes less reads fulfilled the quality control criteria to be included in the alignment to the reference sequence. The substantially higher number of variants called using the molecular barcodes can be explained by the fact that PCR errors could not be distinguished from low-frequency mutations without molecular barcodes.

Table 43: Effect of different alignment and variant calling parameters for the sample C01untreated

\begin{tabular}{|l|l|l|l|}
\hline Parameters & Profile I & Profile II & Profile III \\
\hline Reads include primers & yes & yes & no \\
\hline $\begin{array}{l}\text { Minimum absolute } \\
\text { coverage of the variant }\end{array}$ & 5 per direction & 2 per direction & 5 per direction \\
\hline File size (byte) & 3.208 .694 .797 & 3.208 .694 .797 & 3.457 .242 .449 \\
\hline $\begin{array}{l}\text { Total number of aligned } \\
\text { amplicon reads }\end{array}$ & 9.629 .511 & 9.629 .513 & 42.547 .572 \\
\hline $\begin{array}{l}\text { Mean number of tagged } \\
\text { reads per consensus read }\end{array}$ & 4 & 4 & - \\
\hline Original read depth (mean) & 300.922 & 300.925 & 247.786 \\
\hline $\begin{array}{l}\text { Read depth of consensus } \\
\text { reads (mean) }\end{array}$ & 28.743 & 28.743 & 247.786 \\
\hline $\begin{array}{l}\text { Total number of variants } \\
\text { called }\end{array}$ & 1.394 & 8.613 & 38 \\
\hline $\begin{array}{l}\text { Number of variants } \\
\text { with a VAF >= 0.1\% }\end{array}$ & 266 & 307 & 38 \\
\hline
\end{tabular}


With profile II, in which the minimum absolute coverage of the variant was set to two consensus reads per direction, the highest number of total variants and the highest number of variants with a VAF above $0.1 \%$ were called. Thus, the Seqpilot settings profile II was chosen for the analysis of further samples.

\subsection{Test of Data Analysis and Data Visualization Using Data from Fibroblast Control Cells C01 Treated with Genotoxins}

As the quantification of low-frequency mitochondrial variants is new, we selected different genotoxic treatments that have a known effect on nuclear DNA (nDNA) and analyzed their impact on mtDNA. 150,000 C01 control fibroblasts were seeded into T25 flasks and treated after 24 hours for two hours $0.2 \mathrm{mM}$ etoposide, $0.1 \mathrm{mM}$ hydroxyurea, $500 \mu \mathrm{M} \mathrm{H}_{2} \mathrm{O}_{2}, 10 \mu \mathrm{M}$ $\mathrm{H}_{2} \mathrm{O}_{2}$, or once with UV light with a dose of $100 \mathrm{~J} / \mathrm{m}^{2}$. Next, the cells were left to grow for four days to allow the induced mutations to be amplified when the fibroblasts and with them the mitochondria replicated. DNA extraction, library preparation, and sequencing were performed simultaneously for all samples to reduce variance between the samples.

The sequencing data of the fibroblast sample C01 untreated and treated with the genotoxic substances etoposide, hydroxyurea, $\mathrm{H}_{2} \mathrm{O}_{2}$, and UV light were subjected to alignment and variant calling using the Seqpilot settings profile II. The mean read depth of consensus reads, the total number of variants called, and the distribution by VAF of the total number of variants called are depicted in Figure 8. The mean read depth of consensus reads varied in the samples between 20,000x and 30,000x (Figure 8B), while the total number of variants called varied between 4,000 and 8,000 with a dependency on the mean read depth (Figure 8C). Dividing the number of variants by the VAF shows that the VAF of over $90 \%$ of variants is below $0.1 \%$ (Figure 8D). A correlation analysis by F-test confirmed the high correlation of read depth and the total number of variants called with a Pearson correlation coefficient of $r=0.9301$ and $p=0.0072$ (Figure 8G). Thus, a quantitative statement on the level of mtDNA variants could not be given on the basis of the total number of variants called. Excluding variants with a VAF below $0.1 \%$, the number of variants did not correlate with the mean read depth of consensus reads, indicated by a Pearson correlation coefficient of $r=-0.1939$ and $p=0.7128$ (Figure 8F). 

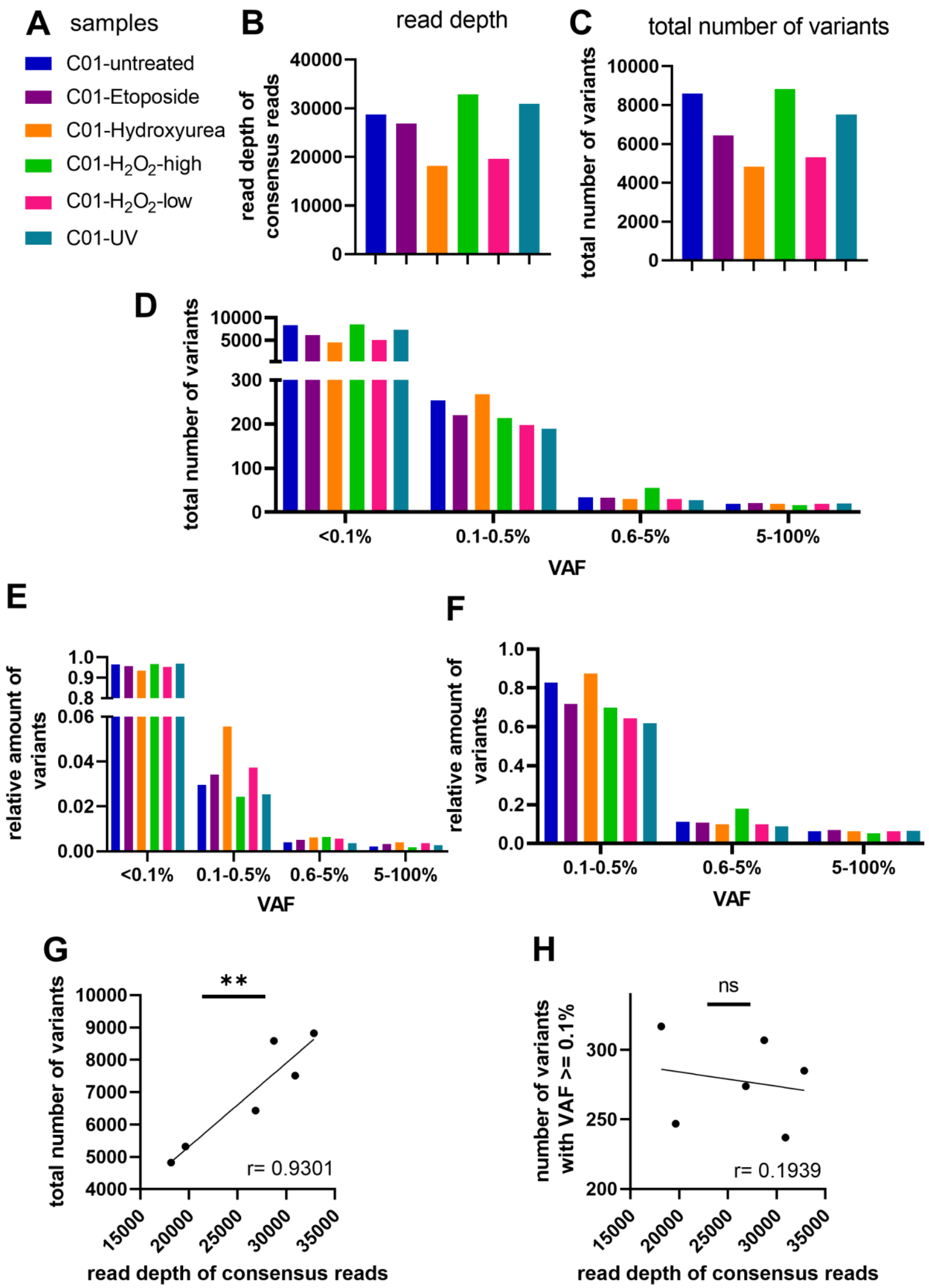

Figure 8: MtDNA sequencing results of fibroblast control sample C01 treated with different genotoxic substances 
Figure 8: MtDNA sequencing results of fibroblast control sample C01 treated with different genotoxic substances

A: The control fibroblasts $\mathrm{CO} 1$ were treated with the DNA damaging agents etoposide, hydroxyurea, $\mathrm{H}_{2} \mathrm{O}_{2}$, and UV-light. B: The mean read depth of the consensus reads of all the samples was between $18,000 x$ and $32,000 x$. C: The total number of variants called ranged between 5,000 and 8,000 and seemed to be dependent on the mean consensus read depth. D: Showing the number of variants by VAF indicated that most of the detected variants had a VAF $<0.1 \%$. The sample treated with a high concentration of $\mathrm{H}_{2} \mathrm{O}_{2}$ shows a higher number of variants with a VAF between 0.6 and $5 \%$. E: To account for the unequal read depth, the distribution of variants of the VAF groups $<0.1 \%, 0.1 \%-0.5 \%, 0.6 \%-5 \%$, and $5 \%-100 \%$ is shown relative to the total number of variants. Over $90 \%$ of the variants occurred with a VAF <0.1\%. F: Excluding variants with a VAF $<0.1 \%$ yielded a distribution of the relative amount of variants that is similar to the pattern seen in $\mathbf{D}$ with the absolute number of variants. The higher percentage of variants with 0.6-5\% VAF in the $\mathrm{H}_{2} \mathrm{O}_{2}$-treated sample is evident with this depiction as well. G: The correlation of the total number of variants and read depth was tested and confirmed by the Pearson correlation coefficient of $r=0.9301$. The result of the two-tailed t-test was significant with $p=0.0072$. H: There was no correlation of the number of variants with a VAF between $0.1 \%$ and $100 \%$ and the read depth with a Pearson correlation coefficient of $r=-0.1939$. The result of the two-tailed t-test was not significant, with $p=0.7128$.

The correlation of read depth and the number of variants is expected. As a constant read depth was technically not possible, the exclusion of variants with a VAF below $0.1 \%$ enabled a quantitative analysis. The loss of correlation by the exclusion of these variants indicated that all variants with a VAF between $0.1 \%$ and $100 \%$ were detected. A higher read depth only led to the detection of more variants with lower VAF. As the number of variants between samples was the same, relative values are displayed whenever possible. The number of variants with a $0.1 \%$ or higher VAF will be designated as "number of variants" in the figures in demarcation from "total number of variants" to simplify axis labeling and reading. 


\subsection{Analysis of the Effect of Genotoxic Treatments on C01 Control Fibroblasts}

The test data set from $\mathrm{CO}$ control fibroblasts treated with different genotoxins was submitted to variant calling using the Seqpilot profile II. Before data analysis, variants with a VAF of below $0.1 \%$ were excluded to avoid the influence of the variable read depth. The samples C01untreated, C01-Etoposide, C01-Hydroxyurea, C01- $\mathrm{H}_{2} \mathrm{O}_{2}$-high, $\mathrm{C} 01-\mathrm{H}_{2} \mathrm{O}_{2}-\mathrm{low}$, and C02-UV were compared (Figure 9A). The number of variants of all samples was between 250 and 300 (Figure $9 B)$, and no sample showed a noticeable difference. The VAF of the samples was divided into groups of $0.1-0.5 \%, 0.6-5 \%$, and $5-100 \%$ and normalized by the number of variants. The relative amount of variants with a VAF between $0.5-5 \%$ in the sample $\mathrm{CO} 1-\mathrm{H}_{2} \mathrm{O}_{2}$ was noticeably higher than the other samples. After treatment, the induced mutations were expected to accumulate during the five days when the fibroblasts and with them the mitochondria divided. Thus, a difference in the VAF was expected in low-frequency mutations. In addition, mutation types of the detected variants were analyzed (Figure 9C). The relative amount of transitions ( $T-C, A-G, G-A, C-T$ ), transversion (G-C, A-C, T-G, A-T, T-A, G-T), indels, deletions, and insertions are depicted in Figure 9D. Also, in this visualization of the data by mutation type, the sample $\mathrm{CO} 1-\mathrm{H}_{2} \mathrm{O}_{2}$-high was noticeable as the relative amount of indels doubled compared to the untreated sample C01-untreated. We concluded that we were able to generate a positive control as the $\mathrm{H}_{2} \mathrm{O}_{2}$-treatment caused a higher relative amount of variants with a VAF of $0.6-5 \%$ and a higher relative amount of indels. This result also confirmed that this newly developed method can be used to quantify mtDNA variants from NGS data. No statistical tests were be performed as the measurement was not repeated. 

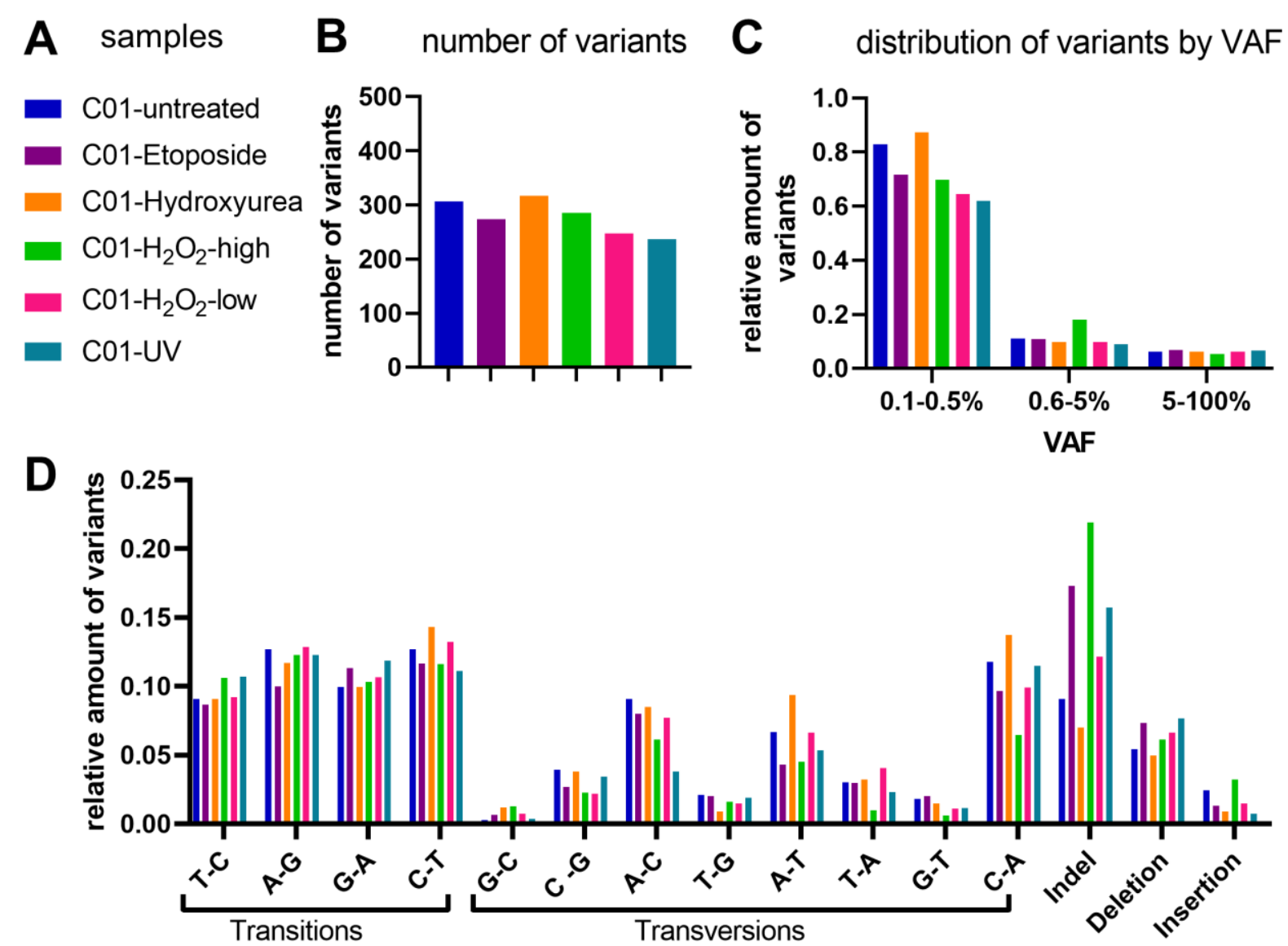

Figure 9: MtDNA sequencing result of $\mathrm{CO} 1$ control fibroblasts after genotoxic treatment

A: The fibroblasts control sample C01 was treated with the DNA damaging agents etoposide, hydroxyurea, $\mathrm{H}_{2} \mathrm{O}_{2}$, and UV light or left untreated as control. B: The number of variants was calculated to be between 200 and 300 in all samples analyzed. C: Grouping the number of VAF showed that most of the detected variants had a VAF between $0.1 \%$ and $0.6 \%$. The sample treated with a high concentration of $\mathrm{H}_{2} \mathrm{O}_{2}$ showed a higher relative amount of variants with a VAF between 0.6 and $5 \%$ VAF. D: The relative amount of mutations is shown for all possible conversions, indels, deletions, and insertions. The relative amount of indels was increased twofold in $\mathrm{C}_{01}-\mathrm{H}_{2} \mathrm{O}_{2}$-high compared to the untreated control.

\subsection{Influence of Sample Preparation and Sequencing on the Variance of Technical Replicates}

To test the reproducibility of this newly developed method, we compared eight different control samples derived from blood samples (C23, C14, C15, C22, C39, C43, C38, C44) that were prepared and sequenced at the same time (sequencing run number 1 ) to two samples $(P 13, P 11)$ which were sequenced in four different sequencing runs each $(2,3,4,5)$. The second, third, and fourth sequencing runs were done from the same library, while the fifth sequencing run was done with separately prepared samples. Figure 10 depicts the comparison of read depth (Figure 10A) and the comparison of the number of variants (Figure 10B). The 
variance of the mean read depth of consensus reads was not significantly different between the samples sequenced in one sequencing run and the repeated measurements according to the result of the F-test for equal variance $p=0.1410$. When comparing the number of variants between these two groups, the F-Test identified a significantly lower variance in the number of variants in eight different control samples in the same sequencing run compared to the two samples that were sequenced in four different sequencing runs with $p=0.0006$. We conclude that it is crucial to compare samples that were prepared and sequenced at the same time.
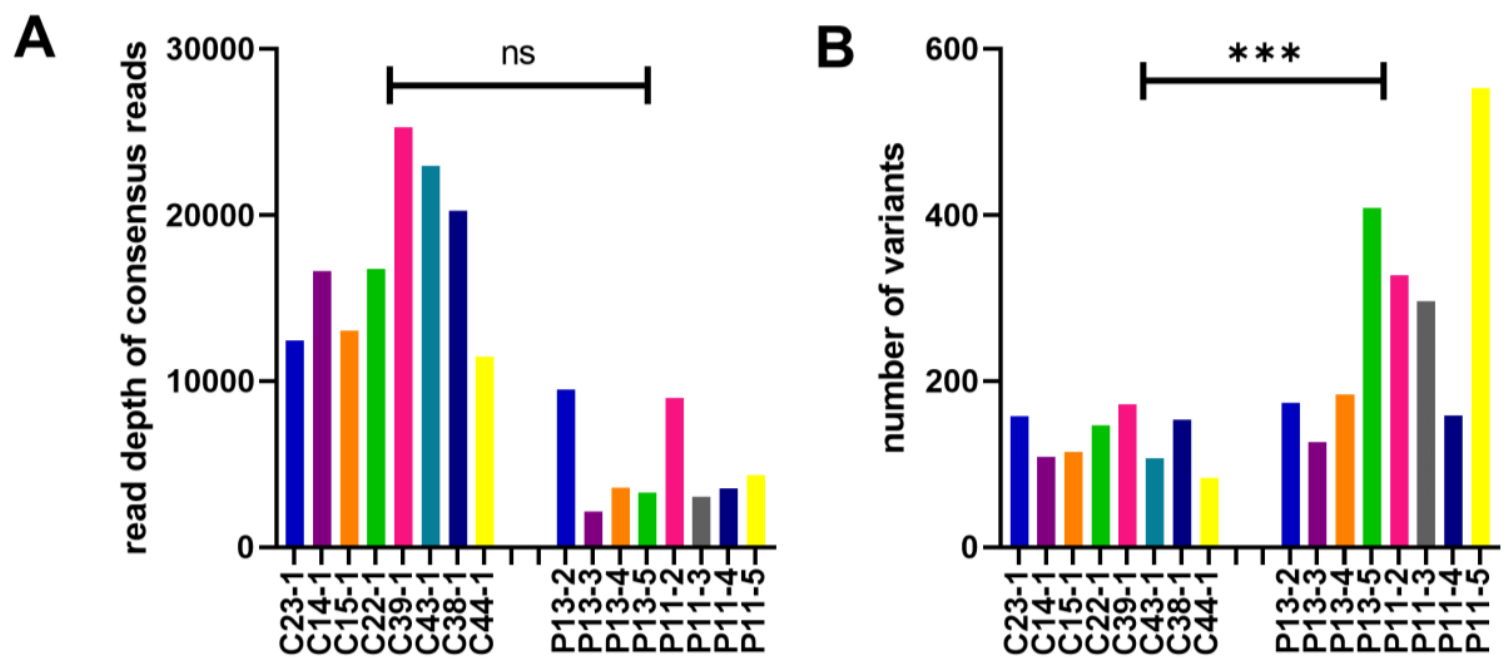

Figure 10: Test of variance in mtDNA sequencing result of control samples

Eight different control samples from one preparation and sequencing run were compared to two samples that were sequenced in four different sequencing runs each to test the reproducibility of sequencing and analysis. A: Comparing the variance of the read depth between these two groups, the result of the F-Test was not significant with a $p$-value of $p=0.1410$. B: The comparison of variances of the number of variants revealed a significant difference with $p=0.0006$ using the F-Test. 


\subsection{MtDNA Sequencing of DNA Sample from a Patient Suffering from CODAS Syndrome as Disease Control}

As the last step of method establishment, we performed mtDNA sequencing on a DNA sample of a patient harboring a homozygous mutation in LONP1. Mutations in LONP1 cause the autosomal-recessively inherited CODAS syndrome. LONP1 encodes the mitochondrial protease Lon Peptidase 1. CODAS syndrome patients suffer from cerebral, ocular, dental, auricular, and skeletal anomalies. Depletion of the LONP1 protein causes swelling of mitochondria and a reduced amount of mtDNA (159). A reduced amount of mtDNA cannot be detected with this novel method as the comparison to the amount of nuclear DNA is missing. An increased incidence of large deletions had been previously shown in fibroblasts from P26LONP1 (Wollnik et al., unpublished data).

To analyze if these changes in the mtDNA can also be detected by ultra-deep sequencing of mtDNA, DNA of patient P26-LONP1 and the two unaffected siblings (C121-LONP1 and C122LONP1), who were previously shown to be heterozygous carriers of the identified LONP1 mutation, were subjected to analysis. The result of mtDNA sequencing of the patient samples is shown in Figure 11. Neither the number of variants, the relative amount of variants in the VAF groups, nor the relative amount of mutations of each mutation type were different in sample P26-LONP1 compared to three samples from his siblings and age-matched control. As the DNA was fragmented to 150 base pair fragments for target enrichment, larger deletions probably cannot be detected by this method. Thus this method is unsuitable for detecting large deletions. For detection of large deletions, a bioinformatic tool for quantifying reads followed by the calculation of putative large mtDNA deletions is necessary. 
A samples

- $\mathrm{C} 11$

P26-LONP1

C121-LONP1 C122-LONP1
B

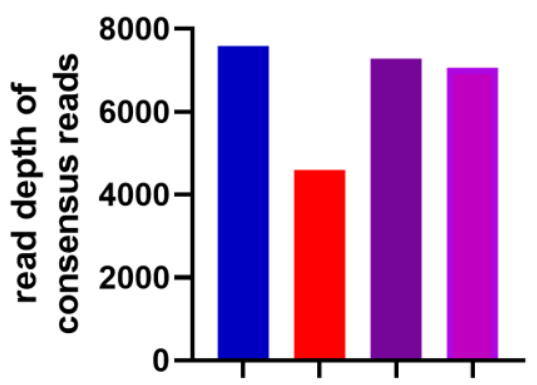

C number of variants

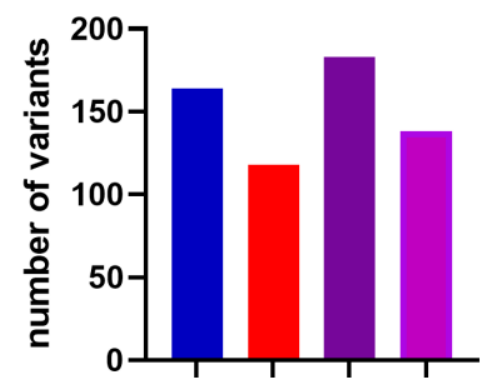

D

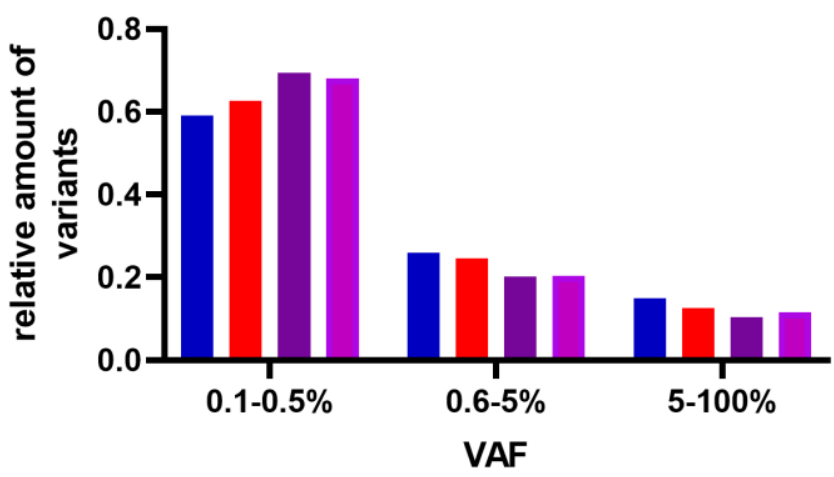

E

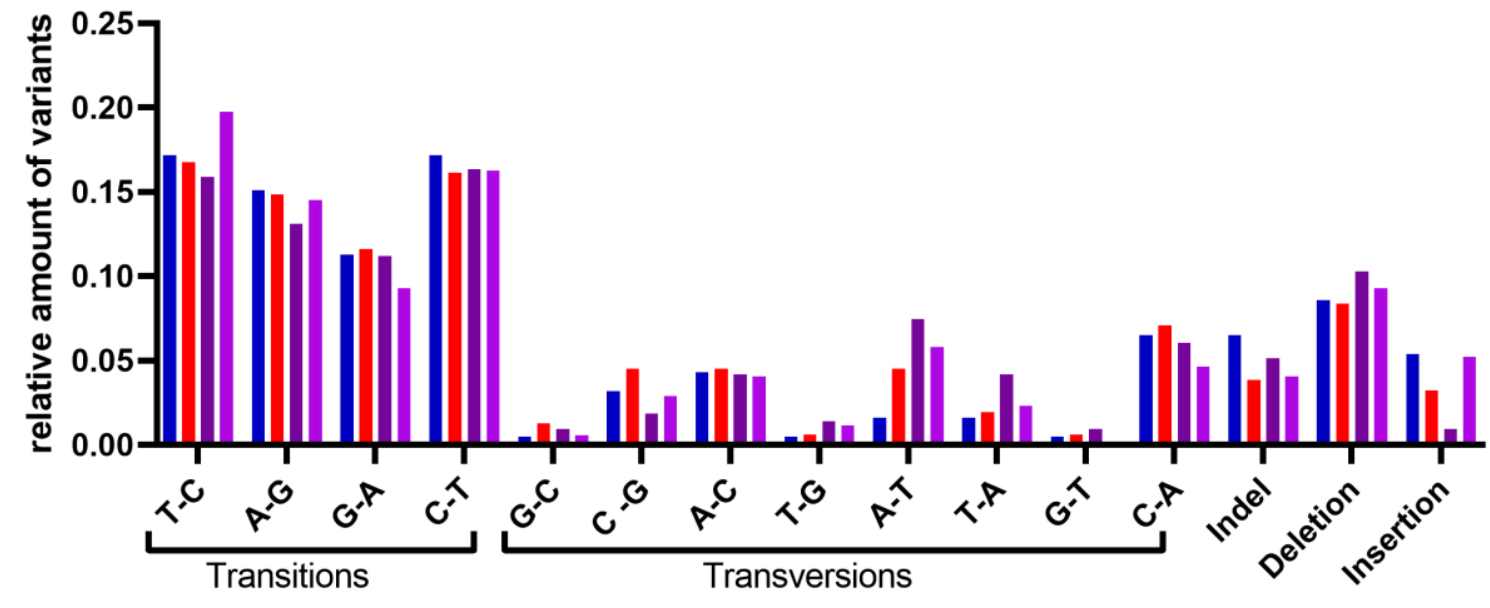

Figure 11: MtDNA sequencing result of P26-LONP1

A: The mtDNA sequencing results of the samples C11, P26-LONP1, C121-LONP1, and C122-LONP1 were compared. B: The read depth of the four samples varied between 4,000 and 8,000. C: The number of variants was not different in these four samples. D: Also, in the distribution of variants by VAF, no differences could be observed. E: The distribution of variants by mutation type is depicted, and no difference was observed. 


\subsubsection{Application of the Newly Established MtDNA Sequencing Method to Quantify Low-} Frequency MtDNA Variants to the Progeria Patient Cohort

To analyze the link between the accumulation of mtDNA variants and aging, we proceeded to sequence the samples of our progeria patient cohort and matched controls. We hypothesized that some progeria samples might harbor a higher level of mtDNA variants as a cause for or as a consequence of mitochondrial dysfunction.

\subsection{Quantification of Low-Frequency MtDNA Mutation in the Progeria Patient Cohort}

For the fibroblast patient cohort, the mtDNA of fifteen fibroblast patient samples and nine fibroblast control samples were sequenced for comparison. Alignment, variant calling, and data analysis were done according to previously established parameters. Figure 12A shows the number of variants in DNA samples from fibroblasts compared to controls. No patient sample was found to have a significantly higher number of variants. Noticeable was the high variance of the number of variants detected in the fibroblast samples in control and patient samples.

In addition, thirteen patient DNA samples derived from blood samples and eighteen control samples were sequenced. In this blood patient cohort, the variance in the number of variants was low, and the number of variants approximately 200 (Figure 12B). Noticeable were two samples with a higher number of variants. The sample P17-XPC was found to harbor 781 variants with a VAF above $0.1 \%$. Additionally, mtDNA sequencing of the sample P21-LTBP4 revealed 11,377 mtDNA variants (Figure 12B).

The correlation of the read depth and the number of variants was tested to exclude the influence of the varying read depth on the number of variants. In the fibroblast samples no significant correlation between mean consensus read depth and the number of variants could be detected with a Pearson coefficient of $r=0.1692$ and a $p$-value of $p=0.4292$ (Figure 12C). Also, no significant correlation was found in the blood samples with a Pearson coefficient of $r=0.0556$ and $p=0.7662$ (Figure 12D). 

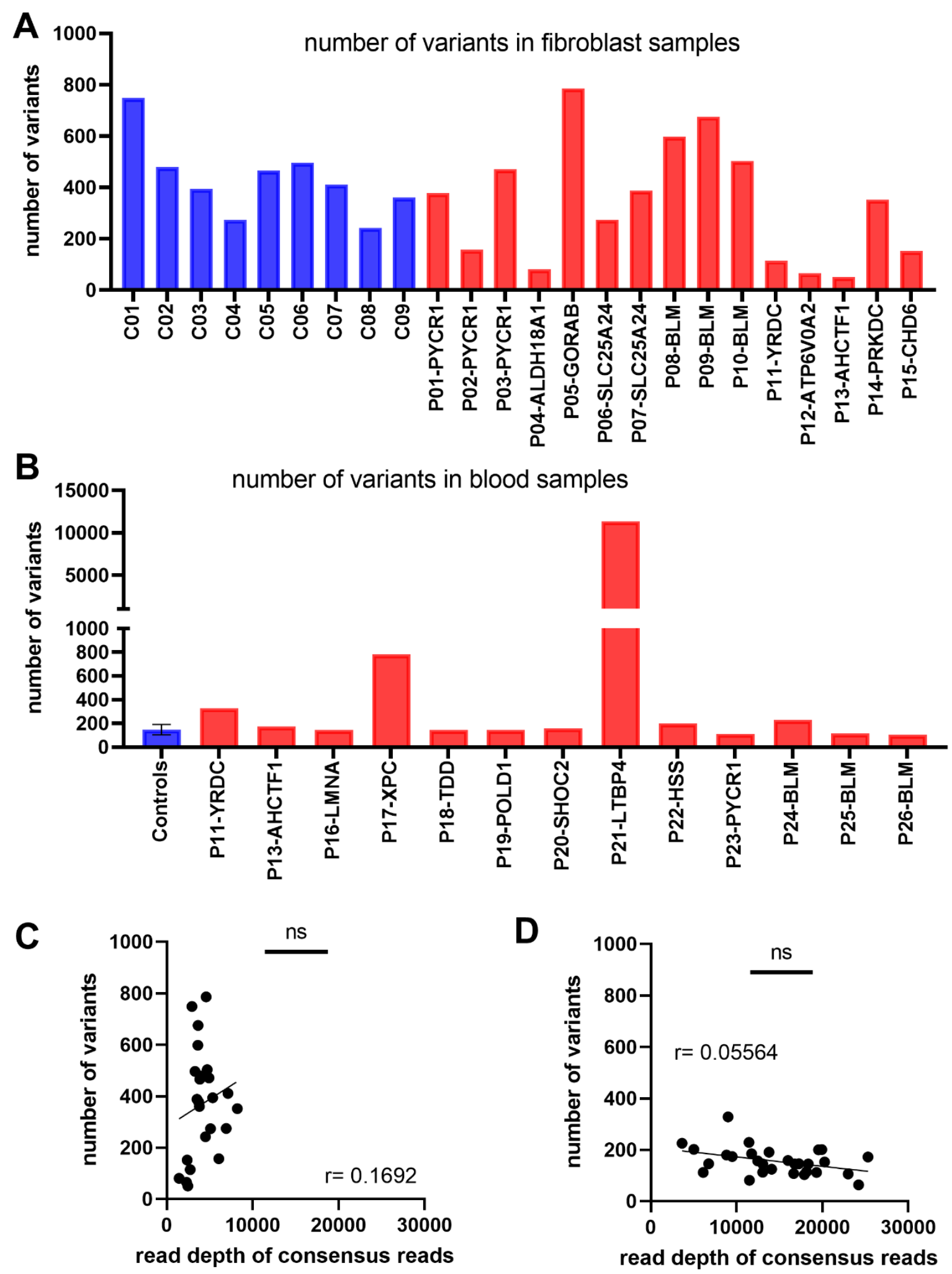

Figure 12: MtDNA sequencing result of the progeria patient cohort and control samples 
Figure 12: MtDNA sequencing result of the progeria patient cohort and control samples

A: Number of variants in patient fibroblasts and control fibroblasts. A high variation between the fibroblast samples was observed. No patient fibroblast sample was noticeably different from the controls. B: The number of mtDNA variants of the patient blood-derived DNA samples is shown. The controls are represented as the mean of all controls as the number of variants had little variance across all controls. Two samples stood out from all patient and control samples: P17-XPC and P21-LTBP4. The number of variants in P17-XPC was 781 and in P21-LTBP4 was 11,377 , while the number of variants in all control samples was below 200. C, D: The read depth of consensus reads was not correlated with the number of variants. C: The number of variants and read depth in fibroblast samples did not correlate. The Pearson coefficient was $r=0.1692$, and the $p$-value $p=0.4292$. D: The number of variants and read depth in blood samples did not correlate with a Pearson correlation coefficient of $r=0.0556$. The two-tailed t-test did not show a significant correlation with a $p$-value of $p=0.7662$. The patient samples P17-XPC and P21-LTBP4 are not shown in the graph but were included in the analysis of correlation.

\subsection{Variance Between Fibroblast and Blood-derived Control DNA Samples}

Next, I investigated the high variance in the number of variants in the fibroblast control sample. Figure 13 shows the comparison of variance of the control samples of DNA from blood samples and fibroblasts. Fibroblasts and blood control samples showed a significant difference in variance $(p=<0.0001)$ as well as a significant difference in the number of variants $(p=0.0004)$. A possible explanation for this observation could be the long cultivation time of the fibroblasts after the skin biopsy. Long times of cultivation in cell culture under the influence of antibiotics and antimycotics might cause the occurrence and multiplication of variants in the mtDNA. This finding underlines how important close matching of control samples to the patient samples is.
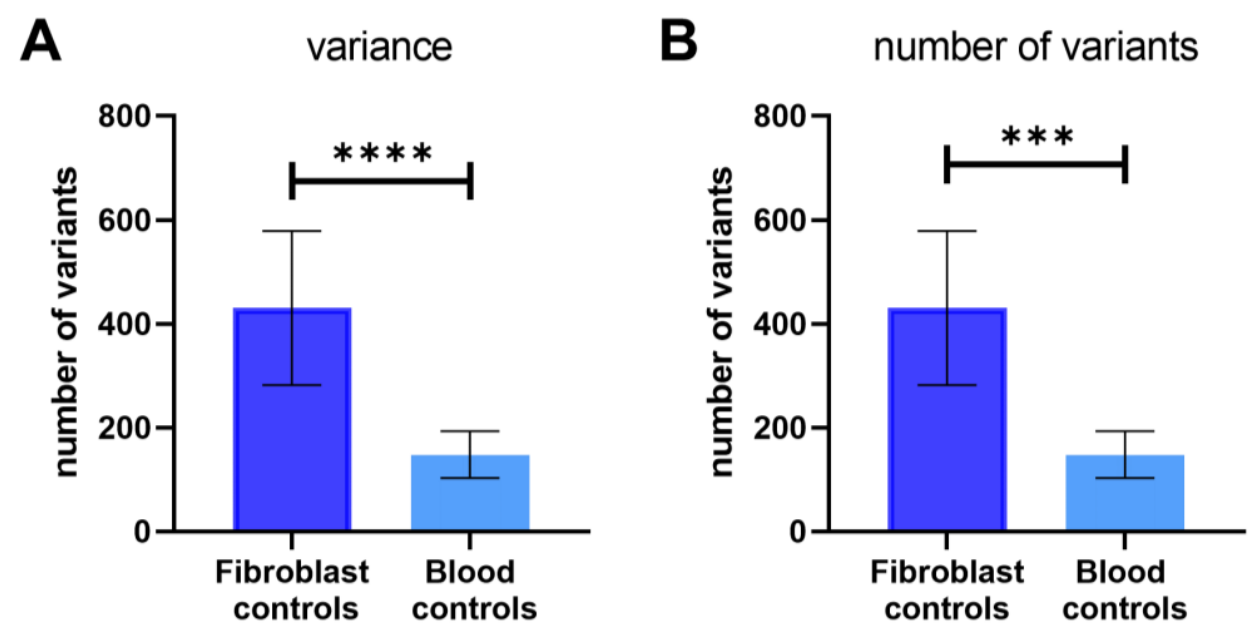

Figure 13: Comparison of fibroblast and blood control samples for variance and number of variants

A: Comparing the variance in the number of variants in fibroblast and blood samples, the F-test showed a significant difference in variance $p=<0.0001$. B: The unpaired and two-tailed t-test using Welch's correction for unequal variance detected a significant difference in the number of variants in fibroblasts and blood samples with a $p$-value of $p=0.0004$. 


\subsection{In-Depth Analysis of the MtDNA Sequencing Result of the Samples P17-XPC and P21-LTBP4}

I showed that simultaneous library preparation and sequencing is essential for the comparability of the results. In order to verify the results for the patient samples P17-XPC and P21-LTBP4 were compared to the control samples C23, C14, C15, and C22 as they were agematched to the patient samples and prepared and sequenced at the same time. The higher number of variants that was detected initially could be confirmed with this analysis. Additionally, the relative amount of variants in the VAF groups was different in the patients. Both patient samples displayed a higher relative amount of low-frequency variants with frequencies between $0.1 \%$ and $0.5 \%$ (Figure 14D). Moreover, a difference between the two patient samples and the control sample concerning the distribution of variants by mutation types was observed (Figure 14E). While fewer transitions occurred in both of the patient samples, the relative amount of transversions was increased. The analysis of the distribution of mutation types in the three groups of VAF in the C11 control sample showed that this phenomenon occurred in control samples as well. Low-frequency variants display a higher amount of transversions compared to high-frequency variants. As the two patient samples have a higher relative amount of low-frequency variants, this explains the shift in the overall distribution of mutation types (Figure 14F). 

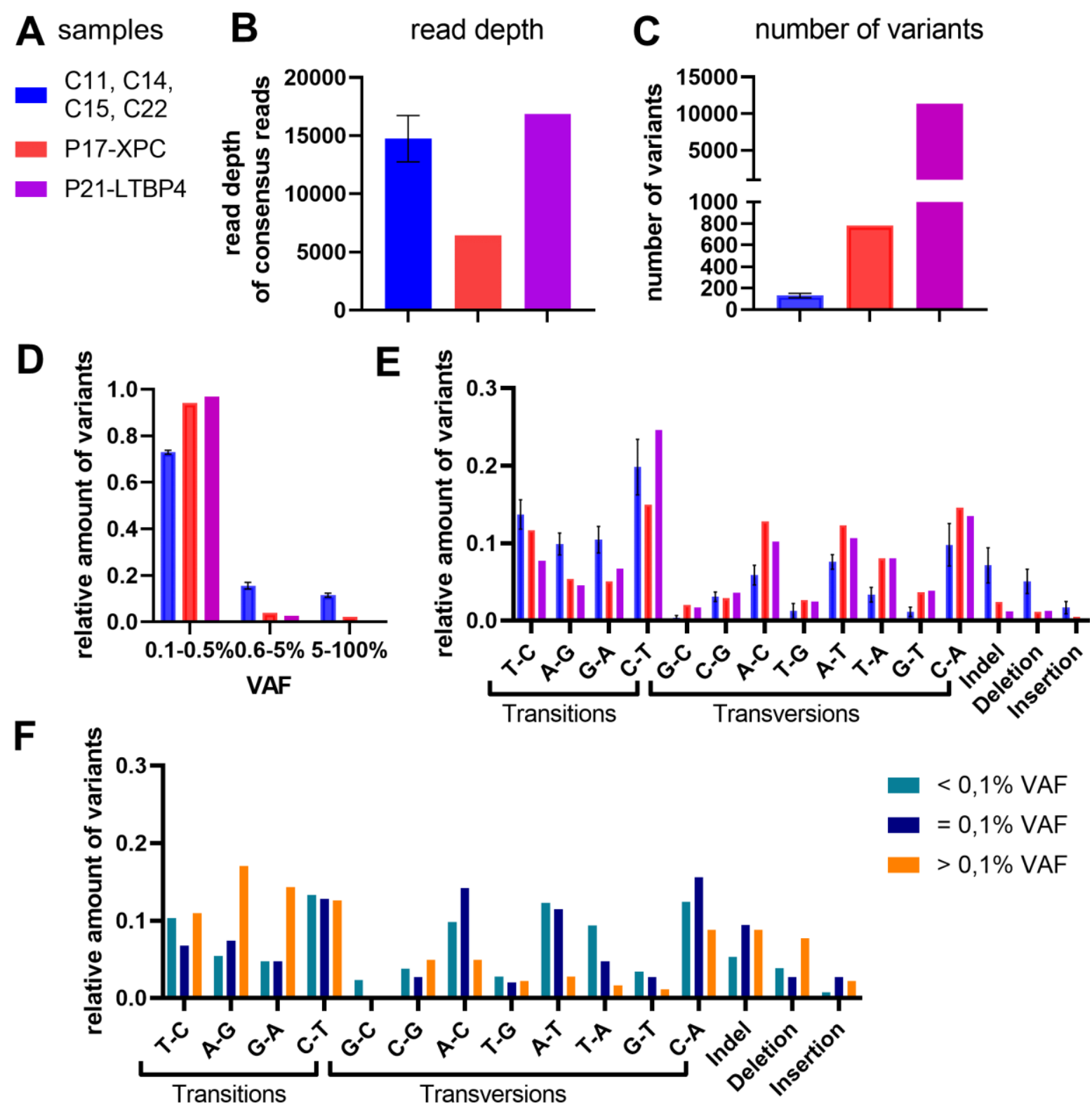

Figure 14: In-depth analysis of the mtDNA sequencing result for P17-XPC and P21-LTBP4

A: The patient samples P17-XPC and P21-LTBP4 were compared to the four control samples C11, C14, C15, and C22. B: The read depth of control and patient samples is shown. The mean read depth of the control samples was 15,000, while the read depth of P17-XPC was 6,000 and of P21-LTBP4 was 16,000. C: The number of variants is displayed for the controls at below 200, for P17-XPC at 780, and for P21-XPC at 11,377. D: The relative amount of variants is depicted for the VAF $0.1-0.5 \%, 0.6-5 \%$, and $5-100 \%$. The relative amount of variants between $0.1 \%$ and $0.5 \%$ was increased in both patient samples compared to the controls. E: The distribution of variants by mutation type is shown and differed in the patient samples. While fewer transitions occured in both of the patient samples, the relative amount of transversions was increased. F: The distribution of variants by mutation types grouped into different VAFs in the control sample C11 showed that the distribution is not even. Variants with a VAF below $0.1 \%$ and equal to $0.1 \%$ VAF showed a similar distribution to the patient samples P17-XPC and P21-LTBP4. The variants with a higher than $0.1 \%$ VAF showed a similar distribution to the controls. 


\subsection{Technical Replication of MtDNA Sequencing of the Samples P17-XPC, P21-LTBP4, and C11}

To calculate the significance of the increase of the number of variants that were observed in the samples P21-LTBP4 and P17-XPC library preparation and sequencing of the samples P17XPC, P21-LTBP4, and C11 were independently repeated three times (Figure 15A). Read depth and number of variants in these measurements are depicted in Figure 15B, C. Read depth was comparable in the three replicates of all three samples (Figure 15B). Comparing the number of variants of the sample P17-XPC to the control sample C11 by paired and two-sided t-test did not show a significant difference $(p=0.415)$. However, the increase in the number of variants in sample P21-LTBP4 was significant $(p=0.0375)$ compared to the control sample C11 by paired t-test (Figure 15C).
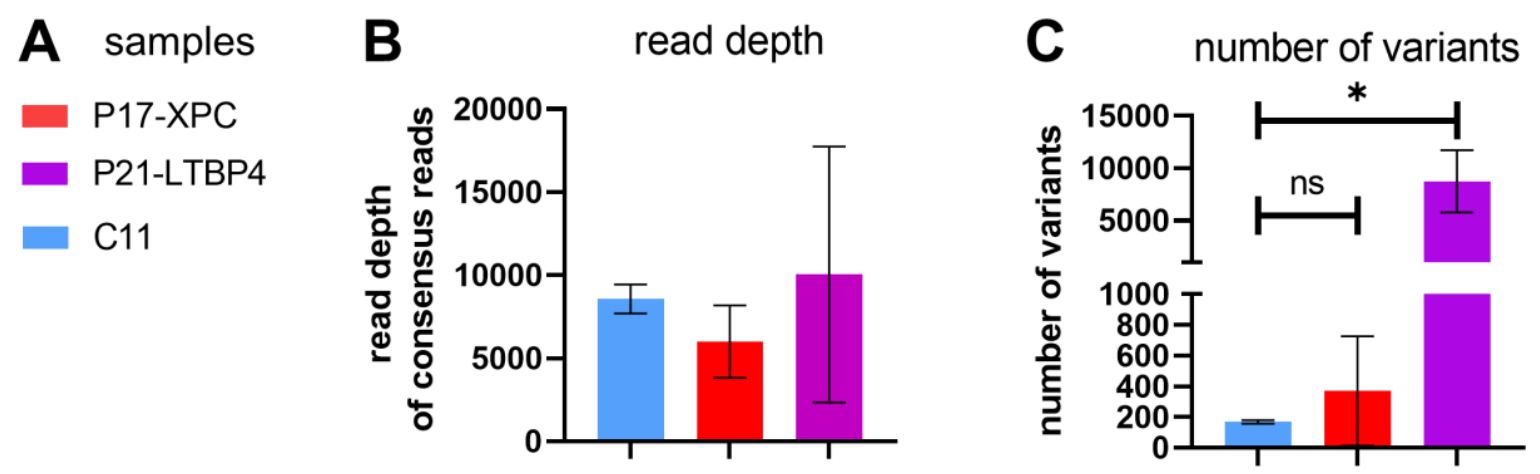

Figure 15: Technical replication of mtDNA sequencing of the samples P17-XPC, P21-LTBP4, and C11

A:The control sample C11 and the patient samples P17-XPC and P21-LTBP4 were prepared and sequenced independently three times to generate technical replicates. B: The variance in read depth and the number of variants was high. C: The number of variants was significantly increased (paired two-tailed t-test) in P21-LTBP4 with $p=0.0375$, but not in P17-XPC $(p=0.415)$ compared to C11. 


\subsubsection{Oxygen Consumption Rate Measurements using Seahorse Mitochondrial Stress Test}

Mitochondrial dysfunction is one of the hallmarks of aging and can be measured by assessing the performance of the oxidative phosphorylation system (OXPHOS). For that purpose, we measured oxygen consumption rates (OCR) in intact cells using the Seahorse analyzer. Patient samples P01-PYCR1, P02-PYCR1, P03-PYCR1, P06-SLC25A24, and P07-SLC24A25 were selected as the mutations identified in these patients affected mitochondrial proteins. PYCR1 encodes the protein Pyrroline-5-carboxylate reductase that localizes to mitochondria and catalyzes the final step of the de novo proline synthesis. The gene SLC25A24 encodes the calcium-binding mitochondrial carrier protein SCaMC-1. It imports adenine nucleotides into the mitochondrial matrix and exports phosphate to the cytosol in a calcium-dependent way. I performed the measurement in cooperation with the working group of Prof. Dr. rer. nat. Peter Rehling and together with Dr. rer. nat David Pacheu-Grau.

The oxygen consumption in fibroblasts was measured using the Seahorse mitochondrial stress test. Four chemicals with different effects on the respiration chain in three different injection ports were added to the medium of each well (Figure 16A). After the measurement of the basal respiration, oligomycin was injected, which inhibits the ATP synthase and thus decreases the electron flow through the respiration chain. When FCCP is added, the protons are transported back to the matrix by FCCP, thereby bypassing the ATP synthase, which is the limiting step. Thus the resulting measurement reflects an uninhibited flow of electrons through the respiration chain, making the measurement of maximal respiration possible. The difference between basal and maximal respiration reflects the spare respiratory capacity, which corresponds to the cell's ability to react to increased energy demand. With the third injection of a mixture of rotenone, which inhibits complex I, and antimycin A, which inhibits complex III, the mitochondrial respiration is halted, enabling the measurement of nonmitochondrial respiration. 
Four different fibroblast lines were plated in a 96-well plate, resulting in at least 23 technical replicates on each plate. The fibroblasts were seeded at the same cell density and allowed to attach. The OCR was measured 24 hours after seeding to avoid that different cell proliferation rates affected the measurement. In addition, cell number was assessed for each well after the measurement and used for normalization.

For the samples P01-PYCR1, P02-PYCR1, and P03-PYCR1, no difference in the OCR compared to the control cells $\mathrm{CO} 2$ and $\mathrm{CO} 4$ could be observed (data not shown). Further, no significant difference was observed when comparing basal respiration of patient cell lines P06-SLC25A24 and P07-SLC25A24. In the same way, oxygen consumption of all cell lines after the addition of oligomycin was similar. Interestingly, when measuring maximal respiration after the addition of FCCP, the patient sample P06-SLC25A24 displayed significantly higher OCR than the control cells. In contrast, the patient sample P07-SLC25A24 with the identical mutation in the same gene did not show any difference from the age-matched control samples. Remarkably, patient fibroblasts P06-SLC25A24 only showed increased respiration when it was uncoupled from ATP production, showing an increased spare respiratory capacity that would allow them to have a better response in stress conditions. 


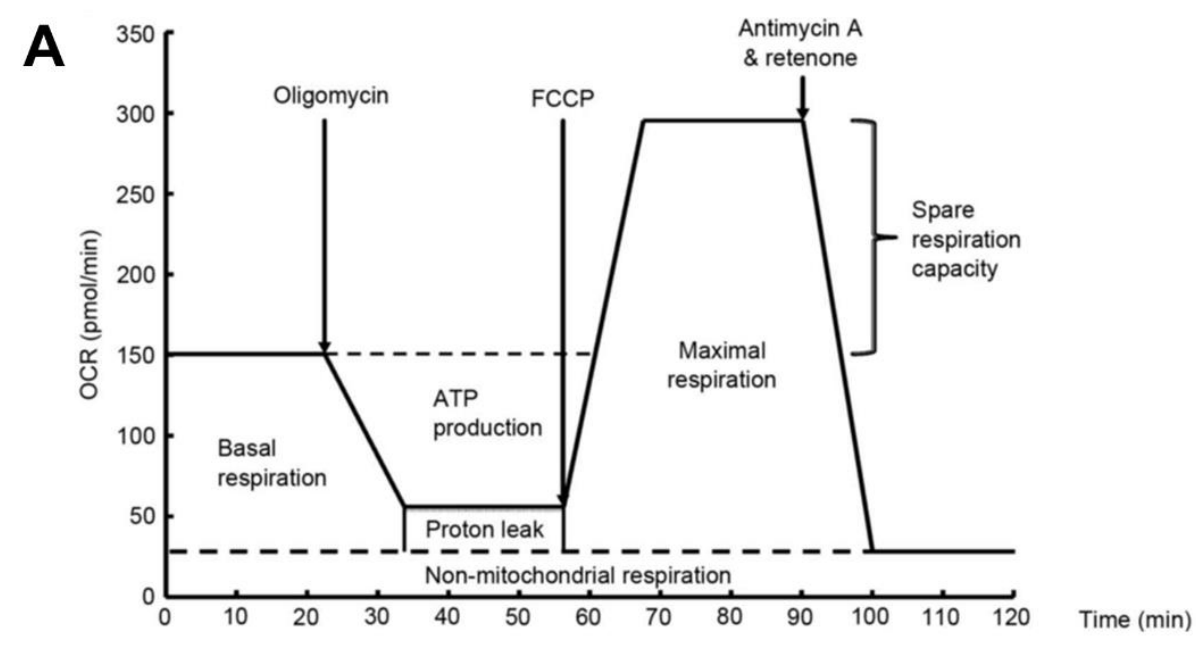

B

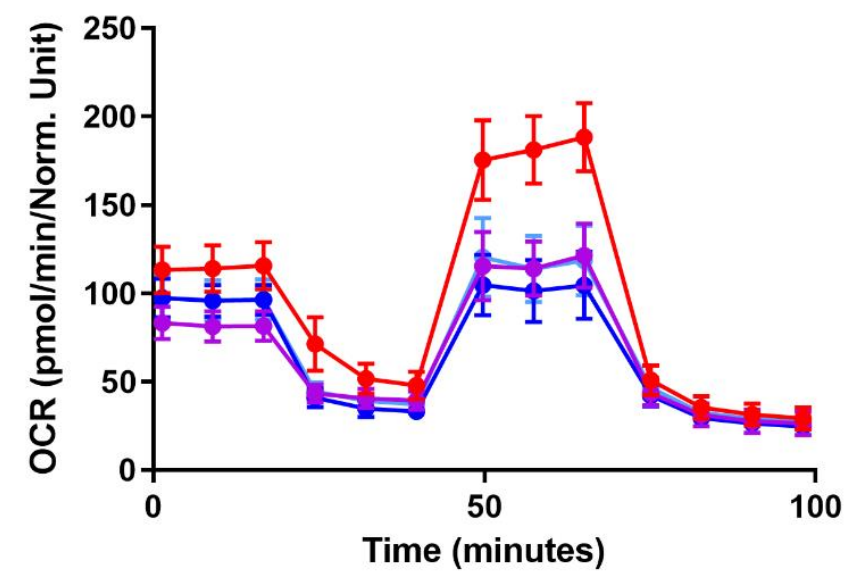

\section{Maximal Respiration}

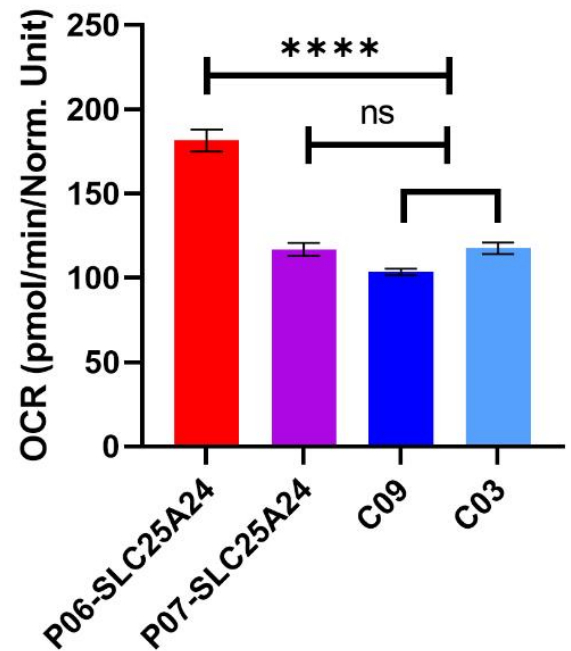

Figure 16: Oxygen consupmtion rate measurement in P06-SLC25A24 and P07-SLC25A24

A: Schematic representation of the sequence and measured parameters of the Seahorse mitochondrial stress test. The figure is taken from Li et al. (160). B: Representative real-time respirometry analysis of patient and control fibroblasts $(n=23)$. C: The maximal respiration of each patient sample $(n=23)$ was compared by a one-way ANOVA to the two control fibroblasts. P06-SLC25A24 is significantly different from the control cells with a $p$-value of $p=<0.0001$. The measurement was repeated three times with the same result. 


\subsection{Telomere Length Measurement}

Attrition of telomere length over time is a hallmark of aging and is implicated by the genome maintenance theory of aging as the result of DNA damage $(22,69)$. Telomere length was measured in the patient and controls blood samples by the telomere real-time PCR and in three patient and three control fibroblast samples by a novel telomer qFISH method.

\subsubsection{Telomere Length Measurement in Progeroid Syndrome Patients by Telomere Real-Time PCR}

The telomere real-time PCR was established to measure the relative telomere length in the blood patient cohort and matched control samples.

\subsubsection{Establishment of the Telomere Length Measurement by Real-Time PCR}

Telomeres are repetitive sequences (TTAGGG) at the end of each chromosome. The longer the telomeres, the more repeats of the telomeric sequence are present in the nucleus. Realtime PCR is often used to compare the expression levels of two different transcripts: one transcript of interest and the other a transcript of a housekeeping gene. The amplification of the PCR product is quantified after each PCR cycle via a fluorescent dye that intercalates with any double-stranded DNA but not single-stranded DNA. A threshold level is chosen where the amplification curve is exponential to calculate the threshold cycle (Ct) values for a comparison of samples. This principle of real-time PCR can also be applied to measure telomere length. Relative telomere length can be estimated by comparing the telomere reaction to a single copy gene reaction (SCR). The ratio of the amount of telomere repeats to the single-copy gene is the relative telomere length.

Each reaction was pipetted in triplicates on each plate. From the Ct value of each triplicate measurement, a mean $\mathrm{Ct}$ value was calculated. From the mean $\mathrm{Ct}$ value of the telomere and

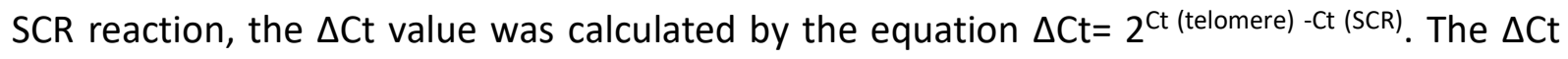
value of a sample was then divided by the $\Delta \mathrm{Ct}$ value of the reference sample to normalize the measurements of one plate and achieve inter-plate comparability with the equation $\Delta \Delta \mathrm{Ct}=$ $\Delta \mathrm{Ct}$ (sample)/ $\Delta \mathrm{Ct}$ (reference sample). This measurement was repeated on three separate 
plates with the same plate layout. From the $\Delta \Delta \mathrm{Ct}$-value of measurement, the mean, standard deviation, and coefficient of variation were calculated.

Despite rigorous cleaning procedures and the separation of workspaces for pipetting of master mix and DNA, the "no template control" (NTC) for the telomere reaction was repeatedly positive (Figure 17A). The melting curve plot of the resulting product indicated specific amplification of telomere sequences (Figure 17B). However, the NTC of the SCR reaction was always negative. We concluded that telomere sequences must be so frequent and the PCR reaction so sensitive that it was not possible to achieve a negative NTC for the telomere reaction. Thus we set rigorous quality control criteria for sample measurement: (1) A dilution series was included on every plate, (2) an NTC was included on every plate, (3) the plate was discarded if the difference of $\mathrm{Ct}$ value of a sample to the $\mathrm{Ct}$ value of the NTC was less than 10 (Figure 17A). Also, (4) three replicates of the reference sample were included on every plate, (5) the same plate layout was used for repeated measurements, (6) a sample was excluded from the analysis if the DNA Integrity Number (DIN) measured by the Tape Station was below seven or (7) the coefficient of variation of the three replicate measurements was above 0.1 .

A dilution series of five DNA concentrations between $5 \mathrm{ng}$ and $0.3125 \mathrm{ng}$ was done to test the PCR efficiency of both PCR reactions (Figure 18A). The PCR efficiency was calculated from the slope of the standard curve: $E=-1+10^{(-1 / \text { slope })}$. The PCR efficiency of the telomere and reference reaction was $95 \%$ and $97 \%$, respectively (Figure 18C). Moreover, the melting curves were analyzed to ensure that only one PCR product was amplified (Figure 18B). 
A

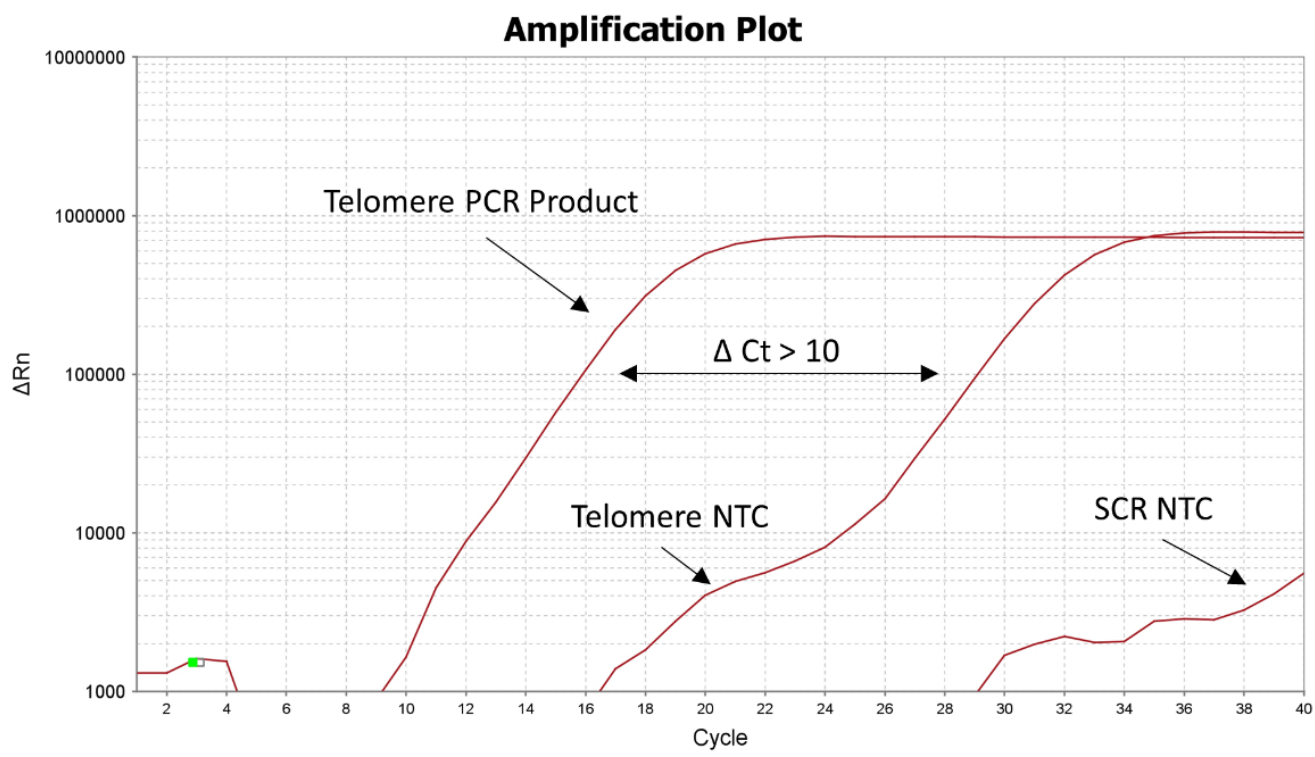

B

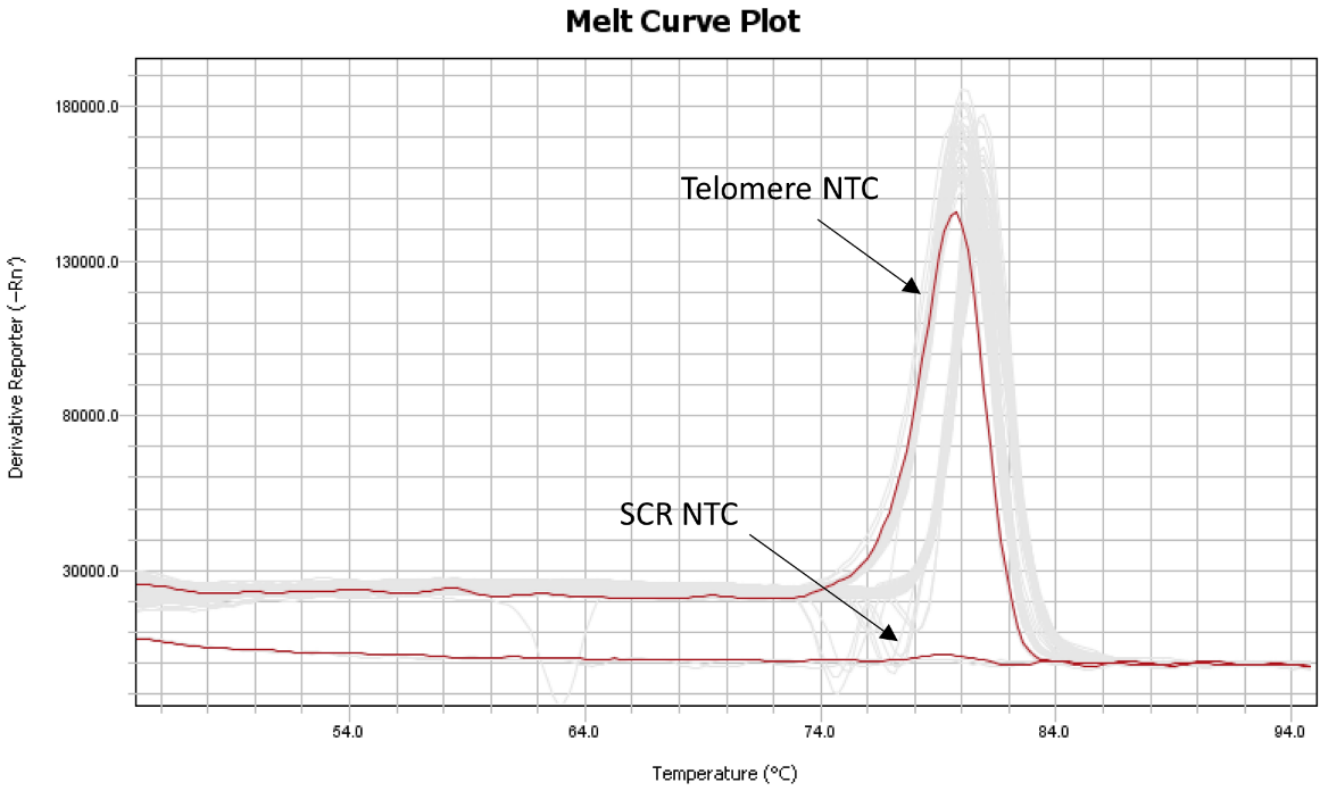

Figure 17: Specific amplification of the telomere PCR product in the NTC

A: A plate was included in the measurement if the telomere NTC Ct value was at least $10 \mathrm{Ct}$ values higher than the highest $C t$ value of a telomere reaction from a DNA sample. B: The melting curve plot shows that the telomere product from a NTC is a specific PCR product, while there is no specific product from the NTC of the SCR reaction. 
A

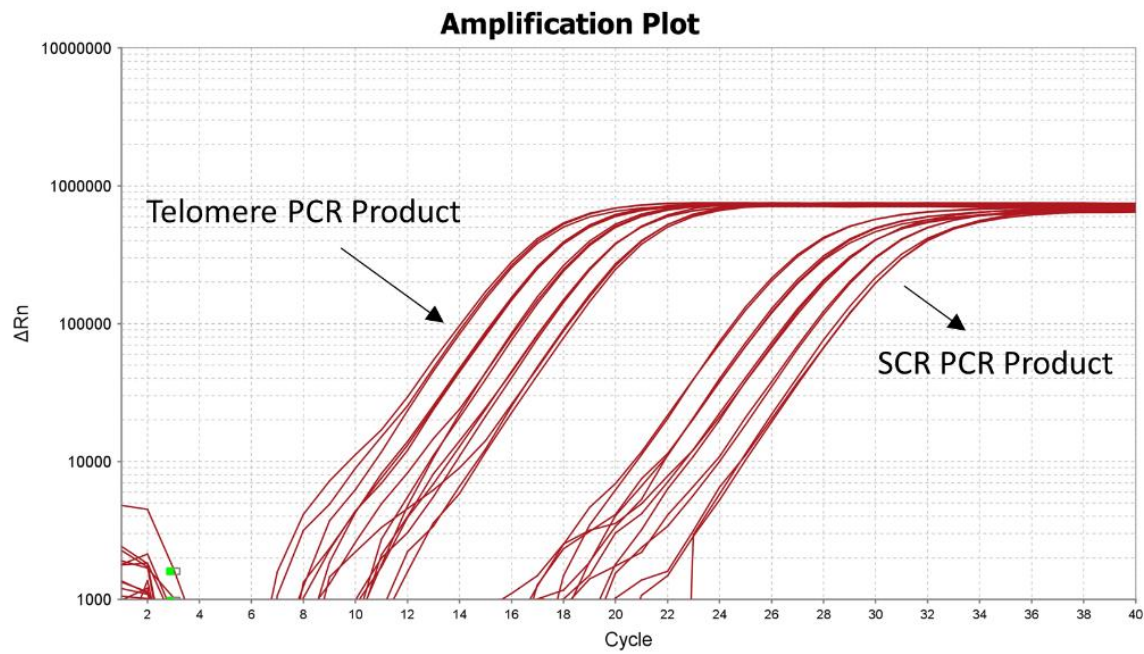

B

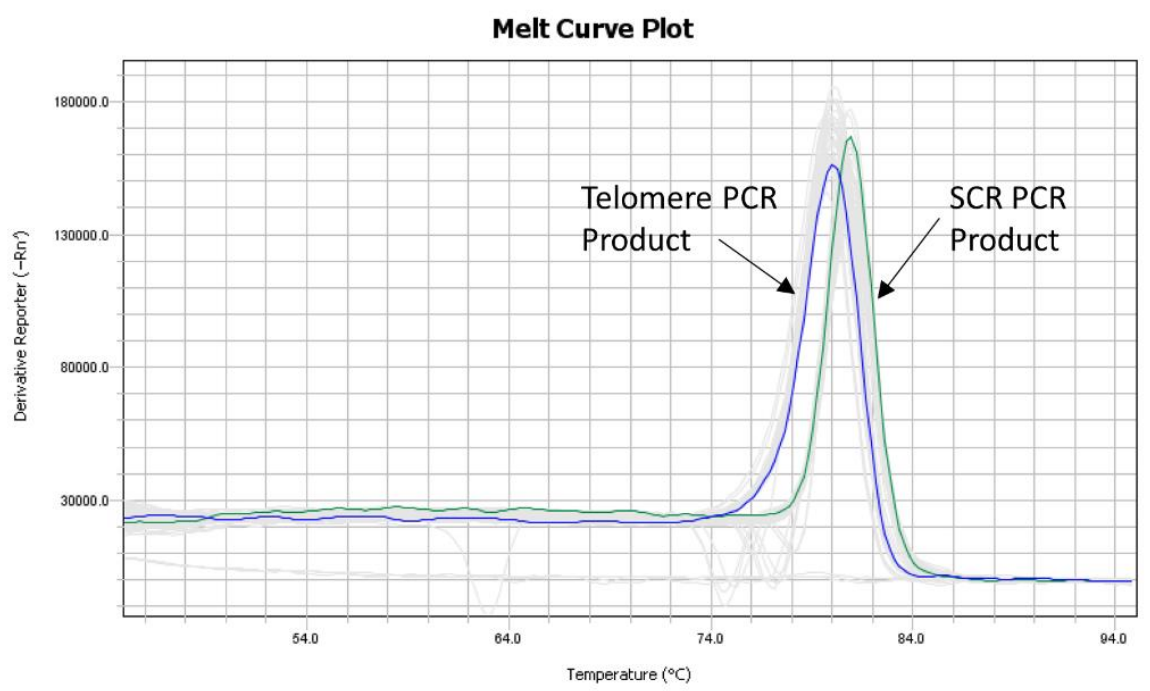

C

Standard Curve

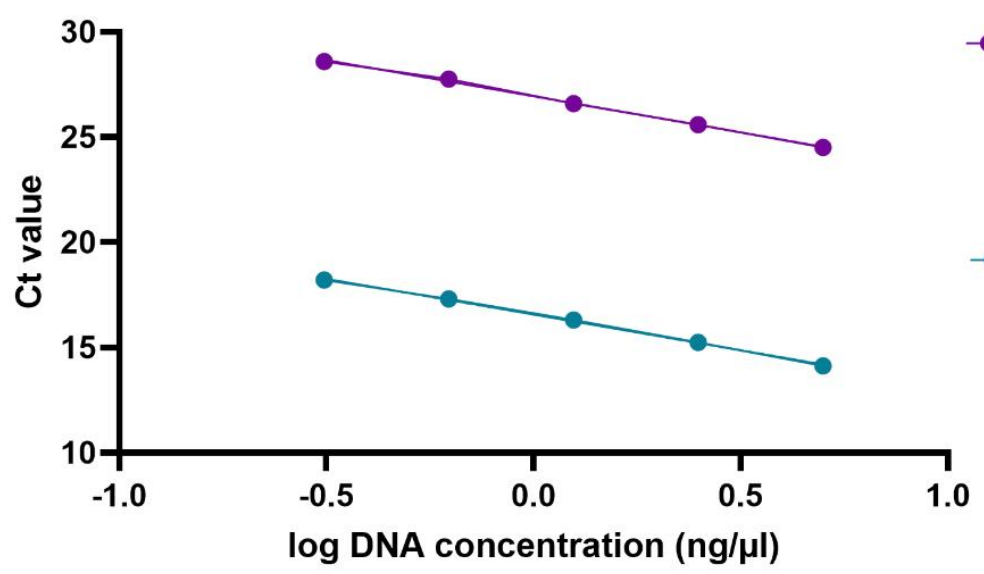

SCR Reaction

slope $=-3.434$

$R^{2}=0.9979$

Efficiency $=97 \%$

Telmere Reaction

slope $=-3.395$

$R^{2}=0.9985$

Efficiency $=95 \%$

log DNA concentration (ng/pl)

Figure 18: Establishment of telomere real-time PCR

A: The amplification plots of the telomere and SCR PCR for the dilution series show specific amplification. B: The melting curve plot for a telomere and a SCR product show specific amplification. C: The standard curve was calculated from the Ct values of the dilution series to calculate PCR efficiency. The PCR efficiency was $97 \%$ and $95 \%$ for telomere and SCR reactions, respectively. The $R^{2}$ value for both reactions was $>0.99$ 


\subsubsection{Measurement of Relative Telomere Length by Real-Time PCR did not Reveal Significant Telomere Attrition in the Blood Patient Cohort}

As telomere length is influenced by many factors, it is of high importance to collect many agematched control samples. The origin of the blood control samples is described in section 3.1. In total, 110 control samples and 13 patient samples were measured. Data analysis was performed in cooperation with Dr. rer. nat. Andreas Leha, Department of Medical Statistics, University Medical Center Göttingen, as part of the statistical consultation for Ph.D. students. Figure 19 shows the measured relative telomere length plotted against the age of the patient at the time of blood donation. The distribution of telomere length in the control samples showed the anticipated sigmoidal distribution and a high variance of telomer length in samples of the same age. From the telomere length of the control samples, a prediction of telomere length by age was calculated. None of the patient samples lay outside the predicted range of telomere length, and thus, none were significantly different. The reduced telomere length of P23-PYCR1 and P24-BLM approach significance with $p=0.0729$ and $p=0.0599$, respectively. The relative telomere lengths measured and the $p$-values for each patient sample are listed in Table 44 in the appendix. 


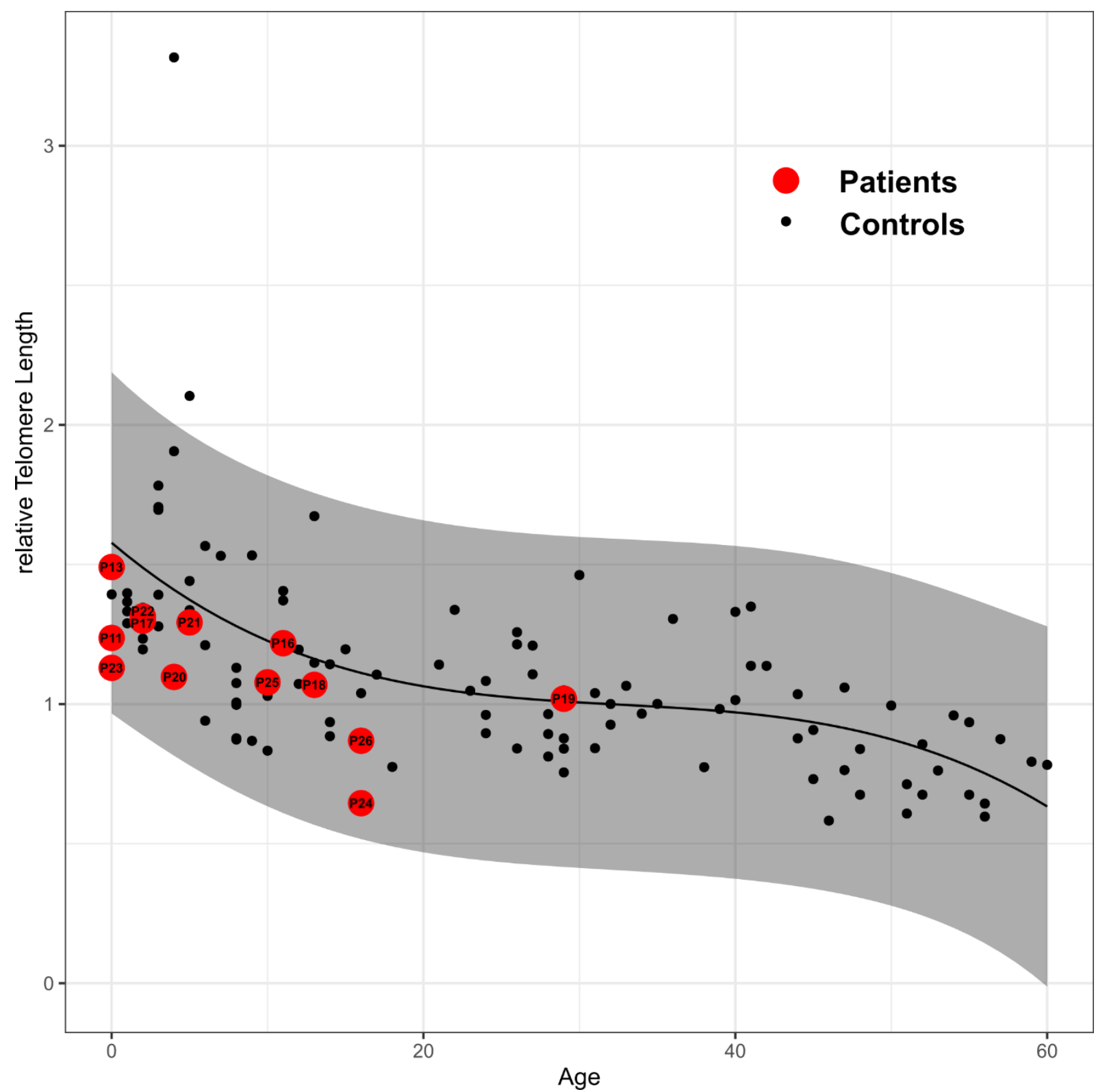

Figure 19: Results of telomere real-time PCR measurement in the blood patient cohort

Relative telomere length is plotted against age for 110 control (black dots) and 13 patient samples (red dot). The patient ID is indicated in the red dots. Based on the sigmoidal distribution of the control samples, a prediction (gray area) was made. A sample with a relative telomere length outside of this area would be significantly different from the control samples. P23-PYCR1 and P24-BLM lie on the edge of the predicted area and approach significance with $p=0.072$ and $p=0.059$, respectively. 


\subsubsection{Telomere Length Measurement of Fibroblasts from Bloom Syndrome Patients by Optimized QFISH Method}

An alternative method to the widely-used telomere real-time PCR is the Telomere qFISH method to assess telomere length. Prof. Dr. med. Stephan Lehnart and his working group set out to optimize the classical telomere qFISH method. I collaborated on this project by contributing to the establishment of sample preparation and by providing a Southern blot analysis and a real-time telomere measurement of the test samples to compare the results of the optimized method to. After method establishment was successfully completed, I did the sample preparation and took the images for optimized telomere qFISH measurement in six fibroblast samples in collaboration with Dr. rer. nat. Tobias Kohl and Dr. rer. nat. Tatiana Pochechueva. Niko Schwenzer, M.Sc, performed the image analysis and the statistical analysis.

\subsubsection{Optimized QFISH Method Allows Telomere Length Measurement in Single Nuclei by 3D Confocal Imaging}

For classical telomere qFISH measurement of telomere length, multiple single-plane confocal images are taken and the mean telomere intensity from all images is calculated. The optimization of this classical method allows more detailed measurement of single nuclei as it uses [1] a 3D confocal image, [2] longer recording time, [3] a STED image, and [4] a custommade macro for image analysis. In this way, errors due to focussing, clustering of spots, and low rates of spot recognition per cell can be avoided.

The fibroblasts were harvested, fixed, dropped onto slides, and FISH staining was performed. A telomere-sequence-specific PNA (peptide nucleic acid) probe, depicted in Figure 20A, was used to stain telomeres. The samples were also stained with DAPI. All samples were processed at the same time to ensure comparability. Per sample, at least 20 nuclei were imaged. For this, a z-stack containing ten image planes was taken, and afterward, one STED image was recorded. Image analysis and statistical tests were performed by Niko Schwenzer, M. Sc. using a custom-made macro for ImageJ. The z-stack was used to find the plane with maximal signal intensity for each telomere signal, which is the major improvement to the classical telomere qFISH method. Figure 20B shows a schematic representation of telomere signal detection. A spot was detected if the brightness was above a set threshold and it passeed specific size and 
fit quality parameters. There was no limit to the number of telomere detections per nucleus.

Additional to the confocal image, the STED image of the nucleus provided a higher resolution of telomere spots allowing a qualitative evaluation of spot clustering. The difference between a confocal image and a STED image is shown in Figure 20 C, D.

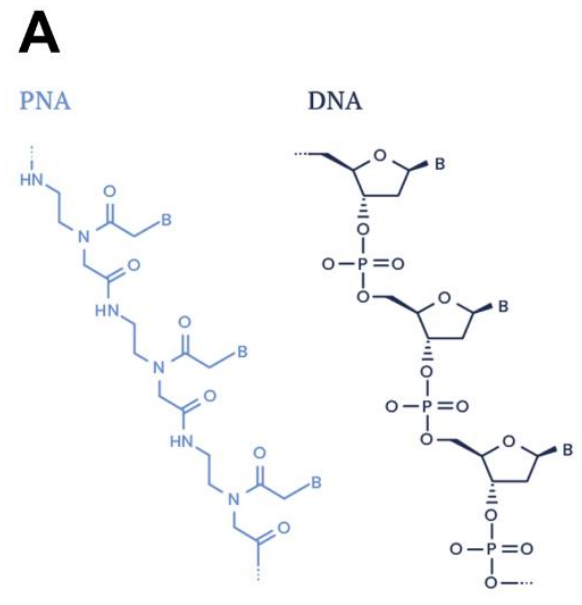

C

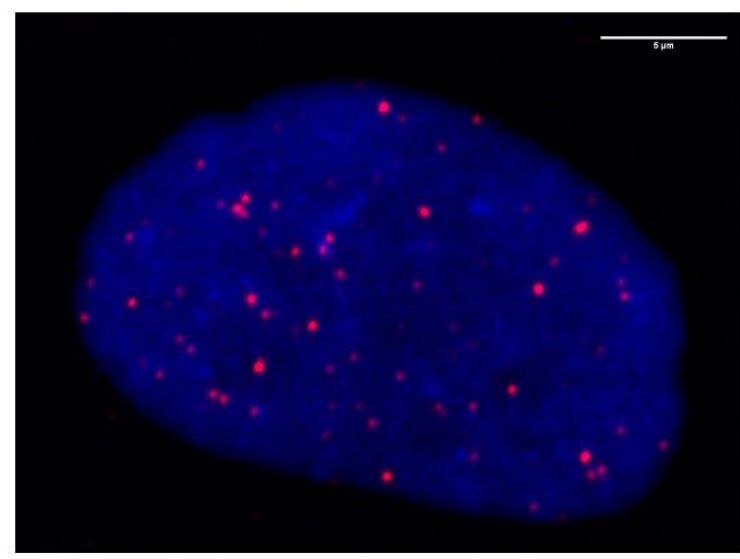

B

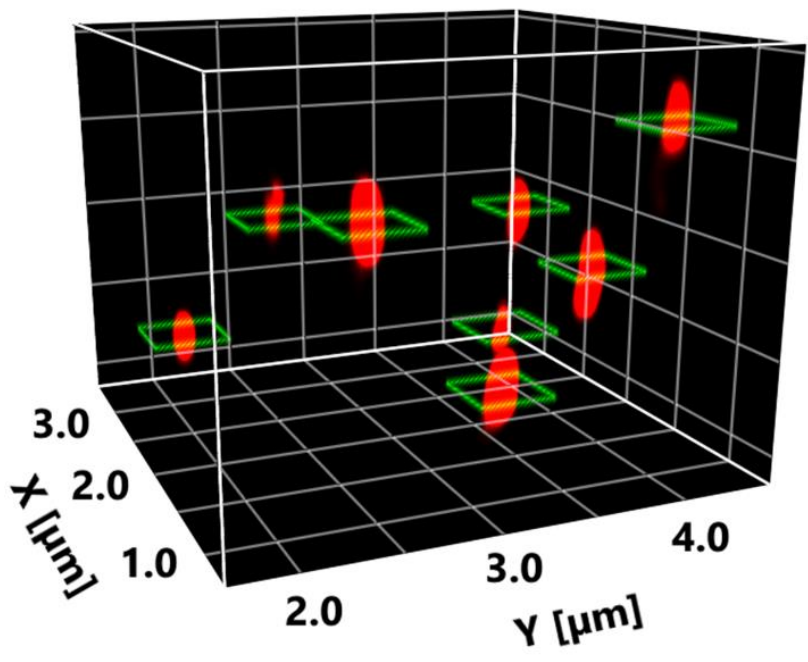

4.0

3.5

3.0 冚

2.5

2.0
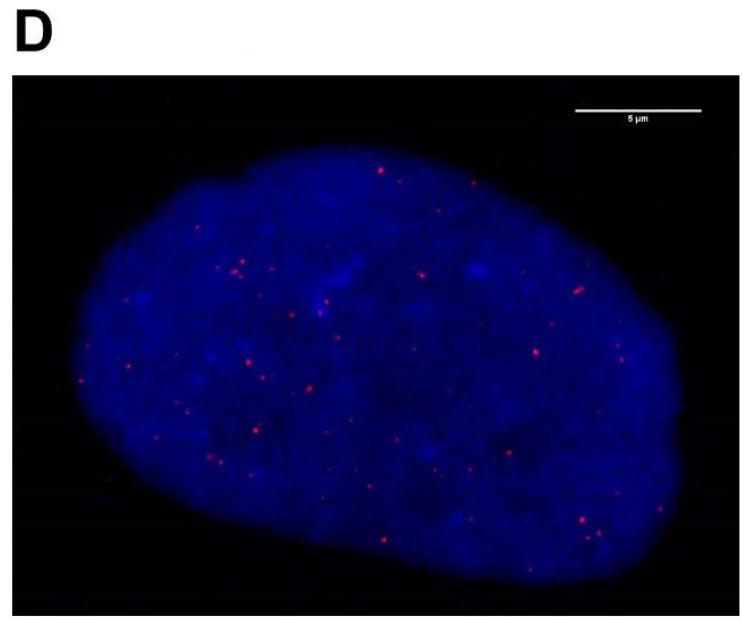

Figure 20: Principle of the optimized telomere qFISH method

A: A PNA probe binds sequence-specifically to the repetitive sequence of telomeres. The figure is taken from the probe manufacturer's website (161). B: The schematic representation depicts the principle of telomere spot recognition. The different planes of the $z$-stack are analyzed to find the plane with maximal signal intensity for each spot. The figure was created by Niko Schwenzer (unpublished data). C, D: Confocal image and STED image of the same DAPI-stained nucleus with telomere spots in red. 


\subsubsection{Telomere QFISH Measurement Showed an Increased Number and Brightness of Telomere Signals in the P08-BLM Sample}

After method development and establishment of the optimized method was done on Hela cells with different telomere lengths, I performed this optimized telomere qFISH method on six fibroblast samples. We chose the three fibroblast samples from patients with Bloom syndrome as the loss BLM has been implicated to affect telomere length, but this has not been proven. Also, the telomere length of the blood sample P24-BLM approached significance in the telomere real-time PCR measurement (section 3.3.1.2).

A confocal z-stack and a STED image from at least 20 nuclei per sample were taken in cooperation with Dr. rer nat Tobias Kohl and Dr. rer nat. Tatiana Pochechueva. Image analysis and statistical tests were then performed by Niko Schwenzer, M. Sc. using a custom-made macro for ImageJ and Graph Pad Prism. Representative STED images of each fibroblast sample are shown in Figure 21. 

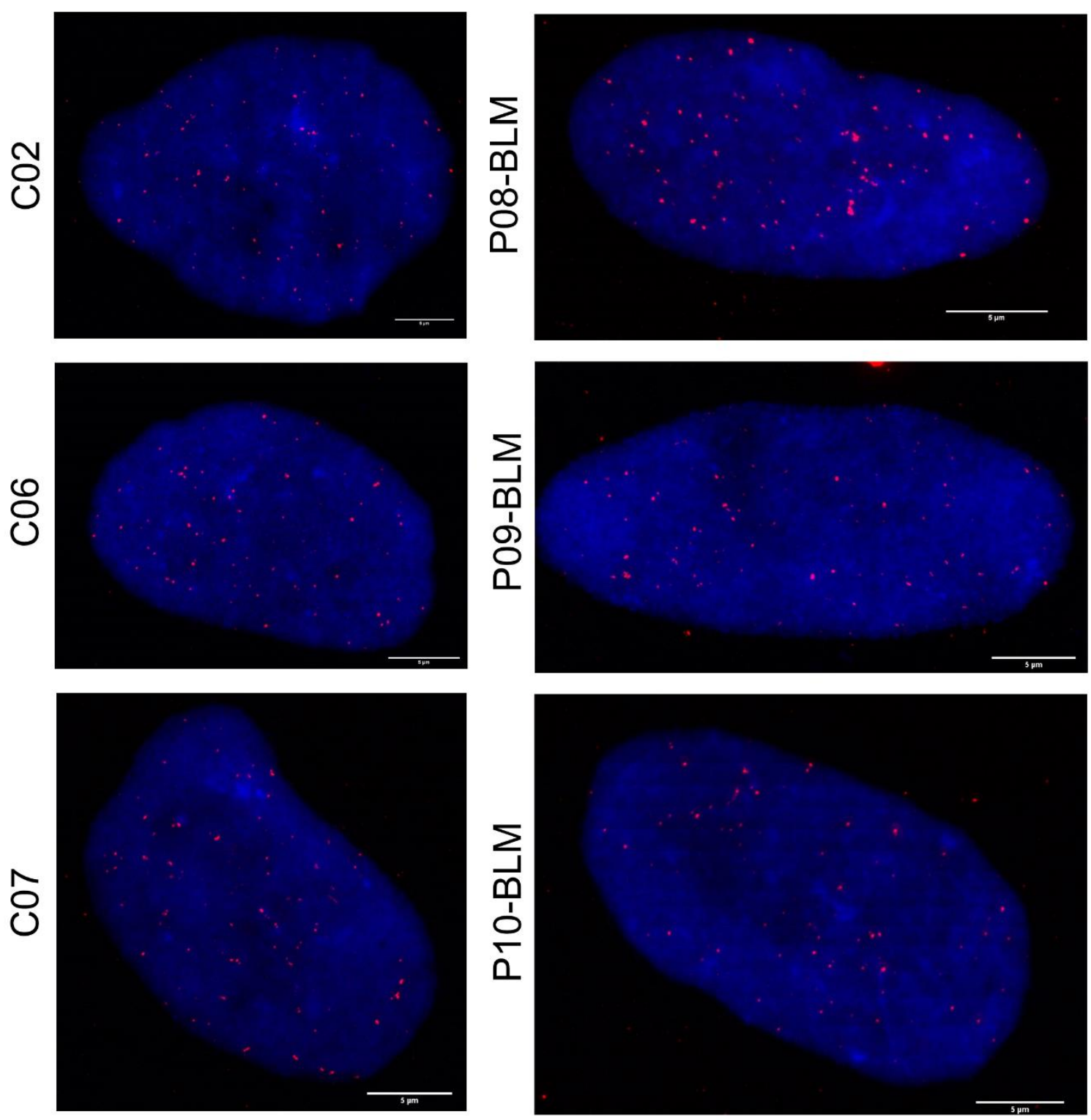

Figure 21: Representative STED-images of patient and control samples

STED images of fibroblasts stained with DAPI (blue) and the telomere probe (red) are shown. Depicted are the three control fibroblasts C02, C06, and C07 as well as the three patient fibroblasts P08-BLM, P09-BLM, and P10-BLM. Noticeable is the nucleus of P08-BLM, which contains more telomere spots than the other 'nuclei.

The telomere spot brightness and the number of telomere signals were measured for each nucleus. The telomere spot brightness and the number of telomere spots were significantly increased in the patient sample P08-BLM compared to the three age-matched control fibroblast samples (Figure 22A, B). This result was contrary to our hypothesis that telomere length might be reduced in samples from Bloom syndrome patients. In the following experiments, we thus wanted to find the cause of the increased number of telomere spots 
and test whether the increased brightness was caused by the increased number of spots and is thus was an artifact or whether this measurement reflected the actual telomere length of the sample P08-BLM.

As a starting point, the values for telomere spot brightness and telomere count were plotted against each other to test whether they correlated. Figure $22 \mathrm{C}$ shows that that the number of telomere spots and the telomere spot brightness are independently high in P08-BLM. Additionally, a bimodal distribution of the number of telomere signals in the sample P08-BLM was observed. As the number of telomere signals should be constant to ensure comparability of the measurement of telomere spot brightness, further analysis of the fibroblast sample P08-BLM was needed.
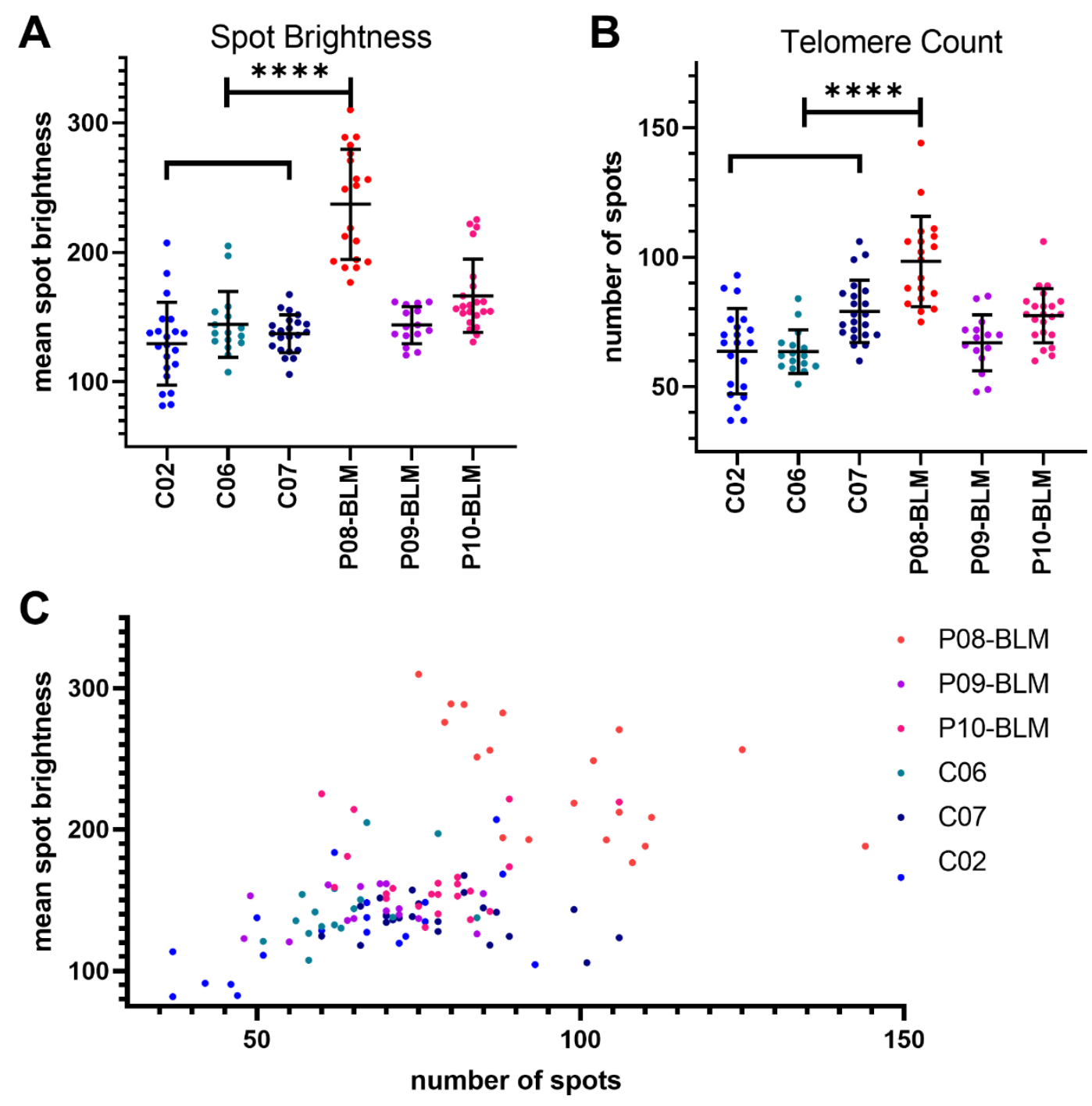

Figure 22: Mean spot brightness and the number of telomere signals is independently high in P08-BLM 
Figure 22: Mean spot brightness and the number of telomere signals is independently high in P08-BLM

A: The mean spot brightness for each analyzed nucleus is shown as one dot for each of the analyzed nuclei. By one-way ANOVA analysis, the mean spot brightness, which corresponds to mean telomere length in P08-BLM was significantly higher than in the three control samples with $p=<0.0001$. B: The number of telomere spots detected is depicted for each nucleus analyzed for each sample. Again, the sample P08-BLM showed a higher telomere count compared to control samples. The one-way ANOVA analysis detected a significant increase with $p=<0.0001$. C: Telomere count and spot brightness are plotted against each other. Telomere count and telomere spot brightness were independently high in P08-BLM.

\subsubsection{Comparison of the QFISH Telomere Length Measurement to Telomere Length Measurement by Southern Blot Analysis}

To validate the relative telomere length measurement determined by $\mathrm{qFISH}$, the absolute telomere length was determined by classical Southern blot analysis. DNA was extracted from the fibroblast cultures, and the DNA concentration and intactness of DNA were assessed using the Agilent Tape Station. Digestion of the DNA by the two restriction enzymes, Hinfl and Rsal that do not cut in the repetitive telomere sequence was used for digestion of all except for the telomere regions of gDNA. The DNA was applied to an agarose gel to separate the telomere fragments by length, and then the DNA fragments were blotted onto a membrane. Telomere-specific digoxigenin-labeled probes and enzymatic detection of the probes, the telomere signal indicated the amount and the size of the telomere fragments by intensity. By comparing this profile to a molecular weight marker, the absolute mean telomere length could be determined. The results of the Southern blot analysis of six fibroblast samples is shown in Figure 23A. Using two y-axes, the two telomere length values determined for each sample by telomere qFISH and telomere Southern blot are compared in Figure 23B. While the two telomere measurements of the samples P09-BLM, P10-BLM, C02, and C07 match, the qFISH measurement of the telomere length in P08-BLM is higher than than the value determined by telomere Southern blot. For the control sample C06, the telomere Southern blot measurement is higher than the qFISH measurement.

The Southern blot measurement of telomere length did not confirm the higher telomere length of the sample P08-BLM measured by telomere qFISH. Thus the higher number of telomere signals could be an explanation for the increased telomere length measurement in these cells. As the number of telomere signals was increased, the original images were re- 
examined to determine whether the measurement was due to an error in image analysis. Manual re-counting revealed more than 92 telomere signals per cell. A cell in the G1 phase with 46 chromosomes contains 92 telomeres. Thus 92 telomere signals are the maximal number of telomeres expected in a nucleus. In the other five samples, the mean number of telomere signals was approximately 60 , indicating that not all telomeres were detected with this method. Three possible explanations come to mind when presuming the high number of telomere signals was correct: (1) A chromosome aberration could have occurred early after the skin biopsy, thereby gaining additional chromosomes and increasing the number of telomeres per nucleus. Through the passages, the cells containing the chromosome aberration could have overgrown the wild-type cells. (2) The cell cycle progression could be different in the P08-BLM patient cells. More fibroblasts in the G2/M phase than in the other samples resulted in more images of cells in the G2/M phase. (3) Preferential imaging of nuclei in the $\mathrm{G} 2 / \mathrm{M}$ phase could have caused this increased number of telomere signals. With the following experiments, we tried to determined which explanation was correct.
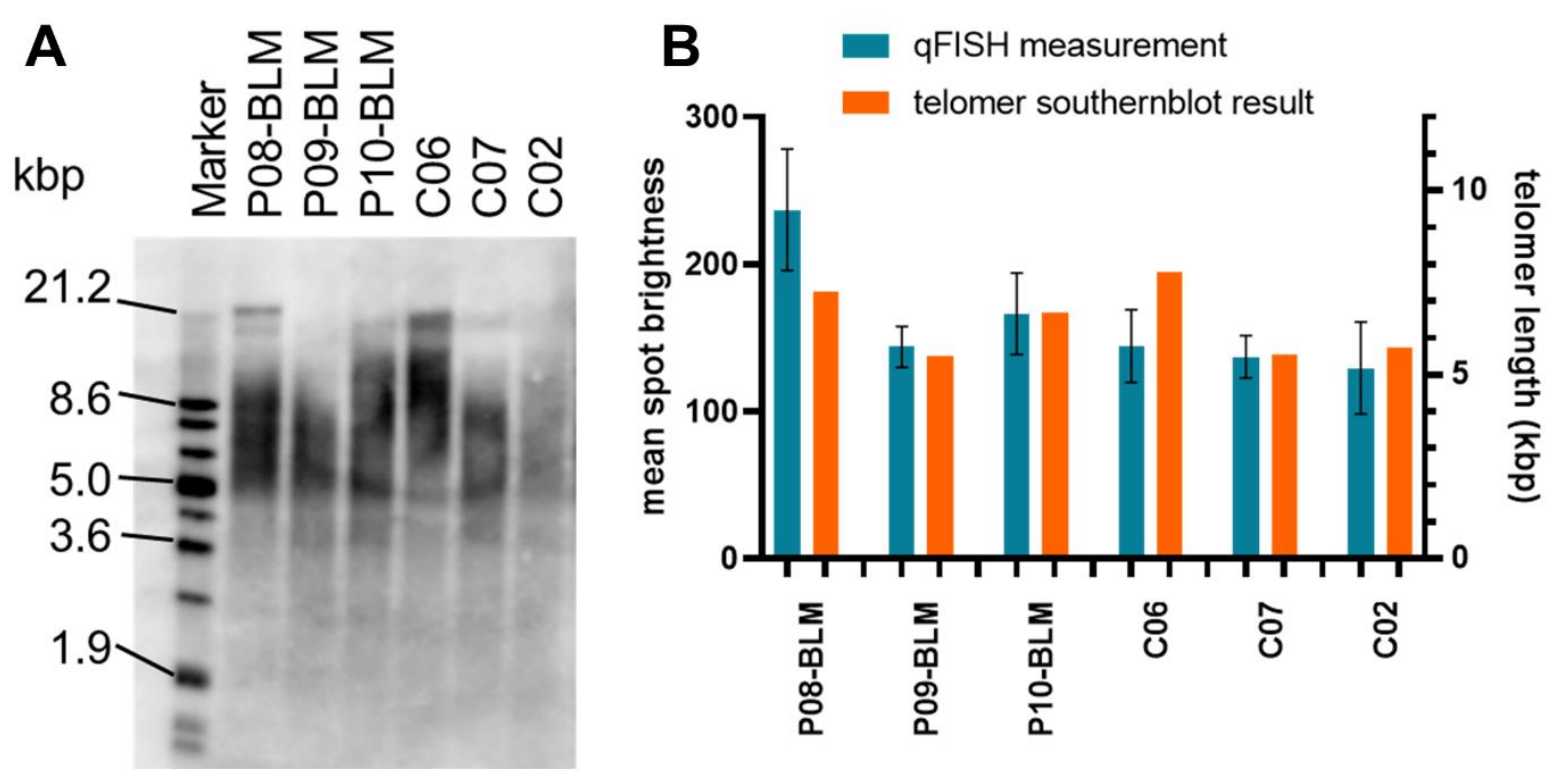

Figure 23: Comparison of the telomere length measurement results from qFISH and Southern blot

A: Telomere Southern blot of the six fibroblasts analyzed with the qFISH method. B: The mean telomere spot brightness determined by the qFISH measurement is compared to the mean telomere length calculated from the telomere Southern blot. The difference between the samples is low. A deviant result can be observed in two samples: P08-BLM and C06. The higher telomere length of P08-BLM could not be confirmed. 


\subsubsection{Karyotype Analysis of P08-BLM}

To investigate whether a chromosomal aberration could have caused the higher number of telomere signals, a karyotype analysis was performed for all six fibroblast samples in the Department of Cytogenetics of the Institute of Human Genetics, University Medical Center Göttingen. Indeed a chromosomal aberration could be detected in P08-BLM fibroblasts. The karyogram is shown in Figure 24. As the quality of the staining was not optimal, the chromosomal aberration was named using the distinguishable groups of chromosomes A-G after (162). Surprisingly as many chromosomes were lost as were gained, and thus the number of telomeres remained constant at 92 . Therefore, the chromosomal aberration alone could not be the direct cause of a higher number of telomere signals.
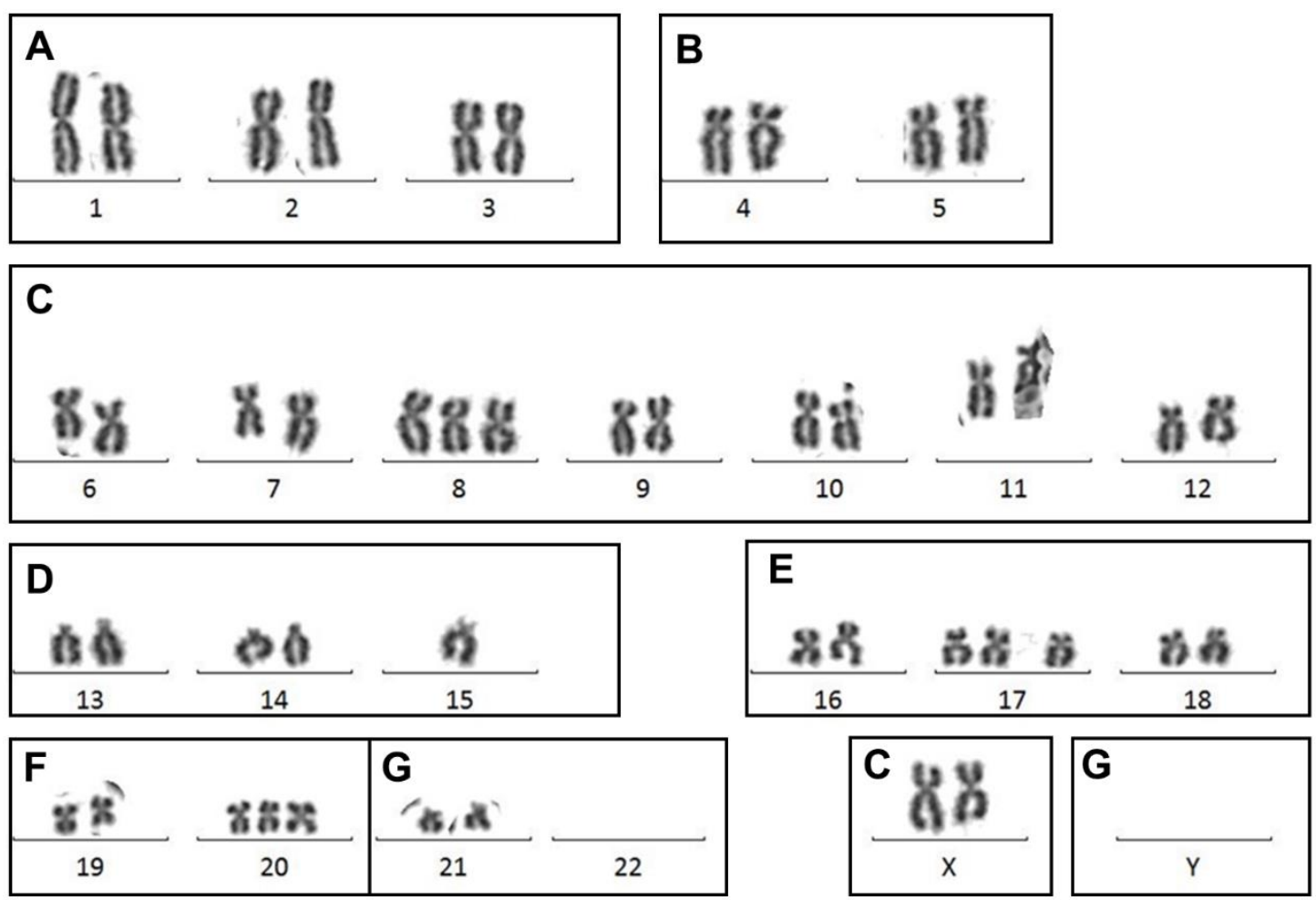

Figure 24: Karyogram of P08-BLM fibroblasts

The karyotype analysis revealed the chromosomal aberration 46+C+E+F-D-G-G in P08-BLM fibroblasts. The distinguishable groups of chromosomes A-G are indicated by the boxes around the chromosomes. 


\subsubsection{Cell Cycle Analysis by Flow Cytometry shows a Different Cell Cycle Progression of P08-BLM cells}

As the chromosome aberration could not directly cause a higher number of telomere signals, we decided to analyze cell cycle progression as another possible reason for the increased number of telomere signals.

Fibroblasts were seeded at the same cell density and harvested after four days. After ethanol fixation, the cells were stained with propidium iodide, a dye that stains nucleic acid and can thus be used to determine the DNA content of cells. Then the cell phase could be determined by DNA content.

The flow cytometry measurement was done by Sabrina Becker in the Core Facility Cell-Sorting of the University Medical Center Göttingen. The cell cycle profiles obtained by the flow cytometry are depicted in Figure 25 as well as the quantitative analysis of the cell cycle measurement. A significantly higher relative amount of P08-BLM cells was in the G2/M phase compared to four control cells, whereas the relative amount of cells in the G2/M phase in P09BLM and P10-BLM fibroblasts was not significantly different from the control cells (Figure 25C). 
A
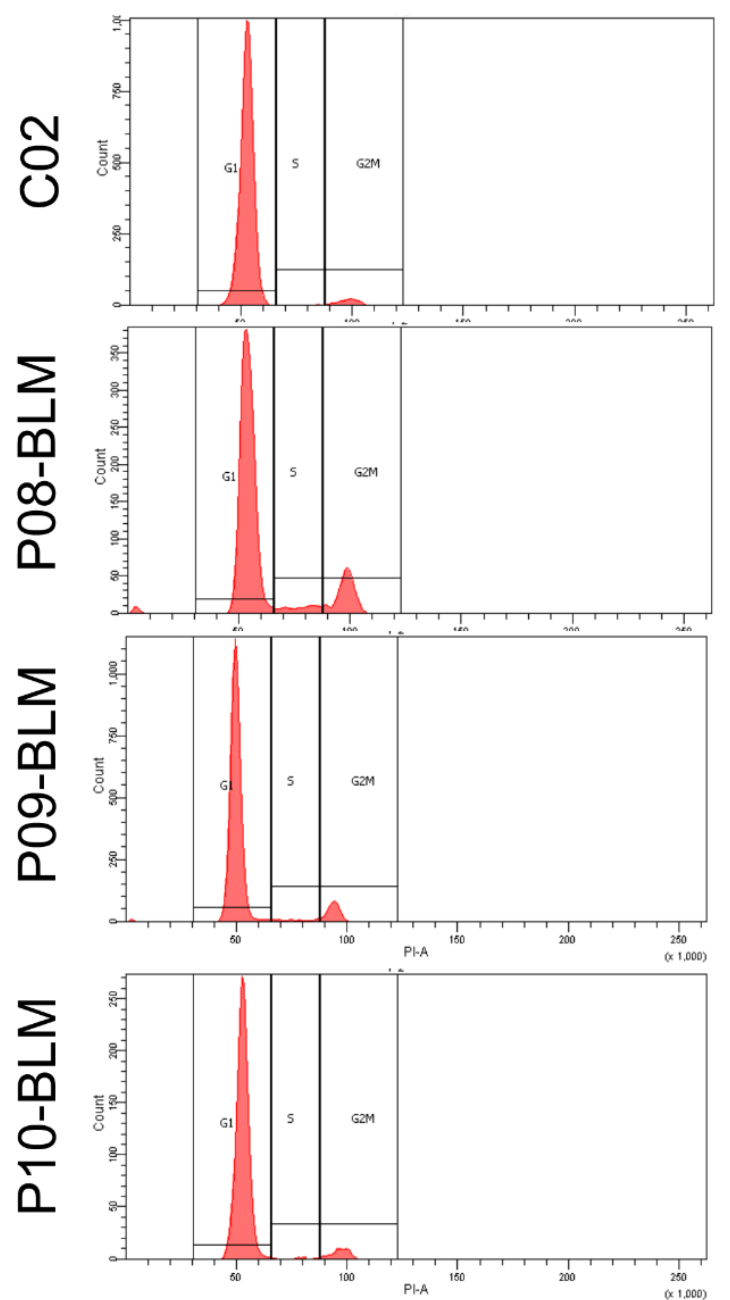

B
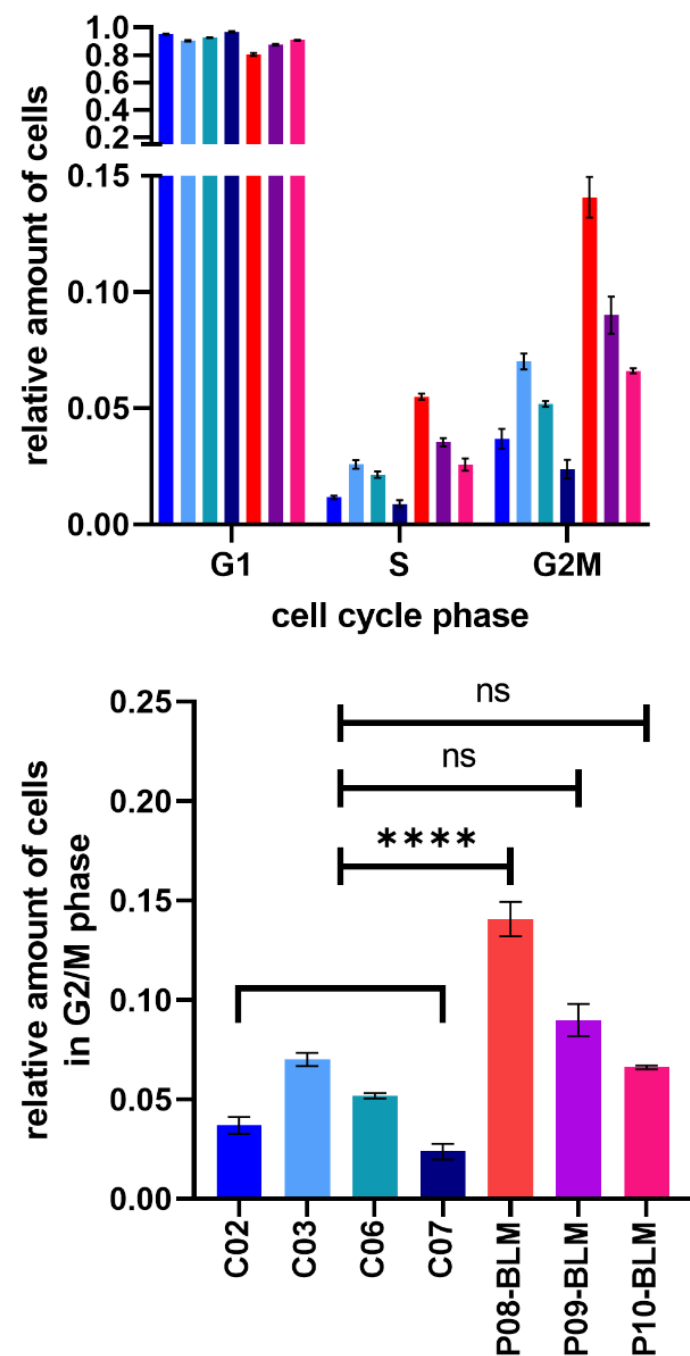

Figure 25: Cell cycle analysis by flow cytometry

A: Cell cycle analysis by flow cytometry was performed. Depicted are the cell cycle profiles of the fibroblast samples C01, P08-BLM, P09-BLM, and P10-BLM. B: The relative amount of cells in the phases $G 1, S$, and $G 2 / M$ are plotted for each of the analyzed fibroblasts. The data of three technical replicates are shown as mean and standard deviation. C: The relative amount of cells in the G2/M phase is plotted for four control and three patient samples, P08-BLM, P09-BLM, and P10-BLM. A one-way ANOVA analysis concluded that the increase of the relative amount of cells in P08-BLM was significantly different to the four control cells with a $p$-value of $p=<0.0001$, while the difference of the samples P09-BLM and P10-BLM was not significant. 
While around $15 \%$ of the cells analyzed in the cell cycle experiment were in the G2/M phase (Figure 25C), in around 50\% of the nuclei the number of telomere signals was above 92 (Figure 22B). This fact might point to the conclusion that the increased number of telomere signals was due to the higher number of cells in the G2/M phase as well as the preferential imaging of nuclei in the G2/M phase. The increased signal intensity might have been caused by signal clustering in these cells.

In summary, telomere attrition in the three Bloom syndrome patient-derived fibroblasts samples could not be detected. However, the inclusion of samples with a chromosomal aberration and a different cell cycle progression led to the conclusion that it is highly important to do a chromosomal analysis before using cell lines to make sure that the measurements are comparable. Also, the addition of a marker for cells in the G1 phase would help to exclude cells in the $\mathrm{G} 2 / \mathrm{M}$ phase from the analysis.

\subsection{Assessment of Genome Instability}

The genome maintenance theory of aging suggests DNA damage and the resulting genome instability to be one of the causes and drivers of aging. Therefore, we decided to measure DNA damage in the fibroblast progeria cohort.

\subsubsection{Measurement of DNA Damage and DNA Repair by yH2AX Assay}

To assess DNA damage, single aspects such as the amount of DNA double-strand breaks can be quantified by staining for markers of DNA damage. The histone H2AX represents such an early marker of DNA damage. As a reaction to a DNA double-strand break, H2AX is phosphorylated at the position serine 139 at sites of DNA damage, thus measurement of the amount of Ser 139 polphorylated $\mathrm{H} 2 \mathrm{AX}$ (also named $\mathrm{\gamma H} 2 \mathrm{AX}$ ) can be used to measure and quantify DNA damage and DNA damage repair processes in cells.

\subsubsection{Establishment of the $\mathrm{YH} 2 \mathrm{AX}$ Assay in Fibroblasts}

The $\mathrm{yH} 2 \mathrm{AX}$ assay was established in our lab to quantify DNA damage and DNA repair in fibroblasts. Fibroblasts were seeded into a 24-well plate containing coverslips. After 24 hours genotoxic treatments were applied to the cells. Cells were fixed at different time points to 
quantify DNA damage repair. The cells were simultaneously stained using a primary antibody against the phosphorylated form of $\mathrm{H} 2 \mathrm{AX}$, and DAPI was used to stain DNA. For each condition and repeated measurement, 15 images were taken randomly with a confocal microscope with 100x magnification. The images were analyzed using the software Focinator, which counts foci with a size and intensity above a certain threshold in the area determined by the DNA staining. At least 50 nuclei were analyzed per condition and repeated measurement.

The effects of treatments with different concentrations of etoposide, UV, and irradiation were tested on control cells, and the cells were fixed at different time points $(2,8,24$, and 48 hours) after treatments and subsequently analyzed to determine the optimal condition for analysis (data not shown). Finally, we decided to use the irradiation treatment and analyzed cells at the time points 24 and 48 hours after treatment in the fibroblast patient cohort.

\subsubsection{Measurement of DNA damage and DNA repair by $\mathrm{yH} 2 \mathrm{AX}$ Assay in the Fibroblast Patient Cohort}

Quantification $\mathrm{\gamma H} 2 \mathrm{AX}$ foci revealed increased DNA damage in untreated cells in P05-GORAB and P06-SLC25A24 (Figure 27A). The quantification of $\mathrm{yH} 2 \mathrm{AX}$ foci after 24 hours showed how different the speed of DNA repair was even in the control cells (Figure 27B). There was no significant difference between patient and control fibroblasts observed after 24 hours. After 48 hours, the level of $\mathrm{\gamma H} 2 \mathrm{AX}$ foci had not dropped to the level of untreated samples. The patient samples P01-PYCR1 and P05-GORAB displayed a significantly higher number of $\mathrm{YH} 2 \mathrm{AX}$ foci compared to the nine control fibroblast samples 48 hours after treatment, indicating delayed DNA damage repair. In Figure 26, representative images of two control fibroblast samples and the three patient fibroblast samples that show a significant increase in $\mathrm{PH} 2 \mathrm{AX}$ foci are displayed. The result of the quantitative analysis of $\mathrm{yH} 2 \mathrm{AX}$ foci is depicted in Figure 27. The statistical analysis of the increase in $\mathrm{YH} 2 \mathrm{AX}$ foci was done by one-way ANOVA analysis. Additionally, a pair-wise comparison between the control fibroblast sample and the patient fibroblast sample was performed using an unpaired t-test. Table 46 in the appendix lists the $p$-values for each of these comparisons. In the pairwise comparison, the t-test also finds a significant increase in foci, but for P05-GOBAB, one comparison is not significant, and for P06SLC25A24, three pairwise comparisons with control fibroblasts are not significant. Due to time restrictions, no other markers or treatments were analyzed. 
Results

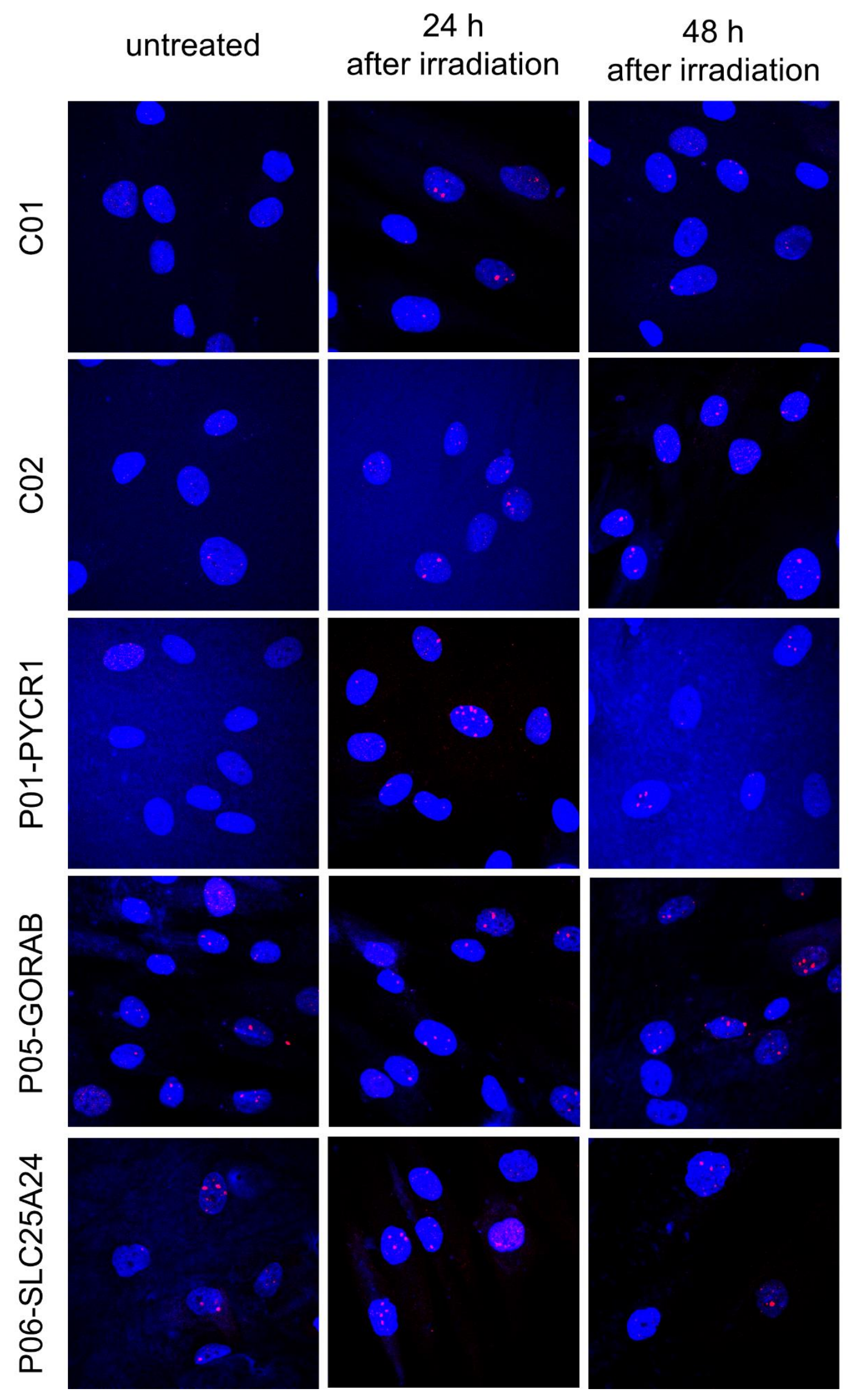

Figure 26: Representative images of $\mathrm{\gamma H} 2 \mathrm{AX}$ - and DAPI-stained fibroblasts at the time points 24 and 48 hours after irradiation 
A untreated
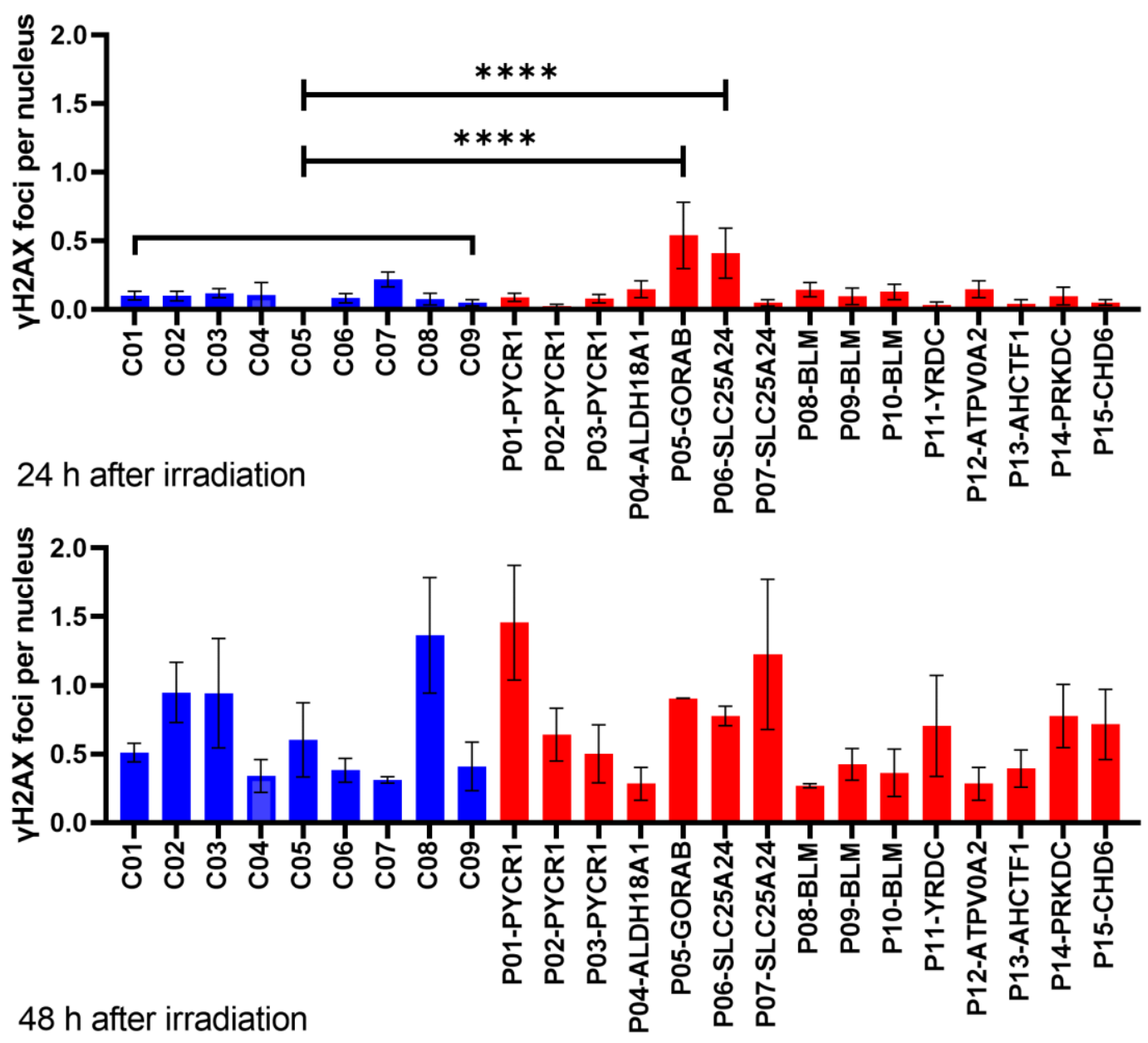

C $48 \mathrm{~h}$ after irradiation

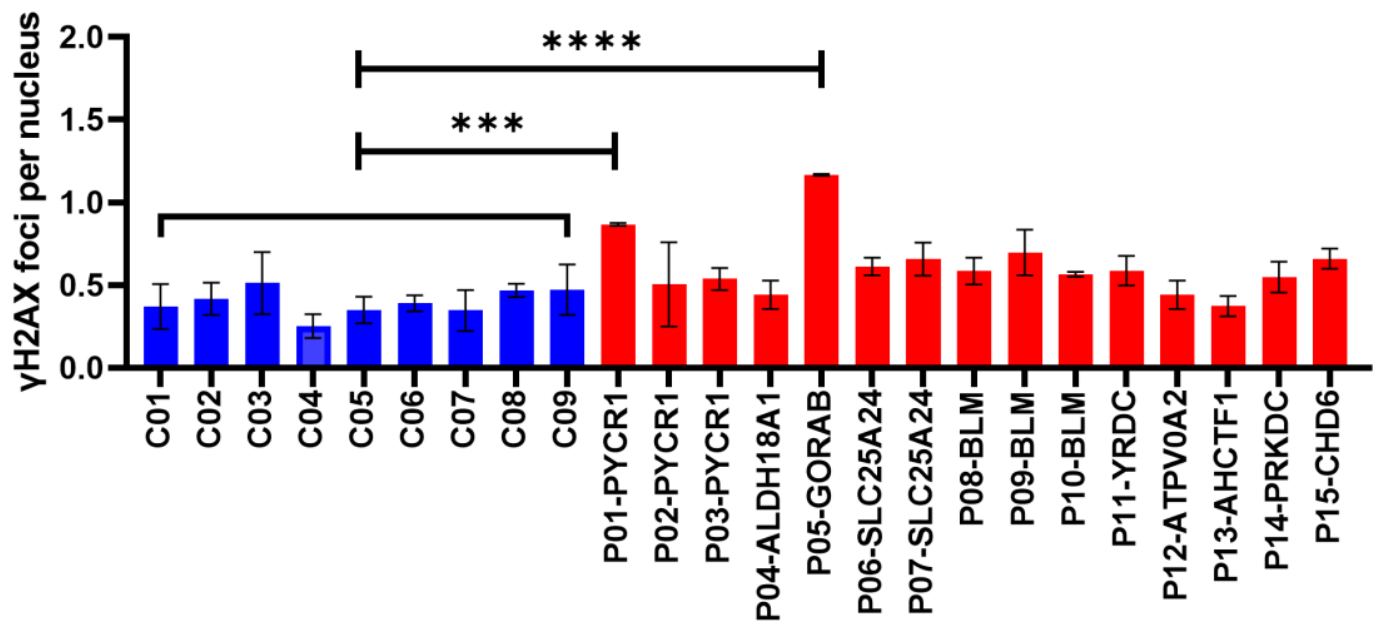

Figure 27: Analysis of DNA damage repair in patient and control fibroblasts by $\mathrm{yH}_{2} \mathrm{AX}$ assay 
Figure 26: Representative images of $\mathrm{YH} 2 \mathrm{AX}$ - and DAPI-stained fibroblasts

For the fibroblast samples, C01, C02, P01-PYCR1, P05-GORAB, and P06-SLC25A24, representative images of the conditions untreated, 24 hours after irradiation and 48 hours after irradiation are displayed.

Figure 27: Analysis of DNA damage repair in patient and control fibroblasts

YH2AX foci were counted in untreated fibroblasts and after 24 and 48 hours after irradiation. The data represent the mean and standard deviation of three independent experiments. Significance was calculated using the one-way ANOVA analysis. The result of the pairwise comparison by t-test is detailed in the appendix in Table 46. A: In untreated fibroblasts, P05GORAB and P06-SLC25A24 display a significantly higher number of $\mathrm{YH} 2 \mathrm{AX}$ foci per nucleus with $p=<0.0001$ and $p=<0.0001$, respectively. B: After 24 hours, the variance of control samples is high, and no patient sample is significantly different. C: In fibroblasts 48 hours after treatment, P01-PYCR 1 and P05-GORAB display a significantly higher number of $Y$ H2AX foci per nucleus with $p=0.0001$ and $p=<0.0001$, respectively. 


\section{Discussion}

The aims of this study were [1] to gather samples of patients suffering from segmental progeroid syndromes, [2] to establish assays for the analysis of genome instability, telomere attrition, and mitochondrial dysfunction; and [3] to perform these assays on the patient and control samples in order to gain insights into the molecular and cellular mechanisms underlying accelerated aging processes.

\subsection{Assessment of Mitochondrial Dysfunction}

Mitochondrial dysfunction is a known and important mechanism in aging processes. Mitochondrial dysfunction was assessed from two angles: the amount of low-frequency mutations in mtDNA was quantified using the newly developed ultra-high coverage mtDNA sequencing method. Additionally, mitochondrial dysfunction was assessed in five patient fibroblast samples by oxygen consumption rate measurement.

\subsubsection{Ultra-High Coverage MtDNA Sequencing of Blood and Fibroblast Samples of Progeria Patients Cohort}

Mitochondria have the unique feature that they possess their own circular DNA and contain multiple copies (37). Human mtDNA is $16.6 \mathrm{~kb}$ long and encodes thirteen respiratory complex subunits, two ribosomal RNAs and twenty-two transfer RNAs (163). The reasons for retaining a portion of their own genome are thought to be the high GC content of the genes, hydrophobicity of the proteins, and the ability to modulate mitochondria individually (164). During the long coevolution of mtDNA and nDNA, most genes necessary for mitochondrial function have been integrated into the nDNA. The majority of the proteins necessary for mitochondrial function are encoded in the nucleus. The integration of mtDNA into the nuclear genome also resulted in nuclear-encoded mitochondrial fragments (NUMTs), which are pseudogenes and do not encode proteins that are transported to the mitochondria. Today these NUMTs impede mtDNA sequencing as they are homologous to mtDNA and are thus challenging to discern from the mtDNA contained in the mitochondria (165). 
In contrast to nDNA, mtDNA can be present in hundreds to thousands of copies per cell. Thus mutated mtDNA can coexist with wild-type mtDNA in a condition called heteroplasmy. A measurable respiratory chain dysfunction might be caused when a pathogenic mutation reaches 70-90\% heteroplasmy. This phenomenon is called the "threshold effect" (166). It is widely accepted that the mutation rate of mtDNA is two to six-fold higher than in nuclear DNA (167). This has been attributed to the endogenous DNA repair mechanisms of mitochondria, the higher exposure to ROS, the lack of protection by histones, and finally, the higher error rate of the DNA polymerase $\gamma$. Recent studies have questioned the role of ROS as the leading cause of mtDNA damage, and emerging data rather suggest that the high error rate of the DNA polymerase $\psi$ is the cause of most mtDNA mutations (168).

The majority of data linking mtDNA mutations and aging are correlative (169): MtDNA copy number declines in whole blood with age (170-172). By whole-genome sequencing, an accumulation of higher levels of mutant mtDNA was found in aged individuals, and these were associated with age-related blood markers (171). A five kb deletion, which is associated with mitochondrial disease, has been shown to accumulate in the heart, brain, and muscle of older individuals $(173,174)$. High levels of point mutations accumulate in the non-coding D-loop region of mtDNA with age in the brain, blood, skin, muscle, and heart (175-177). The closest link between aging and mtDNA damage is provided by the mutator mouse, which has a defect in the proofreading subunit of the mtDNA polymerase $\gamma$. These mice develop a progeroid phenotype by nine months of age and the lifespan is reduced. However, these mice harbor an order of magnitude more somatic point mutations than aged human tissues (178). Even though multiple segmental progeroid syndromes are caused by mutations in genes encoding mitochondrial proteins, an increased level of mtDNA mutations in human segmental progeroid syndrome has not been identified so far. Clearly, more basic research and further development of sequencing techniques are necessary to address the link between aging and mtDNA mutations.

By Sanger sequencing, the lowest heteroplasmy ratio detectable is approximately 15\%. In 2004 a microarray for mitochondrial mutation detection was developed (179). Only the development of NGS techniques allowed high-coverage mtDNA sequencing, and thus detection of low-frequency mutations is now possible (180). Prior to the sequencing step, there are three ways to enrich mtDNA: [1] Ultra-centrifugation in density gradients, [2] PCR-based enrichment, and [3] enrichment by target-specific probes (180). For the development of our mtDNA sequencing 
method, we decided to use the enrichment by target-specific probes as a high enrichment as well as a low error rate is possible with this strategy.

I developed a method to sequence the mtDNA with ultra-high coverage to quantify the level of mtDNA variants in our patient cohort. When extracting DNA from a cell, this already contains both nDNA and mtDNA. Only 200 ng pure DNA was necessary for target enrichment of mitochondrial DNA. By enzymatic digestion, DNA was fragmented to 200 to 400 base pairs. Molecular barcodes were then hybridized to the fragments before the first amplification step to ensure the detection of low-frequency variants. By creating a consensus sequence from reads with the same molecular barcode, low-frequency variants could be distinguished from PCR and sequencing errors. Library preparation is followed by sequencing with a theoretical coverage of $100,000 x$. Depending on the calculated sequencing data of the whole run, output coverage varied between every single run as much as by a magnitude of 10 . Alignment and variant calling was performed using the software Seqpilot and for data analysis, "count-if functions" in MS Excel were employed.

Only few studies have been published in recent years that utilized ultra-deep next-generation sequencing of the mitochondrial genome to detect low-frequency mitochondrial variants. The strategy for enrichment of mtDNA from total DNA depended in these studies on PCR amplification, which bears the danger of introducing PCR errors into the amplified mtDNA.This was counteracted in these studies by setting the detection limit for variants to $1 \%$ VAF with an average sequencing depth ranging from $3,000 x$ to $8,000 x$ (181-185). Also, in nDNA, the detection of low-frequency mutations is of interest. The PCR-free duplex consensus sequencing approach used in this study for mtDNA sequencing has recently been successfully applied high-coverage genome-wide sequencing for detection of low-fequency variants $(186,187)$.

Our newly developed mtDNA sequencing method for the detection of low-frequency mtDNA variants based on molecular barcodes and high-coverage sequencing was established using samples treated with genotoxins, and one sample of a patient with CODAS syndrome served as a disease control. To generate positive controls for the development of variant calling parameters and data analysis, genotoxic treatments that are known to cause mutations in the nDNA were analyzed. Etoposide targets the DNA topoisomerase II and causes DNA breaks (188). Hydroxyurea decreases the production of desoxyribonucleotides by inhibiting the enzyme ribonucleotide reductase and thereby stalling the replication fork and inducing DNA damage (189). $\mathrm{H}_{2} \mathrm{O}_{2}$ treatment induces mitochondrial dysfunction and can be used to exacerbate a mitochondrial 
phenotype $(46,190)$. UV light induces a variety of DNA lesions resulting mostly in point mutations (191). Whether or not these treatments affect the mtDNA was unclear as this has not been analyzed before. Interestingly, the treatment with $500 \mu \mathrm{M} \mathrm{H}_{2} \mathrm{O}_{2}$ showed an increase in the relative amount of low-frequency mtDNA variants with a VAF of $0.6-5 \%$. Based on this data set, data analysis and data representation were established. By excluding variants with a VAF below $0.1 \%$, the number of variants was independent of the consensus read depth. Thus read depth was sufficiently high to detect all variants with a VAF above $0.1 \%$.

No difference in the number of mitochondrial variants or in the distribution of mutation type could be detected in the disease control P26-LONP1. Especially the expected increased number of deletions was not detected. The gene LONP1 (OMIM: 605490) encodes the mitochondrial protein LON Peptidase 1. Mutations in the gene cause the autosomal-recessive CODAS syndrome (OMIM: 600373). CODAS is an acronym and stands for cerebral, ocular, dental, auricular, and skeletal anomalies. Typical symptoms are developmental delay, craniofacial anomalies, hearing loss, and short stature (192). Depletion of LONP1 in human skin fibroblasts causes impairment of the expression of mtDNA and a defect in ribosome biogenesis. Further, LONP1 could be shown to be necessary for cleavage of the mitochondrial targeting sequences of the protein SSBP1, MTERFD2, FASTKD2, and CKPX. In LONP1-depleted cells, these four proteins accumulated in the insoluble fraction. By electron microscopy, the accumulation of protein aggregates in the mitochondrial matrix could be shown in LONP1-depleted cells (159). A reduced amount of mtDNA content and an increase in large deletions were observed in patient fibroblasts previously (Wollnik et al., unpublished). As the DNA was fragmented to 150 base pair fragments for target enrichment, large deletions can most probably not be detected by using this data analysis strategy.

Further, I employed the mtDNA sequencing method to sequence DNA samples from fibroblast patient and control samples as well as patient DNA samples from blood and control samples. The control samples of fibroblasts and blood samples showed a significantly higher variance and a significantly higher number of mtDNA variants. A possible explanation for this observation is the long cultivation time of the fibroblasts after skin biopsy. Months of cultivation in an artificial atmosphere under the influence of antibiotics and antimycotics could cause the occurrence and amplification of mutations in the mtDNA. Passage-dependent accumulation of somatic mutations in nDNA has recently been shown in mesenchymal stomal cells by whole-genome sequencing (193). Thus the increase in mtDNA variants by repeated passaging is comprehensible. 
A significant increase in the number of variants in sample P21-LTBP4 was detected. LTBP4 (OMIM: 604710) encodes the Latent-transforming Growth factor beta-binding protein 4. Mutations in the gene cause the autosomal-recessive Cutis laxa type IC (OMIM: 613177). The syndrome is characterized by cutis laxa, early-onset pulmonary emphysema, peripheral pulmonary artery stenosis, and symptoms of a generalized connective disorder as inguinal hernias and hollow visceral bladder. Other symptoms are congenital heart disease, intestinal malrotation, and ectopic kidneys (194).

In patient fibroblasts of three patients with LTBP4 mutations, decreased transcript levels indicated the nonsense-mediated decay of the mutated transcripts due to premature termination codons (195). As patient P21-LTBP4 harbors a homozygous frameshift mutation likely this disease mechanism also applies to this patient. By electron microscopy, anomalies in elastic fibers in the extracellular matrix were detected. An increased level of secreted TGF-beta could be detected using co-culture of the fibroblasts with reporter cells (195). Later it was shown that despite the elevated level of extracellular TGF-beta, downstream signaling molecules of the TGF-beta pathway were downregulated in patient fibroblasts. Additionally, the TGF-beta receptors 1 and 2 (TGFBR1 and TGFBR2) were decreased at the protein level but not at the mRNA level (126). Treatment with a TGFBR1 kinase inhibitor, an endocytosis inhibitor, or a lysosome inhibitor normalized the levels of TGFBR1 and TGFBR2. Co-immunoprecipitation proved the direct interaction between LTBP4 and TGFBR2 (126).

The mouse model with an LTBP4 deficiency shows many symptoms associated with Cutis laxa type IC: pulmonary emphysema, cardiomyopathy, and colorectal cancer (196). In this disease model, the intracellularly reduced TGF-beta signaling could also be normalized by TGFBR1 kinase inhibitor treatment. These results indicate that LTBP4 interacts with TGFBR2 and stabilizes TGFBR1 and TGFBR2 by preventing their endocytosis and lysosomal degradation (126). As lung development was not impaired in a mouse model expressing LTBP4 that is unable to bind TGF-beta1, the authors of the study concluded that the role of LTBP4 in elastogenesis and TGF-beta regulation might be independent of each other $(196,197)$.

Loss of LTBP4 causes increased extracellular TGF-beta signaling and a decreased intracellular signaling. Recently a link between TGF-beta signaling and mitochondrial biogenesis has been found in human lung fibroblasts in the context of asthma research (198) and during stem cell differentiation (199). During the differentiation of human embryonic stem cells (hESCS) to 
definitive endoderm (DE), fragmented and punctate mitochondria fuse into an extensive and branched network. Mitochondrial mass and mtDNA content increase with the upregulation of the mitochondrial biogenesis regulator PGC-1 during differentiation, and large amounts of TGF-b1 protein are secreted. When TGF-beta signaling was blocked by the inhibitor repsox in differentiated cells, mitochondrial mass and mtDNA copy number decreased (199). The findings in human airway wall fibroblasts were similar: TGF-beta treatment increased the protein argenine methyltransferase-1 (PRMT1) expression through the SMAD2/3 pathway and subsequently upregulated the expression of the mitochondria regulators PGC-1 and heat shock protein 60 . The inhibition of the SMAD2/3 pathway or PRMT1 reduces mitochondrial mass (198). These findings suggest that mitochondrial mass can be regulated by TGF-beta signaling acting on the expression of the mitochondrial regulator PGC-1.

Even though the extracellular matrix protein LTBP4 has no direct connection to mitochondria, a significant increase in the number of variants in the mitochondrial DNA could be detected. Mitochondrial dysfunction has not been described in patients harboring mutations in LTBP4, but it is possible that due to the extracellular location of the protein, cellular dysfunction was not assessed systematically, and a mitochondrial phenotype might have been overlooked. To establish this link of LTBP4 deficiency to reduced intracellular TGF-beta signaling, mitochondrial mass, and increased number of mtDNA mutations, additional blood samples or patient-derived fibroblasts are necessary.

In summary, the advantage of the mtDNA sequencing method presented is the detection of lowfrequency variants up to $0.1 \%$ VAF. Disadvantages and possibilities for improvement are the highly variable read depth impeding quantitative analysis, lack of recognition of large deletions, and the lack of a classification of the pathogenicity of the detected variants due to the data analysis strategy used in this study.

\subsubsection{Measurement of Oxidative Consumption Rates to Assesses Mitochondrial Dysfunction}

Basal respiration, ATP production, maximal respiration, and non-mitochondrial respiration were measured in a specific set of fibroblasts using the Seahorse mitochondrial stress test. For the samples P01-PYCR1, P02-PYCR1, and P03-PYCR1, no difference to the control cells could be observed. Maximal respiration was significantly increased in P06-SLC25A24, but the patient 
sample P07-SLC25A24 carrying the identical mutation in the same gene did not show any difference from the age-matched control samples.

PYCR1 encodes the Pyrroline-5-carboxylate reductase, a mitochondrial enzyme that catalyzes the final step of proline biosynthesis in mitochondria. Numerous different homozygous and compound heterozygous mutations have been identified in this gene. In two patient-derived fibroblast samples, a strongly reduced PYCR1 protein level was detected, pointing to the loss of function as a disease mechanism. Altered mitochondrial morphology, as well as reduced membrane potential, were found in patient-derived fibroblasts (45). Nevertheless, a difference in oxygen consumption rate could not be found in the three patient fibroblasts P01-PYCR1, P02-PYCR1, and P03-PYCR1.

SLC25A24 encodes the mitochondrial inner membrane ATP-Mg/ $\mathrm{P}_{\mathrm{i}}$ carrier ScaMC1, which consists of an N-terminal calcium-binding domain followed by six transmembrane helices and a short Cterminus (200). Patient P06-SLC25A24 and P07-SLC25A24 carry the identical missense mutation c.650G >A in SLC25A24, causing the amino acid substitution p.(Arg217His) on protein level. The mutation is located in the first transmembrane domain of the protein. Previous experiments on the dermal fibroblasts P06-SLC25A24 detected no changes in SLC25A24 gene expression, indicating the stability of the mutant transcript. Furthermore, no difference in protein level was detected by immunoblot analysis, indicating the stability of the protein. Under standard cell culture conditions, the fibroblasts showed mitochondrial swelling, which was exasperated by $\mathrm{H}_{2} \mathrm{O}_{2}$ treatment, and the mitochondrial membrane potential was intact in the patient-derived fibroblasts. However, ATP content in the mitochondrial matrix was lower than in the control cells. Upon $\mathrm{H}_{2} \mathrm{O}_{2}$ treatment, the membrane potential was significantly elevated in the patient cells. The authors of this study concluded that the heterozygous de novo mutation likely causes increased sensitivity to oxidative stress by a gain of function effect (46). A second publication describing four patients carrying the mutation c.650G >A or c.649G > T overexpressed the latter mutation with the aminoacid change p.(Arg217Cys) in Hela cells and found a decreased ATP-linked mitochondrial oxygen consumption rate after oligomycin treatment. As a molecular dynamic simulation predicts the mutations to cause the substrate cavity of the protein to narrow, the authors speculate that mutations disrupt transporter dynamics by causing a proton leak (47).

There are two major differences between the current study and the study by Writzl et al. (47): [1] The measurement of the oxygen consumption rate in this study was performed on patient-derived fibroblasts and not on Hela cells overexpressing the mutant protein. [2] P06-SLC25A24 and P07- 
SLC25A24 carry the mutation c.650G>A, causing the amino acid substitution p.(Arg217His) on protein level, and the overexpression experiment was performed using the $\mathrm{p}$.(Arg217Cys) mutant.

A slight decrease in ATP-linked mitochondrial oxygen consumption rate after oligomycin treatment was visible in P06-SLC25A24, but the change was not significant (Figure 16). As P06-SLC25A24 and P07-SLC25A24 harbor exactly the same de novo mutation, this difference is not comprehensible. It is expected that the same mutation causes the same effect on protein and cellular level. Of note: the fibroblast sample P06-SLC25A24 grew very slowly, and fibroblast morphology was noticeably different, while P07-SLC25A24 fibroblasts had a normal proliferation rate. It is possible that P06SLC25A24 acquired changes during cell culture that caused the increased spare respiratory capacity. As this increase in maximal respiration was not observed in the Hela cells overexpressing the similar mutation c.649G>T, the increase in maximal respiration is likely, not due to the mutation c.650G $>A$ in the SLC25A24 gene. Moreover, the overexpression of the mutant protein might have caused a higher relative amount of mutated transcript to wildtype transcript in the Hela cells compared to the heterozygous state in the patient fibroblasts. Thus even though the effect is detectable in the Hela cells overexpressing the mutant transcript, the effect must not necessarily be detectable in patient-derived fibroblasts.

\subsection{Telomere Length Measurement}

Telomere length has been proposed as a biomarker of biological age and reduced telomere length as a risk factor for aging-related diseases (201). Mean lymphocyte telomere length at birth is approximately eleven $\mathrm{kb}$ and declines to less than four $\mathrm{kb}$ with age. Telomere attrition follows a log-linear relationship with age with a higher rate of telomere loss during development (202). Telomeres shorten progressively with age in somatic cells due to the DNA end replication problem during cell division (203) and damage caused by oxidative stress (204). The individual telomere length at any age is dependent on three processes: [1] the initial telomere length of the zygote, [2] the amount of attrition experienced, [3] and the amount of elongation. These three processes are all influenced by both genetic and environmental factors (205). The environmental factors found to influence telomere length are sex (206), physical activity (207), smoking status (208), body mass index (209), alcohol consumption (210), paternal age (211), perceived stress levels (212), and nutrition (213). Consequently, reduced telomere length is linked to cardiovascular diseases (60) and Alzheimer's disease (214). By contrast, the relationship between telomere length 
and cancer is not so clear: Shorter as well as longer telomeres have been associated with increased cancer risk (215).

A number of segmental progeroid syndromes are caused by mutations in genes involved in telomere maintenance and DNA repair. Consequently, the following syndromes are characterized by accelerated telomere attrition (94): Dyskeratosis congenita (216), Werner syndrome (137), Fanconi anemia (217), Ataxia teleangiectasia (218), Nijmegen breakage syndrome (219), and Hutchinson-Gilford progeria syndrome (220).

The fact that telomeres are involved in many diseases underscores the need for methods to accurately measure telomere length and assess different aspects of telomere biology. Generally, these methods can be divided into methods based on isolated DNA and methods based on intact cells (221). The Southern blot technique was the first method developed and is still considered as the gold standard for telomere length measurement. The mean absolute telomere length is the result of a telomere Southern blot. The method is laborious, a high amount of DNA is needed ( $>1$ $\mu \mathrm{g})$, and only a few samples can be processed in parallel (222). The telomere real-time PCR requires amplification to the telomeric region and a single-copy gene. After each cycle, the amount of fluorescence emitted by a fluorophore that intercalates with double-stranded DNA is quantified, and the quantity of the starting material can be inferred. Relative telomere length is then quantified as the amount of telomere sequence compared to the amount of the single-copy gene and expressed as relative telomere length. The technique is fast, highly sensitive, only requires very low amounts of DNA ( $<10 \mathrm{ng})$, and is thus the method of choice for large studies. At the cellular level, telomere length can be evaluated by quantitive fluorescence in situ hybridization (qFISH) and by flow cytometry (flow-FISH). For both techniques, a telomeric PNA probe hybridizes to telomeres and is detected by the fluorescence emission $(223,224)$.

Recently two methods have been developed to measure other aspects of telomere biology. Single telomere length analysis (STELA) was designed to measure telomere length on individual chromosomes. The abundance of the shortest telomeres is measured using a combination of ligation, PCR-based methods, and Southern blot analysis (225). With the telomere shortest length assay (TeSLA), a more sensitive, accurate, and unbiased method to measure the length of all the telomeres, including the shortest telomeres, is possible. TeSLA requires a small amount of DNA and employs ligation and digestion strategy and the classical Southern blot analysis (226). 


\subsubsection{Telomere Length Measurement in Progeroid Syndrome Patients by Telomere Real-Time PCR}

A high-throughput telomere analysis method for blood mononuclear cells based on the qFISH method was published recently and included an imaging and data analysis workflow (227). To measure telomere length in a large number of DNA samples, real-time PCR is the method of choice today (228). However, a novel high-throughput approach to measuring telomere length in DNA samples based on the digital real-time PCR method was published recently (229).

Telomere length was measured by telomere real-time PCR in 110 blood control samples and 12 patient DNA samples extracted from blood. Blood control samples from individuals aged between 0 and 60 have been chosen from our pool of individuals that underwent exome sequencing for research purposes. Most of the samples of individuals between the ages of 0 and 20 stem from patients diagnosed with a genetic syndrome. Patients suffering from syndromes with a connection to DNA damage and accelerated aging were excluded. The samples from individuals between the ages of 20 and 60 stem from apparently healthy relatives of these patients. Rigorous quality control criteria were employed, and data analysis was done in cooperation with Dr. rer. nat. Andreas Leha, Department of Medical Statistics, University Medical Center Göttingen. The distribution of telomere length in the control samples showed the anticipated sigmoidal distribution and high variance of telomere length. From the telomere length of the control samples, a prediction of telomer length by age was made. None of the patient samples was located outside the predicted range of telomere length, and thus, none were significantly different. The reduction of telomere length in P23-PYCR1 and P24-BLM approached significance with $p=0.0729$ and $p=0.0599$, respectively.

Mutations in PYCR1 (OMIM: 179035) cause the autosomal recessive Cutis laxa type 2 (OMIM: 612940). PYCR1 encodes the Pyrroline-5-carboxylate reductase that localizes to mitochondria and catalyzes the final step of the de novo proline synthesis (45). Frequently reported symptoms are cutis laxa of variable severity, abnormal growth, developmental delay, and associated skeletal abnormalities (230). In addition, patient fibroblasts displayed an altered mitochondrial morphology, altered membrane potential, and an increased apoptosis rate upon oxidative stress (45). By mass spectrometry, the interaction of PYCR1, PYCR2, and RRM2B was identified. Silencing of PYCR1 and PYCR2 induces slowed proliferation, partial fragmentation of the mitochondrial network, and hypersensitivity to oxidative stress. The protective role of RRM2B for cells is 
abolished by silencing PYCR1 and PYCR2, indicating an anti-oxidative function of PYCR1 (231). The Pycr1-knock-out zebrafish displayed a progeria-like phenotype with a higher mortality rate, reduced locomotion activity, aggression, dysregulated color preference, dysregulated circadian rhythm, and reduced telomerase activity (232). The knockout mouse displayed milder symptoms than the patient with hypoplasia of the dermis, mild osteopenia, and disproportion of muscle fibers (233). Thus two mechanisms resulting in telomere attrition are possible: the reduced telomerase activity or increased oxidative damage could both lead to telomere attrition in PYCR1 deficient cells.

Mutations in BLM (OMIM: 604610) cause the autosomal-recessive Bloom syndrome (OMIM: 210900). Common symptoms of Bloom syndrome are prenatal and postnatal growth deficiency, photosensitive skin, immune deficiency, insulin resistance, an increased risk of early-onset cancer, as well as an increased risk for the development of multiple cancers (125). BLM encodes an ATPdependent DNA helicase located in the nucleus that unwinds single- and double-stranded DNA and participates in DNA replication and repair (234-236). Patient-derived cells are characterized by increased chromosomal aberrations, telomere associations, and quadriradial chromosomes, which result from unresolved recombination between homologous chromosomes and exhibit an increased mutation rate (237). Bloom syndrome has been studied in multiple model organisms: Caenorhabditis elegans, Drosophila melanogaster, Danio rerio, and Mus musculus. A homozygous loss of function mutation is embryonic lethal in mice. The heterozygous mice display an increased cancer incidence and genomic instability (125). The influence of BLM on telomere length has not been shown in Bloom syndrome patients. However, a connection to telomere length was published recently. The BLM protein is part of the BTR complex, which localizes to telomeres and suppresses alternative lengthening of telomeres (238).

Of the evaluated progeroid syndromes, only for patient P11-YRDC a reduced telomere length was observed previously in patient-derived fibroblasts. The measurement was done by the optimized qFISH measurement, and a significant difference was detected in comparison to two other fibroblast samples (Schmidt and Wollnik et al., unpublished). The mean relative telomere length measured in this study in P11-YRDC in DNA from blood was low, but the reduction of telomere length was not significantly different based on the comparison to the 110 control samples and the log-linear distribution telomere length and age. 
Telomere length can be affected by genetic and environmental factors, and it is known that the natural variance is high. It is possible that the loss of PYCR1 and BLM in human patients affects telomere dynamics but cannot be detected by measurement of mean telomere length. The selection of the control samples could also have influenced the result. As most of the control samples between the ages of 0 and 20 stem from patients suffering from genetic syndromes, it is possible that these diseases could have caused a slight reduction of telomere length in the control samples. Moreover, these telomere maintenance processes could function in a tissue-specific manner with different pathways being active in different tissues. The telomere length has been published to be tissue-specific and to reflect the replicative history of the tissue $(239,240)$. As the mean telomere length is the result of the telomere length in the zygote, telomere attrition, and telomere elongation, it is well possible that the telomere attrition has not resulted in a significant reduction in mean telomere length by the time of the measurement as telomere length has a high natural variability. As telomere dynamics cannot be measured in immortalized cells, knockout experiments in cell lines are not suitable to elucidate the effect of PYCR1 and BLM on telomere length.

In summary, the screening approach by telomere real-time PCR points to the involvement of the protein PYCR1 and BLM in telomere dynamics, and further experiments are necessary to elucidate the mechanism.

\subsubsection{Telomere Length Measurement of Fibroblasts of Bloom Syndrome Patients by Optimized QFISH Method}

In order to analyze telomere length in BLM in more detail, I collaborated on the optimization of the telomere qFISH method. Samples were prepared using standard qFISH sample preparation. Imaging was performed on a confocal and STED microscope. Using 3D confocal images and a fully automated macro within ImageJ, the signal intensity of approximately 70 telomere sports per nucleus could be quantified. STED images were used qualitatively to compare the telomere spot resolution in the confocal images to avoid signal clustering. This new technique has the advantage of a highly increased telomere recognition rate per nucleus compared to standard qFISH methods. Moreover, a mean telomere brightness result per nucleus and the telomere count per nucleus are possible (Niko Schwenzer, unpublished data). 
Telomere length was assessed in three fibroblast samples of Bloom syndrome patients and three age-matched control fibroblast samples using this optimized qFISH method. The telomere spot brightness and the number of telomere spots were significantly increased in the patient sample P06-BLM compared to the three age-matched control fibroblast samples, but not in the other two patient samples. A chromosomal aberration was found in the patient sample, and also a delayed cell cycle progression was detected by flow cytometry. As chromosomal aberrations and DNA damage have been shown to affect cell cycle progression, likely the two findings are connected (241). Possibly the double set of chromosomes also led to clustering of telomere spots and thus to the detection of a higher telomere spot brightness. By comparison to the telomere length measured by Southern blot, the higher telomere length was not confirmed.

Another explanation for the increased telomere intensity might be that BLM encodes a helicase that is involved in DNA repair. The missing helicase activity and a higher rate of DNA repair could cause a higher rate of decompaction of chromosomes. This could have caused a higher efficiency of PNA probe hybridization and thus a higher signal intensity. This hypothesis is contradicted by the fact that the three patient samples share a similar genotype and the loss of BLM helicase activity. Thus this phenomenon would have affected all three patient samples.

In summary, telomere attrition in the three fibroblast samples from Bloom syndrome patients could not be detected. Nevertheless, possible improvements for the method are evident: [1] The addition of a marker for cells in G1 phase would prevent a different cell cycle progression from affecting the measurement. [2] Depending on the cell type, a chromosome analysis before performing the telomere qFISH method would ensure the exclusion of cells with a chromosomal aberration.

\subsection{Assessment of DNA Damage and DNA Repair by pH2AX Assay}

Irradiation directly causes DNA DSBs but also causes the formation of ROS, which are indirectly involved in DNA damage. These ROS then cause abasic sites, single-strand breaks, and adducted bases $(242,243)$. DNA double-strand breaks trigger the phosphorylation of the histone $H 2 A X$ in the position Serin 139, which is then called $\gamma \mathrm{H} 2 \mathrm{AX}$. The proteins ATM, ATR, and DNA-PK, phosphorylate the histones $\mathrm{H} 2 \mathrm{AX}$ over kilobases around the DSB as one of the first steps of the DNA repair mechanism. $\mathrm{YH} 2 \mathrm{AX}$ itself recruits other DNA damage signaling factors and repair proteins such as MDC1, 53BP1, and the MRN complex. The cascade activated by the phosphorylation of $\mathrm{H} 2 \mathrm{AX}$ 
induces DNA repair by NHEJ and HR (see Figure 1). After the DNA is repaired, the phosphorylated histone H2AX is dephosphorylated $(24,244,245)$.

Quantification of DNA DSBs by $\mathrm{YH} 2 \mathrm{AX}$ foci detection is a routine method and revealed increased DNA damage in untreated cells in P05-GORAB and P06-SLC25A24 (Figure 27A). After 48 hours, the patient samples P01-PYCR1 and P05-GORAB displayed a significantly increased number of $\mathrm{YH} 2 \mathrm{AX}$ foci compared to the control fibroblast samples indicating delayed DNA damage repair.

A delayed DNA DSB repair has not been previously reported for patient-derived fibroblasts lacking PYCR1. PYCR1 and PYCR2 have been shown to interact with the RRM2B complex, which was initially identified to be induced by DNA damage and to supply dNTPs for DNA repair and DNA synthesis $(231,246,247)$. Thus the mechanism for the lack of PYCR1 to cause delayed DNA DSB repair through the interaction with RRM2B is comprehensible. Nevertheless, the question remains why this effect was not observed in the two other patient-derived fibroblasts as the pathomechanism in all three cases is the most likely loss of protein function. This result of the screening can only be the first clue, and additional DNA damage markers are needed to verify the initial result.

Mutations in GORAB (OMIM: 607983) cause the autosomal-recessive disease Geroderma osteodysplasticum (OMIM: 231070). GORAB encodes the RAB6-interacting golgin that localizes to the trans-side of the Golgi apparatus (152). The GORAB protein functions in intra-Golgi trafficking as a scaffolding protein for the coat protein complex I (COPI). COPI allows the precise sorting of lipids and proteins between Golgi cisternae and retrieval from the Golgi to the ER (248). The GORAB protein forms stable membrane domains that stabilize COPI assembly at the trans-Golgi. Loss of GORAB function reduces the recycling of trans-Golgi enzymes and causes the improper glycosylation of cargo proteins (249). Elevated TGF-beta signaling was identified in patient-derived fibroblasts and in a conditional knockout in a mouse model. The conditional knockout of GORAB in the mouse model caused an altered osteoblastogenesis, matrix abnormalities, an overactivated TGF- $\beta$ - Nox4 signaling, increased ROS levels, and an accumulation of DNA damages (250). Thus the increased DNA damage in untreated cells as well as the delayed DNA repair detected by $\mathrm{YH} 2 \mathrm{AX}$ staining and irradiation treatment confirmes the previous finding of increased DNA damage in the mouse model for Gerodermia osteodysplastica. 
An increased occurrence of DNA DSBs has not been previously reported for patient-derived fibroblasts harboring the pathogenic variants in SLC25A24 causing Fontaine progeroid syndrome. The gain-of-function mutation in the gene encoding mitochondrial carrier protein likely does not cause this DNA damage directly as the protein level is normal, and the mutant protein localizes to mitochondria. The authors of this study concluded that the heterozygous de novo mutation likely causes increased sensitivity to oxidative stress by a gain of function effect (46). It is possible that this increase in oxidative stress causes an increase in DNA damage. However, the increased DNA damage was only detected in P06-SLC25A24 and not in P07-SLC25A24. The increase in DNA damage possibly has the same cause as the mitochondrial phenotype, and the cellular mechanism is yet unknown.

Increased DNA damage was not detected in P14-PRKDC in this study. PRKDC encodes the protein DNA-dependent protein kinase catalytic subunit. Mutations in PRKDC (OMIM: 600899) have been described to cause Immunodeficiency 26, with or without neurologic abnormalities (OMIM: 615966) that are inherited autosomal recessively. Only two patients with homozygous or compound heterozygous mutations in the PRKDC gene have been reported so far.

The first patient was clinically diagnosed with immunodeficiency at five months of age due to recurrent infections. B and T cells were virtually absent from peripheral blood, but NK cells were normal. Bone marrow analysis showed a complete block in B-cell differentiation, suggesting a defect in $V(D) J$ recombination during immune development. Patient fibroblasts showed radiation sensitivity with a slow repair of DNA double-strand breaks. The patient showed no signs of microcephaly or mental retardation (251). In patient-derived fibroblasts after irradiation at a dose of $1 \mathrm{~Gy}$ and $\mathrm{\gamma H} 2 \mathrm{AX}$, a delayed DNA repair was detected. A dominant-negative effect of one of the two heterozygous mutations in PRKDC could be proven to cause the DNA repair defect. However, the mutated kinase was expressed and localized normally and still had autophosphorylation capacity (251). Thus the molecular dysfunction might be limited to the missense mutation found in this patient.

Five years later, a second patient with two compound heterozygous mutations in the PRKDC gene was reported. The immunodeficiency was characterized by absent circulating B and T cells and normal NK cells. The patient had intrauterine growth retardation and presented with suspected sepsis and persistent oral and perineal candidiasis at three weeks of age. He was microcephalic and had dysmorphic features. He showed little developmental progress, and he was found to have 
profound hearing loss and severe visual impairment. Defective DSB repair was shown by irradiation and $\mathrm{\gamma H} 2 \mathrm{AX}$ staining (252).

The PRKDC gene encodes the protein DNA-dependent protein kinase catalytic subunit. It is a Serine/threonine-protein kinase that acts as a molecular sensor for DNA damage. It is involved in DNA NHEJ required for DSB repair and V(D)J recombination $(253,254)$. Among many other targets, it phosphorylates Serine at the position 139 of histone variant $\mathrm{H} 2 \mathrm{AX}$, thereby regulating the DNA damage response mechanism (255).

Most likely, the heterozygous missense mutation in PRKDC of P14-PRKDC causes a completely different pathomechanism. Moreover, patient P14-PRKDC did not suffer from immunodeficiency as the two patients so far described but displayed a Bloom syndrome phenotype. This lack of immunodeficiency also points towards a different pathomechanism that does not involve a DNA DSB repair defect.

For patient-derived fibroblasts P11-YRDC, recently an increased susceptibility to the genotoxic agents etoposide, cisplatin, camptothecin, and hydroxyurea were shown. Additionally, a delayed DNA damage repair after treatments with etoposide, cisplatin, camptothecin, and hydroxyurea was observed by $\mathrm{\gamma H} 2 \mathrm{AX}$ staining, which was especially pronounced at 24 hours after treatment. The experimental setup in the study consisted of multiple genotoxic substances, multiple time points, multiple DNA damage markers, and an automated microscopy setup that made the measurement of 2,000 nuclei per condition and repeat possible. The only drawback was that the patient sample was compared to only one control sample (Schmidt and Wollnik et al., unpublished).

In this study, I did not observe the delayed DNA repair in P11-YRDC. There are major differences between the current study and the study by Schmidt and Wollnik et al.: [1] In this study, nine fibroblast samples were used as controls. The high variance of the level of $\gamma \mathrm{H} 2 \mathrm{AX}$ foci 24 hours after treatment may reflect the natural variance due to the different genetic backgrounds of individuals. [2] I used irradiation treatment in this study to cause DNA damage. The variance of the three repats was high even though 50 nuclei were imaged per condition. It is possible that the treatment of the fibroblasts was not even. [3] The microscope I used in this study did not have an autofocus, nor could images be taken automatically. Thus the number of images per condition and repeat was limited. More images would have decreased the standard deviation and would have 
made the detection of smaller differences possible. In summary, this study was limited to one DNA damage marker and one treatment as well as in the number of images analyzed due to the choice to use this microscope to analyzed 24 fibroblast samples. With a more elaborate setup, a more sensitive measurement would have been possible.

\subsection{Patient-Derived Fibroblasts and Blood Samples as In-Vitro Models of Segmental Progeroid Syndromes}

Fibroblasts are isolated from a $2 \mathrm{~mm}$ punch skin biopsy. As it does not benefit the patient, written consent and approval of the study by the ethics committee are necessary. The availability of skin biopsies from healthy children is highly restricted, and thus age-matched control samples are rare. The control fibroblasts used in this study were obtained from the Coriell Institute with many challenges during the import of live cells in an FCS-containing medium. As the skin is often affected in progeroid syndromes and some aspects of aging cannot be studied in immortalized cells, fibroblasts are an ideal in-vitro model system for the respective syndromes. Also, fibroblasts are relatively easy to cultivate as they are insensitive to environmental changes as temperature or cell culture medium. Their slow population doubling time of 35 to 70 hours is highly dependent on the fibroblast sample and low compared to cancer cell lines (256). Additionally, the possibility of treating the cells and following the reaction to the stimulus bears the potential to study the reaction to many physiological challenges. An example of this is the irradiation treatment to follow DNA DSB repair by the $\mathrm{\gamma H} 2 \mathrm{AX}$ assay. A drawback is the long cultivation time before performing the experiments. During this time, fibroblasts grow in an unnatural environment with fetal calf serum, antibiotics, antimycotics, and in the absence of an immune system, a clonal amplification of few fibroblast cells is possible. The sample P08-BLM, which acquired a chromosomal aberration during cell culture, and the difference between the fibroblast samples P06-SLC25A24 and P07-SLC25A24 are examples of this. Also, the high variation in the number of mtDNA variants in fibroblast samples in comparison to the low variation in the blood samples gives evidence to this problem. Thus fibroblasts are well suited for functional analysis, such as the expression of the mutated gene or the localization of the mutated protein. They are rather not well suited to screen for unspecific cellular phenotypes as the cultivation is labor-intensive, and the results are possibly influenced by changes that occurred during the long cultivation time or by the genetic background of the individual. 
A blood sample can be drawn quite easily. The delivery of a blood sample by mail is well established. The cultivation of lymphocytes for a few days is possible, but they cannot be stored and cultivated as fibroblasts. DNA extraction nowadays is a fully automated process, and DNA can be stored at $4^{\circ} \mathrm{C}$ almost indefinitely without degradation. The disadvantage that blood cells cannot be cultivated is outweighed by the fact that the DNA extracted from blood reflects the situation in the patient without bias. Blood is continually renewed and may thus reflect the status of many precursor cells. Another important advantage of DNA samples from blood is the availability of control samples. The result of the telomere real-time PCR underlines the importance of a high number of age-matched control samples in aging research as the measured parameters are highly variable. A clear disadvantage of the utilization of DNA samples is the missing possibility for treatment.

Patient samples reflect in part the in-vivo situation of the patient, but not every difference can be attributed to the mutation(s) the patient carries. These patient samples also reflect the different genetic backgrounds of each individual. Thus, especially when screening for unspecific cellular dysfunctions, as many controls as possible should be used, and the findings should be confirmed by a second and independent method. 


\subsection{Outlook}

The systematic analysis of segmental progeroid syndromes for various cellular processes could be extended by the inclusion of further patient samples and the analysis of further hallmarks of aging such as senescence or autophagy.

\subsubsection{Ultra-High Coverage MtDNA Sequencing}

I developed and established an NGS-based method to sequence the mtDNA with high coverage for the detection of low-frequency variants. The method should be further validated by analyzing a disease control, where an increased number of point mutations or small deletions has been detected. Comparing samples from the mutator mouse to heterozygous siblings would be possible only after designing a SureSelect custom capture library based on the mouse mitochondrial reference sample.

As data analysis was done by filtering the variant tables, the information is limited by the output of Seqpilot. It is apparent that the development of a bioinformatic pipeline for variant calling and to analyze the detected variants further would be advantageous. The integration of databases like the mtDNA-Server (257) or Mitomaster (258) would enable the classification of the pathogenicity of the variants.

Since DNA can be extracted from most biological samples, there is virtually no limitation of the samples subjected to mtDNA sequencing. Of particular interest are cancer biopsies and their comparison to a biopsy of healthy tissue to elucidate further how mitochondria are affected or influence the development of cancer. To study samples from mice or other animal models, only the design of the SureSelect custom capture library would have to be adapted to the respective mitochondrial reference genome.

A further improvement of sensitivity could be achieved by increasing the read depth even further, for example, by using the platform Nova Seq for sequencing the libraries. With higher read depth, variants with a VAF of below $0.1 \%$ could be detected and included in the quantitative analysis.

Treatment with genotoxic substances was used in this study to generate positive controls. This principle could be applied analogously to the $\mathrm{YH} 2 \mathrm{AX}$ assay to assess mtDNA repair or the resistance 
to the treatment. Via knockdown experiments, the role of mtDNA maintenance proteins in the mitochondria could also be investigated.

Of particular interest to aging research would be the analysis of samples from young and old individuals to confirm and further refine the finding that mtDNA mutations accumulate during aging. By analyzing the mutation type and position, the mechanisms causing the mutations could also be discerned.

By designing a SureSelect custom capture library or employing an existing gene panel e.g., for progeroid syndromes, low-frequency mutations in nuclear DNA could be examined. The result of DNA repair of nuclear DNA after irradiation treatment could be studied analogous to the $\mathrm{YH} 2 \mathrm{AX}$ assay. Also, DNA maintenance in a cell line harboring disease-causing mutations could be analyzed.

\subsubsection{Influence of LTBP4 on MtDNA Maintenance}

First of all, the influence of LTBP4 on mtDNA maintenance should be confirmed by sequencing the mtDNA of additional patient samples as biological replicates. In addition to that, the effect of LTBP4 knockdown in a cell line could be analyzed. The number of mtDNA variants could be measured over many passages to follow the accumulation of variants after the knockdown. In this system, also the pathomechanism could be discerned:

[1] Is the TGF-beta signaling intracellularly downregulated?

[2] Can the effect on mtDNA be rescued by treatment with TGF-beta?

[3] Could inhibition of TGF-beta without the knockdown of LTBP4 by treatment with the inhibitor repsox cause an accumulation of mtDNA mutations?

[4] Is the expression of mitochondrial biogenesis regulator PGC-1 decreased by knockdown of LTBP4 as it is by inhibiting TGF-beta? 


\subsubsection{Telomere Length Measurement by Optimized QFISH Method}

The optimized telomere qFISH method to measure telomere length was so far applied to Hela cell lines of different telomere lengths and fibroblast samples. With patient-derived fibroblasts, we found that cells should be imaged in G1 phase. Thus, introducing a cell cycle-specific marker would be useful. The telomere FISH could be combined with an antibody against the spliceosome component SC35, an established marker for nuclear speckles and a cell cycle phase indicator (259).

However, the potential of this method has not been exhausted. This technique could also be applied to tissues of non-dividing cells, as well as to mouse tissues. Furthermore, the potential of this method could be extended by staining for specific chromosomes and measuring telomere length chromosome-specifically. Thus, the telomere attrition could be analyzed in different ages, tissues, or cell passages chromosome-specifically.

Chromosome-specific telomere length measurement could also be achieved using a long-read sequencing approach. Recently a method was developed to tag and sequence telomeres in yeast with the Nanopore long-read sequencing. By long-read sequencing, the telomere, subtelomeric region, and part of the chromosome could be sequenced from one molecule allowing the chromosome-specific measurement of telomere length (260). Also, with PacBio long-read sequencing, a chromosome-specific telomere length measurement should be possible as the reads are 10 to $50 \mathrm{kbp}$ long (261).

\subsection{Conclusion}

This unique cohort of patients affected by multiple segmental progeroid syndromes bears the potential to unravel mechanisms of aging beyond the analysis of genotypes. By analyzing the hallmarks of aging genome instability, telomere attrition, and mitochondrial dysfunction, I could discover a novel link between LTBP4 and the accumulation of mtDNA variants as well as a possible influence of BLM and PYCR1 on telomere length. This study provided the basis for further studies to unravel the underlying pathomechanisms causing this dysfunction. The elucidation of the pathomechanisms causing accelerated aging has only begun and might also shed light on the basis of physiological aging processes. 


\section{References}

1. Aunan, J.R., Watson, M.M., Hagland, H.R. and Søreide, K. (2016) Molecular and biological hallmarks of ageing. The British journal of surgery, 103, e29-46.

2. Costantino, S., Paneni, F. and Cosentino, F. (2016) Ageing, metabolism and cardiovascular disease. The Journal of physiology, 594, 2061-2073.

3. Campisi, J. (2013) Aging, cellular senescence, and cancer. Annual review of physiology, 75, 685705.

4. Bloomgarden, Z. and Ning, G. (2013) Diabetes and aging. Journal of diabetes, 5, 369-371.

5. Juan, S.M.A. and Adlard, P.A. (2019) Ageing and Cognition. Sub-cellular biochemistry, 91, 107122.

6. Salomon, J.A., Wang, H., Freeman, M.K., Vos, T., Flaxman, A.D., Lopez, A.D. and Murray, C.J.L. (2012) Healthy life expectancy for 187 countries, 1990-2010: a systematic analysis for the Global Burden Disease Study 2010. Lancet (London, England), 380, 2144-2162.

7. United Nations Department of Economic and Social Affairs, Population Division (2019) World Population Ageing 2019.

8. Medvedev, Z.A. (1990) An attempt at a rational classification of theories of ageing. Biological reviews of the Cambridge Philosophical Society, 65, 375-398.

9. Kirkwood, T.B.L. (2005) Understanding the odd science of aging. Cell, 120, 437-447.

10. Goldsmith, T.C. (2016) Evolution of Aging Theories: Why Modern Programmed Aging Concepts Are Transforming Medical Research. Biochemistry. Biokhimiia, 81, 1406-1412.

11. Kirkwood, T.B.L. and Melov, S. (2011) On the programmed/non-programmed nature of ageing within the life history. Current biology : $C B, 21$, R701-7.

12. Röhme, D. (1981) Evidence for a relationship between longevity of mammalian species and life spans of normal fibroblasts in vitro and erythrocytes in vivo. Proceedings of the National Academy of Sciences of the United States of America, 78, 5009-5013.

13. Carruth, L.L., Jones, R.E. and Norris, D.O. (2002) Cortisol and Pacific Salmon: A New Look at the Role of Stress Hormones in Olfaction and Home-stream Migration. Integrative and comparative biology, 42, 574-581.

14. Skulachev, M.V. and Skulachev, V.P. (2018) Phenoptosis: Programmed Death of an Organism. In Radosevich, J.A. (ed.), Apoptosis and beyond. The many ways cells die. Wiley Blackwell, Hoboken, NJ, 77, pp. 237-288. 
15. Flatt, T. and Partridge, L. (2018) Horizons in the evolution of aging. BMC biology, 16, 93.

16. Walker, F.O. (2007) Huntington's disease. Lancet (London, England), 369, 218-228.

17. Rubinsztein, D.C., Amos, W., Leggo, J., Goodburn, S., Ramesar, R.S., Old, J., Bontrop, R., McMahon, R., Barton, D.E. and Ferguson-Smith, M.A. (1994) Mutational bias provides a model for the evolution of Huntington's disease and predicts a general increase in disease prevalence. Nature genetics, 7, 525-530.

18. Flatt, T. (2011) Survival costs of reproduction in Drosophila. Experimental gerontology, 46, 369375.

19. Kirkwood, T.B. and Holliday, R. (1979) The evolution of ageing and longevity. Proceedings of the Royal Society of London. Series B, Biological sciences, 205, 531-546.

20. Berry, R.J. and Bronson, F.H. (1992) Life history and bioeconomy of the house mouse. Biological reviews of the Cambridge Philosophical Society, 67, 519-550.

21. Austad, S.N. (1993) Retarded senescence in an insular population of Virginia opossums ( Didelphis virginiana ). Journal of Zoology, 229, 695-708.

22. Niedernhofer, L.J., Gurkar, A.U., Wang, Y., Vijg, J., Hoeijmakers, J.H.J. and Robbins, P.D. (2018) Nuclear Genomic Instability and Aging. Annual review of biochemistry, 87, 295-322.

23. Chatterjee, N. and Walker, G.C. (2017) Mechanisms of DNA damage, repair, and mutagenesis. Environmental and molecular mutagenesis, 58, 235-263.

24. Vermeij, W.P., Hoeijmakers, J.H.J. and Pothof, J. (2016) Genome Integrity in Aging: Human Syndromes, Mouse Models, and Therapeutic Options. Annual review of pharmacology and toxicology, 56, 427-445.

25. Vijg, J. (2014) Aging genomes: a necessary evil in the logic of life. BioEssays : news and reviews in molecular, cellular and developmental biology, 36, 282-292.

26. Maynard, S., Fang, E.F., Scheibye-Knudsen, M., Croteau, D.L. and Bohr, V.A. (2015) DNA Damage, DNA Repair, Aging, and Neurodegeneration. Cold Spring Harbor perspectives in medicine, 5 .

27. Burla, R., La Torre, M., Merigliano, C., Vernì, F. and Saggio, I. (2018) Genomic instability and DNA replication defects in progeroid syndromes. Nucleus (Austin, Tex.), 9, 368-379.

28. Black, J.O. (2016) Xeroderma Pigmentosum. Head and neck pathology. First published on March $14,2016,10.1007 / \mathrm{s} 12105-016-0707-8$.

29. Armstrong, G.T., Kawashima, T., Leisenring, W., Stratton, K., Stovall, M., Hudson, M.M., Sklar, C.A., Robison, L.L. and Oeffinger, K.C. (2014) Aging and risk of severe, disabling, life-threatening, 
and fatal events in the childhood cancer survivor study. Journal of clinical oncology : official journal of the American Society of Clinical Oncology, 32, 1218-1227.

30. Blokzijl, F., Ligt, J. de, Jager, M., Sasselli, V., Roerink, S., Sasaki, N., Huch, M., Boymans, S., Kuijk, E. and Prins, P. et al. (2016) Tissue-specific mutation accumulation in human adult stem cells during life. Nature, 538, 260-264.

31. Li, Z., Zhang, W., Chen, Y., Guo, W., Zhang, J., Tang, H., Xu, Z., Zhang, H., Tao, Y. and Wang, F. et al. (2016) Impaired DNA double-strand break repair contributes to the age-associated rise of genomic instability in humans. Cell death and differentiation, 23, 1765-1777.

32. Hyun, M., Lee, J., Lee, K., May, A., Bohr, V.A. and Ahn, B. (2008) Longevity and resistance to stress correlate with DNA repair capacity in Caenorhabditis elegans. Nucleic acids research, 36, 1380-1389.

33. Symphorien, S. and Woodruff, R.C. (2003) Effect of DNA repair on aging of transgenic Drosophila melanogaster: I. mei-41 locus. The journals of gerontology. Series A, Biological sciences and medical sciences, 58, B782-7.

34. HARMAN, D. (1956) Aging: a theory based on free radical and radiation chemistry. Journal of gerontology, 11, 298-300.

35. Simcox, E.M. and Reeve, A.K. (2016) An Introduction to Mitochondria, Their Structure and Functions. InReeve, A.K., Simcox, E.M., Duchen, M.R. and Turnbull, D.M. (eds.), Mitochondrial Dysfunction in Neurodegenerative Disorders. Springer International Publishing, Cham, s.l., pp. 3-30.

36. Fontana, G.A. and Gahlon, H.L. (2020) Mechanisms of replication and repair in mitochondrial DNA deletion formation. Nucleic acids research, 48, 11244-11258.

37. Castellani, C.A., Longchamps, R.J., Sun, J., Guallar, E. and Arking, D.E. (2020) Thinking outside the nucleus: Mitochondrial DNA copy number in health and disease. Mitochondrion. First published on June 13, 2020, 10.1016/j.mito.2020.06.004.

38. Rusecka, J., Kaliszewska, M., Bartnik, E. and Tońska, K. (2018) Nuclear genes involved in mitochondrial diseases caused by instability of mitochondrial DNA. Journal of applied genetics. First published on January 17, 2018, 10.1007/s13353-017-0424-3.

39. Gorman, G.S., Chinnery, P.F., DiMauro, S., Hirano, M., Koga, Y., McFarland, R., Suomalainen, A., Thorburn, D.R., Zeviani, M. and Turnbull, D.M. (2016) Mitochondrial diseases. Nature reviews. Disease primers. First published on October 20, 2016, 10.1038/nrdp.2016.80.

40. Turrens, J.F. (2003) Mitochondrial formation of reactive oxygen species. The Journal of physiology, 552, 335-344. 
41. Ozawa, T. (1997) Genetic and functional changes in mitochondria associated with aging. Physiological reviews, 77, 425-464.

42. Khrapko, K., Coller, H.A., André, P.C., Li, X.C., Hanekamp, J.S. and Thilly, W.G. (1997) Mitochondrial mutational spectra in human cells and tissues. Proceedings of the National Academy of Sciences of the United States of America, 94, 13798-13803.

43. Larsson, N.-G. (2010) Somatic mitochondrial DNA mutations in mammalian aging. Annual review of biochemistry, 79, 683-706.

44. Trifunovic, A., Wredenberg, A., Falkenberg, M., Spelbrink, J.N., Rovio, A.T., Bruder, C.E., Bohlooly-Y, M., Gidlöf, S., Oldfors, A. and Wibom, R. et al. (2004) Premature ageing in mice expressing defective mitochondrial DNA polymerase. Nature, 429, 417-423.

45. Reversade, B., Escande-Beillard, N., Dimopoulou, A., Fischer, B., Chng, S.C., Li, Y., Shboul, M., Tham, P.-Y., Kayserili, H. and Al-Gazali, L. et al. (2009) Mutations in PYCR1 cause cutis laxa with progeroid features. Nature genetics, 41, 1016-1021.

46. Ehmke, N., Graul-Neumann, L., Smorag, L., Koenig, R., Segebrecht, L., Magoulas, P., Scaglia, F., Kilic, E., Hennig, A.F. and Adolphs, N. et al. (2017) De Novo Mutations in SLC25A24 Cause a Craniosynostosis Syndrome with Hypertrichosis, Progeroid Appearance, and Mitochondrial Dysfunction. American journal of human genetics, 101, 833-843.

47. Writzl, K., Maver, A., Kovačič, L., Martinez-Valero, P., Contreras, L., Satrustegui, J., Castori, M., Faivre, L., Lapunzina, P. and van Kuilenburg, A.B.P. et al. (2017) De Novo Mutations in SLC25A24 Cause a Disorder Characterized by Early Aging, Bone Dysplasia, Characteristic Face, and Early Demise. American journal of human genetics, 101, 844-855.

48. Traba, J., Del Arco, A., Duchen, M.R., Szabadkai, G. and Satrústegui, J. (2012) SCaMC-1 promotes cancer cell survival by desensitizing mitochondrial permeability transition via ATP/ADPmediated matrix $\mathrm{Ca}(2+)$ buffering. Cell death and differentiation, 19, 650-660.

49. Knight, J.A. (2000) The biochemistry of aging. Advances in clinical chemistry, 35, 1-62.

50. Wei, Y.-H. and Lee, H.-C. (2002) Oxidative stress, mitochondrial DNA mutation, and impairment of antioxidant enzymes in aging. Experimental biology and medicine (Maywood, N.J.), 227, 671682.

51. Miranda-Vizuete, A. and Veal, E.A. (2017) Caenorhabditis elegans as a model for understanding ROS function in physiology and disease. Redox biology, 11, 708-714.

52. Stuart, J.A., Maddalena, L.A., Merilovich, M. and Robb, E.L. (2014) A midlife crisis for the mitochondrial free radical theory of aging. Longevity \& healthspan, 3, 4. 


\section{References}

53. Hayflick, L. and MOORHEAD, P.S. (1961) The serial cultivation of human diploid cell strains. Experimental cell research, 25, 585-621.

54. Olovnikov, A.M. (1996) Telomeres, telomerase, and aging: Origin of the theory. Experimental gerontology, 31, 443-448.

55. Maestroni, L., Matmati, S. and Coulon, S. (2017) Solving the Telomere Replication Problem. Genes, 8.

56. Collins, K. and Mitchell, J.R. (2002) Telomerase in the human organism. Oncogene, 21, 564-579.

57. Reaper, P.M., Di Fagagna, F.d. and Jackson, S.P. (2004) Activation of the DNA damage response by telomere attrition: a passage to cellular senescence. Cell cycle (Georgetown, Tex.). First published on May 08, 2004.

58. Benetos, A., Okuda, K., Lajemi, M., Kimura, M., Thomas, F., Skurnick, J., Labat, C., Bean, K. and Aviv, A. (2001) Telomere length as an indicator of biological aging: the gender effect and relation with pulse pressure and pulse wave velocity. Hypertension (Dallas, Tex. : 1979), 37, 381-385.

59. Heidinger, B.J., Blount, J.D., Boner, W., Griffiths, K., Metcalfe, N.B. and Monaghan, P. (2012) Telomere length in early life predicts lifespan. Proceedings of the National Academy of Sciences of the United States of America, 109, 1743-1748.

60. Zhan, Y. and Hägg, S. (2019) Telomere length and cardiovascular disease risk. Current opinion in cardiology.

61. Willeit, P., Willeit, J., Kloss-Brandstätter, A., Kronenberg, F. and Kiechl, S. (2011) Fifteen-year follow-up of association between telomere length and incident cancer and cancer mortality. JAMA, 306, 42-44.

62. Cai, Z., Yan, L.-J. and Ratka, A. (2013) Telomere shortening and Alzheimer's disease. Neuromolecular medicine, 15, 25-48.

63. Maeda, T., Guan, J.Z., Koyanagi, M., Higuchi, Y. and Makino, N. (2012) Aging-associated alteration of telomere length and subtelomeric status in female patients with Parkinson's disease. Journal of neurogenetics, 26, 245-251.

64. Muñoz-Lorente, M.A., Cano-Martin, A.C. and Blasco, M.A. (2019) Mice with hyper-long telomeres show less metabolic aging and longer lifespans. Nature communications, 10, 4723.

65. Armanios, M., Alder, J.K., Parry, E.M., Karim, B., Strong, M.A. and Greider, C.W. (2009) Short telomeres are sufficient to cause the degenerative defects associated with aging. American journal of human genetics, 85, 823-832. 


\section{References}

66. Hofer, A.C., Tran, R.T., Aziz, O.Z., Wright, W., Novelli, G., Shay, J. and Lewis, M. (2005) Shared phenotypes among segmental progeroid syndromes suggest underlying pathways of aging. The journals of gerontology. Series A, Biological sciences and medical sciences, 60, 10-20.

67. Calado, R.T. and Dumitriu, B. (2013) Telomere dynamics in mice and humans. Seminars in hematology, 50, 165-174.

68. Victorelli, S. and Passos, J.F. (2017) Telomeres and Cell Senescence - Size Matters Not. EBioMedicine. First published on March 21, 2017, 10.1016/j.ebiom.2017.03.027.

69. López-Otín, C., Blasco, M.A., Partridge, L., Serrano, M. and Kroemer, G. (2013) The hallmarks of aging. Cell, 153, 1194-1217.

70. Barbosa, M.C., Grosso, R.A. and Fader, C.M. (2018) Hallmarks of Aging: An Autophagic Perspective. Frontiers in Endocrinology. First published on January 09, 2019, 10.3389/fendo.2018.00790.

71. Palikaras, K., Lionaki, E. and Tavernarakis, N. (2015) Coordination of mitophagy and mitochondrial biogenesis during ageing in C. elegans. Nature. First published on April 20, 2015, $10.1038 /$ nature14300.

72. Rana, A., Oliveira, M.P., Khamoui, A.V., Aparicio, R., Rera, M., Rossiter, H.B. and Walker, D.W. (2017) Promoting Drp1-mediated mitochondrial fission in midlife prolongs healthy lifespan of Drosophila melanogaster. Nat Commun. First published on September 06, 2017, 10.1038/s41467-017-00525-4.

73. Drummond, M.J., Addison, O., Brunker, L., Hopkins, P.N., McClain, D.A., LaStayo, P.C. and Marcus, R.L. (2014) Downregulation of E3 ubiquitin ligases and mitophagy-related genes in skeletal muscle of physically inactive, frail older women: a cross-sectional comparison. The journals of gerontology. Series A, Biological sciences and medical sciences. First published on February 13, 2014, 10.1093/gerona/glu004.

74. Sun, N., Yun, J., Liu, J., Malide, D., Liu, C., Rovira, I.I., Holmström, K.M., Fergusson, M.M., Yoo, Y.H. and Combs, C.A. et al. (2015) Measuring In Vivo Mitophagy. Molecular cell. First published on November 05, 2015, 10.1016/j.molcel.2015.10.009.

75. Rubinsztein, D.C., Mariño, G. and Kroemer, G. (2011) Autophagy and aging. Cell, 146, 682-695.

76. Pyo, J.-O., Yoo, S.-M., Ahn, H.-H., Nah, J., Hong, S.-H., Kam, T.-I., Jung, S. and Jung, Y.-K. (2013) Overexpression of Atg5 in mice activates autophagy and extends lifespan. Nat Commun, 4, 2300. 


\section{References}

77. Vidacek, N.Š., Nanic, L., Ravlic, S., Sopta, M., Geric, M., Gajski, G., Garaj-Vrhovac, V. and Rubelj, I. (2017) Telomeres, Nutrition, and Longevity: Can We Really Navigate Our Aging? The journals of gerontology. Series A, Biological sciences and medical sciences, 73, 39-47.

78. Riley, J.C. (2005) Estimates of Regional and Global Life Expectancy, 1800-2001. Population \& Development Review, 31, 537-543.

79. Ferderal Statistical Office and Wiesbaden Germany's Population by 2050, Results of the 11th coordinated population projection.

80. van den Berg, N., Rodríguez-Girondo, M., van Dijk, I.K., Mourits, R.J., Mandemakers, K., Janssens, A.A.P.O., Beekman, M., Smith, K.R. and Slagboom, P.E. (2019) Longevity defined as top $10 \%$ survivors and beyond is transmitted as a quantitative genetic trait. Nature communications, 10, 35 .

81. vB Hjelmborg, J., lachine, I., Skytthe, A., Vaupel, J.W., McGue, M., Koskenvuo, M., Kaprio, J., Pedersen, N.L. and Christensen, K. (2006) Genetic influence on human lifespan and longevity. Human genetics, 119, 312-321.

82. Lagunas-Rangel, F.A. and Chávez-Valencia, V. (2017) Learning of nature: The curious case of the naked mole rat. Mechanisms of ageing and development, 164, 76-81.

83. Seim, I., Fang, X., Xiong, Z., Lobanov, A.V., Huang, Z., Ma, S., Feng, Y., Turanov, A.A., Zhu, Y. and Lenz, T.L. et al. (2013) Genome analysis reveals insights into physiology and longevity of the Brandt's bat Myotis brandtii. Nature communications, 4, 2212.

84. Reardon, S. (2015) Poo turns naked mole rats into better babysitters. Nature.

85. Melzer, D., Pilling, L.C. and Ferrucci, L. (2020) The genetics of human ageing. Nature reviews. Genetics, 21, 88-101.

86. Rincon, M., Muzumdar, R., Atzmon, G. and Barzilai, N. (2004) The paradox of the insulin/IGF-1 signaling pathway in longevity. Mechanisms of ageing and development, 125, 397-403.

87. Panowski, S.H. and Dillin, A. (2009) Signals of youth: endocrine regulation of aging in Caenorhabditis elegans. Trends in endocrinology and metabolism: TEM. First published on July 29, 2009, 10.1016/j.tem.2009.03.006.

88. Kapahi, P., Zid, B.M., Harper, T., Koslover, D., Sapin, V. and Benzer, S. (2004) Regulation of lifespan in Drosophila by modulation of genes in the TOR signaling pathway. Current biology: $C B, 14,885-890$.

89. Bartke, A. (2005) Minireview: role of the growth hormone/insulin-like growth factor system in mammalian aging. Endocrinology. First published on May 26, 2005, 10.1210/en.2005-0411. 
90. Fontana, L., Partridge, L. and Longo, V.D. (2010) Extending healthy life span--from yeast to humans. Science (New York, N.Y.), 328, 321-326.

91. Johnson, S.C. and Kaeberlein, M. (2016) Rapamycin in aging and disease: maximizing efficacy while minimizing side effects. Oncotarget, 7, 44876-44878.

92. Bozzini, S. and Falcone, C. (2017) Genetic Factors Associated with Longevity in Humans. InDorszewska, J. and Kozubski, W. (eds.), Senescence - Physiology or Pathology. InTech.

93. Martin, G.M. (2005) Genetic modulation of senescent phenotypes in Homo sapiens. Cell, 120, 523-532.

94. Carrero, D., Soria-Valles, C. and López-Otín, C. (2016) Hallmarks of progeroid syndromes: lessons from mice and reprogrammed cells. Disease models \& mechanisms, 9, 719-735.

95. Lessel, D. and Kubisch, C. (2019) Hereditary Syndromes with Signs of Premature Aging. Deutsches Arzteblatt international, 116, 489-496.

96. Erkrankungen | Institut für Humangenetik in Göttingen (2020). First published on Apr 24, 2020, https://www.humangenetik-umg.de/genetische-diagnostik/molekulargenetischediagnostik/erkrankungen/\#progerie.

97. Wollnik, B. and Kornak, U. (2012) Progeroide Erkrankungen und ihre Mechanismen. medgen, $24,253-256$.

98. Gonzalo, S., Kreienkamp, R. and Askjaer, P. (2017) Hutchinson-Gilford Progeria Syndrome: A premature aging disease caused by LMNA gene mutations. Ageing research reviews, 33, 18-29.

99. Cenni, V., D'Apice, M.R., Garagnani, P., Columbaro, M., Novelli, G., Franceschi, C. and Lattanzi, G. (2018) Mandibuloacral dysplasia: A premature ageing disease with aspects of physiological ageing. Ageing research reviews, 42, 1-13.

100. Cabanillas, R., Cadiñanos, J., Villameytide, J.A.F., Pérez, M., Longo, J., Richard, J.M., Alvarez, R., Durán, N.S., Illán, R. and González, D.J. et al. (2011) Néstor-Guillermo progeria syndrome: a novel premature aging condition with early onset and chronic development caused by BANF1 mutations. American journal of medical genetics. Part A, 155A, 2617-2625.

101. Paolacci, S., Bertola, D., Franco, J., Mohammed, S., Tartaglia, M., Wollnik, B. and Hennekam, R.C. (2017) Wiedemann-Rautenstrauch syndrome: A phenotype analysis. American journal of medical genetics. Part A, 173, 1763-1772.

102. Oshima, J., Sidorova, J.M. and Monnat, R.J. (2017) Werner syndrome: Clinical features, pathogenesis and potential therapeutic interventions. Ageing research reviews, 33, 105-114. 
103. Maskey, R.S., Flatten, K.S., Sieben, C.J., Peterson, K.L., Baker, D.J., Nam, H.-J., Kim, M.S., Smyrk, T.C., Kojima, Y. and Machida, Y. et al. (2017) Spartan deficiency causes accumulation of Topoisomerase 1 cleavage complexes and tumorigenesis. Nucleic acids research, 45, 45644576.

104. Karikkineth, A.C., Scheibye-Knudsen, M., Fivenson, E., Croteau, D.L. and Bohr, V.A. (2017) Cockayne syndrome: Clinical features, model systems and pathways. Ageing research reviews, 33, 3-17.

105. Mareddy, S., Reddy, J., Babu, S. and Balan, P. (2013) Xeroderma pigmentosum: man deprived of his right to light. TheScientificWorldJournal, 2013, 534752.

106. Arora, H., Chacon, A.H., Choudhary, S., McLeod, M.P., Meshkov, L., Nouri, K. and Izakovic, J. (2014) Bloom syndrome. International journal of dermatology, 53, 798-802.

107. Passarge, E., Robinson, P.N. and Graul-Neumann, L.M. (2016) Marfanoid-progeroidlipodystrophy syndrome: a newly recognized fibrillinopathy. European journal of human genetics : EJHG, 24, 1244-1247.

108. Avila, M., Dyment, D.A., Sagen, J.V., St-Onge, J., Moog, U., Chung, B.H.Y., Mo, S., Mansour, S., Albanese, A. and Garcia, S. et al. (2016) Clinical reappraisal of SHORT syndrome with PIK3R1 mutations: toward recommendation for molecular testing and management. Clinical genetics, $89,501-506$.

109. Masotti, A., Uva, P., Davis-Keppen, L., Basel-Vanagaite, L., Cohen, L., Pisaneschi, E., Celluzzi, A., Bencivenga, P., Fang, M. and Tian, M. et al. (2015) Keppen-Lubinsky syndrome is caused by mutations in the inwardly rectifying K+ channel encoded by KCNJ6. American journal of human genetics, 96, 295-300.

110. Johnston, J.J., Sanchez-Contreras, M.Y., Keppler-Noreuil, K.M., Sapp, J., Crenshaw, M., Finch, N.A., Cormier-Daire, V., Rademakers, R., Sybert, V.P. and Biesecker, L.G. (2015) A Point Mutation in PDGFRB Causes Autosomal-Dominant Penttinen Syndrome. American journal of human genetics, 97, 465-474.

111. Mohamed, M., Voet, M., Gardeitchik, T. and Morava, E. (2014) Cutis Laxa. Advances in experimental medicine and biology, 802, 161-184.

112. Whyte, M.P., Blythe, A., McAlister, W.H., Nenninger, A.R., Bijanki, V.N. and Mumm, S. (2015) Lenz-Majewski hyperostotic dwarfism with hyperphosphoserinuria from a novel mutation in PTDSS1 encoding phosphatidylserine synthase 1. Journal of bone and mineral research : the official journal of the American Society for Bone and Mineral Research, 30, 606614. 
113. Lu, L., Jin, W. and Wang, L.L. (2017) Aging in Rothmund-Thomson syndrome and related RECQL4 genetic disorders. Ageing research reviews, 33, 30-35.

114. Li, F., Li, W., Qiao, X. and Xie, X. (2019) Clinical features of dyskeratosis congenita in mainland China: case reports and literature review. International journal of hematology.

115. Rothblum-Oviatt, C., Wright, J., Lefton-Greif, M.A., McGrath-Morrow, S.A., Crawford, T.O. and Lederman, H.M. (2016) Ataxia telangiectasia: a review. Orphanet journal of rare diseases, $11,159$.

116. Morais, P., Magina, S., Ribeiro, M.d.C., Rodrigues, M., Lopes, J.M., Le Thanh, H.T., Wehnert, M. and Guimarães, H. (2009) Restrictive dermopathy--a lethal congenital laminopathy. Case report and review of the literature. European journal of pediatrics, 168, 1007-1012.

117. Fiesco-Roa, M.O., Giri, N., McReynolds, L.J., Best, A.F. and Alter, B.P. (2019) Genotypephenotype associations in Fanconi anemia: A literature review. Blood reviews, 37, 100589.

118. Lambert, W.C., Gagna, C.E. and Lambert, M.W. (2010) Trichothiodystrophy: Photosensitive, TTD-P, TTD, Tay syndrome. Advances in experimental medicine and biology, 685, 106-110.

119. Mori, T., Yousefzadeh, M.J., Faridounnia, M., Chong, J.X., Hisama, F.M., Hudgins, L., Mercado, G., Wade, E.A., Barghouthy, A.S. and Lee, L. et al. (2018) ERCC4 variants identified in a cohort of patients with segmental progeroid syndromes. Human mutation, 39, 255-265.

120. Chrzanowska, K.H., Gregorek, H., Dembowska-Bagińska, B., Kalina, M.A. and Digweed, M. (2012) Nijmegen breakage syndrome (NBS). Orphanet journal of rare diseases, 7, 13.

121. Akkurt, M.O., Pakay, K., Akkurt, I., Temur, M. and Korkmazer, E. (2019) Prenatal diagnosis of Seckel syndrome at 21 weeks' gestation and review of the literature. The journal of maternalfetal \& neonatal medicine : the official journal of the European Association of Perinatal Medicine, the Federation of Asia and Oceania Perinatal Societies, the International Society of Perinatal Obstetricians, 32, 1905-1908.

122. Ogi, T., Walker, S., Stiff, T., Hobson, E., Limsirichaikul, S., Carpenter, G., Prescott, K., Suri, M., Byrd, P.J. and Matsuse, M. et al. (2012) Identification of the first ATRIP-deficient patient and novel mutations in ATR define a clinical spectrum for ATR-ATRIP Seckel Syndrome. PLoS genetics. First published on November 08, 2012, 10.1371/journal.pgen.1002945.

123. Ahmed, M.S., Ikram, S., Bibi, N. and Mir, A. (2018) Hutchinson-Gilford Progeria Syndrome: A Premature Aging Disease. Molecular neurobiology. First published on June 28, 2017, 10.1007/s12035-017-0610-7. 
124. Muftuoglu, M., Oshima, J., Kobbe, C. von, Cheng, W.-H., Leistritz, D.F. and Bohr, V.A. (2008) The clinical characteristics of Werner syndrome: molecular and biochemical diagnosis. Human genetics. First published on September 23, 2008, 10.1007/s00439-008-0562-0.

125. Cunniff, C., Bassetti, J.A. and Ellis, N.A. (2017) Bloom's Syndrome: Clinical Spectrum, Molecular Pathogenesis, and Cancer Predisposition. Molecular syndromology, 8, 4-23.

126. Su, C.-T., Huang, J.-W., Chiang, C.-K., Lawrence, E.C., Levine, K.L., Dabovic, B., Jung, C., Davis, E.C., Madan-Khetarpal, S. and Urban, Z. (2015) Latent transforming growth factor binding protein 4 regulates transforming growth factor beta receptor stability. Human molecular genetics. First published on April 16, 2015, 10.1093/hmg/ddv139.

127. Schnabel, F., Kornak, U. and Wollnik, B. (2021) Premature aging disorders: A clinical and genetic compendium. Clinical genetics. First published on September 29, 2020, 10.1111/cge.13837.

128. Ullrich, N.J. and Gordon, L.B. (2015) Hutchinson-Gilford progeria syndrome. Handbook of clinical neurology, 132, 249-264.

129. Scaffidi, P. and Misteli, T. (2006) Lamin A-dependent nuclear defects in human aging. Science. First published on April 27, 2006, 10.1126/science.1127168.

130. Harhouri, K., Frankel, D., Bartoli, C., Roll, P., Sandre-Giovannoli, A. de and Lévy, N. (2018) An overview of treatment strategies for Hutchinson-Gilford Progeria syndrome. Nucleus (Austin, Tex.), 9, 246-257.

131. Koblan, L.W., Erdos, M.R., Wilson, C., Cabral, W.A., Levy, J.M., Xiong, Z.-M., Tavarez, U.L., Davison, L.M., Gete, Y.G. and Mao, X. et al. (2021) In vivo base editing rescues HutchinsonGilford progeria syndrome in mice. Nature. First published on January 06, 2021, 10.1038/s41586-020-03086-7.

132. Kulminski, A.M. and Culminskaya, I. (2013) Genomics of human health and aging. Age (Dordrecht, Netherlands). First published on December 16, 2011, 10.1007/s11357-011-9362-x.

133. Lautrup, S., Caponio, D., Cheung, H.-H., Piccoli, C., Stevnsner, T., Chan, W.-Y. and Fang, E.F. (2019) Studying Werner syndrome to elucidate mechanisms and therapeutics of human aging and age-related diseases. Biogerontology. First published on January 21, 2019, 10.1007/s10522019-09798-2.

134. Shamanna, R.A., Croteau, D.L., Lee, J.-H. and Bohr, V.A. (2017) Recent Advances in Understanding Werner Syndrome. F1000Research. First published on September 28, 2017, 10.12688/f1000research.12110.1. 
135. Shamanna, R.A., Lu, H., Freitas, J.K. de, Tian, J., Croteau, D.L. and Bohr, V.A. (2016) WRN regulates pathway choice between classical and alternative non-homologous end joining. Nat Commun. First published on December 06, 2016, 10.1038/ncomms13785.

136. Chang, S., Multani, A.S., Cabrera, N.G., Naylor, M.L., Laud, P., Lombard, D., Pathak, S., Guarente, L. and Depinho, R.A. (2004) Essential role of limiting telomeres in the pathogenesis of Werner syndrome. Nature genetics. First published on July 04, 2004, 10.1038/ng1389.

137. Ishikawa, N., Nakamura, K.-I., Izumiyama-Shimomura, N., Aida, J., Ishii, A., Goto, M., Ishikawa, Y., Asaka, R., Matsuura, M. and Hatamochi, A. et al. (2011) Accelerated in vivo epidermal telomere loss in Werner syndrome. Aging (Albany NY), 3, 417-429.

138. Maierhofer, A., Flunkert, J., Oshima, J., Martin, G.M., Haaf, T. and Horvath, S. (2017) Accelerated epigenetic aging in Werner syndrome. Aging, 9, 1143-1152.

139. Talaei, F., van Praag, V.M. and Henning, R.H. (2013) Hydrogen sulfide restores a normal morphological phenotype in Werner syndrome fibroblasts, attenuates oxidative damage and modulates mTOR pathway. Pharmacological research. First published on May 20, 2013, 10.1016/j.phrs.2013.04.011.

140. Li, B., Iglesias-Pedraz, J.M., Chen, L.-Y., Yin, F., Cadenas, E., Reddy, S. and Comai, L. (2014) Downregulation of the Werner syndrome protein induces a metabolic shift that compromises redox homeostasis and limits proliferation of cancer cells. Aging cell, 13, 367-378.

141. Das, A., Boldogh, I., Lee, J.W., Harrigan, J.A., Hegde, M.L., Piotrowski, J., Souza Pinto, N. de, Ramos, W., Greenberg, M.M. and Hazra, T.K. et al. (2007) The human Werner syndrome protein stimulates repair of oxidative DNA base damage by the DNA glycosylase NEIL1. The Journal of biological chemistry. First published on July 03, 2007, 10.1074/jbc.M703343200.

142. Goh, K.J., Chen, J.-H., Rocha, N. and Semple, R.K. (2020) Human pluripotent stem cell-based models suggest preadipocyte senescence as a possible cause of metabolic complications of Werner and Bloom Syndromes. Scientific reports. First published on May 04, 2020, 10.1038/s41598-020-64136-8.

143. Wu, Z., Zhang, W., Song, M., Wang, W., Wei, G., Li, W., Lei, J., Huang, Y., Sang, Y. and Chan, P. et al. (2018) Differential stem cell aging kinetics in Hutchinson-Gilford progeria syndrome and Werner syndrome. Protein \& cell. First published on February 23, 2018, 10.1007/s13238-0180517-8.

144. Goto, M., Hayata, K., Chiba, J., Matsuura, M., Iwaki-Egawa, S. and Watanabe, Y. (2015) Multiplex cytokine analysis of Werner syndrome. Intractable \& rare diseases research, 4, 190197. 
145. Saha, B., Cypro, A., Martin, G.M. and Oshima, J. (2014) Rapamycin decreases DNA damage accumulation and enhances cell growth of WRN-deficient human fibroblasts. Aging cell. First published on February 05, 2014, 10.1111/acel.12190.

146. Davis, T., Brook, A.J.C., Rokicki, M.J., Bagley, M.C. and Kipling, D. (2016) Evaluating the Role of p38 MAPK in the Accelerated Cell Senescence of Werner Syndrome Fibroblasts. Pharmaceuticals (Basel, Switzerland). First published on April 28, 2016, 10.3390/ph9020023.

147. Herbert, A.D., Carr, A.M. and Hoffmann, E. (2014) FindFoci: a focus detection algorithm with automated parameter training that closely matches human assignments, reduces human inconsistencies and increases speed of analysis. PloS one. First published on December 05, 2014, 10.1371/journal.pone.0114749.

148. Lincz, L.F., Scorgie, F.E., Garg, M.B., Gilbert, J. and Sakoff, J.A. (2020) A simplified method to calculate telomere length from Southern blot images of terminal restriction fragment lengths. BioTechniques. First published on December 11, 2019, 10.2144/btn-2019-0082.

149. Oeck, S., Malewicz, N.M., Hurst, S., Al-Refae, K., Krysztofiak, A. and Jendrossek, V. (2017) The Focinator v2-0 - Graphical Interface, Four Channels, Colocalization Analysis and Cell Phase Identification. Radiation research. First published on May 11, 2017, 10.1667/RR14746.1.

150. Guerra, D., Fornieri, C., Bacchelli, B., Lugli, L., Torelli, P., Balli, F. and Ferrari, P. (2004) The De Barsy syndrome. Journal of cutaneous pathology, 31, 616-624.

151. Fischer-Zirnsak, B., Escande-Beillard, N., Ganesh, J., Tan, Y.X., Al Bughaili, M., Lin, A.E., Sahai, I., Bahena, P., Reichert, S.L. and Loh, A. et al. (2015) Recurrent De Novo Mutations Affecting Residue Arg138 of Pyrroline-5-Carboxylate Synthase Cause a Progeroid Form of AutosomalDominant Cutis Laxa. American journal of human genetics, 97, 483-492.

152. Hennies, H.C., Kornak, U., Zhang, H., Egerer, J., Zhang, X., Seifert, W., Kühnisch, J., Budde, B., Nätebus, M. and Brancati, F. et al. (2008) Gerodermia osteodysplastica is caused by mutations in SCYL1BP1, a Rab-6 interacting golgin. Nature genetics, 40, 1410-1412.

153. Lisker, R., Hernández, A., Martínez-Lavin, M., Mutchinick, O., Armas, C., Reyes, P. and Robles-Gil, J. (1979) Gerodermia osteodysplastica hereditaria: report of three affected brothers and literature review. American journal of medical genetics, 3, 389-395.

154. Fischer, B., Dimopoulou, A., Egerer, J., Gardeitchik, T., Kidd, A., Jost, D., Kayserili, H., Alanay, Y., Tantcheva-Poor, I. and Mangold, E. et al. (2012) Further characterization of ATP6VOA2related autosomal recessive cutis laxa. Human genetics, 131, 1761-1773.

155. Kargapolova, Y., Rehimi, R., Kayserili, H., Brühl, J., Sofiadis, K., Zirkel, A., Palikyras, S., Mizi, A., Li, Y. and Yigit, G. et al. (2021) Overarching control of autophagy and DNA damage response 


\section{References}

by CHD6 revealed by modeling a rare human pathology. Nat Commun. First published on May $21,2021,10.1038 / s 41467-021-23327-1$.

156. Schmidt, J. and Wollnik, B. (2018) Hallermann-Streiff syndrome: A missing molecular link for a highly recognizable syndrome. American journal of medical genetics. Part $C$, Seminars in medical genetics, 178, 398-406.

157. Akawi, N., Ali, B. and Al Gazali, L. (2013) A progeroid syndrome with neonatal presentation and long survival maps to 19p13.3p13.2. Birth defects research. Part A, Clinical and molecular teratology. First published on May 20, 2013, 10.1002/bdra.23136.

158. Yamaguchi, I., Watanabe, T., Ohara, O. and Hasegawa, Y. (2019) PCR-free whole exome sequencing: Cost-effective and efficient in detecting rare mutations. PloS one. First published on September 13, 2019, 10.1371/journal.pone.0222562.

159. Zurita Rendón, O. and Shoubridge, E.A. (2018) LONP1 Is Required for Maturation of a Subset of Mitochondrial Proteins, and Its Loss Elicits an Integrated Stress Response. Molecular and cellular biology. First published on September 28, 2018, 10.1128/МСB.00412-17.

160. Li, Y., Chang, Y., Ye, N., Chen, Y., Zhang, N. and Sun, Y. (2017) Advanced glycation end products-induced mitochondrial energy metabolism dysfunction alters proliferation of human umbilical vein endothelial cells. Molecular medicine reports. First published on March 10, 2017, 10.3892/mmr.2017.6314.

161. Eurogentec PNA FISH Probes.

162. McGowan-Jordan, J. and Hastings, R.J. (2020) ISCN 2020: An International System for Human Cytogenomic Nomenclature (2020). Kager, Basel.

163. Nunnari, J. and Suomalainen, A. (2012) Mitochondria: in sickness and in health. Cell, 148, 1145-1159.

164. Johnston, I.G. and Williams, B.P. (2016) Evolutionary Inference across Eukaryotes Identifies Specific Pressures Favoring Mitochondrial Gene Retention. Cell systems. First published on February 18, 2016, 10.1016/j.cels.2016.01.013.

165. Santibanez-Koref, M., Griffin, H., Turnbull, D.M., Chinnery, P.F., Herbert, M. and Hudson, G. (2019) Assessing mitochondrial heteroplasmy using next generation sequencing: A note of caution. Mitochondrion. First published on August 09, 2018, 10.1016/j.mito.2018.08.003.

166. Rossignol, R., Faustin, B., Rocher, C., Malgat, M., Mazat, J.-P. and Letellier, T. (2003) Mitochondrial threshold effects. The Biochemical journal, 370, 751-762. 
References

167. Allio, R., Donega, S., Galtier, N. and Nabholz, B. (2017) Large Variation in the Ratio of Mitochondrial to Nuclear Mutation Rate across Animals: Implications for Genetic Diversity and the Use of Mitochondrial DNA as a Molecular Marker. Molecular biology and evolution, 34, 2762-2772.

168. Melvin, R.G. and Ballard, J.W.O. (2017) Cellular and population level processes influence the rate, accumulation and observed frequency of inherited and somatic mtDNA mutations. Mutagenesis, 32, 323-334.

169. Chocron, E.S., Munkácsy, E. and Pickering, A.M. (2019) Cause or casualty: The role of mitochondrial DNA in aging and age-associated disease. Biochimica et biophysica acta. Molecular basis of disease, 1865, 285-297.

170. Mengel-From, J., Thinggaard, M., Dalgård, C., Kyvik, K.O., Christensen, K. and Christiansen, L. (2014) Mitochondrial DNA copy number in peripheral blood cells declines with age and is associated with general health among elderly. Human genetics. First published on June 06, 2014, 10.1007/s00439-014-1458-9.

171. Zhang, R., Wang, Y., Ye, K., Picard, M. and Gu, Z. (2017) Independent impacts of aging on mitochondrial DNA quantity and quality in humans. BMC genomics, 18, 890.

172. Lee, J.-W., Park, K.D., Im, J.-A., Kim, M.Y. and Lee, D.-C. (2010) Mitochondrial DNA copy number in peripheral blood is associated with cognitive function in apparently healthy elderly women. Clinica chimica acta; international journal of clinical chemistry. First published on January 28, 2010, 10.1016/j.cca.2010.01.024.

173. Cortopassi, G.A. and Arnheim, N. (1990) Detection of a specific mitochondrial DNA deletion in tissues of older humans. Nucleic acids research, 18, 6927-6933.

174. Fayet, G., Jansson, M., Sternberg, D., Moslemi, A.-R., Blondy, P., Lombès, A., Fardeau, M. and Oldfors, A. (2002) Ageing muscle: clonal expansions of mitochondrial DNA point mutations and deletions cause focal impairment of mitochondrial function. Neuromuscular disorders : NMD, 12, 484-493.

175. Jazin, E.E., Cavelier, L., Eriksson, I., Oreland, L. and Gyllensten, U. (1996) Human brain contains high levels of heteroplasmy in the noncoding regions of mitochondrial DNA. Proceedings of the National Academy of Sciences of the United States of America, 93, 1238212387.

176. Michikawa, Y., Mazzucchelli, F., Bresolin, N., Scarlato, G. and Attardi, G. (1999) Agingdependent large accumulation of point mutations in the human mtDNA control region for replication. Science (New York, N.Y.), 286, 774-779. 
177. Nekhaeva, E., Bodyak, N.D., Kraytsberg, Y., McGrath, S.B., van Orsouw, N.J., Pluzhnikov, A., Wei, J.Y., Vijg, J. and Khrapko, K. (2002) Clonally expanded mtDNA point mutations are abundant in individual cells of human tissues. Proceedings of the National Academy of Sciences of the United States of America. First published on April 09, 2002, 10.1073/pnas.072670199.

178. Khrapko, K., Kraytsberg, Y., Grey, A.D.N.J. de, Vijg, J. and Schon, E.A. (2006) Does premature aging of the mtDNA mutator mouse prove that mtDNA mutations are involved in natural aging? Aging cell, 5, 279-282.

179. Maitra, A., Cohen, Y., Gillespie, S.E.D., Mambo, E., Fukushima, N., Hoque, M.O., Shah, N., Goggins, M., Califano, J. and Sidransky, D. et al. (2004) The Human MitoChip: a high-throughput sequencing microarray for mitochondrial mutation detection. Genome research, 14, 812-819.

180. Ye, F., Samuels, D.C., Clark, T. and Guo, Y. (2014) High-throughput sequencing in mitochondrial DNA research. Mitochondrion, 17, 157-163.

181. Kelly, P.S., Clarke, C., Costello, A., Monger, C., Meiller, J., Dhiman, H., Borth, N., Betenbaugh, M.J., Clynes, M. and Barron, N. (2017) Ultra-deep next generation mitochondrial genome sequencing reveals widespread heteroplasmy in Chinese hamster ovary cells. Metabolic engineering, 41, 11-22.

182. Kim, M.-Y., Cho, S., Lee, J.H., Seo, H.J. and Lee, S.D. (2018) Detection of Innate and Artificial Mitochondrial DNA Heteroplasmy by Massively Parallel Sequencing: Considerations for Analysis. Journal of Korean medical science, 33, e337.

183. Cavalcante, G.C., Marinho, A.N.R., Anaissi, A.K., Vinasco-Sandoval, T., Ribeiro-Dos-Santos, A., Vidal, A.F., Araújo, G.S. de, Demachki, S. and Ribeiro-Dos-Santos, Â. (2019) Whole mitochondrial genome sequencing highlights mitochondrial impact in gastric cancer. Scientific reports. First published on October 31, 2019, 10.1038/s41598-019-51951-x.

184. Yin, C., Li, D.Y., Guo, X., Cao, H.Y., Chen, Y.B., Zhou, F., Ge, N.J., Liu, Y., Guo, S.S. and Zhao, Z. et al. (2019) NGS-based profiling reveals a critical contributing role of somatic D-loop mtDNA mutations in HBV-related hepatocarcinogenesis. Annals of oncology : official journal of the European Society for Medical Oncology, 30, 953-962.

185. Zhou, K., Mo, Q., Guo, S., Liu, Y., Yin, C., Ji, X., Guo, X. and Xing, J. (2020) A Novel NextGeneration Sequencing-Based Approach for Concurrent Detection of Mitochondrial DNA Copy Number and Mutation. The Journal of molecular diagnostics : JMD. First published on October 01, 2020, 10.1016/j.jmoldx.2020.09.005.

186. You, X., Thiruppathi, S., Liu, W., Cao, Y., Naito, M., Furihata, C., Honma, M., Luan, Y. and Suzuki, T. (2019) Detection of genome-wide low-frequency mutations with Paired-End and 
References

Complementary Consensus Sequencing (PECC-Seq) revealed end-repair derived artifacts as residual errors.

187. Ahn, E.H. and Lee, S.H. (2019) Detection of Low-Frequency Mutations and Identification of Heat-Induced Artifactual Mutations Using Duplex Sequencing. International journal of molecular sciences. First published on January 08, 2019, 10.3390/ijms20010199.

188. Montecucco, A., Zanetta, F. and Biamonti, G. (2015) Molecular mechanisms of etoposide. EXCLI Journal. First published on January 19, 2015, 10.17179/excli2015-561.

189. Singh, A. and Xu, Y.-J. (2016) The Cell Killing Mechanisms of Hydroxyurea. Genes. First published on November 17, 2016, 10.3390/genes7110099.

190. Liu, L., Trimarchi, J.R. and Keefe, D.L. (2000) Involvement of mitochondria in oxidative stress-induced cell death in mouse zygotes. Biol Reprod, 62, 1745-1753.

191. Rastogi, R.P., Richa, Kumar, A., Tyagi, M.B. and Sinha, R.P. (2010) Molecular mechanisms of ultraviolet radiation-induced DNA damage and repair. Journal of nucleic acids. First published on December 16, 2010, 10.4061/2010/592980.

192. Strauss, K.A., Jinks, R.N., Puffenberger, E.G., Venkatesh, S., Singh, K., Cheng, I., Mikita, N., Thilagavathi, J., Lee, J. and Sarafianos, S. et al. (2015) CODAS syndrome is associated with mutations of LONP1, encoding mitochondrial AAA+ Lon protease. American journal of human genetics, 96, 121-135.

193. Kim, M., Rhee, J.-K., Choi, H., Kwon, A., Kim, J., Lee, G.D., Jekarl, D.W., Lee, S., Kim, Y. and Kim, T.-M. (2017) Passage-dependent accumulation of somatic mutations in mesenchymal stromal cells during in vitro culture revealed by whole genome sequencing. Sci Rep. First published on November 06, 2017, 10.1038/s41598-017-15155-5.

194. Urban, Z., Hucthagowder, V., Schürmann, N., Todorovic, V., Zilberberg, L., Choi, J., Sens, C., Brown, C.W., Clark, R.D. and Holland, K.E. et al. (2009) Mutations in LTBP4 cause a syndrome of impaired pulmonary, gastrointestinal, genitourinary, musculoskeletal, and dermal development. American journal of human genetics. First published on October 15, 2009, 10.1016/j.ajhg.2009.09.013.

195. Callewaert, B., Su, C.-T., van Damme, T., Vlummens, P., Malfait, F., Vanakker, O., Schulz, B., Mac Neal, M., Davis, E.C. and Lee, J.G.H. et al. (2013) Comprehensive clinical and molecular analysis of 12 families with type 1 recessive cutis laxa. Human mutation. First published on August 13, 2012, 10.1002/humu.22165.

196. Sterner-Kock, A., Thorey, I.S., Koli, K., Wempe, F., Otte, J., Bangsow, T., Kuhlmeier, K., Kirchner, T., Jin, S. and Keski-Oja, J. et al. (2002) Disruption of the gene encoding the latent 
transforming growth factor-beta binding protein 4 (LTBP-4) causes abnormal lung development, cardiomyopathy, and colorectal cancer. Genes \& development, 16, 2264-2273.

197. Dabovic, B., Robertson, I.B., Zilberberg, L., Vassallo, M., Davis, E.C. and Rifkin, D.B. (2015) Function of latent TGF $\beta$ binding protein 4 and fibulin 5 in elastogenesis and lung development. Journal of cellular physiology, 230, 226-236.

198. Sun, Q., Fang, L., Tang, X., Lu, S., Tamm, M., Stolz, D. and Roth, M. (2019) TGF- $\beta$ Upregulated Mitochondria Mass through the SMAD2/3 $\rightarrow C / E B P \beta \rightarrow P R M T 1$ Signal Pathway in Primary Human Lung Fibroblasts. The Journal of Immunology. First published on December 10, 2018, 10.4049/jimmunol.1800782.

199. Li, S., Huang, Q., Mao, J. and Li, Q. (2020) TGFB-dependent mitochondrial biogenesis is activated during definitive endoderm differentiation. In vitro cellular \& developmental biology. Animal. First published on June 08, 2020, 10.1007/s11626-020-00442-9.

200. Del Arco, A. and Satrústegui, J. (2004) Identification of a novel human subfamily of mitochondrial carriers with calcium-binding domains. The Journal of biological chemistry. First published on March 30, 2004, 10.1074/jbc.M401417200.

201. Vaiserman, A. and Krasnienkov, D. (2020) Telomere Length as a Marker of Biological Age: State-of-the-Art, Open Issues, and Future Perspectives. Frontiers in genetics. First published on January 21, 2021, 10.3389/fgene.2020.630186.

202. Aubert, G., Hills, M. and Lansdorp, P.M. (2012) Telomere length measurement-caveats and a critical assessment of the available technologies and tools. Mutation research, 730, 59-67.

203. Levy, M.Z., Allsopp, R.C., Futcher, A., Greider, C.W. and Harley, C.B. (1992) Telomere endreplication problem and cell aging. Journal of molecular biology, 225, 951-960.

204. Zglinicki, T. von (2002) Oxidative stress shortens telomeres. Trends in biochemical sciences, $27,339-344$.

205. Dugdale, H.L. and Richardson, D.S. (2018) Heritability of telomere variation: it is all about the environment! Philosophical Transactions of the Royal Society B: Biological Sciences, 373.

206. Dalgård, C., Benetos, A., Verhulst, S., Labat, C., Kark, J.D., Christensen, K., Kimura, M., Kyvik, K.O. and Aviv, A. (2015) Leukocyte telomere length dynamics in women and men: menopause vs age effects. International journal of epidemiology. First published on September 18, 2015, 10.1093/ije/dyv165.

207. Arsenis, N.C., You, T., Ogawa, E.F., Tinsley, G.M. and Zuo, L. (2017) Physical activity and telomere length: Impact of aging and potential mechanisms of action. Oncotarget, 8, 4500845019. 


\section{References}

208. Astuti, Y., Wardhana, A., Watkins, J. and Wulaningsih, W. (2017) Cigarette smoking and telomere length: A systematic review of 84 studies and meta-analysis. Environmental research. First published on July 10, 2017, 10.1016/j.envres.2017.06.038.

209. am Valdes, Andrew, T., Gardner, J.P., Kimura, M., Oelsner, E., Cherkas, L.F., Aviv, A. and Spector, T.D. (2005) Obesity, cigarette smoking, and telomere length in women. Lancet (London, England), 366, 662-664.

210. Dixit, S., Whooley, M.A., Vittinghoff, E., Roberts, J.D., Heckbert, S.R., Fitzpatrick, A.L., Lin, J., Leung, C., Mukamal, K.J. and Marcus, G.M. (2019) Alcohol consumption and leukocyte telomere length. Scientific reports. First published on February 05, 2019, 10.1038/s41598-019-38904-0.

211. Kimura, M., Cherkas, L.F., Kato, B.S., Demissie, S., Hjelmborg, J.B., Brimacombe, M., Cupples, A., Hunkin, J.L., Gardner, J.P. and Lu, X. et al. (2008) Offspring's leukocyte telomere length, paternal age, and telomere elongation in sperm. PLoS genetics, 4 , e37.

212. Epel, E.S., Blackburn, E.H., Lin, J., Dhabhar, F.S., Adler, N.E., Morrow, J.D. and Cawthon, R.M. (2004) Accelerated telomere shortening in response to life stress. Proceedings of the National Academy of Sciences of the United States of America. First published on December 01, 2004, 10.1073/pnas.0407162101.

213. Paul, L. (2011) Diet, nutrition and telomere length. The Journal of nutritional biochemistry. First published on March 22, 2011, 10.1016/j.jnutbio.2010.12.001.

214. Fani, L., Hilal, S., Sedaghat, S., Broer, L., Licher, S., Arp, P.P., van Meurs, J.B.J., Ikram, M.K. and Ikram, M.A. (2020) Telomere Length and the Risk of Alzheimer's Disease: The Rotterdam Study. Journal of Alzheimer's disease : JAD, 73, 707-714.

215. Aviv, A., Anderson, J.J. and Shay, J.W. (2017) Mutations, Cancer and the Telomere Length Paradox. Trends in cancer, 3, 253-258.

216. Alter, B.P., Rosenberg, P.S., Giri, N., Baerlocher, G.M., Lansdorp, P.M. and Savage, S.A. (2012) Telomere length is associated with disease severity and declines with age in dyskeratosis congenita. Haematologica, 97, 353-359.

217. Hanson, H., Mathew, C.G., Docherty, Z. and Mackie Ogilvie, C. (2001) Telomere shortening in Fanconi anaemia demonstrated by a direct FISH approach. Cytogenetics and cell genetics, 93, 203-206.

218. Renault, A.-L., Mebirouk, N., Cavaciuti, E., Le Gal, D., Lecarpentier, J., d'Enghien, C.D., Laugé, A., Dondon, M.-G., Labbé, M. and Lesca, G. et al. (2017) Telomere length, ATM mutation status and cancer risk in Ataxia-Telangiectasia families. Carcinogenesis, 38, 994-1003. 
219. Habib, R., Kim, R., Neitzel, H., Demuth, I., Chrzanowska, K., Seemanova, E., Faber, R., Digweed, M., Voss, R. and Jäger, K. et al. (2020) Telomere attrition and dysfunction: a potential trigger of the progeroid phenotype in nijmegen breakage syndrome. Aging. First published on June 20, 2020, 10.18632/aging.103453.

220. Decker, M.L., Chavez, E., Vulto, I. and Lansdorp, P.M. (2009) Telomere length in HutchinsonGilford progeria syndrome. Mechanisms of ageing and development, 130, 377-383.

221. Herrmann, M., Pusceddu, I., März, W. and Herrmann, W. (2018) Telomere biology and agerelated diseases. Clinical chemistry and laboratory medicine, 56, 1210-1222.

222. Lai, T.-P., Wright, W.E. and Shay, J.W. (2018) Comparison of telomere length measurement methods. Philosophical transactions of the Royal Society of London. Series B, Biological sciences, 373.

223. Ourliac-Garnier, I. and Londoño-Vallejo, A. (2017) Telomere Length Analysis by Quantitative Fluorescent in Situ Hybridization (Q-FISH). Methods in molecular biology (Clifton, N.J.), 1587, 29-39.

224. Baerlocher, G.M., Vulto, I., Jong, G. de and Lansdorp, P.M. (2006) Flow cytometry and FISH to measure the average length of telomeres (flow FISH). Nature protocols, 1, 2365-2376.

225. Baird, D.M., Rowson, J., Wynford-Thomas, D. and Kipling, D. (2003) Extensive allelic variation and ultrashort telomeres in senescent human cells. Nature genetics. First published on January $21,2003,10.1038 / n g 1084$.

226. Lai, T.-P., Zhang, N., Noh, J., Mender, I., Tedone, E., Huang, E., Wright, W.E., Danuser, G. and Shay, J.W. (2017) A method for measuring the distribution of the shortest telomeres in cells and tissues. Nat Commun. First published on November 07, 2017, 10.1038/s41467-017-01291Z.

227. Pedro, N. de, Díez, M., García, I., García, J., Otero, L., Fernández, L., García, B., González, R., Rincón, S. and Pérez, D. et al. (2020) Analytical Validation of Telomere Analysis Technology ${ }^{\circledR}$ for the High-Throughput Analysis of Multiple Telomere-Associated Variables. Biological procedures online. First published on January 15, 2020, 10.1186/s12575-019-0115-z.

228. Blauwkamp, M.N., Fasching, C.L., Lin, J., Guegler, K., Hytopoulos, E., Watson, D. and Harley, C.B. (2017) Analytical Validation of Relative Average Telomere Length Measurement in a Clinical Laboratory Environment. Jrnl App Lab Med, 2, 4-16.

229. Luo, Y., Viswanathan, R., Hande, M.P., Loh, A.H.P. and Cheow, L.F. (2020) Massively parallel single-molecule telomere length measurement with digital real-time PCR. Science advances. First published on August 21, 2020, 10.1126/sciadv.abb7944. 
230. Morava, E., Guillard, M., Lefeber, D.J. and Wevers, R.A. (2009) Autosomal recessive cutis laxa syndrome revisited. European journal of human genetics : EJHG, 17, 1099-1110.

231. Kuo, M.-L., Lee, M.B.-E., Tang, M., den Besten, W., Hu, S., Sweredoski, M.J., Hess, S., Chou, C.-M., Changou, C.A. and Su, M. et al. (2016) PYCR1 and PYCR2 Interact and Collaborate with RRM2B to Protect Cells from Overt Oxidative Stress. Scientific reports, 6, 18846.

232. Liang, S.-T., Audira, G., Juniardi, S., Chen, J.-R., Lai, Y.-H., Du, Z.-C., Lin, D.-S. and Hsiao, C.D. (2019) Zebrafish Carrying pycr1 Gene Deficiency Display Aging and Multiple Behavioral Abnormalities. Cells, 8.

233. Sprenger, S. (2014) The role of Pycr1 in the pathomechanism of autosomal recessive cutis laxa. Technische Universität Berlin.

234. Newman, J.A., Savitsky, P., Allerston, C.K., Bizard, A.H., Özer, Ö., Sarlós, K., Liu, Y., Pardon, E., Steyaert, J. and Hickson, I.D. et al. (2015) Crystal structure of the Bloom's syndrome helicase indicates a role for the HRDC domain in conformational changes. Nucleic acids research, 43, 5221-5235.

235. Wan, L., Han, J., Liu, T., Dong, S., Xie, F., Chen, H. and Huang, J. (2013) Scaffolding protein SPIDR/KIAA0146 connects the Bloom syndrome helicase with homologous recombination repair. Proceedings of the National Academy of Sciences of the United States of America, 110, 10646-10651.

236. Langland, G., Elliott, J., Li, Y., Creaney, J., Dixon, K. and Groden, J. (2002) The BLM helicase is necessary for normal DNA double-strand break repair. Cancer research, 62, 2766-2770.

237. Renty, C. de and Ellis, N.A. (2017) Bloom's syndrome: Why not premature aging?: A comparison of the BLM and WRN helicases. Ageing research reviews, 33, 36-51.

238. Lu, R., O'Rourke, J.J., Sobinoff, A.P., Allen, J.A.M., Nelson, C.B., Tomlinson, C.G., Lee, M., Reddel, R.R., Deans, A.J. and Pickett, H.A. (2019) The FANCM-BLM-TOP3A-RMI complex suppresses alternative lengthening of telomeres (ALT). Nat Commun. First published on May 28, 2019, 10.1038/s41467-019-10180-6.

239. Demanelis, K., Jasmine, F., Chen, L.S., Chernoff, M., Tong, L., Delgado, D., Zhang, C., Shinkle, J., Sabarinathan, M. and Lin, H. et al. (2020) Determinants of telomere length across human tissues. Science, 369.

240. Lulkiewicz, M., Bajsert, J., Kopczynski, P., Barczak, W. and Rubis, B. (2020) Telomere length: how the length makes a difference. Molecular biology reports. First published on September 02, 2020, 10.1007/s11033-020-05551-y. 


\section{References}

241. Dutrillaux, B., Gerbault-Seureau, M., Zafrani, B. and Prieur, M. (1991) Prolonged G2 phase of breast cancer cells and chromosome damage. European Journal of Cancer and Clinical Oncology, 27, 1307-1312.

242. Aparicio, T., Baer, R. and Gautier, J. (2014) DNA double-strand break repair pathway choice and cancer. DNA repair. First published on April 18, 2014, 10.1016/j.dnarep.2014.03.014.

243. Redon, C.E., Nakamura, A.J., Zhang, Y.-W., Ji, J.J., Bonner, W.M., Kinders, R.J., Parchment, R.E., Doroshow, J.H. and Pommier, Y. (2010) Histone gammaH2AX and poly(ADP-ribose) as clinical pharmacodynamic biomarkers. Clinical cancer research : an official journal of the American Association for Cancer Research. First published on September 07, 2010, 10.1158/1078-0432.CCR-10-0523.

244. Shrivastav, M., Haro, L.P. de and Nickoloff, J.A. (2008) Regulation of DNA double-strand break repair pathway choice. Cell research, 18, 134-147.

245. Kuo, L.J. and Yang, L.-X. (2008) Gamma-H2AX - a novel biomarker for DNA double-strand breaks. In vivo (Athens, Greece), 22, 305-309.

246. Pontarin, G., Ferraro, P., Håkansson, P., Thelander, L., Reichard, P. and Bianchi, V. (2007) p53R2-dependent ribonucleotide reduction provides deoxyribonucleotides in quiescent human fibroblasts in the absence of induced DNA damage. The Journal of biological chemistry. First published on April 07, 2007, 10.1074/jbc.M701310200.

247. Tanaka, H., Arakawa, H., Yamaguchi, T., Shiraishi, K., Fukuda, S., Matsui, K., Takei, Y. and Nakamura, Y. (2000) A ribonucleotide reductase gene involved in a p53-dependent cell-cycle checkpoint for DNA damage. Nature, 404, 42-49.

248. Arakel, E.C. and Schwappach, B. (2018) Formation of COPI-coated vesicles at a glance. Journal of cell science, 131.

249. Witkos, T.M., Chan, W.L., Joensuu, M., Rhiel, M., Pallister, E., Thomas-Oates, J., Mould, A.P., Mironov, A.A., Biot, C. and Guerardel, Y. et al. (2019) GORAB scaffolds COPI the trans-Golgi for efficient enzyme recycling and correct protein glycosylation. Nature communications, 10 , 127.

250. Chan, W.L., Steiner, M., Witkos, T., Egerer, J., Busse, B., Mizumoto, S., Pestka, J.M., Zhang, H., Hausser, I. and Khayal, L.A. et al. (2018) Impaired proteoglycan glycosylation, elevated TGF$\beta$ signaling, and abnormal osteoblast differentiation as the basis for bone fragility in a mouse model for gerodermia osteodysplastica. PLoS genetics. First published on March 21, 2018, 10.1371/journal.pgen.1007242. 
251. van der Burg, M., ljspeert, H., Verkaik, N.S., Turul, T., Wiegant, W.W., Morotomi-Yano, K., Mari, P.-O., Tezcan, I., Chen, D.J. and Zdzienicka, M.Z. et al. (2009) A DNA-PKcs mutation in a radiosensitive T-B- SCID patient inhibits Artemis activation and nonhomologous end-joining. The Journal of clinical investigation, 119, 91-98.

252. Woodbine, L., Neal, J.A., Sasi, N.-K., Shimada, M., Deem, K., Coleman, H., Dobyns, W.B., Ogi, T., Meek, K. and Davies, E.G. et al. (2013) PRKDC mutations in a SCID patient with profound neurological abnormalities. The Journal of clinical investigation, 123, 2969-2980.

253. Soubeyrand, S., Pope, L., Pakuts, B. and Haché, R.J.G. (2003) Threonines 2638/2647 in DNAPK are essential for cellular resistance to ionizing radiation. Cancer research, 63, 1198-1201.

254. Ma, Y., Pannicke, U., Schwarz, K. and Lieber, M.R. (2002) Hairpin Opening and Overhang Processing by an Artemis/DNA-Dependent Protein Kinase Complex in Nonhomologous End Joining and V(D)J Recombination. Cell, 108, 781-794.

255. Park, E.-J., Chan, D.W., Park, J.-H., Oettinger, M.A. and Kwon, J. (2003) DNA-PK is activated by nucleosomes and phosphorylates $\mathrm{H} 2 \mathrm{AX}$ within the nucleosomes in an acetylation-dependent manner. Nucleic acids research, 31, 6819-6827.

256. Boraldi, F., Annovi, G., Tiozzo, R., Sommer, P. and Quaglino, D. (2010) Comparison of ex vivo and in vitro human fibroblast ageing models. Mechanisms of ageing and development. First published on September 09, 2010, 10.1016/j.mad.2010.08.008.

257. Weissensteiner, H., Forer, L., Fuchsberger, C., Schöpf, B., Kloss-Brandstätter, A., Specht, G., Kronenberg, F. and Schönherr, S. (2016) mtDNA-Server: next-generation sequencing data analysis of human mitochondrial DNA in the cloud. Nucleic acids research, 44, W64-9.

258. Lott, M.T., Leipzig, J.N., Derbeneva, O., Xie, H.M., Chalkia, D., Sarmady, M., Procaccio, V. and Wallace, D.C. (2013) mtDNA Variation and Analysis Using Mitomap and Mitomaster. Current protocols in bioinformatics, 44, 1.23.1-26.

259. Tripathi, K. and Parnaik, V.K. (2008) Differential dynamics of splicing factor SC35 during the cell cycle. Journal of biosciences, 33, 345-354.

260. Sholes, S.L., Karimian, K., Gershman, A., Kelly, T.J., Timp, W. and Greider, C.W. (2021) Chromosome specific telomere lengths and the minimal functional telomere revealed by nanopore sequencing. bioRxiv, 2021.06.07.447263.

261. Amarasinghe, S.L., Su, S., Dong, X., Zappia, L., Ritchie, M.E. and Gouil, Q. (2020) Opportunities and challenges in long-read sequencing data analysis. Genome Biol. First published on February 07, 2020, 10.1186/s13059-020-1935-5. 


\section{Appendix}

Table 44: Relative telomere length and $p$-Values for the telomere length measurement by telomere real-time PCR

\begin{tabular}{|l|l|l|l|}
\hline Patient ID & Age & Relative telomere length & P-value \\
\hline P11-YRDC & 0 & 1.23691852 & 0.1343096 \\
\hline P13-AHCTF1 & 0 & 1.49083294 & 0.38897348 \\
\hline P16-LMNA & 11 & 1.21812049 & 0.51998114 \\
\hline P17-XPC & 2 & 1.29879046 & 0.26527603 \\
\hline P18 & 10 & 1.06876956 & 0.37824598 \\
\hline P19-POLD1 & 29 & 1.01921811 & 0.51322028 \\
\hline P20-SHOC2 & 4 & 1.09723589 & 0.14869495 \\
\hline P21-LTBP4 & 5 & 1.29249027 & 0.39329303 \\
\hline P22 & 2 & 1.31420476 & 0.28224569 \\
\hline P23-PYCR1 & 0 & 1.12971018 & 0.07293631 \\
\hline P24-BLM & 16 & 0.64501707 & 0.05993812 \\
\hline P25-BLM & 10 & 1.07791374 & 0.30948856 \\
\hline P26-BLM & 16 & 0.86854149 & 0.20895447 \\
\hline
\end{tabular}


Table 45: Overview Controls

\begin{tabular}{|c|c|c|c|c|c|c|c|c|c|}
\hline $\begin{array}{l}\text { Patient } \\
\text { ID }\end{array}$ & Reference ID & Syndrome & Gene & Mutation & $\begin{array}{l}\text { Effect on } \\
\text { protein }\end{array}$ & $\begin{array}{l}\text { Age } \\
\text { (years) }\end{array}$ & Gender & Material & Source \\
\hline $\mathrm{CO1}$ & WT W & Breast Reduction & & & & 30 & Female & Fibroblasts & $\begin{array}{l}\text { Institute of Human } \\
\text { Genetics, Göttingen }\end{array}$ \\
\hline $\mathrm{CO2}$ & WT M & Apparently Healthy & & & & 30 & male & Fibroblasts & $\begin{array}{l}\text { Institute of Human } \\
\text { Genetics, Göttingen }\end{array}$ \\
\hline $\mathrm{CO3}$ & $\begin{array}{l}\text { Goe1301, } \\
\text { GM05658A }\end{array}$ & Apparently Healthy & & & & 1 & male & Fibroblasts & Corielle Institute \\
\hline $\mathrm{CO4}$ & $\begin{array}{l}\text { Goe1302, } \\
\text { GM05565B }\end{array}$ & Apparently Healthy & & & & 3 & male & Fibroblasts & Corielle Institute \\
\hline $\mathrm{CO5}$ & $\begin{array}{l}\text { Goe1303, } \\
\text { GM02936C }\end{array}$ & Apparently Healthy & & & & 0 & male & Fibroblasts & Corielle Institute \\
\hline C06 & $\begin{array}{l}\text { Goe1304, } \\
\text { GM08398D }\end{array}$ & Apparently Healthy & & & & 8 & male & Fibroblasts & Corielle Institute \\
\hline $\mathrm{CO7}$ & $\begin{array}{l}\text { Goe1305, } \\
\text { GM00409D }\end{array}$ & Apparently Healthy & & & & 7 & male & Fibroblasts & Corielle Institute \\
\hline $\mathrm{CO8}$ & $\begin{array}{l}\text { Goe1307, } \\
\text { GM05659F }\end{array}$ & Apparently Healthy & & & & 1 & male & Fibroblasts & Corielle Institute \\
\hline C09 & $\begin{array}{l}\text { Goe1310, } \\
\text { GM05381C }\end{array}$ & Apparently Healthy & & & & 5 & male & Fibroblasts & Corielle Institute \\
\hline C11 & Gö882 & Raine Syndrome & & & & 1 & male & Blood & $\begin{array}{l}\text { Institute of Human } \\
\text { Genetics, Göttingen }\end{array}$ \\
\hline C12 & Gö409, 39534B & Ohdo-Syndrome & MED12 & c. $886 \mathrm{C}>\mathrm{T}$ & p.Arg296Trp & 2 & male & Blood & $\begin{array}{l}\text { Institute of Human } \\
\text { Genetics, Göttingen }\end{array}$ \\
\hline C13 & Gö425, 39412 & $\begin{array}{l}\text { Mental retardation and distinctive facial features with or } \\
\text { without cardiac defects }\end{array}$ & MED13L & c.4976dupT & $\begin{array}{l}\text { p.Gly1660Argf } \\
\text { s*6 }^{*}\end{array}$ & 2 & male & Blood & $\begin{array}{l}\text { Institute of Human } \\
\text { Genetics, Göttingen }\end{array}$ \\
\hline C14 & Gö438 & Developmental and epileptic encephalopathy 5 & SPTAN1 & c. $316 \mathrm{G}>\mathrm{A}$ & p.Gly106Arg & 2 & female & Blood & $\begin{array}{l}\text { Institute of Human } \\
\text { Genetics, Göttingen }\end{array}$ \\
\hline C15 & Gö574, 50593 & Epileptic Enzephalopathia & & & & 2 & male & Blood & $\begin{array}{l}\text { Institute of Human } \\
\text { Genetics, Göttingen }\end{array}$ \\
\hline C16 & Gö92, 37589 & $\begin{array}{l}\text { Epilepsy, focal, with speech disorder, and with or } \\
\text { without mental retardation }\end{array}$ & GRIN2A & c. $1841 \mathrm{~A}>\mathrm{G}$ & p.N614S & 3 & female & Blood & $\begin{array}{l}\text { Institute of Human } \\
\text { Genetics, Göttingen }\end{array}$ \\
\hline C17 & Gö406, 39411B & Microcephaly, Developmental Delay & & & & 3 & male & Blood & $\begin{array}{l}\text { Institute of Human } \\
\text { Genetics, Göttingen }\end{array}$ \\
\hline
\end{tabular}




\begin{tabular}{|c|c|c|c|c|c|c|c|c|c|}
\hline C18 & Gö513, 37581 & Developmental Delay & & & & 3 & male & Blood & $\begin{array}{l}\text { Institute of Human } \\
\text { Genetics, Göttingen }\end{array}$ \\
\hline C19 & Gö562, 50002 & Complex Malformations & & & & 3 & male & Blood & $\begin{array}{l}\text { Institute of Human } \\
\text { Genetics, Göttingen }\end{array}$ \\
\hline $\mathrm{C} 20$ & Gö775, 50914 & Developmental Delay & & & & 3 & female & Blood & $\begin{array}{l}\text { Institute of Human } \\
\text { Genetics, Göttingen }\end{array}$ \\
\hline $\mathrm{C} 21$ & Gö581, 50908 & Heart Malformation & & & & 4 & male & Blood & $\begin{array}{l}\text { Institute of Human } \\
\text { Genetics, Göttingen }\end{array}$ \\
\hline $\mathrm{C} 22$ & Gö586, 39549B & Developmental Delay & & & & 4 & female & Blood & $\begin{array}{l}\text { Institute of Human } \\
\text { Genetics, Göttingen }\end{array}$ \\
\hline $\mathrm{C} 23$ & Gö95, 33892 & $\begin{array}{l}\text { Epilepsy, focal, with speech disorder and with or without } \\
\text { mental retardation }\end{array}$ & GRIN2A & c. $1841 \mathrm{~A}>\mathrm{G}$ & p.N614S & 5 & Female & Blood & $\begin{array}{l}\text { Institute of Human } \\
\text { Genetics, Göttingen }\end{array}$ \\
\hline C24 & Gö578, 33878 & $\begin{array}{l}\text { Neurodevelopmental disorder with or without } \\
\text { hyperkinetic movements and seizures, autosomal } \\
\text { dominant }\end{array}$ & GRIN1 & $\begin{array}{l}\text { c.1858G }>A \\
\text { (het) }\end{array}$ & p.Gly620Arg & 5 & female & Blood & $\begin{array}{l}\text { Institute of Human } \\
\text { Genetics, Göttingen }\end{array}$ \\
\hline $\mathrm{C} 25$ & Gö671 & Developmental and epileptic encephalopathy 59 & GABBR2 & c.1699G >A & p.Ala567Thr & 5 & female & Blood & $\begin{array}{l}\text { Institute of Human } \\
\text { Genetics, Göttingen }\end{array}$ \\
\hline C26 & Gö606, 51442 & X-linked mental retardation, Type Turner & HUWE1 & c.12929G>A & p.Gly4310Asp & 6 & male & Blood & $\begin{array}{l}\text { Institute of Human } \\
\text { Genetics, Göttingen }\end{array}$ \\
\hline $\mathrm{C} 27$ & Gö721, 36528 & Developmental Delay, Mild Dysmorfies, Epilepsy & & & & 7 & male & Blood & $\begin{array}{l}\text { Institute of Human } \\
\text { Genetics, Göttingen }\end{array}$ \\
\hline $\mathrm{C} 28$ & Gö369, 50651 & Autism & & & & 8 & male & Blood & $\begin{array}{l}\text { Institute of Human } \\
\text { Genetics, Göttingen }\end{array}$ \\
\hline C29 & Gö928, 52069 & apparently healthy & & & & 8 & male & Blood & $\begin{array}{l}\text { Institute of Human } \\
\text { Genetics, Göttingen }\end{array}$ \\
\hline C30 & Gö929, 52548 & apparently healthy & & & & 8 & female & Blood & $\begin{array}{l}\text { Institute of Human } \\
\text { Genetics, Göttingen }\end{array}$ \\
\hline C31 & Gö930, 52720 & apparently healthy & & & & 8 & female & Blood & $\begin{array}{l}\text { Institute of Human } \\
\text { Genetics, Göttingen }\end{array}$ \\
\hline C32 & Gö931, 52694 & apparently healthy & & & & 8 & female & Blood & $\begin{array}{l}\text { Institute of Human } \\
\text { Genetics, Göttingen }\end{array}$ \\
\hline C33 & Gö373, 33571 & $\begin{array}{l}\text { Multiple congenital anomalies-hypotonia-seizures } \\
\text { syndrome } 2\end{array}$ & PIGA & $\begin{array}{l}\text { c.154C>T } \\
\text { (hemizygot) }\end{array}$ & p.His54TYr & 9 & male & Blood & $\begin{array}{l}\text { Institute of Human } \\
\text { Genetics, Göttingen }\end{array}$ \\
\hline C34 & Gö577, 37651 & Developmental and epileptic encephalopathy 7 & KCNQ2 & $\begin{array}{l}\text { c. } 430 \mathrm{C}>\mathrm{T} \\
\text { (het) }\end{array}$ & p.Arg144Trp & 9 & male & Blood & $\begin{array}{l}\text { Institute of Human } \\
\text { Genetics, Göttingen }\end{array}$ \\
\hline C35 & Gö589, 40018 & Sotos Syndrome Type 2 & NFIX & c.775delG & p.Val259*fs & 9 & female & Blood & $\begin{array}{l}\text { Institute of Human } \\
\text { Genetics, Göttingen }\end{array}$ \\
\hline C36 & Gö608, 51327B & Cleft palate, cardiac defects, and mental retardation & MEIS2 & c.998G $>A$ & p.Arg333Lys & 9 & female & Blood & $\begin{array}{l}\text { Institute of Human } \\
\text { Genetics, Göttingen }\end{array}$ \\
\hline
\end{tabular}




\begin{tabular}{|c|c|c|c|c|c|c|c|c|}
\hline C37 & Gö714, 36507C & Developmental Delay & & & 10 & male & Blood & $\begin{array}{l}\text { Institute of Human } \\
\text { Genetics, Göttingen }\end{array}$ \\
\hline C38 & Gö724, 32772 & Developmental Delay, Muscle Hypotonia & & & 10 & male & Blood & $\begin{array}{l}\text { Institute of Human } \\
\text { Genetics, Göttingen }\end{array}$ \\
\hline C39 & Gö392, 28954B & Developmental Delay, Short Stature, Mental Retardation & & & 11 & male & Blood & $\begin{array}{l}\text { Institute of Human } \\
\text { Genetics, Göttingen }\end{array}$ \\
\hline $\mathrm{C} 40$ & Gö900, 30851 & Mental retardation, autosomal dominant 26 & AUTS2 & large deletion & 11 & female & Blood & $\begin{array}{l}\text { Institute of Human } \\
\text { Genetics, Göttingen }\end{array}$ \\
\hline C41 & Gö399, 52449 & apparently healthy & & & 12 & female & Blood & $\begin{array}{l}\text { Institute of Human } \\
\text { Genetics, Göttingen }\end{array}$ \\
\hline C42 & Gö824, 52449 & Dysmorpies & & & 12 & female & Blood & $\begin{array}{l}\text { Institute of Human } \\
\text { Genetics, Göttingen }\end{array}$ \\
\hline C43 & Gö654, 36840B & hypoplastic Amelogenesis imperfecta & & & 13 & male & Blood & $\begin{array}{l}\text { Institute of Human } \\
\text { Genetics, Göttingen }\end{array}$ \\
\hline $\mathrm{C} 44$ & Gö728, 27878 & Developmental Delay & & & 13 & male & Blood & $\begin{array}{l}\text { Institute of Human } \\
\text { Genetics, Göttingen }\end{array}$ \\
\hline C45 & Gö689 & Autism & ANXA1 & $\begin{array}{l}\text { c.984+5delG } \\
\text { (het) }\end{array}$ & 14 & male & Blood & $\begin{array}{l}\text { Institute of Human } \\
\text { Genetics, Göttingen }\end{array}$ \\
\hline C46 & Gö690 & Autism & ANXA1 & $\begin{array}{l}\text { c.984+5delG } \\
\text { (het) }\end{array}$ & 14 & female & Blood & $\begin{array}{l}\text { Institute of Human } \\
\text { Genetics, Göttingen }\end{array}$ \\
\hline $\mathrm{C} 47$ & Gö789 & Alpha-Mannosidosis & & & 14 & male & Blood & $\begin{array}{l}\text { Institute of Human } \\
\text { Genetics, Göttingen }\end{array}$ \\
\hline C48 & Gö565, 51167 & Deafness, Dental Anomalies, facial Dysmorphies & & & 15 & male & Blood & $\begin{array}{l}\text { Institute of Human } \\
\text { Genetics, Göttingen }\end{array}$ \\
\hline C49 & Gö758 & apparently healthy & & & 16 & female & Blood & $\begin{array}{l}\text { Institute of Human } \\
\text { Genetics, Göttingen }\end{array}$ \\
\hline C50 & Gö757 & apparently healthy & & & 17 & male & Blood & $\begin{array}{l}\text { Institute of Human } \\
\text { Genetics, Göttingen }\end{array}$ \\
\hline C51 & Gö874 & apparently healthy & & & 18 & female & Blood & $\begin{array}{l}\text { Institute of Human } \\
\text { Genetics, Göttingen }\end{array}$ \\
\hline C52 & Gö888, 51826 & cerebellar Ataxia & & & 21 & male & Blood & $\begin{array}{l}\text { Institute of Human } \\
\text { Genetics, Göttingen }\end{array}$ \\
\hline C53 & Gö600, 51525 & apparently healthy & & & 22 & male & Blood & $\begin{array}{l}\text { Institute of Human } \\
\text { Genetics, Göttingen }\end{array}$ \\
\hline C54 & Gö793, 52126 & apparently healthy & & & 23 & female & Blood & $\begin{array}{l}\text { Institute of Human } \\
\text { Genetics, Göttingen }\end{array}$ \\
\hline C55 & Gö218 & apparently healthy & & & 24 & female & Blood & $\begin{array}{l}\text { Institute of Human } \\
\text { Genetics, Göttingen }\end{array}$ \\
\hline
\end{tabular}




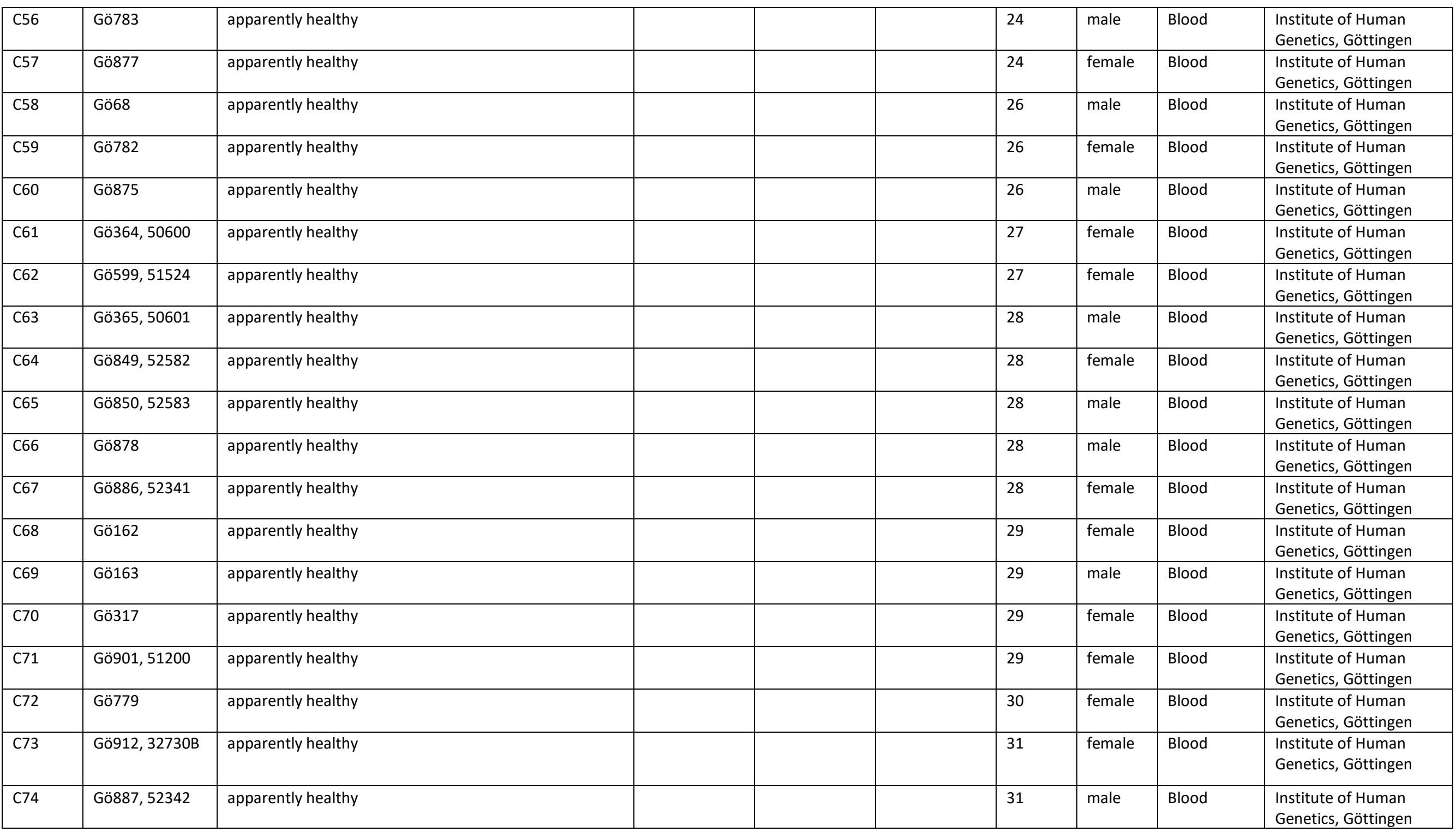




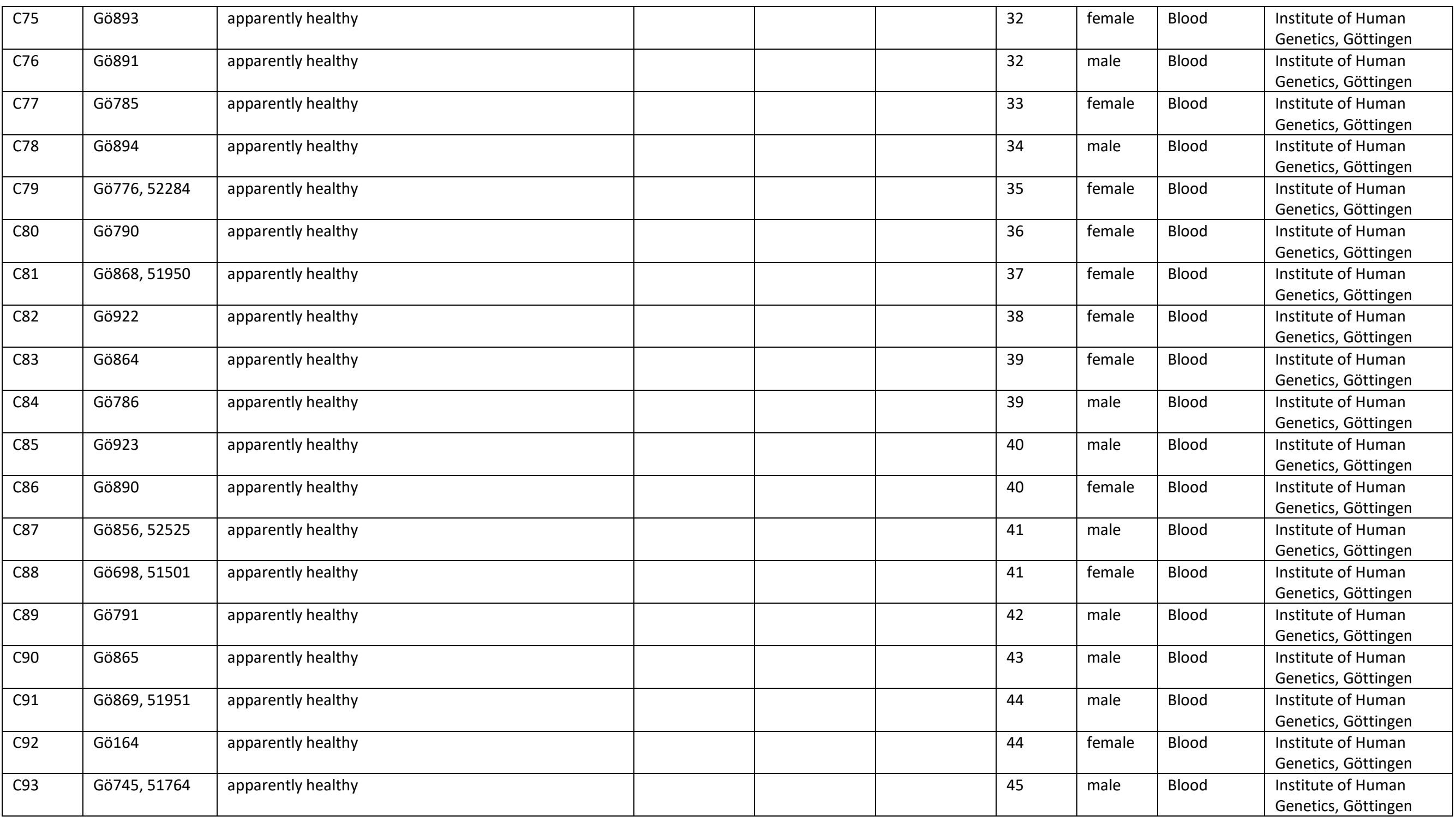




\begin{tabular}{|c|c|c|c|c|c|c|}
\hline C94 & Gö462, 51096 & apparently healthy & 45 & female & Blood & $\begin{array}{l}\text { Institute of Human } \\
\text { Genetics, Göttingen }\end{array}$ \\
\hline C95 & Gö804, 32778B & apparently healthy & 46 & female & Blood & $\begin{array}{l}\text { Institute of Human } \\
\text { Genetics, Göttingen }\end{array}$ \\
\hline C96 & Gö797, 37474 & apparently healthy & 47 & male & Blood & $\begin{array}{l}\text { Institute of Human } \\
\text { Genetics, Göttingen }\end{array}$ \\
\hline C97 & Gö744, 51765 & apparently healthy & 47 & female & Blood & $\begin{array}{l}\text { Institute of Human } \\
\text { Genetics, Göttingen }\end{array}$ \\
\hline C98 & Gö601 & apparently healthy & 48 & female & Blood & $\begin{array}{l}\text { Institute of Human } \\
\text { Genetics, Göttingen }\end{array}$ \\
\hline C99 & Gö584, 51375 & apparently healthy & 48 & male & Blood & $\begin{array}{l}\text { Institute of Human } \\
\text { Genetics, Göttingen }\end{array}$ \\
\hline C100 & Gö401 & apparently healthy & 50 & female & Blood & $\begin{array}{l}\text { Institute of Human } \\
\text { Genetics, Göttingen }\end{array}$ \\
\hline C101 & Gö834, 52413 & apparently healthy & 51 & male & Blood & $\begin{array}{l}\text { Institute of Human } \\
\text { Genetics, Göttingen }\end{array}$ \\
\hline C102 & Gö796, 37473 & apparently healthy & 51 & female & Blood & $\begin{array}{l}\text { Institute of Human } \\
\text { Genetics, Göttingen }\end{array}$ \\
\hline C103 & Gö833, 52412 & apparently healthy & 52 & female & Blood & $\begin{array}{l}\text { Institute of Human } \\
\text { Genetics, Göttingen }\end{array}$ \\
\hline C104 & Gö805, 32779B & apparently healthy & 52 & male & Blood & $\begin{array}{l}\text { Institute of Human } \\
\text { Genetics, Göttingen }\end{array}$ \\
\hline C105 & Gö419 & apparently healthy & 53 & female & Blood & $\begin{array}{l}\text { Institute of Human } \\
\text { Genetics, Göttingen }\end{array}$ \\
\hline C106 & Gö420 & apparently healthy & 54 & male & Blood & $\begin{array}{l}\text { Institute of Human } \\
\text { Genetics, Göttingen }\end{array}$ \\
\hline C107 & Gö719, 51830 & apparently healthy & 55 & female & Blood & $\begin{array}{l}\text { Institute of Human } \\
\text { Genetics, Göttingen }\end{array}$ \\
\hline C108 & Gö307, 50276B & apparently healthy & 55 & male & Blood & $\begin{array}{l}\text { Institute of Human } \\
\text { Genetics, Göttingen }\end{array}$ \\
\hline C109 & Gö583, 51361 & apparently healthy & 56 & male & Blood & $\begin{array}{l}\text { Institute of Human } \\
\text { Genetics, Göttingen }\end{array}$ \\
\hline C110 & Gö594, 51688 & apparently healthy & 56 & male & Blood & $\begin{array}{l}\text { Institute of Human } \\
\text { Genetics, Göttingen }\end{array}$ \\
\hline C111 & Gö442, 50960 & apparently healthy & 57 & male & Blood & $\begin{array}{l}\text { Institute of Human } \\
\text { Genetics, Göttingen }\end{array}$ \\
\hline C112 & Gö503 & apparently healthy & 59 & male & Blood & $\begin{array}{l}\text { Institute of Human } \\
\text { Genetics, Göttingen }\end{array}$ \\
\hline
\end{tabular}




\begin{tabular}{|c|c|c|c|c|c|c|c|}
\hline C113 & Gö720, 51831 & apparently healthy & & 60 & male & Blood & $\begin{array}{l}\text { Institute of Human } \\
\text { Genetics, Göttingen }\end{array}$ \\
\hline C114 & Gö1236, 53926 & apparently healthy & & 6 & male & Blood & $\begin{array}{l}\text { Institute of Human } \\
\text { Genetics, Göttingen }\end{array}$ \\
\hline C115 & Gö1231, 51874 & Developmental Delay, Epilepsy, Contractures & & 1 & female & Blood & $\begin{array}{l}\text { Institute of Human } \\
\text { Genetics, Göttingen }\end{array}$ \\
\hline C116 & Gö1186, 51301 & Mental Retardation, Seizures & & 8 & male & Blood & $\begin{array}{l}\text { Institute of Human } \\
\text { Genetics, Göttingen }\end{array}$ \\
\hline C117 & Gö1142, 52335 & facial anomalies & & 1 & male & Blood & $\begin{array}{l}\text { Institute of Human } \\
\text { Genetics, Göttingen }\end{array}$ \\
\hline C118 & Gö1105, 51895 & developmental delay & & 6 & female & Blood & $\begin{array}{l}\text { Institute of Human } \\
\text { Genetics, Göttingen }\end{array}$ \\
\hline C129 & Gö1098 & Mental Retardation, Seizures & & 8 & male & Blood & $\begin{array}{l}\text { Institute of Human } \\
\text { Genetics, Göttingen }\end{array}$ \\
\hline C120 & Gö941, 52621 & Cleft palate & & 1 & male & Blood & $\begin{array}{l}\text { Institute of Human } \\
\text { Genetics, Göttingen }\end{array}$ \\
\hline $\begin{array}{l}\text { C121- } \\
\text { LONP1 }\end{array}$ & K3054 & unaffected carrier of LONP1 mutation & LONP1 & & & Blood & $\begin{array}{l}\text { Institute of Human } \\
\text { Genetics, Göttingen }\end{array}$ \\
\hline $\begin{array}{l}\text { C122- } \\
\text { LONP1 }\end{array}$ & K3055 & unaffected carrier LONP1 mutation & LONP1 & & & Blood & $\begin{array}{l}\text { Institute of Human } \\
\text { Genetics, Göttingen }\end{array}$ \\
\hline
\end{tabular}


Appendix

Table 46: P-values of pairwise comparisons of controls and patient samples by t-test

\begin{tabular}{|c|c|c|c|c|}
\hline Condition & Control sample & Patient sample & $\begin{array}{l}\text { P-value of two- } \\
\text { sided t-test }\end{array}$ & Significance \\
\hline untreated & $\mathrm{CO1}$ & P05 & 0.0879 & significant \\
\hline untreated & $\mathrm{CO2}$ & P05 & 0.035 & significant \\
\hline untreated & $\mathrm{CO3}$ & P05 & 0.0403 & significant \\
\hline untreated & $\mathrm{CO4}$ & P05 & 0.0435 & significant \\
\hline untreated & $\mathrm{CO5}$ & P05 & 0.019 & significant \\
\hline untreated & $\mathrm{CO6}$ & P05 & 0.0312 & significant \\
\hline untreated & $\mathrm{CO7}$ & P05 & 0.0879 & not significant \\
\hline untreated & $\mathrm{C08}$ & P05 & 0.0305 & significant \\
\hline untreated & $\mathrm{CO9}$ & P05 & 0.0248 & significant \\
\hline untreated & $\mathrm{CO1}$ & P06 & 0.0445 & significant \\
\hline untreated & $\mathrm{CO2}$ & P06 & 0.0439 & significant \\
\hline untreated & $\mathrm{CO3}$ & P06 & 0.0531 & not significant \\
\hline untreated & $\mathrm{CO4}$ & P06 & 0.0611 & not significant \\
\hline untreated & $\mathrm{CO5}$ & P06 & 0.0191 & significant \\
\hline untreated & $\mathrm{C06}$ & P06 & 0.0375 & significant \\
\hline untreated & $\mathrm{CO7}$ & P06 & 0.157 & not significant \\
\hline untreated & $\mathrm{CO8}$ & P06 & 0.0365 & significant \\
\hline untreated & CO9 & P06 & 0.0274 & significant \\
\hline $48 \mathrm{~h}$ after irradiation & $\mathrm{CO1}$ & P01 & 0.0032 & significant \\
\hline $48 \mathrm{~h}$ after irradiation & $\mathrm{CO2}$ & P01 & 0.0014 & significant \\
\hline $48 \mathrm{~h}$ after irradiation & $\mathrm{CO3}$ & P01 & 0.0305 & significant \\
\hline $48 \mathrm{~h}$ after irradiation & $\mathrm{CO4}$ & P01 & 0.0001 & significant \\
\hline $48 \mathrm{~h}$ after irradiation & $\mathrm{CO5}$ & P01 & 0.0004 & significant \\
\hline $48 \mathrm{~h}$ after irradiation & $\mathrm{C06}$ & P01 & $<0,0001$ & significant \\
\hline $48 \mathrm{~h}$ after irradiation & $\mathrm{CO7}$ & P01 & 0.0019 & significant \\
\hline $48 \mathrm{~h}$ after irradiation & $\mathrm{CO8}$ & P01 & $<0,0001$ & significant \\
\hline $48 \mathrm{~h}$ after irradiation & C09 & P01 & 0.0112 & significant \\
\hline $48 \mathrm{~h}$ after irradiation & $\mathrm{CO1}$ & P05 & 0.0005 & significant \\
\hline $48 \mathrm{~h}$ after irradiation & $\mathrm{CO2}$ & P05 & 0.0002 & significant \\
\hline $48 \mathrm{~h}$ after irradiation & $\mathrm{CO3}$ & P05 & 0.0037 & significant \\
\hline $48 \mathrm{~h}$ after irradiation & $\mathrm{CO4}$ & P05 & $<0,0001$ & significant \\
\hline $48 \mathrm{~h}$ after irradiation & $\mathrm{CO5}$ & P05 & $<0,0001$ & significant \\
\hline $48 \mathrm{~h}$ after irradiation & C06 & P05 & $<0,0001$ & significant \\
\hline $48 \mathrm{~h}$ after irradiation & $\mathrm{CO7}$ & P05 & 0.0003 & significant \\
\hline $48 \mathrm{~h}$ after irradiation & $\mathrm{C08}$ & P05 & $<0,0001$ & significant \\
\hline $48 \mathrm{~h}$ after irradiation & C09 & P05 & 0.0014 & significant \\
\hline
\end{tabular}




\section{Acknowledgments}

First, I would like to thank my supervisor and director of the Institute of Human Genetics Göttingen Prof. Dr. med. Bernd Wollnik for giving me the great opportunity to work on this exciting project. Thanks for always being enthusiastic about the project and motivating me. I thank the members of my thesis advisory committee, Prof. Dr. med Bernd Wollnik, Prof. Dr. rer. nat. Peter Rehling, and Prof. Dr. rer. nat. Holger Bastians for their guidance and the fruitful discussions during the TAC meetings. Further, I thank Prof. Dr. rer. nat. Lutz Walter, Prof. Dr. med Ralf Dressel, and Dr. rer. nat. Ufuk Günesdogan for their willingness to serve as examiners during the defense of my thesis. I also wish to thank the members of my graduate school, GGNB, GAUSS, and everyone involved who enabled this Ph.D. project. I am especially grateful to Henriette Irmer, the coordinator of the graduate school IMPRS-GS, for creating a welcoming and caring atmosphere.

I am very grateful to Silke Kaulfuß, Jessica Nolte-Kaitschick, Roser Ufartes Mas, Peter Burfeind, and Loukas Argyriou for their methodological advice and open ears in difficult times. Thank you, Nadine Rosin, for your support during the first part of my thesis. Special thanks to Floriane Henning for supporting me with your excellent Inkscape skills. Christian Müller, I will miss our political discussions over a cup of tea in the morning. Thanks to Lukasz Smorag for all the fruitful discussions and support and to Gökhan Yigit for proofreading my thesis at the last minute.

Special thanks to Prof. rer nat. Stephan Lehnart, Dr. rer nat. Tobias Kohl, Dr. rer. nat. Tatiana Pochechueva, and Niko Schwenzer, for your reliability and active support in the context of our cooperation on the qFISH project. Thanks again to Prof. rer. nat. Peter Rehling and Dr. rer. nat. David Pachau-Grau for supporting the Seahorse measurements. I am also grateful to Alexandra Bitter and Juliane Kasten-Krapp for their expertise and support for the irradiation treatment of my cells. Ute Teske and Britta König, thank you for showing me the NGS library preparation and for always making me feel welcome.

Finally, I thank my parents for their motivation and support throughout my studies and time as Ph.D. student and Johannes for your love and patience with long working hours. 